\title{
ANNALS MEDEDELINGEN
}

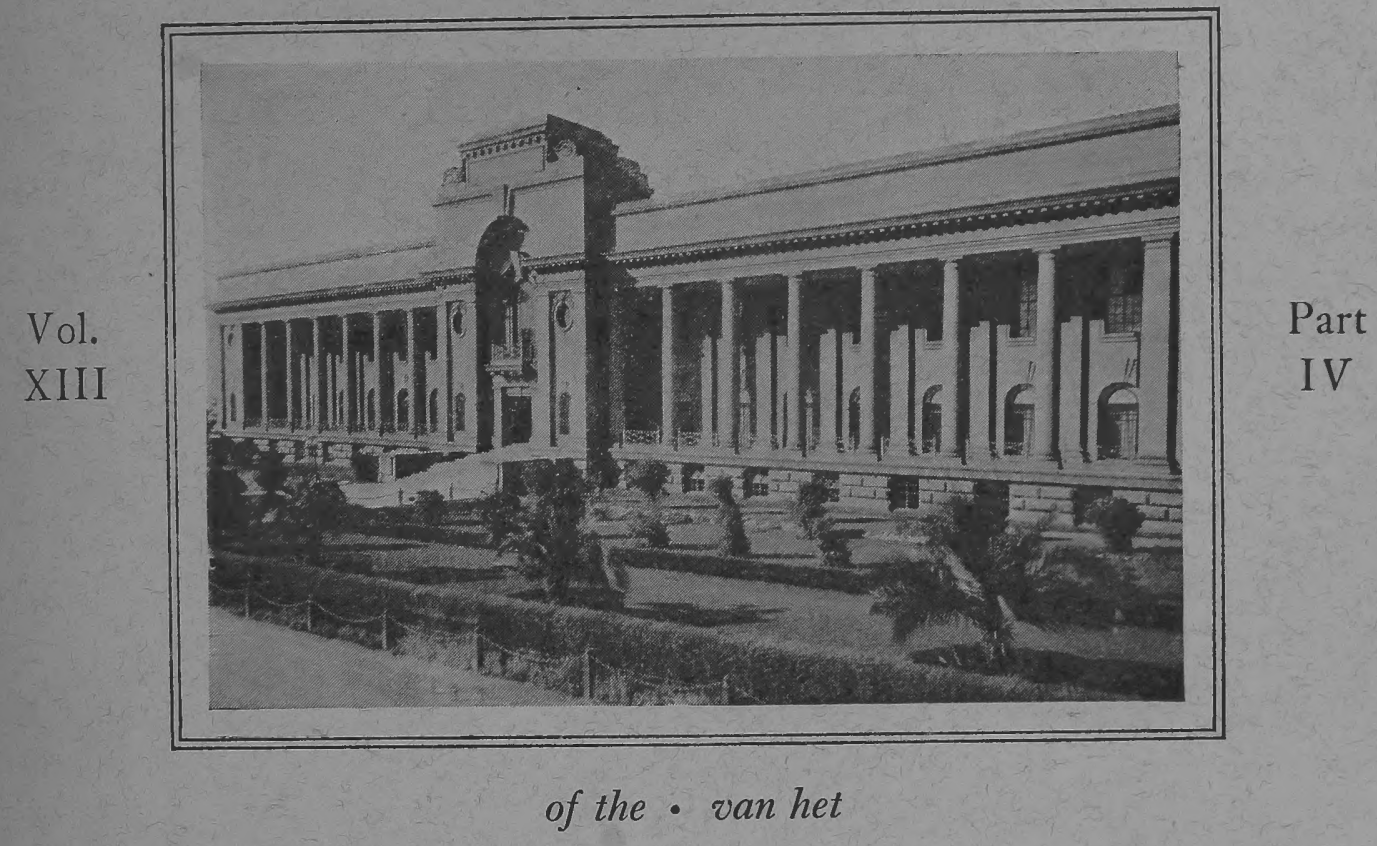

\section{TRANSVAAL M USEUM}

THE SPHEGIDAE OF SOUTH AFRICA PARTS XII-XIV

By George Arnold, D.Sc., A.R.C.Sc., F.E.S.

Issued I8 December I929 


\section{ANNALS MEDEDELINGEN}

OF THE

VAN HET

\section{TRANSVAAL MUSEUM}

VOL. 13

PART 4

\section{THE SPHEGIDAE OF SOUTH AFRICA}
BY GEORGE ARNOLD, D.Sc., A.R.C.Sc., F.E.S. Curator of the Rhodesia Museum, Bulawayo

\section{PART XII}

With 62 Text-figures

The Genera NYSSON Latr., ARPACTUS Jurine, KOHLIA Handl., and the BEMBEX Group.

THE genus Nysson is an isolated one and cannot be attached to any of 1 the main groups of the Sphegidae. The nearest ally appears to be Paranysson Guerin of the Larra Group. Arpactus Jur. and Kohlia Handl. are also rather isolated, but they occupy an intermediate position between the Alyson Group (not represented in the Ethiopian Region) and the Bembex Group.

The arrangement of the above genera and groups may be set out as follows:

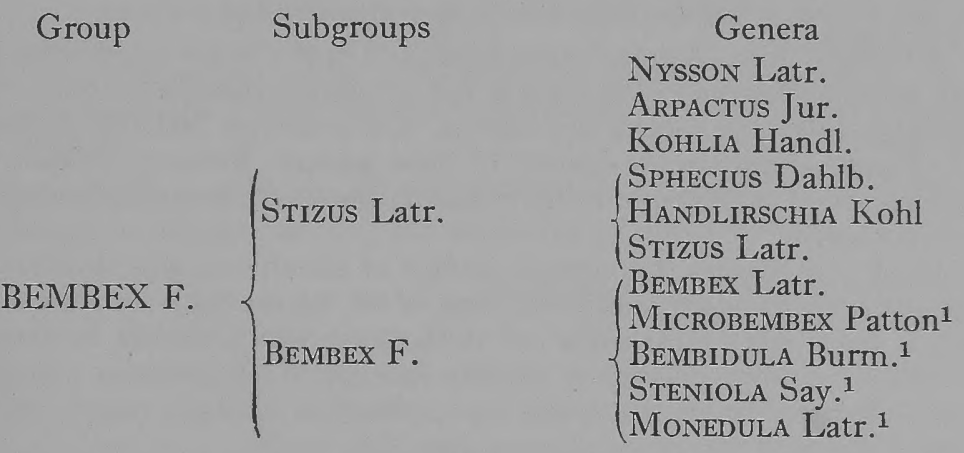

The arrangement adopted by some American authors of uniting Sphecius and Nysson into one tribe, Nyssonini, appears to me to be entirely artificial.

${ }^{1}$ Not African genera. 


\section{Genus Nysson Latr.}

Précis des caract. génériques, p. 125. 1796.

Characters. The eyes reach the base of the mandibles and converge below. Ocelli normal, round and convex. Occiput and temples fairly well developed. Maxillary palpi 6-, labial palpi 4-jointed. Tongue short and broad. Mandibles not excised on the outer margin; the inner margin without teeth, the apex acute. Labrum short and not exposed. Clypeus convex, wider than long. Antennae inserted close to the hind margin of the clypeus, 13 -jointed in the 0 , 12-jointed in the + , the apical joint in the $\delta$ often truncate at the apex, or strongly arcuate, or excised below. Pronotal collar short, but not linear above. Mesopleurae with an epicnemium in front. Episternal suture indistinct. Mesopleurae swollen, the metapleurae distinctly defined. Scutellum flat, sometimes concave, with the sides raised; the metanotum in a few species lobed on each side posteriorly. Epinotum with a well-defined median area, the posterior angles of the dorsum produced into sharp spines. The whole thorax is very convex lengthwise from the scutellum to the end of the epinotum. Abdomen ovate or conical, the first segment wide, rarely much narrower than the second. A pygidial area present in both sexes, triangular in the $q$, trapezoidal in the ${ }^{2}$. In some species the apical angles of the sternites are subdentate, and in some males the sternites have long fimbriae of curved hairs. In the of the abdomen has seven tergites and six sternites visible; the seventh tergite usually bears two or more teeth on the apical margin. Tarsal comb absent; tibiae feebly spinose. Trochaters of the fore legs 2 -jointed. Middle tibiae with two spurs. Claws small and unarmed, the pulvillus developed but not large.

Fore wing. Pterostigma small; radial cell ending on the costa, pointed at the apex, rarely rounded there. Three cubital cells present, the first large, the second small, stalked on the radius and receiving both recurrent veins. The basal vein arises before the end of the first submedial cell, and meets the subcosta close to the pterostigma.

Hind wing. Retinaculum entire. The cubital vein arises close to the end of the submedial cell, either a little before or behind it, or sometimes interstitial. Basal lobe small and round, the basal sinus deep, the anal very shallow.

The $\delta f^{\prime}$ are usually larger than the $q 9$, and in the latter the last two or three abdominal segments are usually curved downwards after death, so that they are not visible when the insect is viewed directly from above.

DisTRIBUTION. In both hemispheres and in all the zoo-geographical regions, with a greater number of species in the temperate than in the tropical regions. Although fully 100 species are known, it is a strange fact that nothing seems to be known about the life-history of these insects. By some authors they have been regarded as parasitic in their habits, but there is no evidence to support such a view.

In all our species the ventral surface of the thorax and abdomen and the legs, excepting the tarsi, and the sides of the thorax more or less, are covered with a dense silky tomentum not unlike that which occurs in many species of Sphex. A long pilosity is usually lacking. The posterior corners of the mesonotum end in a truncated lobe, which is slightly raised and projects beyond the hind margin of the tegulae.

In some species the eyes have a "shot silk" appearance, sometimes with iridescent colouring. In the $q$ the anterior fourth or less of the clypeus is sharply deflected, so that it forms almost a right angle with the rest of that part, and is therefore barely visible from in front. 


\section{KEY TO THE SPECIES, fo AND ô ơ.}

(8) I. Face without a median tubercle behind the antennal sockets.

(5) 2. Abdomen with yellow apical bands on the basal tergites, all black or with the last two or three segments ferruginous.

(4) 3. Tergites black, coarsely and fairly closely punctured, shining between the punctures; apical angles of the pygidium in the of produced into sharp spines.

minutus Arnold

(3) 4. Tergites dull, finely and sparsely punctured, the last two or three segments ferruginous, the apical margin of the pygidium in the $\delta$ tridentate.

(2) 5. Abdomen ferruginous or fusco-ferruginous.

(7) 6 . Tergites $2-5$ blackish in the middle, $\mathrm{I}-3$ with ivory white apical bands; pronotal collar ferruginous above. $5 \mathrm{~mm}$. long. Ruspolii Schult.

(6) 7. Abdomen ferruginous, tergites $\mathrm{I}-5$ with yellow apical bands.

(1) 8. rufoniger Turner

(r) 8. Face with a cariniform tubercle or a low triangular prominence behind the antennal sockets.

(ro) 9. Face with a triangular prominence between the antennal sockets. $4 \cdot 2-5 \cdot 5 \mathrm{~mm}$. long. (Epinotal spines short and broad; posterior tibiae not spinose; the $\delta$ without long apical fimbriae on the sternites.)

Braunsi Handl.

(9) Io. Face with a cariniform tubercle behind the antennal sockets. Larger species, 7-r I mm. long.

(I2) II. Shoulders of the pronotal collar produced into slightly curved, dentiform angles.

decipiens Arnold

(II) I2. Shoulders of the pronotal collar rounded.

(14) 13 . Clypeus with two yellow spots. (First tergite with large deep punctures not very close together, and without a distinct median longitudinal carina. Dorsal face of the pronotal collar two-thirds as long in the middle as the apical joint of the flagellum.) capensis Handl.

(13) r4. Clypeus without yellow spots.

(16). I5. First tergite shallowly and closely punctured, almost reticulatepunctate, and with a shining, somewhat flattened, median longitudinal carina on its basal half; the second tergite very closely and finely punctured in the middle. (Dorsal face of the pronotal collar in the middle less than half the length of the apical joint of the flagellum. In the $\delta$ the apical margin of the seventh tergite is convex between the lateral spines, as in capensis.) rhodesiae Arnold

(15) r6. First two tergites with a puncturation like that of capensis; seventh tergite in the $\hat{f}$ with the apical margin transverse between the lateral spines. ludovici Turner

N. Gregoryi Turner, N. nasutus Cam. and N. Magretti Mant. have not been included in this key as they are unknown to me in nature.

N. Braunsi Handl. (figs. I, r $a$ and b). Verh. Zool. Bot. Ges. Wien, L, p. 5ro,

o. I9oo. Brauns, ibid. Ixr, p. 136, ․ I911.

$+4 \cdot 2-5 \cdot 5 \mathrm{~mm}$. long. Black. Mandibles, scapes, first four or five joints of the flagellum, pronotal tubercles, tegulae and posterior corners of the mesonotum, last three or four abdominal segments and the legs, ferruginous. Sometimes the shoulders of the pronotal collar, the sides of the epinotum and the base of the first tergite are more or less ferruginous. A streak across the middle of the pronotal collar and apical bands on the first two tergites, more or less widely interrupted in the middle, are yellow. Wings hyaline, slightly 
tinged with fuscous, especially round the margins; the veins blackish. Face, clypeus, temples, sternum, sides of the mesothorax and base of the epinotal spines with a short silvery pubescence. The sternites have a sparse whitish tomentum, and the tergites a very fine and sparse whitish pubescence, but fairly dense on the first tergite which is almost pruinose at certain angles.

Face and vertex very finely and closely punctured, with a few larger punctures above in the middle. Occiput and temples with a widely spaced and low reticulate rugosity. The whole head dull. Mesonotum, mesopleurae and scutellum dull, reticulate rugose, the round spaces between the reticulations with a small puncture in the centre. Metanotum reticulate rugose. Median area of the epinotal dorsum with eight longitudinal and slightly oblique carinae, the spaces between them slightly shining. The metapleurae and the sides of the epinotum in front nitidulous and impunctate; the posterior upper part of the sides of the epinotum dull and reticulate rugose. Abdomen dull, the tergites with a microscopic fundamental rugulose sculpture on which is superimposed a sparse and not coarse puncturation. The punctures are largest on the first tergite, mostly separated by spaces four times the width of the largest puncture. Pygidial area elongate triangular, dull, coriaceous and punctate, about one and a half times longer than wide at the base.

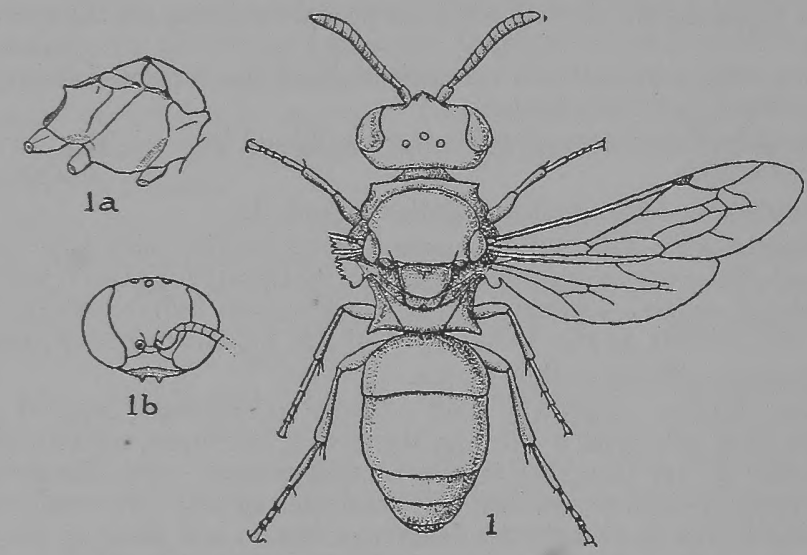

Fig. x. Nysson Braunsi, $;$; $a$, thorax; $b$ head.

Anterior margin of clypeus straight and deflected. Eyes strongly convergent below, the interocular distance on the vertex being a little more than twice the distance between the eyes across the base of the clypeus. First joint of the flagellum ovate, a little longer than wide in the middle and a little longer than the second joint; the latter hardly longer than the third. Frontal tubercle not prominent, rounded in front. Temples produced into a sharp tooth below just behind the mandibles, their lower margins carinate. On the lower surface of the head, on the gular region, there is a spine in the middle. Posterior ocelli as far from the eyes as they are from each other. Pronotal collar convex anteriorly, the shoulders obtusely angular. Mesonotum convex, without a concave longitudinal area in the middle. Scutellum parallel-sided. Mesopleurae with a tubercle just below the base of the wings, not auriculate as in N.capensis. Dorsum of the epinotum about two-thirds the length of the scutellum. Posterior corners of the epinotal dorsum not distinctly spined, having only a short triangular tooth. Second sternite convex, the basal 
truncation rounded. Tibiae not spinose. Second cubital cell about as high as its stalk is long; the cubitus of the hind wing arises at the end of the submedial cell.

0. $4 \cdot 5-5 \cdot 5 \mathrm{~mm}$. long. Pronotal collar nearly all black above, only a very small area in the middle of a dull yellow colour. Sculpture of the head and thorax somewhat stronger than in the o. Sixth tergite on each side with a carina which is free at the end, forming a blunt tooth. Pygidial area trapezoidal, longitudinally rugose and punctured between the rugae, the apical margin tridentate. Otherwise like the \%. Sternites not fimbriated.

Rhodesia to the Cape. A common species. (R.M. and T.M. colls.)

N. capensis Handl. (figs. 2, $2 a$ and b). Sitzungsber. K. Akad. Wiss. Wien, xcv, p. 325 , ‥ 1887 .

ㅇ. 8-10 mm. long. Black. First three joints of the antennae, pronotal collar above excepting a small median area, posterior angles of the mesonotum, tegulae, legs excepting the coxae and trochanters, and the underside more or less of the middle and hind femora, ferruginous. A spot on each side of the

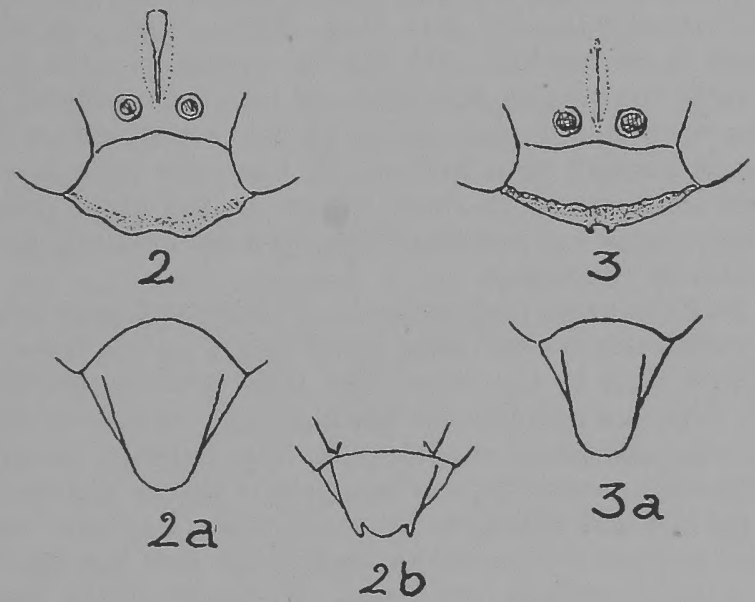

Fig. 2. Nysson capensis, $q$, clypeus; $a, q$, sixth tergite; $b, \sigma$, , seventh tergite.

Fig. 3. Nysson rhodesiae, $q$, clypeus; $a$, $q$, sixth tergite.

clypeus, the base of the mandibles, and a minute spot on each side behind the ocellar area, yellow. Epinotal teeth testaceous. First tergite with a more or less oblong macula on each side; the second, and sometimes also the third tergite, with a transverse yellow band behind the apical margin, narrowed medially and sometimes interrupted. Apical margins of the abdominal segments testaceous. Wings pale fusco-hyaline, the apical margin slightly darker, the veins dark brown. Silky tomentum whitish, almost obscuring the sculpture on the sides of the thorax and on the ventral surface of the abdomen. Clypeus smooth. Face finely and closely punctured below and at the sides, in the middle above it is very coarsely punctured, like the vertex and occiput, with the intervening spaces raised to form a reticulate rugosity. Anterior face of the pronotal collar shining at the sides and sparsely punctured, the rest of the collar, like the mesonotum and mesopleurae, very coarsely punctured and reticulate rugose. The middle longitudinal fourth of the mesonotum is concave and margined by a distinct ridge on each side. Scutellum coarsely 
reticulate rugose. Median area of the epinotal dorsum sharply defined, trapezoidal, with two or three longitudinal rugae in the middle, reticulate rugose at the sides. Declivity and sides of the epinotal spines finely reticulate rugose. The abdomen has a microscopic and fairly dense fundamental puncturation, and a coarser one superimposed. On the first tergite the latter consists of fairly large, elongated punctures set fairly close together; on the second and following tergites the punctures are scanty and barely half as large.

Clypeus about twice as wide as long, the anterior margin feebly concave over the middle third. Interocular distance across the vertex three-quarters greater than across the base of the clypeus. Lower margin of the temples sharply carinate. Scapes short and oblong. First joint of the flagellum globose, the second, third and fourth subequal, all the joints except the first longer than wide. Behind the antennal sockets there is a longitudinal cariniform tubercle, narrowed anteriorly. On the inner margin of the posterior ocelli the surface is raised into a slight ridge, barely visible from above. Posterior ocelli farther from the eyes than from each other. Dorsal face of the pronotal collar flattened, the shoulders rounded, the anterior margin slightly produced over the middle third. Scutellum roundly quadrate, the sides nearly parallel, one-third wider than long. Metanotum coarsely rugose, not distinctly raised in the middle. On the mesopleurae under the wing-bases there is a sharply marginate, and more or less hollowed-out or auriculate tubercle; on the lower margin there is a small and inconspicuous tooth. Pygidial area subtriangular, longer than wide at the base, the apex broadly truncate. Posterior tibiae with a row of short spines on the outer margin. Second cubital cell wider on the cubitus than high, its height slightly greater than the length of its stalk on the radius.

o. $9 \mathrm{~mm}$. long (hitherto undescribed). Colour and sculpture as in the $q$, but the third to fifth tergites also have apical yellow bands, those on the fourth and fifth not extending to the sides. The third to fifth sternites have their apical margins deflected and like the apical margin of the second sternite are fringed with long, yellow and curved hairs. The pubescence on the face and clypeus, and the silky tomentum on the thorax is silvery and very dense, more or less obscuring the underlying sculpture. The sixth tergite bears a tooth on each side at the apex, and the seventh or pygidial area has the apical margin convex, with a sharp tooth on each side. First joint of the flagellum transversely globose, wider than long; the second joint a little longer than the third, the apical joint arcuately emarginate below. Otherwise like the $q$.

Willowmore, C. P. (Dr H. Brauns).

\section{N. nasutus Cam. Sjöstedt, Kiliman Ijaro-Meru Exp. viı, p. 293. I9Io.}

"Black, the basal six joints of the antennae, tegulae, the tubercles, the four front legs and the last abdominal segment dark red; the hinder tarsi of a darker red colour; the basal abdominal segment with a large mark on the sides, narrow at the base, becoming roundly dilated inwardly at the apex towards the middle of the segment, the yellow of this part being bordered with dark rufous, and the third and following segments, yellow; the fourth segment with a narrow, the fifth with a broad black band down the centre; the apices of the second to fourth abdominal segments narrowly pale yellow. Wings hyaline, the apex narrowly smoky, the nervures and stigma black; the third cubital cellule much narrowed in front, it being there not the length of the distance between the second recurrent and the second transverse cubital nervures, the accessory nervure in the hind wing is received at a good distance behind the cubitus. The front below, at the antennae, projects into a pro- 
minent, rounded, nose-like projection, which is keeled in the centre. Clypeus, face and lower two-thirds of the inner orbits densely covered with depressed golden pubescence; the sides of the metanotum densely covered with silvery pubescence. Third joint of antennae slightly, but distinctly longer than the fourth, and almost of the same length as the fifth. Pronotum at the apex clearly separated, the base rounded, the sides oblique. Mesonotum and scutellum irregularly rugosely punctured; the scutellum with the base broadly rounded, flat; the post-scutellum has the middle depressed. Metanotal area smooth, bare, and bearing eight irregular keels; its apex with an oblique slope, smooth. The second ventral abdominal segment is broadly rounded at the base; it is coarsely shagreened. Length II $\mathrm{mm}$.

"Meru low lands, December."

Cameron has omitted to indicate the sex.

N. Gregoryi Turner. Ann. Mag. N.H. Ix, 52, p. 417, ๆ. I9I2.

"ๆ. Nigra; antennis, prothorace, pedibus, tegulisque ferrugineobrunneis; clypeo, segmento dorsali primo macula magna utrinque, secundo fascia apicali subinterrupta, 3-6 totis flavo-ochraceis; alis hyalinis, venis fuscis. Long. $9 \mathrm{~mm}$.

" $q$. Eyes very strongly convergent towards the clypeus, the inner margin sinuate; posterior ocelli a little farther from the eyes than from each other, and more than half as far again from each other as from the anterior ocellus. Antennae inserted a little farther from each other than from the eyes; first joint of the flagellum globular, second distinctly shorter than the third or fourth, all the joints except the first longer than broad. A moderately elevated longitudinal carina between the antennae, the front higher than the base of the clypeus and narrowly truncated at the apical end of the carina. Head rather distinctly and not coarsely punctured; pronotum rounded at the anterior angles; scutellum not separated by a groove from the mesonotum or postscutellum, rectangular, less than twice as broad as long; postscutellum not depressed in the middle; basal area of the median segment coarsely longitudinally striated, the surface of the posterior truncation shining, with a few indistinct transverse striae, the angles of the segment produced into stout spines directed outwards and backwards. Abdomen punctured, most strongly on the basal segment, very finely and indistinctly on the four apical segments. Second ventral segment strongly punctured and moderately convex; sixth dorsal segment distinctly margined at the sides, shallowly emarginate at the apex. Sides of the first ventral and second dorsal segments dark ferruginous. Third cubital cell almost pointed on the radius, not reaching nearer to the apex of the wing than the radius. Both recurrent nervures received by the second cubital cell, the first close to the base, almost interstitial, the second at four-fifths from the base. Spines of the hind tibiae very small and indistinct, almost obsolete.

"Hab. Nyomps Ndogo, British East Africa (Gregory).

"This belongs to the same group as capensis Handl., and nasutus Cam. The cubitus of the hind wing originates far beyond the transverse median nervure. The frontal carina is better defined than in capensis and the antennae inserted farther apart, the posterior ocelli are more widely separated, the proportionate length of the joints of the flagellum very different, and the spines of the hind tibiae much less developed. The colour of the apical abdominal segments is also different, and the punctures on the head are larger in capensis."

To judge by the descriptions it is quite possible that this is synonymous with nasutus Cam. 
N. Ludovici Turner (figs. 4, 4a and b). Ann. S.A. Mus. xvir, p. 495, o, , . r 920.

o. ro $\mathrm{mm}$. long. Black, base of the mandibles, anterior margin of the clypeus, antennae, pronotal tubercles and the collar above, tegulae, posterior corners of the mesonotum and the legs, excepting the coxae, ferruginous. The lateral margins near the apex of the first five tergites, and the whole of the sixth and seventh tergites and sternites, ferruginous. A small spot on each side a little behind the posterior ocelli and the apices of the epinotal spines, yellow. First tergite with a more or less quadrangular spot of yellow on each side near the apex; the spot widens towards the apex and is as wide there as long. Tergites 2-5 with narrow apical bands of yellow, slightly interrupted in the middle on the second and third, entire on the others. Wings hyaline, slightly tinged with fuscous, the veins brown. Clypeus and lower face with a dense yellowish white pubescence; the vertex, pro- and mesonotum, scutellum, metanotum and base of the first tergite have a very short, decumbent and dull yel-

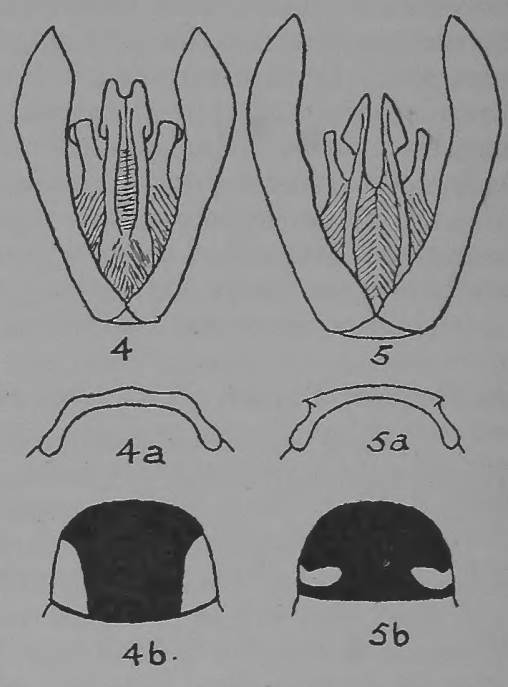

Fig. 4. Nysson Ludovici, ô, genitalia; $a, \hat{o}$, pronotum; $b, \hat{o}$, first tergite.

Fig. 5. Nysson decipiens, $\hat{\sigma}$, genitalia; $0^{\star}, a$, pronotum; $\sigma^{\star}, b$, first tergite. lowish pubescence, somewhat longer and paler on the base of the epinotal spines. On the mesopleurae the pubescence is whitish, and on the underside of the thorax, coxae and second sternite there is a silvery tomentum, very dense on the second sternite and obscuring the sculpture. Sternites 2-5 with long pale yellowish fimbriae on the middle of their apical margins.

Anterior third of the clypeus deflected, the extreme anterior margin with two small and very inconspicuous tubercles in the middle. Face and occiput dull, strongly reticulate rugose, the vertex very closely and finely punctured, with some larger punctures here and there. Pronotal collar finely and closely punctured, with a few large punctures above and in the middle in front. Mesothorax coarsely reticulate rugose, the sides of the epinotum posteriorly above finely so, anteriorly below punctulate and slightly shining, like the metapleurae. Median area of the epinotal dorsum shining, with eight longitudinal carinae. First tergite not quite dull, fairly strongly but not closely punctured, the basal half also longitudinally striato-rugose. Second tergite with punctures less than half as large as those on the first, but equally abundant. Tergites $3-6$ dull, microscopically and closely punctured, the sixth with lateral carinae on the apical half; seventh tergite coriaceous and punctate, the lateral margins carinate, the carinae ending as a blunt tooth at the apex; between the teeth the apical margin is slightly concave. Eyes moderately convergent below, the interocular distance on the vertex being two-thirds greater than across the base of the clypeus. Face with a strong cariniform tubercle in the middle behind the antennal sockets, highest in the middle and longer than high. Posterior ocelli twice as far from the eyes as from each other. First joint of the flagellum globose, a little wider than long, as long as the second which is very slightly longer than the third; the apical joint arcuately emarginate below. 
Temples with a dentiform angle behind the base of the mandibles and with their lower margins feebly carinate. On the underside of the head the anterior margin of the gula is raised and carinate, having the appearance of a spine when viewed in profile. Shoulders of the pronotal collar widely rounded. The epicnemium ends in a dentiform angle below, behind which there is a small black tooth at the junction of the mesopleurae and mesosternum. Mesopleural tubercle below the wing bases well developed, ending in a slight tooth on its lower anterior angle. Scutellum half as wide again as long in the middle, its lateral margins convex. Disc of metanotum raised, its posterior margin serrate owing to the projecting rugae. Epinotal spines long and acute. Posterior tibiae spinose on the outer side. The cubitus of the hind wing originates far beyond the end of the submedial cell.

$.9 .5 \mathrm{~mm}$. long. Tergites ferruginous, fusco-ferruginous to blackish in the middle, the yellow margins as in the $\hat{o}$, but the macula on the first tergite is not widened apically. First joint of the flagellum a little wider than long, only two-thirds as long as the second, which is a trifle longer than wide at the apex and as long as the third. Pygidial area semi-elliptical, two-thirds longer than wide at the base, the apex narrowly rounded. Otherwise like the 0 .

Mfongosi, Zululand, 3 ô including the type (W. E. Jones); Bembesi, S. R. January, $2 \hat{o} \hat{o}$, I $q$ (G. Arnold). Type in S.A. Museum.

A of taken at the same time and place as the type, in the S.A. Museum collection, was wrongly ascribed to this species by Turner, it is the $q$ of the species described hereunder.

$N$. decipiens n.sp. (figs. 5, 5a and $b$ ).

o. 9.5-10.5 mm. long. Deceptively like Ludovici, from which it differs as follows. Colour like that of Ludovici but the third and fourth tergites are entirely yellow, the fifth yellow except for a small ferruginous mark in the middle near the apex, and the maculae on the first tergite are more or less ovate and transverse and continued in a narrow line along the sides of the segment. Last five joints of the flagellum blackish. The pubescence on the vertex, mesonotum and scutellum is denser and has a somewhat brassy yellow tint, very noticeable at some angles. The pubescence on the basal half of the first tergite is slightly golden and denser, obscuring the sculpture at the sides. Posterior ocelli half as far again from the eyes as from each other. Frontal tubercle much more prominent, abruptly truncate in front, highest at that point and as high there as long. First joint of the flagellum less globose, as long as wide in the middle. Pronotal collar with the shoulders produced into slightly curved, dentiform angles. Triangular tooth on the lower margin of the mesopleurae longer and more acute than in Ludovici. Epinotal spines broader towards the apex, which is less acute. Lateral margins of the pygidial area more convex.

These differences alone would not justify the separation of this form as a species, but the genitalia are also different. The inner lobes of the outer paramera are longer and thinner, and the inner paramera are wider in their apical portion and more acute at the apex.

7. $10.5 \mathrm{~mm}$. long. Colour as in the $\hat{o}$ but the fifth tergite is more widely suffused with red in the middle. First joint of the flagellum ovate, as long as wide in the middle, shorter than the second, which is as long as the third. Pygidial area lanceolate, twice as long as wide at the base, the apex narrowly rounded.

Mfongosi, Zululand, I f (W. E. Jones); Bembesi, S. R. 2 ô $\hat{0}$ and I $q$ (G. Arnold); Bulawayo I ô (R. H. R. Stevenson). 
It is remarkable that in both Zululand and S. Rhodesia this insect should have been taken flying with Ludovici, but in view of the differences noted above, it seems necessary to regard it as a distinct species.

The $q$ agrees closely with Turner's description of Gregoryi, but in that species the pygidial area is shallowly emarginate at the apex.

Type in R.M. coll.

N. rufoniger Turner (fig. 6). Ann. Mag. N.H. Ix, 52, p. 4I8, ô. I9I2.

$9.8 \mathrm{~mm}$. long. Head and thorax black. Clypeus, base of the mandibles, scapes, first joint of the flagellum, pronotal collar above excepting a short space in the middle, upper face of the tibiae and apical bands on the first five tergites, yellow. Flagellum, legs and abdomen ferruginous. Tegulae testaceous. Wings hyaline, the veins blackish. Face and clypeus with dense whitish pubescence. Mesopleurae, mesosternum, bases of the epinotal spines and ventral surface of the abdomen with a whitish tomentum. Vertex and base of the first tergite with sparse whitish pubescence. Face, vertex, temples, pronotum and mesopleurae closely and fairly strongly punctured; the sides of the pronotum striate, punctate and slightly shining. Mesonotum and scutellum dull, more closely punctured than the mesopleurae, the punctures larger but shallow. Metanotum longitudinally striate. Median area of the epinotal dorsum coarsely longitudinally striate, the declivity irregularly rugose, the sides striate and' sparsely punctured. The posterior angles of the epinotum are produced into sharp spines, shorter than wide at the base. Tergites I-5 strongly but not very closely punctured, and also with a microscopic rugulose sculpture. The punctures are smallest on the second tergite. Pygidial area dull,
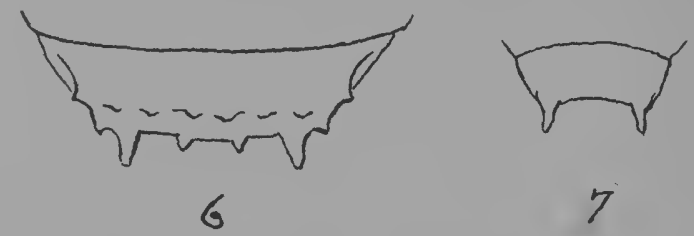

Fig. 6. Nysson rufoniger, $\sigma^{\star}$, seventh tergite.

Fig. 7. Nysson minutus, ô, seventh tergite.

very coarsely and closely punctured, triangular, about as long as wide at the base, the apex rounded. Anterior margin of the clypeus convex, with a feeble incision in the middle. Eyes strongly convergent below, the interocular distance across the vertex being nearly twice as great as across the base of the clypeus. Face with a low tubercle between the antennal sockets, which is rounded apically. First joint of the flagellum globose, the second slightly longer than the third and as long as wide at the apex. Posterior ocelli as far from the eyes as from each other. Anterior margin of the pronotal collar very convex, the shoulders rounded. Mesonotum evenly convex, without a median longitudinal concave depression. Scutellum parallel-sided, two-thirds wider than long in the middle. First and third abscissae of the radius subequal, the second shorter than the stalk of the second cubital cell. The first recurrent vein enters the second cubital cell at one-fifth from its base, and the second recurrent vein is nearly interstitial with the second transverse cubital vein. The cubitus of the hind wing arises from the end of the submedial cell.

o. $7-8 \mathrm{~mm}$. long. Colour and sculpture like that of the $q$. Second joint of the flagellum nearly as long as wide at the apex, almost twice as long as the 
third which is as long as the fourth. The apical joint is arcuately emarginate below at the base, and is about twice as long as wide. Seventh tergite much wider than long, armed with a tooth on each side of the apical margin and a pair of smaller teeth near the middle; the sides with two dentate projections. The sternites are without long fimbriae, but the apical one has a row of short, stiff hairs on the apical margin.

Upper Luangwa River, N. E. Rhodesia; Gwaii, Sawmills, Forest Vale and Sanyati Valley, S. R. (R.M. and T.M. colls.)

N. minutus n.sp. (fig. 7).

o. $4.5 \mathrm{~mm}$. long. At a first glance not unlike a smallspecimen of N. Braunsi, but with a very different sculpture. Black. The underside of the scapes and the first five joints of the flagellum yellowish white. A streak on the pronotal collar widely interrupted in the middle and not reaching the shoulders, and narrow apical bands on the first two tergites also widely interrupted in the middle, yellowish white. Mandibles fusco-ferruginous. Tegulae reddish brown. Fore legs pale brownish yellow, the tarsi a little paler. Middle and hind legs pale brown, the tibiae yellowish on the outside. Wings hyaline, the veins black. Face, clypeus and thorax with a whitish pubescence, fairly dense on the clypeus and face. Abdomen with a microscopic and sparse, greyish pubescence above, and a thin tomentum of the same colour below. Head, excepting the clypeus, strongly punctured, the puncturation fairly sparse on the face but becoming closer and coarser above, without a reticulate rugosity between the punctures, except on the occiput. The vertex and occiput slightly shining between the punctures, the rest of the head dull. Temples carinate on the lower margin and produced into a short tooth below behind the base of the mandibles; a median spiniform process on the gular region, such as is present in Braunsi, is lacking in this species. Mesonotum coarsely and closely punctured, the punctures twice as large as those on the vertex, slightly shining; mesopleurae dull, closely reticulate rugose. Scutellum and metanotum reticulate rugose, the meshes fairly large. Dorsum of epinotum with a well-defined median area, traversed by six oblique rugae; the lateral areas are finely rugose and the apical angles are produced into spines which are as long as wide at the base, and fairly acute. Declivity and sides of the epinotum reticulate rugose. Tergites nitidulous, strongly and fairly closely punctured, much more so than in Braunsi. The punctures of the first tergite are largest, a little larger than those on the vertex and about twice as large as those on the rest of the abdomen. Sternites dull, fairly closely punctured, the apical one coarsely so. The apical margin of the pygidial area is produced into a strong spine on each side, the space between them slightly concave. Anterior margin of the clypeus deflected. Interocular distance on the vertex two and a third times as great as across the base of the clypeus. First joint of the flagellum subglobose, a little longer than wide in the middle, and half as long again as the second, which is as long as the third; apical joint arcuately emarginate below. Posterior ocelli a little farther from the eyes than from each other. Shoulders of the pronotal collar rounded. Mesonotum with a very shallow median longitudinal impression. Scutellum half as wide again as long, its sides feebly convex. Second sternite with the brow of its basal declivity widely rounded. Tibiae not spinose.

Sawmills, S. R., December, I ô. Type in R.M. coll.

N. willowmorensis Brauns. Verh. Zool. Bot. Ges. Wien, LXI, p. 137, f. I9I I.

9. $4 \mathrm{~mm}$. long. Black. The front of the scapes and the mandibles ferruginous, the apices of the latter black. Basal half or more of the flagellum 
fusco-ferruginous below. Tegulae and legs ferruginous, the femora reddish brown. First abdominal segment and the base of the second, ferruginous, with narrow transverse apical yellow streaks on each side. The pronotal tubercles and a small spot on each side of the middle of the pronotal collar are also pale yellow. Wings pale fusco-hyaline, the veins black. Clypeus, face and temples with a sparse whitish pubescence; apical angles of the epinotum also finely pubescent. Sternites without tomentum. Clypeus sparsely punctured. Face and vertex dull, microscopically alutaceous and also with a fairly sparse, fine puncturation. Occiput a little more coarsely and more closely punctured. Temples not dentate below and not carinate on their lower margin. Pronotal collar, mesonotum, metanotum, scutellum and mesopleurae finely reticulate rugose and closely punctured between the reticulations. The auriculate prominence on the upper part of the mesopleurae is low and small. Median area of the epinotum dull, fairly closely and obliquely rugose, the rest rugulose and coriaceous; the apical teeth short and blunt. Tergites dull, the first two closely punctured, the punctures on the first not half as large as those on the vertex, and on the second smaller than on the first except at the sides. The puncturation on the following segments is finer and closer than on the second. Pygidial area triangular, longer than wide at the base, closely punctured. Sternites slightly shining, the second fairly strongly and not sparsely punctured, the punctures larger than those on the first tergite. Clypeus convex, its anterior margin convex, slightly depressed, feebly and narrowly excised in the middle. Eyes not sostrongly convergent below as in our other small species of the genus, the interocular distance on the vertex being only half as great again as across the base of the clypeus. Face without a median tubercle behind the antennal sockets. Posterior ocelli as far from the eyes as from each other. First joint of the flagellum subglobose, as long as wide, the second joint slightly shorter than the third. Anterior margin of the pronotal collar very convex. Legs without spines. Third cubital cell much narrowed above, the distance between the third transverse cubital vein and the stalk of the second cubital cell being barely half the length of the stalk. The cubital vein of the hind wing is emitted from the end of the submedial cell.

Willowmore, C. P. Type in coll. Brauns.

\section{$N$. rhodesiae n.sp. (figs. 3 and $3 a$ ).}

․ $7-8 \mathrm{~mm}$. long. Colour for the greater part like that of capensis but the clypeus is immaculate, the base of the mandibles ferruginous, the basal joints of the flagellum paler and the pronotal collar darker above, almost black. The yellow maculae on the first tergite are wider and more triangular, the yellow apical band on the second much narrower, and the bands on the remaining segments wider than in capensis. The eyes are more convergent below, the interocular distance on the vertex being twice as great as across the base of the clypeus. The sculpture of the head and thorax is like that of capensis, but the mesonotum is convex right across, not having the longitudinal median depression present in that species. The sculpture of the abdomen differs considerably from that of capensis. On the first tergite the puncturation at the sides apically is not very coarse or close, in the middle of the apical half it is shallow, much finer than in capensis and closer, so that the sculpture is almost reticulate punctate; the basal half or less of the segment is longitudinally rugose and punctate, with a flattened, median, longitudinal and shining line. The puncturation on the sides and base of the second tergite is finer than on the sides of the first and not so dense, but in the middle it is very fine and close. Clypeus two and a half times wider than long in the middle, the apical fourth 
sharply deflexed, the anterior margin with two very small teeth in the middle. Frontal carina acute along its whole length, not slightly flattened as in capensis. Pronotal collar shorter, less than half as long in the middle as the apical joint of the flagellum, the anterior margin more evenly convex, the middle third not produced forwards as in capensis. Scutellum half as wide again as long in the middle. Pygidial area longer, nearly half as long again as wide at the base, more parallel-sided than in capensis. Otherwise like capensis

o. $7-8.5 \mathrm{~mm}$. long. Like the o in colour and sculpture. The two apical tergites shaped as in capensis but not coarsely sculptured, only closely punctate. The genitalia hardly differ from those of capensis.

Sawmills, Victoria Falls and Insiza, S. R. Types in R.M. coll.

\section{Genus ARPaCtus Jurine}

Panzer and Jurine, Intelligenzblatt der Litt. Zeitung, Erlangen, pp. I60-5. I801.

Ceropales Latr., Nat. Hist. III, p. 339. I 802.

Gorytes Latr., Hist. Nat. XII, p. 305. I 805.

I have already had occasion in this work to refer to the paper by Morice and Durrant in the Trans. Ent. Soc. London, I9I4, regarding Panzer's review of Jurine's Nouvelle Méthode and to a subsequent paper on the same subject by J. C. Bradley. It would be out of place here to discuss at length the reasons which lead to the adoption of Arpactus for the name of the genus so long known under the name of Gorytes, but they may be stated briefly as follows. The argument of Bradley that Ceropales Latr. should replace Gorytes would hold good if it could be admitted that Ceropales and Arpactus are not, from the modern point of view, synonymous. But this is precisely what they are, and the type of Ceropales, I796, not having been selected by Latreille until I802, that name is antedated by Arpactus Jurine, I80I, with type mystaceus.

The genus was monographed by Handlirsch in 1888 (Sitzungsber. K. Akad. Wiss. Wien, XcVII). In a long introductory chapter he gave a critical review of the taxonomy, and advanced cogent reasons for including in the genus as many as 17 genera and subgenera of other authors. It appears to me that on the whole the soundness of his conclusions are unassailable, and that with the exception of a few species which form a distinct subgenus (Ammatomus Costa), it is not possible to do more than to arrange the species into species-groups. Kohl (Die Gattungen der Sphegiden) rightly says that this is a large genus in a state of dissolution, comparable to the genus Crabro.

Characters. Mandibles not excised on the outer margin, the apex acute, the inner margin with one or more teeth. Maxillary palpi 6-, labial palpi 4-jointed. Labrum hidden or slightly exserted. Inner margins of the eyes not sinuate, parallel or convergent below, sometimes convergent in the and parallel in the $\delta$. The facets on the inner side of the eyes below are often enlarged, as in some species of the genus Thyreopus. Clypeus moderately convex, the anterior margin not dentate. Ocelli round and convex, arranged in a low triangle. Temples well developed or almost obsolete, in the latter case the back of the head is truncate almost immediately behind the eyes, thereby making the vertex very short and the junction between it and the occiput almost rectangular. Antennae I2-jointed in the o, I3-jointed in the $\sigma^{\pi}$, the flagellum filiform or incrassate apically, some of the joints in the often armed with teeth or other projections. Scapes fairly short, inserted a little above the posterior margin of the clypeus. Pronotal collar very short, usually linear above, not sunk much below the level of the mesonotum. The pronotal tubercles do 
not extend back as far as the tegulae. An epicnemium is present on the mesopleurae, and the epinotal suture is sometimes absent. Sometimes there is on each side of the mesosternum a longitudinal carina extending from the epicnemium in front to the metapleurae behind. The metapleurae are short. Epinotum wider than long; the dorsum always has a well-defined median triangular area and its posterior margin is not clearly defined, as the junction of the dorsum with the declivity is nearly always widely rounded, rarely rectangular. The first abdominal segment is either of the usual shape or more or less constricted and elongate, sometimes forming a distinct petiole. Pygidial area distinctly defined in the + , triangular and marginate at the sides. In the $f$ the seventh tergite lacks a pygidial area and is often hidden under the sixth. There are only six ventral plates visible in the $\delta$. The eighth dorsal plate is only feebly chitinised and the eighth ventral is trifurcate at the base and usually produced to a point or truncate at the apex. Trochanters of the first two pairs of legs 2-jointed. Middle coxae inserted close together. Middle tibiae with two spurs. Anterior tarsi usually with a comb of long cilia, the basal joints often asymmetrical. Claws unarmed; pulvilli well developed.

Fore wing. Pterostigma well developed, radial cell lanceolate, without an accessory cell. Three cubital cells present, the second receiving both recurrent veins and narrowed towards the radius. The basal vein is emitted before the end of the submedial cell and meets the subcosta not far from the pterostigma.

Hind wing. Retinaculum unbroken, medial cell long, ending not far from the apical margin, the cubitus originates either in front of or behind the end of the submedial cell, or is sometimes interstitial. Basal lobe oblong, shorter than the submedial cell.

Distribution. Both hemispheres, but the Palaearctic, Neotropical and Nearctic regions are the richest in species.

The insects of this genus provision their larvae with Homoptera (Cicadinidae, Fulgoridae, etc.).

\section{KEY TO THE SPECIES 우.}

(20) I. Temples well developed, the head not being abruptly truncate just behind the eyes; posterior tarsi not very long. Flagellum not clavate.

(7) 2. Mesosternum without a carina on each side.

(6) 3. Median triangular area of the epinotum smooth and shining. Thorax not strongly and closely punctured.

(5) 4. Second abdominal segment almost entirely pale yellow. Large species, I6-19 $\mathrm{mm}$. long.

natalensis Smith

(4) 5. Second abdominal segment black and ferruginous, with a narrow yellow apical band. effugiens Brauns

(3) 6. Median triangular area of the epinotum strongly; closely and longitudinally rugose. Thorax closely and deeply punctured.

Kraepelini Brauns

(2) 7. Mesosternum with a carina extending from the posterior inferior angle of the epicnemium to above the middle coxae.

(9) 8. Epicnemium with an acute curved tooth below. Eyes strongly convergent below, their distance apart at the base of the clypeus being only a fifth of the interocular distance on the vertex, and equal to the length of the first two joints of the flagellum. Puncturation coarse. monstrosus Handl.

(8) 9. Epicnemium unarmed below. Eyes less convergent below, or subparallel.

(II) Io. The raised lateral margins of the pygidial area at about the middle are abruptly deflected inwards towards the base.

aglaia Handl. 
(Iо) II. Lateral margins of the pygidial area not incurved.

(I5) I2. Inner margins of the eyes parallel over the greater part of their length, only slightly convergent below. Small species, about $7 \mathrm{~mm}$. long.

(I4) I3. Thorax, excepting the mesosternum and the median triangular area of the epinotum, bright ferruginous. rufithorax Brauns

(13) I4. Thorax black, the pronotal collar above and the posterior half of the scutellum pale yellow.

(12) I5. Inner margins of the eyes clearly convergent below.

(I9) I6. Thorax and abdomen in greater part ferruginous, with some yellow markings.

(18) I7. Second joint of the flagellum half as long again as the third. Declivity and sides of the epinotum transversely rugose. I I $\mathrm{mm}$. long.

umtalicus Arnold

(I7) 18 . Second joint of the flagellum one-third longer than the third. Declivity and sides of the epinotum without rugae, only punctured. $8.5 \mathrm{~mm}$. long.

Marshalli Turner

(16) I 9. Thorax and abdomen black, with yellow markings. (Second joint of the flagellum not quite one-fourth longer than the third.)

thalia Handl.

(I) 20. Temples almost obsolete, the head being abruptly truncate just behind the eyes; the latter are nearest together at about the middle of the face, divergent above and below. Flagellum strongly clavate. Posterior tarsi very long. (subgenus Ammatomus A. Costa)

(28) 2I. First segment of the abdomen forming a distinct petiole, at least two-thirds longer than wide; the apical margin of the second segment at least twice as wide as that of the first.

(25) 22. Mesonotum coarsely punctured; first segment of the abdomen widest in the middle, the apical margin of the second segment fully three times wider than that of the first.

(24) 23. Petiole two-thirds longer than wide in the middle; puncturation of the mesonotum fairly close.

elongatulus Turner

(23) 24. Petiole twice as long as wide in the middle; puncturation of the mesonotum irregular and scattered.

(22) 25. Mesonotum more finely punctured.

(27) 26. Second tergite half as wide again at the apex as the first. spiniferus

27. Second tergite three times as wide at the apex as the first.

(2x) 28. First segment of the abdomen of the usual shape or only subpetiolate; the second segment at its apex less than twice as wide as the first.

(30) 29. First tergite one-fourth wider at the apex than long; posterior tarsi yellowish white.

Stevensoni Arnold

(29) 30. First tergite subpetiolate, slightly narrowed from the middle to the base, about one-third longer than wide; posterior tarsi brown.

fuscipes Arnold

\section{KEY TO THE SPECIES ơ $0^{\star}$.}

(18) I. Temples well developed, the head not being abruptly truncate behind the eyes; posterior tarsi not very long. Flagellum not clavate.

(7) 2. Mesosternum without a longitudinal carina.

(6) 3. Median triangular area of the epinotum smooth and shining. Thorax not strongly and closely punctured.

(5) 4. Second abdominal segment almost entirely pale yellow.

natalensis Smith

(4) 5. Second abdominal segment ferruginous, with a yellow apical band. 
(3) 6. Median triangular area of the epinotum closely, strongly and longitudinally rugose. Thorax closely and deeply punctured.

(2) 7. Mesosternum with a longitudinal carina.

Kraepelini Brauns

(9) 8. Epicnemium with an acute, curved tooth below. Eyes strongly convergent below, their distance apart at the base of the clypeus being only as long as the first two joints of the flagellum. Puncturation of the head, thorax and abdomen coarse. monstrosus Handl.

(8) 9. Epicnemium unarmed below; eyes less convergent below, or subparallel.

(I I) IO. Thorax, excepting the mesosternum and median area of the epinotum, bright ferruginous. rufithorax Brauns

(Io) II. Thorax black or fusco-ferruginous, the pronotal collar above more or less yellow, the scutellum with yellow markings (or ferruginous if the rest of the thorax is black).

(15) I2. Clypeus short, three times wider than long, or if slightly less then the inner orbits are parallel.

(14) I3. Lateral areas of the epinotal dorsum obliquely rugose. Posterior ocelli nearer to the eyes than to each other. vicarius Handl.

(13) I4. Lateral areas of the epinotal dorsum punctured; posterior ocelli as far from the eyes as from each other. thalia Handl.

(12) 15. Clypeus longer, less than three times wider than long.

(17) 16. Tergites distinctly and not very sparsely punctured; second and third joints of the flagellum slightly dilated below. aglaia Handl.

(I6) 17. Tergites very sparsely and very finely punctured; second and third joints of the flagellum simple.

Marshalli Turner

(I) 18. Temples almost obsolete, the head being abruptly truncate behind the eyes; the latter nearest together at about the middle of the face, divergent above and below. Flagellum strongly clavate. Posterior tarsi very long.

(subgenus Ammatomus A. Costa)

(22) 19. First segment of the abdomen forming a distinct petiole, at least twice as long as wide.

(2I) 20. Mesonotum dull, coarsely and not very sparsely punctured. Interocular distance on the vertex equal to the length of the first four joints of the flagellum.

elongatulus Turner

(20) 2I. Mesonotum coarsely and rather sparsely punctured. Interocular distance on the vertex equal to the length of the first five joints of the flagellum.

gemellus Arnold

(19) 22. First segment of the abdomen less narrow; mesonotum sparsely and not coarsely punctured.

(26) 23. First segment of the abdomen subpetiolate, half as long again as wide, or less, its apical margin only half as wide as that of the second.

(25) 24. Femora black.

(24) 25. Femora ferruginous.

spiniferus Du Buyss.

(23) 26. First segment of the abdomen not subpetiolate, slightly wider at the apex than long, its width there being two-thirds of the width of the second segment at the apical margin.

Stevensoni Arnold

\section{SECTION I.}

Species with well-developed temples. Eyes convergent below. Pronotal collar short and nearly linear. First abdominal segment subpetiolate. The cubitus of the hind wing originates before the end of the submedial cell. Flagellum filiform. Mesosternum not carinate. 
A. natalensis Smith (figs. 8, $8 a$ and $b$ ). Cat. Hymen. B.M. Iv, p. 365 , ․ 1856 . o. 16-19 $\mathrm{mm}$. long. Black, the second abdominal segment pale chrome yellow, except the extreme apical margin and sometimes a small spot in the middle of the base. Mandibles excepting the black apex, flagellum, pronotum, tegulae, the upper corners of the mesopleurae in front, scutellum, last abdominal segment, the fifth tergite and the legs excepting the tarsi, ferruginous. The upper side of the flagellum with a blackish stain along the joints. Scapes in front, base of the clypeus, the frontal triangle, sides of the lower half of the face and the tarsi, yellow. The outer side of the tarsi and the base of the first joint sometimes fusco-ferruginous. The upper side of the coxae, trochanters and femora often fuscous. Wings hyaline, slightly tinged with yellow, and with a brownish cloud on the radial, and on the upper part of the second and third cubital cells, and extending beyond them to the apical margin. Clypeus and lower margin of the face with a thin silvery pubescence, the vertex and upper surface of the thorax with an erect brownish pubescence, short and scanty except on the epinotum. Underside of the thorax and the coxae, trochanters and femora with a fairly dense, very fine and greyish pubescence. Clypeus shallowly, finely and sparsely punctured in front. Face and vertex

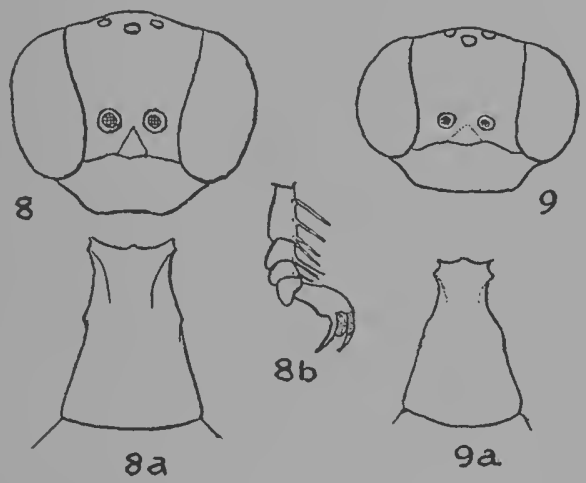

Fig. 8. Arpactus natalensis, + , head; $a,+$, first tergite; $b,+$, anterior tarsus.

Fig. 9. Arpactus effugiens, $q$, head; $a$,, , first tergite.

moderately shining, finely and sparsely punctured, the temples shining and impunctate. Thorax shining, microscopically and very shallowly punctured, except the scutellum, where the punctures are a little larger. Scutellum twice as wide as long, separated from the mesonotum by a clathrate suture. Median triangular area of the epinotum defined by a shallow and feebly clathrate groove on each side. Abdomen smooth and shining above, the pygidial area triangular, sparsely and finely punctured, longer than wide at the base. Sternites shining, the third and following ones finely and sparsely punctured. First segment subpetiolate, narrowed towards the base, about one-third longer than wide at the apex, the tergite with a small tooth on each side at the base, the sternite longitudinally carinate in the middle. Interocular distance on the vertex two-thirds greater than across the base of the clypeus, and equal to the length of the first three joints of the flagellum. The latter is filiform, its second joint nearly half as long again as the third. Posterior ocelli as far from the eyes as from each other. Anterior tarsi with a comb of brownish cilia; the basal joint as long as the following united, the latter wider than long. Second recurrent vein usually interstitial with the second transverse cubital vein. 
The cubitus of the hind wing originates a good distance before the end of the submedial cell.

o. I $5 \mathrm{~mm}$. long. Last two abdominal segments reddish brown. The third and fourth tergites and the apical margins of the fifth and sixth covered with a black, short and fairly dense pubescence. Interocular distance on the vertex nearly twice as great as across the base of the clypeus. Second joint of the flagellum only a trifle longer than the third. Second joint of the anterior tarsi as long as wide. Otherwise like the o.

Natal; Vumbu Mts and Sanyati River, S. R. The prey is a Fulgorid, Ptyelus grossus. (R.M. and T.M. colls.)

A. effugiens Brauns (figs. 9 and 9a). Verh. Zool. Bot. Ges. Wien, LXI, p. I33, ․ 1911 .

A. fugax Turner. Ann. Mag. N.H. xvi, p. 289, ‥ 1915.

o. I $3 \mathrm{~mm}$. long. Black. The following parts are fusco-ferruginous: clypeus, mandibles, pronotum, sides of the mesonotum, pronotal tubercles, tegulae, scutellum and metanotum, sides of the epinotum, first, second and sixth abdominal segments, legs and antennae. Base of the mandibles, scapes in front, sides of the lower half of the face, frontal triangle, pronotal collar above, posterior angles of the mesonotum, posterior margin of the scutellum, apical bands on tergites 2-4 and sides of the second sternite, pale yellow. The apical band on the second tergite is widened laterally, those on the third and fourth very narrow or almost linear. The first tergite is black in the middle, the black mark narrowed towards the apical margin and not reaching it. The second tergite has a transverse lunate black mark on the basal half. Antennae pale ferruginous below, darker above. The tibiae are pale yellow underneath and the tarsi are dark brown. Wings hyaline, tinged with brownish yellow at the base, over the radial cell and on the costal margin. Head with a very sparse, short and greyish yellow pubescence. Epinotum and metapleurae with a thin, fairly long and greyish yellow pilosity. Tergites $2-4$ with decumbent, yellowish and fairly dense pubescence. Clypeus sparsely punctured and slightly shining. Face, vertex and temples shining, with a few small punctures. Thorax shining, with only a microscopic and scanty puncturation. Tergites smooth and shining, the pygidial area sparsely punctured and shaped like that of natalensis; sternites shining, very finely and very sparsely punctured. Clypeus wider than in natalensis, about twice as wide as long, the anterior margin straight. Eyes less convergent below than in natalensis, the interocular distance on the vertex being barely more than one-fourth greater than across the base of the clypeus, but equal to the length of the first three joints of the flagellum as in that species. The second joint of the flagellum is only a trifle longer than the third. Posterior ocelli a little farther from the eyes than from each other. There is a clathrate suture between the scutellum and mesonotum, and clathrate grooves at the sides of the median area of the epinotum, continued at the junction as a single groove to the end of the declivity (as in natalensis). First segment of the abdomen subpetiolate, relatively wider at the apex than in natalensis, being less than one-third longer than wide. Tibiae feebly spinose, the anterior tarsi as in natalensis.

Durban, I 9 , type in coll. Brauns; Makindu, B.E. Africa.

I have no hesitation in sinking fugax Turner in synonymy. Turner was misled by Brauns's description of the eyes as "strongly convergent below" and as for the so-called four short carinae on the anterior part of the mesonotum, no importance can be attached to them since they are very indistinct and when 
riewed somewhat obliquely appear to be grooves such as are stated to be present in fugax. The absence of the yellow band on the third tergite in fugax is merely an individual variation, even in effugiens it is quite inconspicuous.

A. Fonesi Turner (figs. 1o and Io a). Ann. S. Afr. Mus. xvir, p. 494, ô. I920. o. $9 \mathrm{~mm}$. long. Ferruginous. Clypeus and lower half of the face pale yellow, the rest of the head black. Mesonotum in the middle narrowly, the scutellum, metanotum, median area of the epinotal dorsum, apex of the declivity, mesosternum and extreme base of the third to fifth tergites, black. Mandibles at the base, scapes in front, a triangular spot on the temples below, pronotum excepting the anterior face of the collar, posterior margins of the scutellum and metanotum, episternum of the mesothorax, anterior and middle coxae below, narrow apical bands on the first, second and fourth tergites, the whole of the fifth and sixth tergites and sternites, pale yellow. Anterior and middle femora below, anterior and middle tibiae in front and the anterior tarsi, pale yellow. Wings hyaline, the veins dark brown, the pterostigma ochreous. Head and thorax above and the third to fifth tergites with a yellowish decumbent pubescence, the epinotum with longer and whitish pubescence on its sides and declivity. Head, pro-mesothorax and abdomen shining and almost smooth. Sutures between the mesonotum and scutellum and the latter

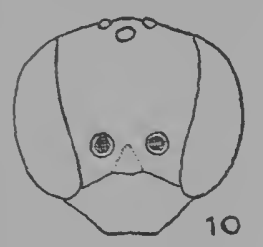
and the metanotum crenulated. Median area of the epinotum strongly and longitudinally rugose, margined on each side by a crenulated groove. Clypeus twice as wide as long, the anterior margin convex. Eyes moderately convergent below, the interocular distance on the vertex being half as great again as across the middle of the clypeus, and equal to the length of the first four joints of the flagellum. Posterior ocelli a little nearer to the eyes than to each other. Flagellum filiform, the third and fourth joints of equal length, the second a little longer than the third. First segment of the abdomen subpetiolate, three-quarters longer than wide at the apex, twice as wide there as at the base. First sternite not carinate longitudinally in the middle. Tibiae not spinose. Second cubital cell receiving both recurrent veins; second abscissa of the radius about as long as the first, the third nearly four times as long as the second. The cubitus of the hind wing originates a little before the end of the submedial cell.

M'fongosi, Zululand (W. E. Jones), I o. Type in S.A. Museum.

The description given above, which differs in one or two small points from that of Turner, is based on an examination of the type. The species is closely allied to effugiens.

A. nyasicus Turner. Ann. Mag. N.H. xvi, p. 288, ô. I915.

" ${ }^{-}$. I I mm. long. Black; antennae, mesonotum and a broad basal band on the second tergite, ferruginous; clypeus, mandibles at the base, the scapes below, the inner orbits narrowly, pronotum, sides of the mesonotum and two longitudinal fasciae, tegulae, the mesopleurae in front, an apical band on the scutellum, postscutellum, a broad, oblique stripe on each side of the epinotum, the metapleurae in front, a basal spot on the first tergite and a band at its apex widely dilated at the sides and interrupted in the middle, wide apical bands on the second to fifth tergites, the whole of the sixth segment, the first sternite, triangular maculae on each side of the second sternite, the coxae above, the 
femora and tibiae below, yellow; the femora and tibiae above and the tarsi fusco-ferruginous; wings hyaline, the veins black, the pterostigma testaceous, the radial cell distinctly clouded.

"Antennae simple, the second joint of the flagellum longer than the scape, equal to the third joint. Clypeus very slightly convex, the apical margin straight; a distinct groove running from the anterior ocellus to the antennae. Eyes converging towards the clypeus, but not quite as strongly as in natalensis Smith. The whole insect shining, the punctures microscopic; head and abdomen clothed with a fine silky pubescence; a transverse row of large punctures at the base of the scutellum; four indistinct longitudinal grooves from the anterior margin of the mesonotum; the marginal and median grooves of the smooth basal area of the median segment striated. First abdominal segment slender, distinctly constricted at the apex. Second abscissa of the radius a little longer than the first; second recurrent nervure received a little farther from the apex of the second cubital cell than in natalensis. Cubitus of the hind wing originating before the transverse median nervure.

"Hab. Nyasaland, S.-W. of Lake Chilwa; January (S. A. Neave)."

\section{Section II.}

A longitudinal carina between the mesopleurae and mesosternum, extending from the epicnemium in front to the metapleurae behind. Wings with some dark markings. Puncturation of the thorax not very fine. Median area of the epinotum longitudinally and coarsely striate. In the $o^{x}$ there is a pencil of hairs at the sides of the clypeus. of with a tarsal comb. First abdominal segment short and wide. Lower margins of the temples carinate; temples well developed, the head not vertically truncate just behind the eyes. Flagellum filiform.

A. intricans Grib. Bull. Soc. Ent. Ital. xvi, p. 276, ô. I884. Rassegna degl' Imen. Mozamb. R. Accad. Bologna, pp. I 30 and 132, + . I894. Handlirsch, Sitzungsber. K. Akad. Wiss. Wien, XCVII, p. 54I, o. I888. Ibid. CIV, p. 893. I 895 .

" d. $9 \mathrm{~mm}$. long. Robust, reddish ferruginous, covered with a pruinose pubescence, the face with silvery pubescence; the apex of the antennae, middle of the mesonotum, median triangular area of the epinotum, the pleurae diffusely, sternum, coxae, trochanters and femora above, a line on the outer side of the tibiae, hind tarsi and the middle segments of the abdomen diffusely at the base, blackish; mandibles, clypeus, cheeks, front of the scape, the pronotal collar above, the pronotal tubercles, apical fasciae on the first to fifth segments, wide on the first, second and fifth, narrow on the third and fourth, and the pygidium, yellow; wings hyaline, with a fuscous cloud on the radial cell and upper half of the second and third cubitals; scapes incrassate; ninth and eleventh joints of the flagellum emarginate below; the head very finely, the thorax fairly coarsely, closely and irregularly punctured, subcoriaceous and dull; median triangular area of the epinotum with divergent and fairly coarse striae; the first two abdominal segments sparsely and moderately strongly punctured, the remaining segments fairly closely but more finely punctured; sixth segment plano-convex, triangular, coarsely and closely punctured; second sternite plano-convex.

"f. 9-10 mm. long. Very much like the of but the body is somewhat more coarsely and more closely punctured, less sericeous and more shining; scapes cylindrical, only very slightly tumid; terminal joints of the flagellum 
not impressed; pygidial area flattened at the apex, carinate on each side, the carinae arcuate, not confluent above; clypeus ferruginous."

Port Elizabeth.

Handlirsch remarks that this species is possibly synonymous with one of those which he himself described from South Africa. Without having seen the type of Gribodo's species I am unable to come to any definite conclusion on that point, but it should be noted that Gribodo's description fits A. aglaia Handl. very closely. Should the synonymy be proved, Gribodo's name takes priority.

A. Emeryi Grib. Loc. cit. p. I30. ơ. Handlirsch, loc. cit. p. 889 .

"o. $8 \mathrm{~mm}$. long. Small but robust, blackish, greyish pruinose, especially on the abdomen; antennae, pronotal tubercles, tegulae, legs, the whole of the first, sixth and seventh abdominal segments, the greater apical part of the fifth and second, the margins of the third and fourth on each side, reddish fer ruginous; mandibles, clypeus, lower half of the face at the sides, scapes in front, dorsal face of the pronotal collar, fore and middle tibiae in front and the hind tibiae on the inner side, tarsi and apical margins of the first four abdominal segments, sulphur yellow; apex of the flagellum fusco-ferruginous; apical half of the posterior tarsi blackish; first abdominal segment suffused with blackish colour lengthwise in the middle; the yellow marginal bands on the first, third and fourth segments narrowed, on the second widened, laterally. Wings clear hyaline, with a fuscous cloud over the whole of the radial and half of the second cubital cells; head and thorax fairly stout, the abdomen comparatively slender; head densely, fairly finely, irregularly punctured and subcoriaceous; the pleurae moderately and unevenly punctured; epinotum closely and coarsely reticulate-punctate, the median triangular area longitudinally, coarsely and irregularly striate; first abdominal segment shining, the following segments dull, all sparsely punctulate, but somewhat more closely and more strongly on the apical margins; scapes slightly swollen; flagellum short and thick, the third to seventh joints short, especially the fourth to seventh, the apical joint fairly long; the third to seventh swollen behind, the eighth to tenth impressed behind; first abdominal segment subpetiolate, feebly constricted; second segment tumid, conical basally, subhemispherical apically; sixth segment acutely conical; the pygidium short and small; wings fairly short."

Magnarra River, Mozambique.

A. aglaia Handl. (figs. I I and I I $a-f$ ). Loc. cit. p. 887, $\sigma^{A}$.

A. euphrosyne Handi. Loc. cit. p. 888, ㅇ.

ㅇ. 10-10.5 mm. long. Black. Clypeus, mandibles excepting the apex, lateral margins of the upper half of the face, anterior margin of the temples, prothorax, tegulae, sides of the mesonotum, the upper part and sometimes the whole of the mesopleurae, scutellum, metanotum more or less, the first abdominal segment excepting the base above, all the sternites and the legs, ferruginous. Second to sixth tergites ferruginous, becoming darker or fuscoferruginous to blackish towards the base. The dorsal face of the pronotal collar sometimes yellow. First, second and fourth tergites with apical bands of yellow, the fifth and sixth sometimes entirely yellow. The lower corners of the face and the lateral margins halfway up, the front of the scapes and the fore and middle tibiae on the inside, the posterior margin of the pronotal tubercles, the base of the mandibles and the apical margin of the second sternite are yellow. Flagellum pale ferruginous, darker towards the apex. 
Wings hyaline, the veins blackish, the pterostigma ochreous. The radial, the greater portion of the upper part of the second and third cubitals, and sometimes the upper margin of the second discoidal are clouded with brown. Lower margin of the face and the clypeus with a thin whitish pubescence. On the rest of the body there is a pruinose pubescence, whitish on the sides and undersurface of the thorax, first tergite and the sternites, yellowish elsewhere, especially on the apical tergites which in some lights look almost dull golden. Clypeus shallowly and not very closely punctured, slightly shining. Face, except at the sides and below, and the vertex strongly but not closely punctured, the spaces between the punctures being mostly three times the width of a puncture. Pronotal collar sparsely and finely punctured. The rest of the thorax, excepting the median triangular area of the epinotum, strongly punctured; the punctures about twice as large as those on the vertex. On the sides of the epinotum anteriorly the punctures are sparse, elsewhere fairly abundant. Median triangular area of the epinotum distinctly defined by the difference of sculpture, with about $12-14$ longitudinal carinae which are more or less parallel. Tergites $I-5$, second sternite and apical margins of the

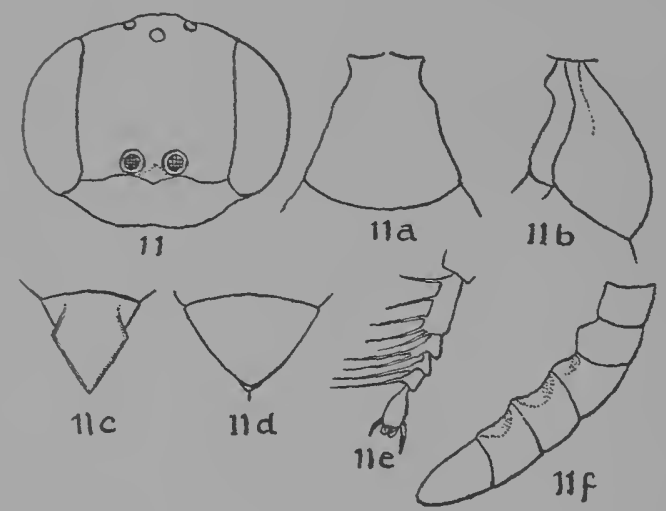

Fig. II. Arpactus aglaia,$q$, head; $a$ and $b, \circ$, first tergite; $c, q$, pygidium $; e, q$, anterior tarsus; $d, \hat{o}$, seventh tergite; $f, \hat{o}$, apical joints of the flagellum.

remaining sternites fairly strongly punctured, but not so closely or strongly as the mesonotum. Pygidial area closely and coarsely punctured, subtriangular, the apex acute, the raised lateral margins abruptly turned inwards at about the middle towards the base. Clypeus convex lengthwise, three times wider than long, the anterior margin nearly straight. Inner margins of the eyes parallel. Interocular distance on the vertex equal to the length of the first six joints of the flagellum. Second joint of the flagellum fully half as long again as the third. Posterior ocelli as far from the eyes as from each other. Vertex convex. First segment of the abdomen reversed trapezoidal, two and a half times wider at the apex than at the base, about as wide at the apex as long in the middle, and not constricted apically. Middle and hind tibiae feebly spinose, the anterior tarsi with a long comb, the second joint asymmetrical. Second abscissa of the radius about as long as the distance between the two recurrent veins on the cubitus.

o. $10.5 \mathrm{~mm}$. long. Colour as in the , but the third tergite sometimes has a very narrow apical band of yellow, and the apical tergite is entirely pale yellow. Mandibles yellow, only the apex reddish. Eyes slightly convergent 
below. The face narrower than in the $q$, and the joints of the flagellum shorter. Interocular distance on the vertex equal to the length of the first seven joints of the flagellum. The second joint of the flagellum is about a quarter longer than the third, the ninth angulated below in the middle and wider than the preceding joint, the Ioth-12th arcuately excavated below. Apical tergite broadly triangular, half as wide again at the base as long, the apex narrowly rounded, not quite so coarsely punctured as in the $\%$.

Trillonmore, C. P.: Bulawayo, Sawmills and Sanyati Valley, S. R. (R.M. and T.M. colls.)

\section{A. Marshalli Turner (figs. I2 and I2a). Ann. Mag. N.H. xvr, p. 287, oै. Igr 5 . \\ " $\hat{0} .9 \mathrm{~mm}$. long. Ferruginous; mandibles, clypeus, inner orbits, scapes} below, pronotum, basal half of the scutellum, a fascia on the apical margin of the first tergite broadly dilated at the sides, apical fasciae on the fourth, very narrow ones on the second and third, yellow; wings hyaline, radial cell infuscated, the pterostigma testaceous, the veins black.

"Clypeus broad, transverse at the apex, labrum shallowly emarginate in the middle; eyes slightly convergent towards the clypeus, posterior ocelli almost twice as far from each other as from the eyes. Second joint of the flagellum longer than broad, joints $3^{-10}$ as broad as long, or broader; a distinct sulcus from the anterior ocellus to the base

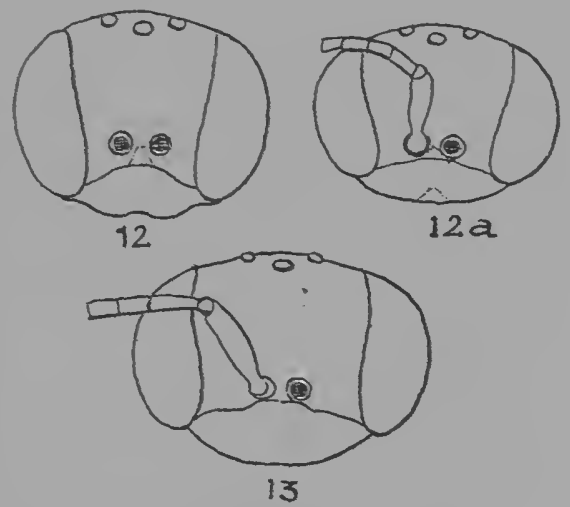

Fig. 12. Arpactus Marshalli, $\hat{0}$, head; $a$,, head.

Fig. 13. Arpactus umtalicus, , head.

of the antennae. Head finely and not very closely punctured, thorax and abdomen with larger punctures, pronotum and first dorsal segment shining and almost smooth, the triangular basal area of the median segment rather coarsely obliquely striate. Mesonotum broad and robust; median segment short. First abdominal segment gradually broadened from the base; pygidium broadly triangular, without a distinct pygidial area. Anterior tarsi without a comb. Carina of the mesosternum as in aglaia Handl. Cubitus of the hind wing interstitial with the transverse median nervure; second abscissa of the radius as long as the first.

"Hab. Chirinda Forest, Gazaland; March Ig07 (G. A. K. Marshall).

"This is a more robust species than aglaia Handl., or thalia Handl. The penultimate joint of the antennae is slightly excavated beneath, but not as strongly as in aglaia. The yellow apical bands on the second and third dorsal segments are extremely narrow, almost obsolete. The thorax is more sparsely punctured than in aglaia."

A $o^{t}$ and a from Bulawayo (coll. Stevenson) appear to belong to this species. If this identification is correct, the following characters may be added to the description of the $\hat{o}$.

Last four joints of the flagellum blackish. Fore and middle tibiae pale vellowish on the outside. Fore and middle tarsi yellowish in front, fuscous behind. Hind femora and tibiae dark brown, the former almost black. Hind 
tarsi blackish, the basal halves of the second and fourth joints pale yellow. Mesonotum sparsely and fairly strongly punctured, scutellum and metanotum smooth and almost impunctate. First tergite slightly shining, and like the rest of the tergites very finely and very sparsely punctured. Interocular distance on the vertex nearly one-third greater than across the base of the clypeus. The latter twice as wide as long. Mesopleurae and epinotum, excepting the median area, sparsely and as strongly punctured as the mesonotum.

\%. $8.5 \mathrm{~mm}$. long. Tarsi ferruginous, the apical joint of the anterior pair yellow. Vertex and the face except at the sides, blackish. Middle of the mesonotum fusco-ferruginous, the median triangular area of the epinotum black. The apical yellow band on the first tergite narrower than in the $\sigma^{*}$; second tergite with a narrow apical band of yellow slightly widened at the sides; third tergite with a very narrow apical band of the same colour, and the fourth with a wide one. Anterior tarsi with a comb of whitish cilia. Pygidial area semi-elliptical, shining, sparsely and strongly punctured. Clypeus three times wider than long, the anterior margin feebly convex. Face wider than in the $\sigma^{*}$, the eyes feebly convergent below; the interocular distance on the vertex is one-third greater than across the base of the clypeus and is equal to the length of the first six joints of the flagellum. Second joint of the flagellum one-third longer than the following joint, the 2nd-6th and the apical joints longer than wide. Posterior ocelli a little nearer together than in the ${ }_{0}$. Median area of the epinotum with about 12 longitudinal carinae, which are much larger than in the $\delta$. Otherwise like the $\delta$.

\section{A. umtalicus n.sp. (fig. $\mathrm{r}_{3}$ ).}

ㅇ. I I mm. long. Very much like Marshalli in colour and sculpture, from which it differs as follows. Sides of the lower half of the face and the whole of the scapes, bright ferruginous. Mandibles pale yellow, excepting only the extreme apex. Pronotal collar testaceous above. The posterior margins of the metanotum and the scutellum yellow. Apical fascia of the first tergite as in Marshalli, but of the following tergites only the second and fourth have apical bands of yellow, which are very narrow, almost linear. Middle of the second tergite, the whole of the basal two-thirds of the third and the basal half of the fourth, black. The decumbent and tomentose pubescence on the thorax is much denser, and the yellowish pubescence on tergites $2-4$ is so dense as to hide the underlying colour when the segments are viewed from behind. Legs darker, the middle and hind femora and tibiae blackish above, the hind tarsi black. Mesonotum with a closer and larger puncturation. Declivity and sides of the epinotum transversely rugose, the former coarsely so. Median area of the epinotal dorsum with $\mathrm{r} 2$ almost parallel longitudinal carinae which are stronger than in Marshalli; the lateral areas of the dorsum shallowly punctured anteriorly, transversely rugose posteriorly. Pygidial area triangular, about as long as wide at the base, the apex narrowly rounded. Lower half of the face smooth, shining and almost impunctate. Head very wide. The inner margins of the eyes are almost parallel, or only feebly convergent below. Interocular distance on the vertex equal to the length of the first four joints of the flagellum plus half of the fifth. Second joint of the flagellum half as long again as the third. Posterior ocelli slightly nearer to the eyes than they are to each other. Otherwise like Marshalli.

Umtali, S. R., r 올 type (G. Arnold); Pinetown, Natal, x ㅇ (Leigh). Type in R.M. coll.

The specimen from Natal in the Transvaal Museum's collection differs a little from the type, the anterior half of the clypeus being ferruginous, and 
the lower half of the sides of the face yellow. The median triangular area of the epinotum is also a little longer.

A. thalia Handl. Sitzungsber. K. Akad. Wiss. Wien, crv, p. 888, ․ 1895 .

A. transvaalensis Cameron. Ann. Trans. Mus. II, p. I43, +. I9Io.

ᄋ. 8-9 $\mathrm{mm}$. long. Black. Tegulae, lateral margins of the mesonotum, sides of the first tergite, apical abdominal segment and the legs, ferruginous. Anterior half or more of the clypeus, the front of the scapes, a streak margining the lower half of the inner orbits, pronotal collar above and the pronotal tubercles, the posterior half of the scutellum and apical margins of the first four tergites, pale yellow. Apical margin of the second sternite yellow at the sides. The colour is decidedly variable, the yellow band on the clypeus is sometimes interrupted in the middle, and all the yellow markings on the thorax may be replaced with ferruginous, and the third tergite may be without a band (= transvaalensis Cam.). A fine pruinose pubescence is present on the head, thorax and abdomen. Clypeus, lower half of the face and the temples smooth and slightly shining; the rest of the head finely and sparsely punctured. Mesonotum, mesopleurae and epinotum, excepting the median area, dull, somewhat irregularly and not closely punctured, the punctures twice as large as those on the vertex; the triangular median area of the epinotum with about I2 slightly divergent carinae. Abdomen very finely and most sparsely punctured, the pygidial area triangular, sparsely punctured, longer than wide at the base, the apex slightly rounded, the lateral margins convex. Eyes very slightly convergent below. Clypeus twice as wide as long in the middle, the anterior margin convex. Second joint of the flagellum not quite one-quarter longer than the third. Posterior ocelli as far from the eyes as from each other. First tergite like that of aglaia, but the second is not slightly constricted at the base as in that species. Anterior tarsi with a comb of whitish cilia. Wings hyaline, with the radial and the second and third cubital cells fuscous.

o. $9 \mathrm{~mm}$. long. Clypeus narrower than in the + , only half as wide again as long. The fourth and eighth joints of the flagellum somewhat dilated below, the ninth to eleventh emarginate below. Seventh tergite not entirely hidden, triangular, the apex rounded. Sternites shining, the second coarsely and sparsely punctured in the basal half. Otherwise like the ?.

Willowmore, C. P.; Lichtenburg, Transvaal and Bothaville, O. F. S.

\section{Section III.}

Inner margins of the eyes parallel or nearly so. Flagellum long, slender and filiform. Anterior tarsi in the o with a comb. Median area of the epinotal dorsum sharply defined. Epicnemium distinctly defined. The suture between the mesonotum and scutellum crenulate. Puncturation of the head and thorax often fairly coarse. Mesopleurae with a carina below, separating them from the mesosternum. Occiput and temples well developed. Pronotal collar short, but not quite linear above. First segment of the abdomen trapezoidal, not petiolate and not very greatly narrowed towards the base. Hind tibiae sparsely and feebly spinose. Wings not entirely hyaline, extensively clouded with fuscous. Eighth ventral plate in the $\sigma^{t}$ bifurcate.

\section{A. Kraepelini Brauns (figs. $14, \mathrm{I}_{4} a$ and b). Ann. K.K.N.H. Mus. Wien, XIII, p. 421, o, $\sigma^{t}$. I899.}

ㅇ. I I-I2 mm. long. Black. Mandibles excepting the apex, antennae, dorsal face of the pronotal collar, posterior margin of the pronotal tubercles and the legs, excepting the middle and hind coxae and trochanters, pale 
ferruginous. Scapes pale yellow below. Clypeus yellow in front, pale ferruginous in the middle and black at the base. The lateral margins of the lower half of the face very narrowly, the disc of the metanotum and apical bands dilated a little at the sides on the first two tergites, pale chrome yellow. Pterostigma of the fore wing ochreous, the veins blackish, the radial, second and third cubital, both the discoidals and the second submedial cells clouded with brown, the rest of the wing dirty hyaline. The apical half of the hind wing is also clouded with brown, but not so deeply as the fore wing. A microscopic pruinose pubescence is present, and on the clypeus a few longer yellowish hairs, otherwise the insect is glabrous. Posterior half of the clypeus fairly strongly and sparsely punctured. Face and vertex dull, owing to a microscopic fundamental puncturation; in addition there is a larger and fairly close puncturation, which is

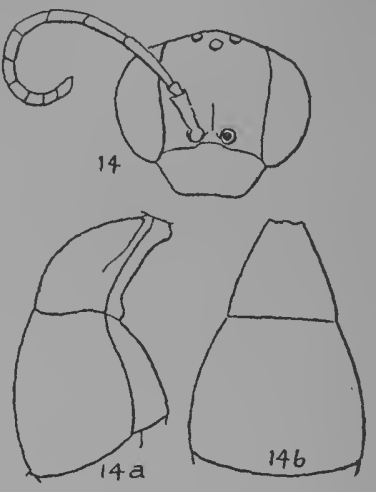

Fig. I4. Arpactus Kraepelini, $q$, head; $a$ and $b$, $q$, first tergite.

fairly scanty behind and at the sides of the ocellar area. Temples very finely and sparsely punctured, nitidulous, seen from the side fully half as wide as the eyes, their lower margins carinate. Anterior face of the pronotal collar smooth and shining, the sides posteriorly feebly rugose. Epicnemium shining, with a few large punctures, its posterior margin carinate, the carina extending back to above the middle coxae and separating the mesopleurae from the sternum. Mesonotum and mesopleurae closely and coarsely punctured, the posterior angles of the mesonotum distinctly elevated. Scutellum less closely punctured than the mesonotum, but quite as coarsely; they are both a little shining between the punctures. Disc of metanotum shining, sparsely and finely punctured. Metapleurae smooth in front, striato-punctate behind. Median triangular area of the epinotum margined at the sides by crenulate grooves, closely finely rugose, the rugae radiating outwards from the base and continued beyond the crenulate margins over the lateral areas of the dorsum and the upper part of the sides of the epinotum. The spaces between the rugae, outside the median area, are closely and deeply punctured. The lower half of the sides of the epinotum is smooth and shining. First two tergites moderately shining, sparsely and finely punctured, the third to fifth tergites dull, microscopically and sparsely punctured, the pygidial area broadly triangular, shining, sparsely sprinkled with elongate punctures, the apex widely rounded. First sternite rugulose and dull, the second sparsely and sharply punctured and very shining, the rest of the sternites a little duller and very finely, sparsely punctured. Inner margins of the eyes nearly parallel, only slightly convergent on the vertex. Clypeus fairly long, only twice as wide as long, moderately convex, the anterior margin straight. Flagellum filiform, all the joints excepting the first longer than wide; the second joint five times longer than wide at the apex and not quite half as long again as the third. Interocular distance on the vertex equal to the length of the second and third joints of the flagellum. Posterior ocelli as far from the eyes as from each other. Dorsal face of the pronotal collar sharply marginate in front. The suture between the mesonotum and scutellum crenulate.

First tergite subconical, very little wider at the apex than long, about three times as wide at the apex as at the base, not nodose. Second tergite more than half as long again as the first, and at its widest nearly one and a half times 
wider than the apical margin of the first tergite. Anterior tarsi with a comb of pale yellow cilia which are not so long as the basal joint. Middle and hind tibiae sparsely spinose outwardly. First abscissa of the radius about as long as the second, the third twice as long as the second. The cubitus of the hind wing originates at the end of the submedial cell.

o. IO-I I mm. long. Clypeus black basally, the anterior third or less fuscoferruginous. Temples narrower than in the 9 . The vertex is slightly shining. Ninth to eleventh joints of the flagellum arcuately emarginate below. Eyes slightly convergent below. Eighth ventral plate deeply bifurcate, the rami projecting beyond the end of the abdomen. Otherwise like the .

In the 0 the hind femora are sometimes black, and the hind tibiae dark brown.

Algoa Bay and Willowmore, C. P. December-January. A very rare species. Types in coll. Brauns.

A. vicarius Handl. (figs. I $_{5}$ and $\mathrm{I}_{5} a$ ). Sitzungsber. K. Akad. Wiss. Wien, cIv, p. 907, o. 1895.

ㅇ. $7 \mathrm{~mm}$. long. Black. The following parts are very pale yellow: labrum, a spot on the lateral margins of the clypeus, the sides of the face widely, the pronotal collar above, the pronotal tubercles, the posterior half or more of the scutellum, a large transverse macula on each side of the first tergite, an apical band abruptly narrowed over the middle third on the second tergite, and the fifth tergite except at the sides. Tibiae and tarsi dark brown. Wings hyaline, faintly tinged with fuscous, the veins and stigma brown.
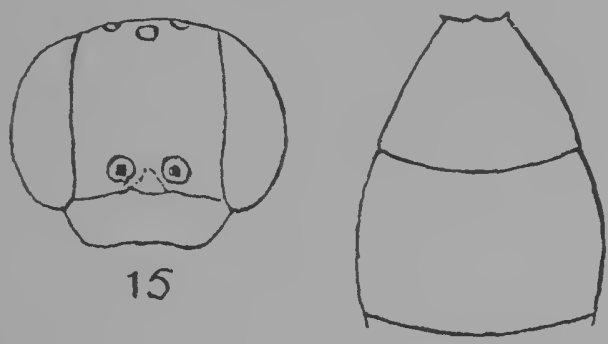

$15 a$

Fig. 15. Arpactus vicarius, + , head; $a$, $q$, first and second tergites.

Clypeus with a scanty white pubescence, elsewhere there is only a microscopic pruinose pubescence which is, however, absent from the dorsum of the thorax. Clypeus and lower part of the face microscopically punctured and dull, the anterior margin of the clypeus depressed and shining. Upper part of the face, vertex and occiput slightly shining, sparsely and finely punctured over a microscopic fundamental puncturation. Temples shining, with a few very small punctures. Mesonotum, mesopleurae, excepting the epicnemium, and the disc of the metanotum with the same fundamental puncturation as the vertex, on which is superimposed a sparse and stronger puncturation. The groove between the mesonotum and scutellum is sharply crenulate, the scutellum shining, with a fine, close puncturation. Metapleurae and anterior half of the sides of the epinotum smooth and shining. Median triangular area of the epinotum margined on each side by a groove, longitudinally and not very closely rugose, with a shallow pit before the apex and a deeper one beyond it on the declivity; lateral areas of the epinotal dorsum, the posterior 
half of the sides and the declivity, closely and obliquely rugose, the rugae finer than those on the median area. First two tergites finely punctured, the first very sparsely; third to fifth tergites microscopically and closely punctured, the pygidial area triangular, a little longer than wide, fairly strongly but not closely punctured. Sternites dull, microscopically and closely punctured. Clypeus three times wider than long, the anterior margin straight. Inner margins of the eyes slightly convergent above, parallel below. Antennae nearer to each other than they are to the eyes. Interocular distance on the vertex equal to the length of the first four joints of the flagellum. Posterior ocelli nearly twice as far from each other as they are from the eyes. Flagellum filiform, all the joints except the first longer than wide; the second joint about two and a half times longer than wide and a little more than one-third longer than the following joint. Pronotal collar not linear above, about as long as the first joint of the flagellum. Posterior corners of the mesonotum elevated, as in Kraepelini. Dorsum of the epinotum fairly long, the median triangular area only half as wide again at the base as long. First segment of the abdomen short, nearly three times wider at the apex than at the base, and as long as the second. Anterior tarsi with a comb of pale fuscous spines, the middle and hind tibiae with only a few thin spines on the outer margin. First abscissa of the radius not much shorter than the second, which is only a little shorter than the third. The cubitus of the hind wing originates beyond the end of the submedial cell.

o. $6 \mathrm{~mm}$. long. Clypeus entirely pale yellow. Flagellum excepting the first two joints ochreous below, the scapes pale yellow in front. Tibiae of the fore and middle legs and the apices of their femora, rufescent. Joints of the flagellum relatively shorter than in the $q$, the ninth and tenth arcuately emarginate below. Seventh tergite exposed, triangular, sparsely and finely punctured. Otherwise like the .

Algoa Bay. Type in coll. Brauns.

A. vicarius var. karrooensis Brauns. Verh. Zool. Bot. Ges. Wien, LXI, p. 130, ㅇ. I9II.

ㅇ. Yellow markings on the clypeus larger, the scapes yellow in front, the legs excepting the coxae, trochanters and base of the femora, ferruginous. The rugae on the median area of the epinotum are more wavy, and the puncturation on the second tergite is a little deeper and closer. Otherwise like the type of the species.

Willowmore, C. P.; Sanyati Valley, S. R. (R. H. R. Stevenson). Type in coll. Brauns.

A. rufithorax Brauns. Loc. cit. p. I30, 우, $\hat{\text {. }}$.

o. $7-7.5 \mathrm{~mm}$. long. Black. The thorax, excepting the median triangular area of the epinotum, sometimes the middle of the declivity, the prosternum and the mesosternum, bright ferruginous. Mandibles ferruginous, pale yellow outside at the base. Clypeus, scapes in front and a streak narrowed above on the lateral margins of the face, pale yellow. A short narrow mark on the upper part of the temples adjacent to the eyes and an indistinct spot behind the ocellar area, fusco-ferruginous. First tergite with a large, transverse, semi-elliptical, yellowish white spot on each side. The second tergite has a round or quadrate mark of the same colour on each side, connected by a narrow apical band. The fifth tergite is entirely yellowish white. Legs blackish, the tarsi and anterior tibiae below, reddish brown; the fore and middle femora at the apex below and the hind tibiae at the base above, with dull 
whitish spots. Wings hyaline, the stigma ochreous, the veins brown. Head and thorax with a sparse, oblique and white pubescence, the abdomen and legs with pruinose pubescence, dense on the legs, sparse on the abdomen. Clypeus, face and vertex dull, closely and microscopically punctured, the temples slightly shining. Thorax, excepting the epinotum, dull, with a microscopic and close fundamental puncturation on which are superimposed larger, shallow and scattered punctures. Median triangular area of the epinotum longitudinally rugose, the rugae curved outwards towards the apex, the lateral areas, the declivity and the sides of the epinotum transversely and rather coarsely rugose, and partially reticulate; the anterior third of the sides smooth and shining. First two tergites very shining, the rest of the abdomen very slightly so; the whole abdomen microscopically and closely punctured, the second tergite with a few larger punctures. Pygidial area triangular, with a few elongate punctures, the sides straight, the apex acute. Inner margins of the eyes parallel. The clypeus is like that of vicarius, and as in that species the flagellum is also fairly short, all the joints except the first are longer than wide. The second joint is twice as long as wide and not longer than the third. Pronotal collar and shape of the epinotum as in vicarius. The first segment of the abdomen is a little wider at the apex than in vicarius, and the venation of the wings is the same as in that species.

3. $4 \cdot 8-7 \mathrm{~mm}$. long. Mandibles pale yellow, fusco-ferruginous at the apex. Fore and middle femora red, the apical spot of yellowish white much larger than in the $o$. The anterior tibiae blackish behind, pale yellow in front. Serenth tergite fusco-ferruginous, elongate triangular, acute at the apex. Fifth and following joints of the flagellum reddish yellow below. Second joint of the flagellum slightly shorter than the third, the ninth to eleventh joints arcuately emarginate below, the apical joint long, as long as the first and second united, subulate and slightly curved. Anterior margin of the clypeus shallowly concave in the middle. Otherwise like the o.

Willowmore, C. P., S. Rhodesia. A common insect, widely distributed throughout Southern Rhodesia. Types in coll. Brauns.

\section{Section IV.}

Eyes large, strongly convergent towards the clypeus, the facets on the inner half below hardly enlarged. Temples wide. Flagellum short. Pronotal tubercles very prominent, the pronotal collar not linear above. Epicnemium margined behind by a carina which is continued at the base of the mesopleurae as far as the middle coxae. Posterior angles of the mesonotum considerably elevated, almost tuberculate. Median triangular area of the epinotum clearly defined and strongly sculptured. First segment of the abdomen subconical, much narrower at its apical margin than the second segment, the latter very globose. Anterior tarsi in the of with a distinct comb, the posterior tibiae and tarsi in both sexes swollen. Wings not clear hyaline. Sculpture very coarse.

A. monstrosus Handl. (figs. I6 and $16 a-e$ ). Ann. K.K.N.H. Mus. Wien, IX, p. 286, o. 1894. Sitzungsber. K. Akad. Wiss. Wien, cIV, p. 940. 1895. A. Silverlocki Turner. Trans. Ent. Soc. London, p. 748 , ‥ I912.

o. $7-7.5 \mathrm{~mm}$. long. Black. A streak on each side of the pronotal collar, the pronotal tubercles and a narrow apical band on the second tergite a little dilated at the sides, pale yellow. A small spot near the base above on the middle and hind tibiae, a spot on the middle of the basal joint of the hind tarsus, the outer halves of the second and third joints, and the basal half or more of the first three joints of the middle tarsi, pale yellow. Sometimes 
the black colour on the first abdominal segment and the legs is replaced by ferruginous. Wings hyaline, the radial cell and the apical margin pale fuscous, the veins and stigma blackish. Face, inner orbits and temples with a very sparse whitish pubescence. A scanty and erect whitish pilosity on the whole body, fairly long on the thorax, especially on the epinotum. Head shining, coarsely but not very closely punctured, the temples more finely and more sparsely punctured than the rest of the head. Mesonotum shining, with a deep and wide longitudinal impression in the middle, shallowly and longitudinally costate, strongly punctured between the costae. Mesopleurae, sides and declivity of the epinotum fairly shining, strongly punctured, the punctures separated by spaces about twice or three times as wide as one of the punctures. Scutellum and metanotum longitudinally rugose and coarsely punctured between the rugae. Median area of the epinotum with about eight longitudinal, slightly divergent and strong rugae, the apex of the area continued as a deep groove down the declivity. The lateral areas of the epinotal dorsum are dull, microscopically reticulate-punctate; they have a few large punctures near the base. Abdomen shining, the third to fifth tergites less so than the others; first two tergites. strongly punctured, but rather sparsely in the middle, the third to fifth closely and strongly punctured, the punctures increasing in size

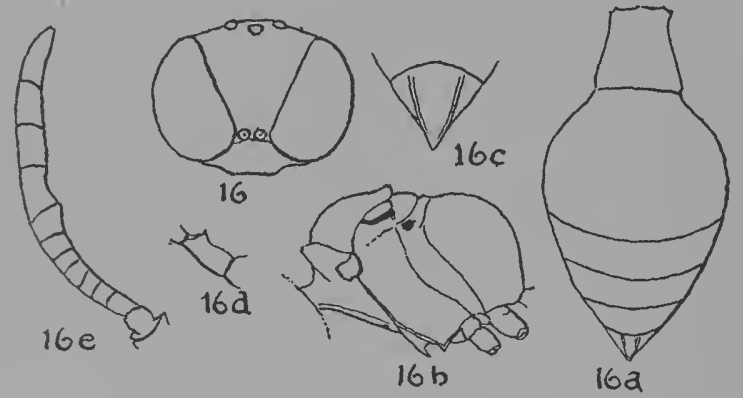

Fig. 16. Arpactus monstrosus, $q$, head; $a$,, , abdomen; $b$,, , thorax; $c$,, pygidium; $d,+$, middle trochanter; $e, \hat{o}$, flagellum.

gradually towards the apical margin. Sternites shining, the second strongly punctured, the rest smooth. Pygidial area elongate triangular, twice as long as wide at the base, coarsely and sparsely punctured at the base, the apex acute. Clypeus short and convex, the anterior margin slightly raised. Interocular distance on the vertex equal to the length of the scape and the first five joints of the flagellum and nearly five times greater than the distance between the eyes across the base of the clypeus. Ocelli arranged in a very obtuse triangle, the posterior pair nearly half as far again from each other as they are from the eyes. Flagellum short, all the joints at least as long as wide, the second barely longer than the first and a little shorter than the third. Dorsal face of the pronotal collar short but not linear, about as long as the first joint of the flagellum, convex transversely. The posterior angles of the mesonotum are strongly elevated. The epicnemium is produced below into an acute, curved tooth. Just behind it there is another but blunter tooth, which is formed by the anterior angle of the carina which separates the mesopleurae from the sternum. Abdomen petiolate, the first segment forming a truncated cone, as long as, or a little longer than, wide at the apex. Second segment coarctate at the base, very globose, widest in the middle where it is quite twice as wide as the apical margin of the first. Anterior tarsi with a comb of dirty white 
cilia, the first joint flat and short, the three following joints wider than long. Middle and hind tibiae with a few whitish spines; the trochanters of the middle pair of legs with a short tooth on the inner margin close to the base. Hind tibiae swollen, the hind tarsi large, with the first two joints cylindrical and swollen. Second abscissa of the radius very slightly shorter than the first. The cubitus of the hind wing originates at the end of the submedial cell.

o. $5 \cdot 5-6 \cdot 5 \mathrm{~mm}$. long. Seventh tergite exposed, broadly triangular, finely punctured. The sixth tergite is rugose and coarsely punctured. Second joint of the flagellum shorter than the first and as long as wide, the third to eighth wider than long, the eighth swollen at its apex below, the ninth arcuately emarginate below, the ninth to twelfth much longer than wide. Otherwise like the ?.

Tanga, East Africa; Sinapunga, N. Rhodesia; Sawmills and Victoria Falls, S. R. and S.-W. Africa. (R.M. and T.M. colls.)

That Silverlocki Turner is a synonym of this species can hardly be doubted. Turner says that it differs from monstrosus in colour, sculpture of the scutellum, postscutellum and epinotum, and in the absence of a spine on the middle trochanters. The colour of the legs, and to a lesser extent of the first abdominal segment, is decidedly variable, and the tooth on the middle trochanter has probably been overlooked in the type of Silverlocki as it is very small and situated close to the base. I can see nothing in Handlirsch's description to justify the statement that Silverlocki differs from monstrosus in sculpture. The absence of the third transverse cubital vein in one wing of Silverlocki type is obviously only an individual variation, as Turner himself has recognised.

\section{SECTION V.}

\section{Subgenus Ammatomus A. Costa. Fauna Napoli, Nyssonid. p. 36. 1859.}

Temples obsolete or nearly so, the head being vertically truncate just behind the posterior margin of the eyes. Flagellum strongly clavate. Eyes nearest together at about the middle of the face, their inner margins divergent above and below, but more strongly so above; the facets on the inner half below greatly enlarged, as in some species of Thyreopus. The frontal triangle, between the clypeus and the antennal sockets, elongate. Pronotal collar linear above. Median triangular area of the epinotum not defined at the sides by crenulate grooves. First abdominal segment of the usual shape, or subpetiolate or petiolate, its apical margin always narrower than the base of the second segment. Posterior tarsi decidedly long and thin, often as long as the femur and tibia united; the of without a comb on the anterior tarsi. Wings clear hyaline, without fuscous maculae. Sculpture much more delicate than in the other sections of the genus. Posterior tibiae strongly spinose on the outside. Mesopleurae without a distinct epicnemium in front, and without a carina between them and the mesosternum.

\section{A. (Ammatomus) africanus Turner. Ann. Mag. N.H. x, p. 374, ․ I9I2.}

"․ $9 \mathrm{~mm}$. long. Black; clypeus, base of the face, scapes below, the posterior margin of the pronotum very narrowly, a small spot on the posterior angles of the mesonotum, a transverse macula on each side of the first tergite, narrow apical bands on the second to fifth tergites, tibiae above and the tarsi, whitish yellow; wings hyaline, the veins black.

"Eyes strongly convergent towards the clypeus, at the base of which they are separated by a distance about equal to two-thirds of the length of the scape; posterior ocelli nearly twice as far from each other as from the eyes. 
Antennae clavate, the four apical joints as broad as long or broader. Opaque, corered with very delicate, close-lying, white pubescence; head almost smooth, with a well-marked frontal sulcus reaching the anterior ocellus; thorax and median seginent sparsely punctured; the basal area of the median segment distinctly defined, triangular, and very sparsely punctured. Mesopleurae rather closely punctured, the sides of the median segment almost smooth, with a few scattered punctures. Abdomen shallowly and rather sparsely punctured; first segment narrow, nearly three times as long as the apical breadth, of almost equal width throughout, not constricted or inflated at the apex, about equal to the second segment in length, but not more than onethird of the apical breadth of the segment. Hind tarsi very long and slender, fully as long as the tibia and femur combined; hind tibiae with very short feeble spines; anterior tarsi without a comb. Second abscissa of the radius about equal to the first, but distinctly less than half as long as the third. Both recurrent nervures received by the second cubital cell, the distance between them on the cubitus slightly exceeding the length of the second abscissa of the radius (in one specimen slightly less). Cubitus of the hind wing originating a little before the transverse median nervure. The yellow band at the apex of the second dorsal segment is narrowly interrupted in the middle.

"Hab. Pakasa, N. Rhodesia (Silverlock); January, 2 우."

\section{A. (Ammatomus) spiniferus Du Buysson. Ann. Soc. Ent. France, Lxvi, p. 359,} 우. $\mathrm{IS}_{97}$.

"ㅇ. $9 \mathrm{~mm}$. long. Dark black, the following parts pale yellow: the clypeus, front of the scapes, the upper margin of the pronotal collar, the pronotal tubercles, a spot above the wing-bases, two spots on the first tergite, subapical bands, interrupted, on the second and third segments, and entire on the fourth and fifth, the tarsi, tibiae above, the knees and the lower third of the anterior and middle femora. Eyes very large, slightly convergent below; clypeus widely sinuate, margined with black in front; antennae strongly incrassate, ferruginous below, the third joint as long as the two following united; puncturation mediocre, not deep, not close; coarser, more dense and deeper on the mesopleurae, posterior tarsi very long and slender, the end of each joint reddish, of the apical joint black; epinotum very much rounded. First abdominal segment very convex, one-third narrower at the apical margin than the second; close to the apical margins of the fourth to sixth segments there are some widely spaced, pale yellow setae; the first four segments have a narrow marginal band of black; the puncturation is fine and sparse, the spaces between finely shagreened; the seventh segment finely coriaceous and rugulose. Sternites black, with large scattered punctures, the spaces between very finely shagreened."

o. $9 \mathrm{~mm}$. long. Like the o. Makapan; Bulawayo.

In the collection of the South African Museum there is a variety of this species, a ?, from Cayimaeis, S.-W. Africa, in which the middle and hind femora are in greater part fusco-ferruginous, and the first abdominal segment is red.

\section{A. (Ammatomus) elongatulus Turner (figs. I7 and $17 a-e$ ). Ann. S.A. Mus.} JVII, p. 493, O. I9 I920.

of (hitherto undescribed). $9 \mathrm{~mm}$. long. Black. Mandibles, tegulae, pronotal tubercles and the legs, excepting the tarsi, ferruginous. Anterior femora with a yellow spot below at the apex. The tarsi pale yellowish white, the last joint of the posterior tarsi blackish apically, the pulvillus also black. Clypeus, face below the antennal sockets, scapes in front, the pronotal collar above, 
a small oblique streak at the posterior angles of the mesonotum, the hind margin of the metanotum in the middle, a transverse spot, narrowed outwardly, behind the apical margin of the first tergite, and transverse bands just behind the apical margins of the second to fourth tergites, pale lemon yellow. The extreme apical margins of tergites $\mathrm{r}-4$ are brownish straw yellow. Flagellum dark brown or blackish brown above, the first six and apical joints ferruginous, the seventh to eleventh blackish, their apical margins narrowly ferruginous. Clypeus and face below the antennae with a fairly dense, whitish pubescence. On the rest of the body there is a very fine, decumbent and whitish pubescence, almost pruinose and not conspicuous. Clypeus with a few small punctures. Face below smooth and shining, the rest of the face and the

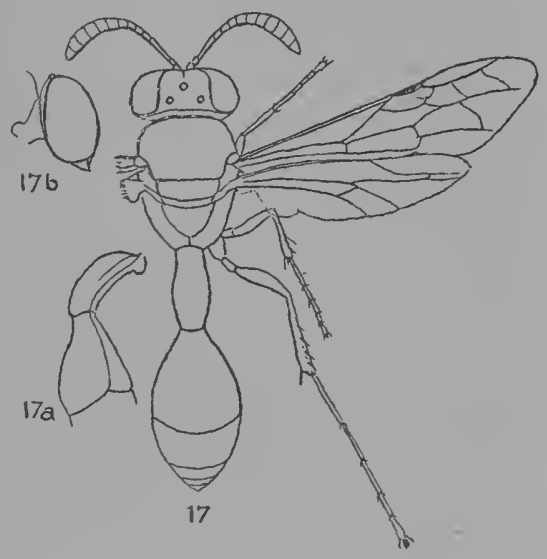

Fig. 17. Arpactus elongatulus, $\hat{0} ; a, \hat{o}$, head; $b, \hat{\sigma}$, first two abdominal segments, lateral view. vertex irregularly and not strongly punctured, almost dull; a median impressed line extends from the antennal sockets to the anterior ocellus. Mesonotum and mesopleurae almost dull, coarsely, irregularly and not closely punctured. Scutellum, metanotum and epinotum with smaller and much more scattered punctures, the median triangular area of the epinotum nitidulous, feebly defined at the sides by a thin impressed line; the declivity concave, with a median longitudinal impressed line. First two tergites slightly shining, the rest nearly dull. First two tergites very sparsely and finely punctured, the punctures much smaller than those on the epinotum, the third to fifth tergites a little more strongly and more closely punctured. Second sternite shallowly and fairly coarsely punctured, its apical margin like that of the third and following sternites, flavo-testaceous. Pygidial area triangular, as wide at the base as long, covered with a dense pubescence, varying from brownish yellow to reddish brown. Eyes nearest together a little below the antennal sockets, where they are separated by a distance equal.to three-quarters the length of the scapes. Clypeus, including the frontal triangle, as long as wide in front, the anterior margin nearly straight. Flagellum strongly clavate, the first joint as long as wide in the middle, the second joint four and a half times longer than wide at the apex and somewhat longer than the third and fourth united, the sixth as long as wide, the seventh and following joints wider than long. Interocular distance on the vertex equal to the length of the first four joints of the flagellum. Posterior ocelli fully three times as far from each other as they are from the eyes. First segment of the abdomen petiolate, narrowed towards the base and the apex, widest a little behind the middle, and when viewed direct from above three-quarters longer than wide, a little shorter than the second segment; its tergite strongly curved. The second segment is bellshaped, three times wider across the apical margin than across the basal. Middle and hind tibiae strongly spinose on the outer side. Tergites three and four with a row of widely spaced, short, whitish spines just behind the apical margin. Second abscissa of the radius two and a quarter times longer than the first, more than half as long as the third. Cubitus of the hind wing originating a little before the end of the submedial cell. 
o. $8 \mathrm{~mm}$. long. Anterior femora blackish in front, with a spot of ivory white on the outside at the apex; the middle femora also with a streak of the same colour outside near the apex. Puncturation somewhat coarser than in the o. First abdominal segment less narrowed at the base and apex and less convex lengthwise than in the $q$, two and a half times longer than wide in the middle, the sides nearly parallel. The second segment is longer and narrower than in the of, one-seventh longer than wide at the apex, the sides less convex than in the ${ }^{\circ}$. Seventh tergite short and

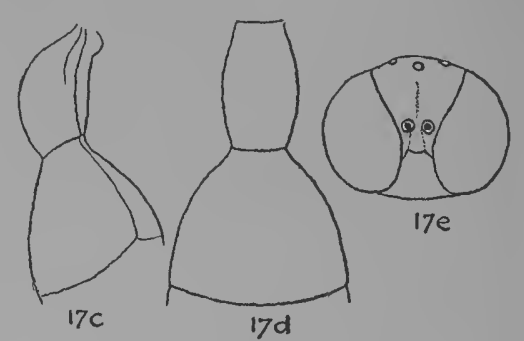

Fig. I7. Arpactus elongatulus, $q ; c$ and $d$, first two abdominal segments ; $e$, head. triangular. Otherwise like the $o$.

Mfongosi, Zululand, type (W. E. Jones); Insiza, Khami, Sawmills, Matopos and Bulawayo, S. R. October to March; Ormiston, E. Griqualand. Type in S.A. Museum.

\section{A. gemellus n.sp. (figs. 18 and $\mathrm{I} 8 a-c$ ).}

\%. $7 \cdot 3 \mathrm{~mm}$. long. Black. Posterior third of the clypeus, face below the antennae, scapes below, posterior margin of the pronotum at the sides, pronotal tubercles, a spot on the posterior angles of the mesonotum, a small transverse spot on each side of the first tergite just in front of the hind margin, a pre-apical band dilated laterally on the second tergite, and narrow pre-apical bands irregularly serrate posteriorly on the third and fourth tergite, pale yellow. The extreme apical margins of the first four tergites brown. Last

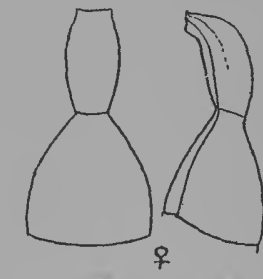

18

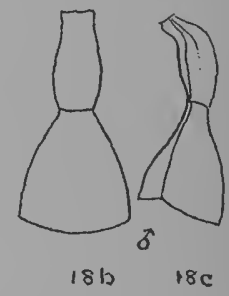

Figs. 18 and $18 a$. Arpactus gemellus,, , first two abdominal segments; $b$ and $c$, $\hat{o}$. two joints of the flagellum ochreous below. Tegulae testaceous. Fore and middle femora and tibiae, and the posterior femora, ferruginous; the posterior tibiae fuscous, the anterior and middle femora fuscous below. The anterior and middle tibiae have a yellow spot at the base. Tarsi pale yellowish white, the apices of the joints on the fore and middle pair ferruginous, on the hind pair black. Wings hyaline, the veins black. Puncturation of the head and thorax coarse and very much like that of elongatulus, but on the mesonotum it is scanty and shallower, and on the mesopleurae finer and closer. The lateral areas of the epinotal dorsum are shining (dull and sparsely punctured in elongatulus), and impunctate. The epinotum is much more narrowed posteriorly than in elongatulus, the width across the apex being less than half as wide as the apical margin of the second tergite (distinctly more than half in elongatulus). Puncturation of the abdomen slightly finer than in elongatulus. Pygidial area triangular, densely covered with black pubescence. Interocular distance on the vertex equal to the length of the first five joints of the flagellum and three times greater than across the base of the clypeus. Second joint of the flagellum not longer than the third and fourth united, or about four-fifths longer than the third. Scapes relatively longer and narrower than in elongatulus. Posterior ocelli nearly three times as far from each other as from the eyes. Petiole slightly widened towards the middle, twice as long as wide at that 
point; second tergite more than one-third longer than the first, its apical margin three and a half times wider than that of the first. Legs long and slender as in elongatulus.

${ }^{*} .6 .7 \mathrm{~mm}$. long. Middle and hind tibiae fusco-ferruginous above and below, otherwise coloured like the ?. Second joint of the flagellum twice as long as the third. Petiole widest a little behind the middle, a little more than twice as long as wide at that point. The vertex and mesonotum are slightly shining, and much more sparsely and more finely punctured than in elongatulus 0 . The petiole has only a few small and very shallow punctures. Otherwise like the ?.

Kamanyab, S.W. Africa, 2 우; Zesfontein and Kaoko Otavi, S.W. Africa, $2{ }^{\top} \hat{0}$. Types in S.A. Museum.

Allied to elongatulus but smaller and with finer puncturation, also closely allied to africanus but differing from that species by the colour of the legs and by the absence of a yellow apical band on the fifth tergite.

$A$. pictipes n.sp. (figs. 19 , I9 $a$ and $b$ ).

c. 8-8.5 mm. long. Colour very much like that of elongatulus, from which species it differs as follows:

Flagellum and metanotum entirely black. Femora ferruginous above, fuscoferruginous below, the fore and middle pair with the apical half on the outside pale lemon yellow; on the anterior pair this colour extends over the upper side of the apex. Anterior and middle tibiae lemon yellow outwardly, fusco-ferruginous inwardly. Posterior tibiae black, with a longitudinal streak of lemon yellow on the outside. Tarsi of a brighter yellow than in elongatulus. Sculpture much finer than in elongatulus. The vertex is almost smooth, slightly shining, with a few small and widely spaced punctures. Mesonotum, scutellum, metanotum and sides of the epinotum shallowly, sparsely punctured, the punctures only half as large as those in elongatulus. Mesopleurae a little more strongly and more closely punctured than the mesonotum. Median area of the epinotum impunctate, the lateral areas

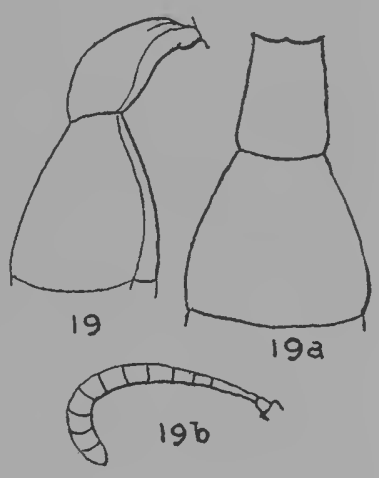

Figs. 19 and $19 a$. Arpactuspictipes, $\hat{0}$, first two abdominal segments; $19 b$, antenna. and the declivity with a very few, exceedingly small punctures.

The abdomen, apart from the microscopic fundamental puncturation, is almost impunctate on the first three tergites, but the fourth has a shallow and very sparse puncturation. First abdominal segment quite different from that of elongatulus. It is widest just before the apex, half as long again as wide, and half as wide at the apex as the apical margin of the second segment. The latter is slightly longer than wide, and one-fifth longer than the first. Flagellum less clavate than in elongatulus; the posterior tarsi long as in that species.

Bulawayo and Sawmills, S. R. Type in R.M. coll.

\section{A. Stevensoni n.sp. (figs. 20, $20 a$ and $b$ ).}

\%. 9-10 $\mathrm{mm}$. long. Black. Pronotal tubercles, tegulae and the legs excepting the tarsi, fusco-ferruginous; the hind tibiae with a pale yellow spot on the inside at the apex. Tarsi pale straw yellow, the apices of the joints of the middle and hind pair ferruginous, the last joint of the hind pair black over the apical two-thirds. Flagellum ferruginous at the base, becoming gradually 
darker or black towards the apex; the scapes yellow in front, ferruginous behind. Clypeus, face below the antennal sockets, a small spot on the posterior angles of the mesonotum, sometimes absent, a small spot on each side of the first tergite near the apical margin, and complete apical bands on the second to fifth tergites, pale yellow. Clypeus and face below the antennae with silvery pubescence. On the rest of the body there is a fine pruinose pubescence, the apical margins of the fourth and fifth tergites with some stiff whitish hairs, the pygidial area with a dense, long and fulvous pubescence. Clypeus and face below the ocellar area with a few, small, scattered punctures. Vertex a little more strongly but still sparsely punctured. Mesonotum, scutellum, metanotum, mesopleurae and median $\mathrm{F}$ triangular area of the epinotum sparsely and irregularly punctured, the punctures shallow and a little larger than those on the vertex,

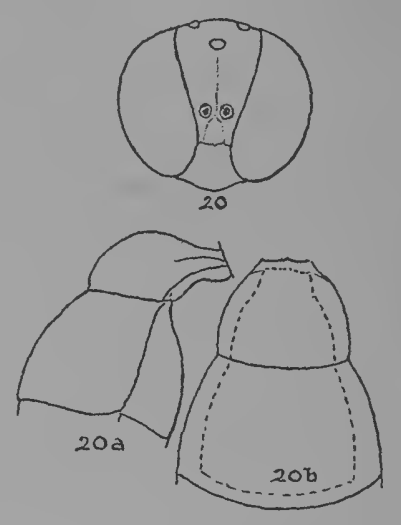

Fig. 20. Arpactus Stevensoni,, , head; $a$ and $b$, first two abdominal segments, dotted line $=\hat{o}$. for the greater part separated by spaces three or four times the width of a puncture. The median area of the epinotum is nitidulous, the rest of that segment dull, finely and very sparsely punctured. First three tergites very finely and sparsely, the fourth and fifth a little more strongly and more closely, punctured. Pygidial area triangular, as long as wide at the base, the sides straight, the apex narrowly rounded; the dense pubescence obscures the sculpture which appears to consist of longitudinal striae. Sternites dull, fairly strongly, evenly and not closely punctured. Interocular distance on the vertex two and a half times greater than across the base of the clypeus, and equal to the length of the first four joints of the flagellum. The second joint of the flagellum is four and a half times longer than wide at the apex, and a little longer than the third and fourth united. The flagellum is strongly clavate, the fifth and following joints being wider than long. Posterior ocelli four and a half times farther from each other than from the eyes. The triangular area of the epinotum is defined only by being shining and less pubescent than the lateral areas, it is not margined by grooves. First segment of the abdomen not petiolate, but more or less campaniform, one-fifth wider at the apex than long. Second segment one-third longer and a little more than one-half wider at the apical margin than the first segment. Posterior tibiae strongly spinose on the outside, the apex with a dense row of whitish spines. Wings clear hyaline, pterostigma and veins black.

o. 6.7-8.5 mm. long. Last three joints of the flagellum ochreous below. Base of the anterior tibiae and a spot near the apex above, pale yellow. Interocular distance on the vertex three times greater than across the base of the clypeus. Second joint of the flagellum a little thinner than in the $\%$. Mesonotum more shining and more finely punctured than in the $\%$. First two abdominal segments less convex at the sides than in the ? the first relatively narrower, very little wider at the apex than long; the second segment at the apex less than onehalf wider than the first. Posterior tibiae feebly spinose. Apical tergite triangular.

Bulawayo, October-December, 9 우, 5 ơ $\delta^{*}$. Type of the $q$ in the Rhodesia Museum, of the $\delta$ in coll. Stevenson.

Allied to mesosternus Handl. and coarctatus Spin., but with different sculpture. 
A. (Ammatomus) fuscipes n.sp. (figs. 2I, 21 $a$ and $b$ ).

․ II $5 \mathrm{~mm}$. long. Black. Mandibles excepting the apex, clypeus, pronotum, lateral margins of the mesonotum, upper angle of the mesopleurae just under the wingbases, and sides of the first two abdominal segments, ferruginous. Fore legs pale ferruginous, the apical tarsal joint yellow above; the middle and hind legs, including the tarsi, fusco-ferruginous. Face below the antennal sockets and the scapes in front, dirty yellow. The back of the scapes and the first five joints of the flagellum and the apical joint below, ferruginous. Second to fourth tergites with narrow apical yellow bands, the fifth tergite on the extreme apical margin and the sixth, fusco-ferruginous. Wings hyaline, the radial cell faintly fuscous, the veins and pterostigma black.

Clypeus and vertex near the ocelli with a few small punctures; otherwise the head is dull and impunctate. Mesonotum, scutellum and meta-

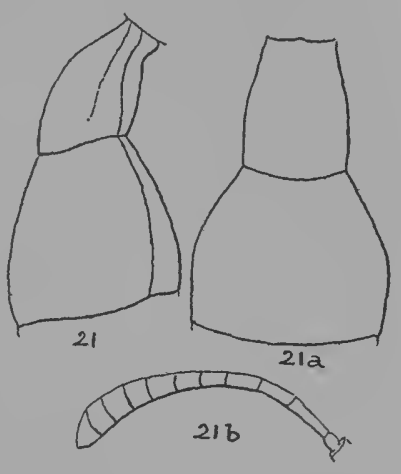

Figs. $2 \mathrm{I}$ and $2 \mathrm{I} a$. Arpactus fuscipes, , first two abdominal segments; $2 \mathrm{I} b$, + , flagellum.

notum dull, with a very scanty, fine, shallow and uneven puncturation. The mesopleurae are fairly strongly but not closely punctured. Epinotum and metapleurae, apart from the microscopic fundamental puncturation, smooth. The median triangular area of the epinotal dorsum is indistinct and defined chiefly by being slightly more shining and less pubescent than the lateral areas. Tergites smooth and dull, the fourth and fifth with a few small and scattered punctures. Sternites dull, sparsely and shallowly punctured. Pygidial area triangular, a little wider at the base than long, the apex narrowly rounded, densely covered with brownish red setae. Clypeus and lower part of the face with whitish pubescence, elsewhere the pubescence is pruinose and sparse, slightly brownish on the epinotum. Interocular distance on the vertex equal to the length of the first three joints of the flagellum and two and a third times greater than across the base of the clypeus. Flagellum less clavate than in Stevensoni; the second joint is only three times longer than wide at the apex, and two-fifths longer than the third, the latter and the fourth are of equal length. Seventh joint as long as wide, the following joints wider than long.

Posterior ocelli a little more than twice as far from each other than they are from the eyes.

First abdominal segment subpetiolate, one-third longer than wide, not much narrowed towards the base, slightly shorter than the second segment which at its apical margin is twice as wide as the first. The first segment is not very convex above nor nodose posteriorly. Middle tibiae feebly, the posterior tibiae more strongly, spinose, the spines whitish.

Umtali, S. R., February, I . Type in the Rhodesia Museum.

Genus KoHLia Handl.

\section{Sitzungsber. K. Akad. Wiss. Wien, cIV, p. 950. 1895 .}

Characters. Head large, wider than the thorax. Eyes large, reaching the base of the mandibles. Maxillary palpi 6-, labial palpi 4-jointed. Clypeus large and prominent. Labrum transversely oval and entirely exposed. Temples nearly obsolete, the head being truncate behind the eyes. Ocelli oval, flat or nearly so, the anterior one situated far in front of the posterior pair. Antennae 
I2-jointed in the o, I2- or I3-jointed in the ot $^{*}$ filiform. Pronotum short and small, depressed far below the level of the mesonotum, the dorsal face linear or obsolete. Pronotal tubercles prominent. Mesopleurae with a narrow epicnemium not distinctly defined above. Episternal suture distinct. Epinotum with a well-defined median triangular area, the apical portion vertical and extending over the upper part of the declivity. Abdomen shaped like that of Stizus, the ventral plates rather flat. A triangular pygidial area present in the . In the of seven tergites and six sternites are visible. Legs slender, the tibiae sparsely, the tarsi strongly, spinose. A tarsal comb present in both sexes, the middle tibiae with two spurs.

Fore wing. Pterostigma distinct but small. Radial cell lanceolate, its apex lying below the costa and continued into a short vein. Three cubital cells present, the second receiving both recurrent veins. The first transverse cubital vein emits at about its middle a short stump which is continued as a vena spuria towards the base of the pterostigma. The first submedial cell is closed before the origin of the basal vein, and the latter joins the subcosta at some distance from the pterostigma.

Hind wing. Retinaculum unbroken, starting at the origin of the radial vein. The submedial cell ends far beyond the origin of the cubitus. Basal lobe moderately large.

Sculpture of the thorax distinctly coarse. The colour pattern of the abdomen is very similar to that of some species of the Masaridae, e.g. Ceramius Lichtensteini.

Only two species of this genus are known, one from Egypt, and the other from South Africa. Kohl says, teste Morice, that the of the Egyptian species has 12 -jointed antennae.

The affinities of the genus are with Sphecius and Bembex.

\section{K. cephalotes Handl. (figs. 22 and $22 a-c$ ). Loc. cit. p. 95I, 9.}

"ㅇ. I $3 \mathrm{~mm}$. long. Head very large. Eyes large and globose. Face fairly wide, about as wide above as below. Temples narrow. Vertex slightly impressed in the middle. The ocelli form an acute angle with one another.

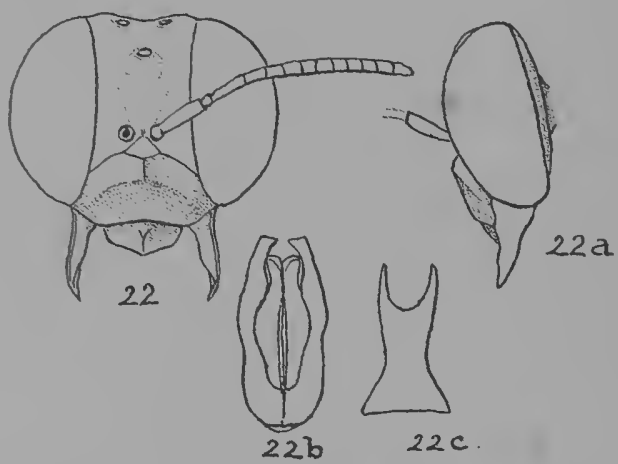

Fig. 22. Kohlia cephalotes, $\hat{o}$, head; $a$, $\hat{o}$, head; $b$, genitalia; $c$, eighth ventral plate.

Clypeus large, prominent, distinctly depressed in its apical part. Labrum transversely elliptical, unusually large, distinctly carinate longitudinally. Antennae nearer to each other than to the eyes, slender and fairly short, the flagellum hardly clavate. Mandibles not excised on the outer margin. 
Thorax large and robust, the prothoracic margin very thin and barely visible from above. Mesonotum very convex, slightly impressed in the middle, and separated from the scutellum by a simple suture. Mesothoracic episternum well-defined, the epimerum merged into the sternum. The declivity of the epinotum is clearly separated from the horizontal dorsum, the median area large, clearly defined and longitudinally rugose, extending over into the declivity. Wings large, almost hyaline, the veins brown. Radial cell four times longer than wide, the apex a little distance from the costa, almost appendiculate. First and third cubital cells of about equal size, the second smaller, considerably narrowed above but not petiolate, receiving both the recurrent veins. The transverse humeral vein ends before the origin of the cubital vein. Stigma distinct. The anal lobe of the hind wing ends a good distance behind the origin of the cubital vein. Legs fairly slender, tibiae feebly, tarsi strongly spinose, the pulvilli distinct; femora not dilated, middle tibiae with two spurs. Anterior tarsi with a very well-formed comb, and not dilated. Abdomen flattened, almost shaped like that of the genus Tachytes, the first tergite wide, very declivous towards the base and not coarctate at the apex. Sixth tergite with a large, triangular and longitudinally striated pygidial area. Densely and coarsely punctured, the epinotum almost punctate-rugose, sparsely pilose, the face with silvery pubescence, the epinotum greyish villose; black, the orbits in front, clypeus, labrum, the margin of the pronotum above and the pronotal tubercles, a spot on the episternum, lateral margins of the mesonotum, an interrupted fascia on the metanotum, wide apical fasciae on the abdominal segments, and nearly the whole of the apical segment, yellow. Sternites pale ferruginous. Antennae ferruginous at the base, fuscous at the apex. Legs ferruginous, the middle and hind tibiae and tarsi variegated with yellow."

$o^{\pi}$ (hitherto undescribed), I $3 \mathrm{~mm}$. long. Costal and subcostal veins of the fore wing ferruginous, the episternum without a yellow spot, mandibles pale yellow outwardly at the base. The tarsi and upper surface of all the tibiae, pale yellow. The yellow on the legs and body is very pale, almost a yellowish white. Otherwise like the $q$ in colour. Lateral areas of the epinotal dorsum covered with a dense, greyish and decumbent pilosity, which obscures the sculpture. Clypeus and labrum nitidulous, sparsely and strongly punctured. Face dull, closely and finely punctured, the back of the head shining, with a sparse but fairly large puncturation. Anterior face of the pronotal collar shining, finely and sparsely punctured. Mesothorax closely, deeply and coarsely reticulate-punctate. Sides of the epinotum with five or six transverse rugae, the spaces between them shining. Tergites fairly dull, the first sparsely and irregularly punctured, the punctures hardly half as large as those on the mesonotum, and much shallower; the remaining tergites fairly finely and more closely punctured than the first. Sternites shining, their apical halves fairly coarsely punctured. Seventh tergite almost semi-circular, the sixth sternite and the apical halves of the fourth and fifth in the middle densely clothed with a yellowish grey and fairly long pubescence. Clypeus almost semicircular, the basal third bevelled off towards the base on each side, thereby forming a short median carina. Eyes slightly divergent above and below. Interocular distance on the vertex equal to a little more than the length of the first five joints of the flagellum. Posterior ocelli nearer to the eyes than to each other, the vertex deeply depressed behind them. Antennae 13 -jointed; flagellum filiform, the second joint three and a half times longer than wide at the apex and almost twice as long as the third joint. Eighth ventral plate deeply forked. Anterior tarsi with a comb of long, whitish cilia as in the $q$. 
For the unique $q$ Handlirsch gives no more definite locality than South Africa. The of described above was taken by Dr A. J. Hesse at Kaross, S.IV. Africa, and is in the South African Museum.

\section{Genus Sphecius Dahlb. \\ Hymen. Eur. I, p. I54. I8+3.}

Characters. Head narrower than the thorax. Eyes large, reaching the base of the mandibles or very nearly, their inner margins nearest together at about the level of the antennal sockets, divergent above and below, rarely parallel. Temples moderately developed. Vertex convex. Ocelli round and moderately convex. Maxillary palpi 6-, labial palpi 4-jointed. Labrum exposed. Clypeus large and prominent. Antennae 12 -jointed in the $q$, I3-jointed in the $\delta$. Flagellum filiform, slightly thickened apically, not distinctly clavate, the apical joint in the of curved. Thorax stout, nearly as wide as long, almost globose. Pronotal collar sunk below the level of the mesonotum, the dorsal face very short or linear. Nesopleurae with a narrow and not very distinctly marginate epicnemium. Dorsum of the epinotum very short, with a large median triangular area which extends over the vertical declivity; the sides of the epinotum concave posteriorly. Abdomen massive, the sixth tergite in the $q$ with a very large pygidial area. In the 0 seven tergites are exposed, the seventh triangular, without a pygidial area; only six sternites are exposed, the seventh being hidden under the sixth, the eighth ends in a sharp spine which projects beyond the end of the abdomen.

Tibiae and tarsi spinose, the anterior tarsi with a short comb in the $q$; middle tibiae with two spurs, those of the hind tibiae long and spatulate.

Fore wing. Pterostigma small. Radial cell lanceolate, ending on the costa. Three cubital cells present, the second more or less narrowed on the radius and receiving both recurrent veins. The basal vein arises at or slightly before the end of the submedial cell.

Hind wing. The cubitus arises a good distance before the end of the submedial cell. The basal lobe is large and the basal sinus deep, as in Kohlia.

Distribution. Palaearctic, Nearctic and Neotropical regions. Only two species are known from the Ethiopian Region.

The insects of this genus provision their young with Cicadas.

S. Milleri Turner (figs. 23 and $23 a-d$ ). Ann. Mag. N.H. xvi, p. 286, o. rgr 5.

ㅇ. 25-30 mm. long. Head, antennae and legs ferruginous, the clypeus, labrum and sides of the face below the antennae, pale ochreous. Thorax black, pronotum, sides of the mesonotum, tegulae and scutellum ferruginous. Abdomen black, with a slight steely blue lustre, the first tergite with a transversely pyriform yellow macula on each side at the apex, the second tergite with a large, more or less semicircular yellow macula on each side, enclosing on the inner side a round black spot. Apical segment of the line, tinged with yellow near the veins

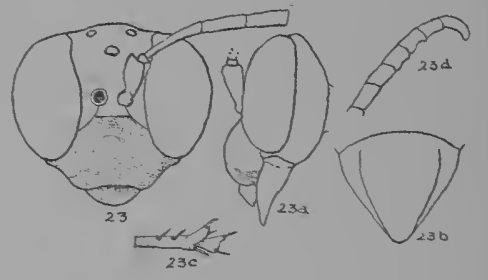

Fig. 23. Sphecius Milleri, ㅇ, head; $a$,, , head; $b$, f, pygidium; $c$, $q$, first two joints of the middle tarsi; $d$, $\hat{o}$, apical half of flagellum. which are yellowish red. Clypeus and face below the antennae with silvery pubescence, the temples and dorsal face of the pronotal collar with whitish 
pubescence, the thorax with a short, erect and greyish pubescence and some longer white hairs on the epinotum. The apical margins of the sternites and of the third to fifth tergites have a row of short, reddish setae; the sixth sternite and sides of the pygidium sparsely covered with longer hairs of the same colour. Head dull, microscopically and closely punctured. Thorax dull, finely and very closely punctured, the scutellum a little less closely than the other parts, and also notso dull. Abdomen moderately shining and fairly strongly punctured, the first two tergites rather sparsely, the rest densely punctured. Pygidial area closely punctured and rugulose lengthwise. Anterior margin of the labrum convex. Clypeus twice as wide as long, bevelled off at the sides behind as in Kohlia cephalotes, the anterior portion flat, the anterior margin moderately concave. Eyes slightly convergent towards the clypeus. Antennae as far from the eyes as from each other, the scape short and thick, the flagellum filiform, the first joint wider than long, the second nearly six times longer than wide at the apex and not quite half as long again as the third. Posterior ocelli two and a half times as far from each other as they are from the eyes. Temples very narrow above but well-developed below. Interocular distance on the vertex equal to the length of the first two joints of the flagellum. Pronotal collar very short above, but not quite linear. Scutellum nearly flat, almost twice as long as the dorsum of the epinotum. The latter is rounded at its junction with the declivity; the median triangular area is defined at the sides by a very fine and shallow impressed line and has a median longitudinal impressed line which extends from the base to the apex, the latter almost reaching the bottom of the declivity. Pygidial area triangular, a little longer than wide at the base, the apex widely rounded. First joint of the middle tarsi asymmetrical, produced at the apex outwardly and ending in a thick spine; the second joint has a similar but shorter projection. Calcaria of the hind tibiae long and flat, three-quarters the length of the basal joint of the tarsus. Second abscissa of the radius only half as long as the first, the recurrent veins both received close to the apex of the second cubital cell. The cubitus is deflected downwards to meet the two recurrent veins.

o. $20-25 \mathrm{~mm}$. long. Labrum, clypeus and sides of the face below the antennae bright lemon yellow. Sixth to eleventh joints of the flagellum more or less fuscous. The black spot enclosed by the yellow maculae on the second tergite is transverse, not round as in the $q$. Otherwise like the $q$ in colour, sculpture and pubescence. Apical joint of the flagellum strongly curved, the tenth and eleventh arcuately emarginate below. Othervise like the $q$.

Ambirisao, N. Rhodesia; Sawmills and Bulawayo, S. Rhodesia. NovemberDecember.

This insect, which is the bulkiest of our Sphegidae, preys on large Cicadas, such as Munza furva Dist., Platypleura quadraticollis Butl., P. lindiana Dist., and P. Marshalli Dist. which live largely on small Mopani trees (Copaifera mopani). The Sphecius circles round these trees and makes a sudden swoop at its prey, bearing it to the ground where it is paralysed by stinging. It is noticeable that when one of these big wasps comes within a foot or so of the trees, the vociferous din of the Cicadas ceases quite suddenly. The nests are at the ends of rather long tunnels, often placed in the loose sandy walls of burrorvs which have been dug by ant-bears. (R.M. and T.M. colls.)

\section{S. citrinus n.sp. (figs. 24 and $24 a-b$ ).}

․ I $5 \mathrm{~mm}$. long. Labrum, clypeus, face below the antennal sockets and the sides of the face to a little beyond the middle of the eyes, chrome yellow; the rest of the head black. Mandibles yellow at the base, ferruginous beyond. 
Antennae reddish ochreous below, a little darker above, the scapes chrome yellow in front. Thorax black, the posterior margin of the pronotum, pronotal tubercles, a streak on the lateral margins of the mesonotum widest in front and not reaching the anterior margin nor extending beyond the tegulae, the scutellum excepting the margins, metanotum and a small spot behind the pronotal tubercles, chrome yellow. Tergites chrome yellow, their apical margins widely rufo-testaceous, the first four with a narrow, transverse, blackish band at the base which is triangularly widened in the middle. The pygidial area is rufescent apically. Sternites fusco-ferruginous at the base of the abdomen, becoming brighter or ferruginous towards the apex, the second with a large, round, chrome
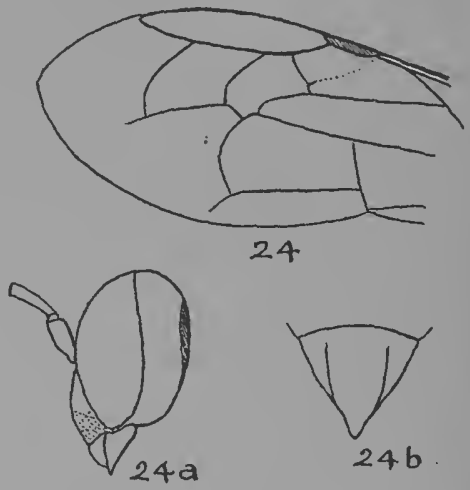

Fig. 24. Sphecius citrinus,, , fore wing; $a$, ㅇ, head; $b$, ㅇ, pygidium. yellow macula on each side, the third to fifth with smaller spots of the same colour. Legs chrome yellow, the femora above and the apices of the tarsal joints more or less yellowish red. Wings flavo-hyaline, the veins ferruginous. Tegulae ochreous. Clypeus, lower half of the face and the mesonotum with a sparse, short, whitish pubescence. The sides of the thorax with a thin white pilosity, the apical margins of the sternites and the fourth and fifth tergites with a row of short, ferruginous setae. Head and thorax closely and finely punctured, the thorax dull, the mesopleurae somewhat less closely and more strongly punctured than the rest of the thorax. Tergites $1-5$ and the second sternite dull, shallowly, finely and closely punctured, the third and following sternites shining, sparsely and coarsely punctured at the sides. Pygidial area half as long again as wide at the base, rounded at the apex, distinctly marginate at the sides and covered with large, shallow punctures which become crowded towards the apex. Temples and occiput much more developed than in S. Milleri, the back of the head not being so steeply truncate behind the eyes. Seen from the side, the temples are about two-thirds as wide as the eyes. Clypeus less prominent than in Milleri, the bevelled-off basal part more oblique, the flattened anterior part with a shallow and large puncturation, the anterior margin concave and narrowly ferruginous. Interocular distance on the vertex nearly one-third greater than across the base of the clypeus, and equal to the length of the second and third joints of the flagellum plus half of the fourth joint. Inner orbits as in Milleri. Second joint of the flagellum about two-thirds longer than the following joint. Posterior ocelli a little nearer to the eyes than to each other. Dorsum of the epinotum very short as in Milleri, but sloping much more steeply downwards and without a median longitudinal impressed line. First two joints of the middle tarsi constructed as in Milleri. The pygidial area is narrower than in that species, and the cubitus of the fore wing is even more deflected downwards at the junction with the recurrent veins.

Van Wyks Vlei, Carnarvon district, C. P. I o (E. Alston). Type in S.A. Museum.

In coloration and build resembling a Stizus of the imperiatis group, for which at a first glance it could easily be mistaken. 


\section{Genus HandliRschia Kohl.}

Ann. K.K.N.H. Mus. Wien, xI, p. 425. 1896.

Sphecius Handlirsch. Sitzungsber. K. Akad. Wiss. Wien, xcvin, p. 467. 1889.

CHARACTERS. "Body moderately slender. Inner margins of the eyes almost parallel; face fairly wide. Antennae fairly far apart, the eighth to eleventh joints of the flagellum excised below, the apical joint entire. The pronotal tubercles do not extend back as far as the tegulae. Mesopleurae without episternal and epimeral sutures and without an epicnemium. Epinotum longer than in Sphecius, parallel-sided, the sides somewhat compressed, the declivity slightly concave, the median area smooth. Abdomen elongate, the apical margins of the segments not depressed. Apical segment without a pygidial area. Six sternites visible, the seventh hidden, the eighth projecting beyond the sixth and not forked. The distance of the radial cell from the junction of the basal and subcostal veins is much less than the length of that cell. First transverse cubital vein hardly curved. First recurrent vein curved at its junction with the cubitus at the second cubital cell. Outer (upper) angle of the second submedial cell obtuse. The cubital vein of the hind wing originates slightly before the end of the submedial cell. Legs slender. Intermediate coxae fairly far apart. Tibiae and tarsi sparsely spinose. Middle tibiae with two spurs. Nearly the whole body coarsely punctured."

One species only, of which only the male is known.

H. aethiops Handl. Loc. cit. p. 467 , o. 1889 .

" $\mathrm{o}$. I4 $\mathrm{mm}$. long. Almost the whole body very coarsely punctured and covered with a dense fuscous pilosity; black, the abdomen with a violaceous lustre; the labrum, clypeus, the lower part of the face and the orbits in front, yellow. Antennae fuscous above, testaceous below. The mandibles yellow, piceous at the apex; legs ferruginous, the coxae to some extent black. Head a little narrower than the thorax, the temples narrower than the eyes, the vertex flattened, the eyes not convergent below. Face and clypeus wider than in Sphecius, the clypeus very feebly convex. Labrum as in Sphecius.

"The ocelli are placed in an obtuse-angled triangle, the base of which lies distinctly in front of a line joining the tops of the eyes; the posterior ocelli are only slightly farther from each other than from the eyes. The antennae are about as far from each other as from the eyes and from the clypeus; the scapes fairly large and much longer than the third joint of the flagellum. The joints of the latter are about equal in width, the first four are of about the same length and cylindrical, more than twice as long as wide, the fifth is barely longer than wide and slightly emarginate below, the following four joints are only a trifle longer but are distinctly excised below. The penultimate joint is decidedly longer than the preceding one, and has two small notches below, the last joint is as long as the first, straight and gradually attenuated apically. The dorsal edge of the pronotal collar is somewhat thicker than in species of Sphecius, and on the mesonotum longitudinal raised lines are barely visible. The scutellum and metanotum are feebly convex. The three portions of the mesothorax are completely fused with one another. The declivity of the epinotum is slightly impressed, and the whole epinotum is smooth and shining and without a median area. The wings, in relation to the body, are very small, the radial cell of the fore wing short, the second cubital cell strongly contracted above, the third feebly so. The anal lobe of the hind 
wing ends just at the level of the cubitus at its origin. The legs are slender and feebly spinose, the tibiae of the middle legs have a pointed tubercle below near the apex, and the apex is also produced into a point; their calcaria are thin and curved. The metatarsus is slender and only feebly curved. The first abdominal segment is, in comparison with its breadth, much longer than in Sphecius species, and is also somewhat constricted off from the second segment. The second sternite is almost angular at its base. The apical margins of the third to fifth sternites bear a row of stiff, short setae. The seventh tergite has no carinae. The segments are not impressed at the apical margins... The sculpture on the head is feebly coriaceous. The thorax, with the exception of the metapleurae, sides and dorsum of the epinotum, is very coarsely punctured, less densely on the back than on the mesosternum. The abdomen is punctured like the thorax, the ventral surface more, and the upper surface less densely. The whole body, particularly the abdomen, is covered with erect, dark and stiff hairs, the face has a pale, whitish pubescence."

South Africa. Type in the Vienna Museum.

\section{Genus Stizus Latr.}

\section{Hist. Nat. III, p. 344. I802.}

Characters. Eyes usually reaching the base of the mandibles, their inner margins entire, nearly parallel, or convergent from above and below towards the base of the clypeus. Temples short, in some groups obsolete or nearly so, the head being vertically truncate just behind the eyes. Vertex never concave. Labrum exposed, wider than long, its anterior margin convex. Tongue bifid, and fairly long. Maxillary palpi 6-, labial palpi 4-jointed. Clypeus convex, with few exceptions wider than long, the anterior margin without teeth and always more or less concave. Antennae 12-jointed in the , 13-jointed in the o. Ocelli round and convex. Mandibles not excised on the outer margin. Pronotum short, depressed below the level of the mesonotum, the collar almost vertical in front (except in $S$. scoliaeformis), and linear or very short above. Mesonotum large, the scutellum fairly flat. The mesopleurae lack both the epicnemium and the episternal suture. Epinotum rounded at the junction of the dorsum and the declivity, or more or less obliquely concave; in the latter case the sides are compressed, thereby making the lateral margins of the declivity very prominent and forming a sharp edge. On the dorsum there is a wide triangular median area which is continued over the declivity, almost to the bottom of that part. Abdomen ovate or subfusiform, the sternites fairly flat. First sternite with a median longitudinal carina, the second or third in the often armed with a tooth or tubercle. Seven sternites are visible in the $\sigma$, and the obtected eighth is nearly always deeply trifurcate on the apical margin. The seventh tergite has a flap on each side which is folded under, lying on the ventral surface of the abdomen between the sixth and seventh sternites (fig. 45a). In some species, e.g. nyasae, loriculatus, these folds are very large, meeting at their bases, and simulating a deeply excised sternite, give a false impression of eight sternites being visible. A marginate pygidial area is very rarely present in the 9 . Legs moderately spinose, the middle tibiae with two spurs. Claws unarmed, the pulvillus well-developed. Anterior tarsi in the of with a comb of long cilia.

Fore wing. Pterostigma very small. Radial cell lanceolate, the apex, which is not very acute, lies on the costa or close to it. Three cubital cells present, the first very large, often larger than the other two united; the second more or less narrowed aboveand receiving both recurrent veins. The basal vein arises before 
the end of the submedial cell and meets the subcosta at a distance from the pterostigma which is greater than the length of the radial cell.

Hind wing. Retinaculum unbroken, beginning at the origin of the radius. The cubitus arises a good distance before the end of the submedial cell. Basal lobe long.

With a few exceptions, the sculpture is of a monotonous similarity throughout the genus. It consists for the most part of a fine, close and shallow puncturation, the punctures being pricked somewhat obliquely (semi-puncturation). The puncturation is usually closer and stronger on the thorax than on the abdomen. The pubescence is very fine and short, on the abdomen decumbent and almost microscopic. A few species have longer, exserted hairs on the epinotum.

DisTRIBUTION. Both hemispheres, but the majority of the known species are found in the Mediterranean portion of the Palaearctic Region.

In spite of the fact that at least 200 species have been described, very little is known about the life-history of these insects. Two species have been recorded as capturing Cicadas for provisioning their nests and another is reported as using larval Mantidae for that purpose.

The genus was monographed by Handlirsch in the Sitzungsber. K. Akad. Wiss. Wien, 1892 and 1895 , who divided it into species-groups, the names of the groups being based on the name of the earliest described species of each group. To these I have added three others, the rhopalocerus, oxydorcus and scoliaeformis groups. In two of the groups, fasciatus and ruficornis, the forms comprised by them are so closely allied that I cannot help suspecting that each one really consists of not more than one or two species, split up into numerous geographical races distinguished chiefly by colour differences. This impression is strengthened on reference to Handlirsch's monograph, wherein the description of nearly all the species is introduced with the statement "speciei praecedenti valde affinis et similis," followed by a recital of what are chiefly differences of colour. The colour and pattern are decidedly variable in this genus and should not be relied on to any great extent for the formation of species.

In the following key only those forms have been included which are known to me in nature.

\section{KEY TO THE SPECIES, $+\circ$.}

(48) I. Only one longitudinal vein emitted from the apex of the medial cell in the hind wing; the anal lobe ends a little beyond the origin of the cubital vein.

(39) 2. Sides of the epinotum compressed, forming with the concave declivity a more or less secant edge which is excised at, or a little below, the middle.

(28) 3. Eyes strongly convergent towards the base of the clypeus, thence divergent. Antennae short, at least the seventh to tenth joints wider than long.

(25) 4. Flagellum feebly clavate.

(tridens group, and also $\mathbf{S}$. Herbsti

(6) 5. Abdomen ferruginous, with yellow apical bands on the second to fourth, or second to third segments.

(5) 6. Abdomen black with yellow markings.

(12) 7. Sixth tergite ferruginous or flavo-ferruginous.

(9) 8. Sixth tergite flavo-ferruginous; legs yellow, the femora reddish yellow.

(8) 9. Sixth tergite and apical margin of the fifth dark ferruginous. polychromus Handl. 
(II) Io. Legs ferruginous; interocular distance on the vertex two and a half times greater than across the base of the clypeus. Buyssoni Brauns

(Io) II. Legs black, with yellow markings; interocular distance on the vertex twice as great as across the base of the clypeus.

(7) 12. Sixth tergite in greater part black.

haemorrhoidalis Handl.

(16) I3. Interocular distance on the vertex from one-half to two-thirds greater than across the base of the clypeus.

(15) I4. Legs black and yellow. Interocular distance on the vertex two-thirds greater than across the base of the clypeus. $6.5 \mathrm{~mm}$. long.

fraterculus Arnold

(I4) I5. Legs ferruginous. Interocular distance on the vertex one-half greater than across the base of the clypeus. $8.5 \mathrm{~mm}$. long.

witzenbergensis Arnold

(13) I6. Interocular distance on the vertex at least twice greater than across the base of the clypeus.

(24) 17. Middle and hind femora in greater part black.

(2I) I8. Median area of the epinotal dorsum with round punctures.

(20) I9. Apical tergites and sternites brownish black. Interocular distance on the vertex nearly two and a half times greater than across the base of the clypeus; scapes three times longer than wide at the apex.

boer Handl.

(19) 20. Apical tergite black, with fusco-ferruginous sides. Interocular distance on the vertex two and a third times greater than across the base of the clypeus; scapes nearly twice as long as wide at the apex.

mitulus Arnold

(18) $2 \mathrm{I}$. Dorsum of the epinotum with an oblique puncturation.

(23) 22. Interocular distance on the vertex equal to the length of the first eight joints of the flagellum.

Braunsi Handl.

(22) 23. Interocular distance on the vertex equal to the length of the first nine joints of the flagellum. Braunsi var. corpulentus Arn.

(I 7) 24. Femora ferruginous. Herbsti Brauns

(4) 25. Flagellum strongly clavate. Basal joint of the anterior tarsi without the usual long spines but with a dense row of short cilia. Clypeus unusually long. Lateral margins of the epinotal declivity with a very wide and deep excision.

(27) 26. Middle and hind tibiae ferruginous, mesonotum, scutellum and metanotum immaculate. II-I3 mm. long.

(cinguliger group) cinguliger Smith

(26) 27. Middle and hind tibiae yellow, mesonotum, scutellum and metanotum with yellow markings. Io-r I mm. long.

(oxydorcus group) oxydorcus Handl.

(3) 28. Eyes less convergent below than in the tridens group, or almost parallel. Antennae filiform, the seventh to tenth joints as long as, or longer than, wide.

(30) 29. Eyes almost parallel; lateral margins of the epinotal declivity with two distinct excisions.

(loriculatus group) loriculatus Smith

(29) 30. Lateral margins of the epinotal declivity with only one distinct excision; sometimes there is a shallow and wide sinus above the excision.

(caffer, discolor and peregrinus groups)

(34) 31 . Yellow apical fasciae of the second to fifth tergites trilobate.

(33) 32. First four joints of the anterior tarsi strongly asymmetrical, the basal joint subtriangular, less than half as long again as wide at the apex. $14 \mathrm{~mm}$. long.

(discolor group) nyasae Turner

(32) 33. Second to fourth joints of the anterior tarsi moderately asymmetrical, the first joint normal, nearly three times longer than wide at the apex. $9 \mathrm{~mm}$. long.

(peregrinus group) proteus Arnold 
(3I) 34. The yellow markings on the tergites consist of large lateral spots, leaving at least the middle third of the segment black or ferruginous. (caffer group)

(36) 35. Second joint of the flagellum half as long again as the third.

haplocerus Handl.

(35) 36. Second joint of the flagellum one-third longer than the third.

(38) 37 . Tergites $1-4$ ferruginous, with yellow lateral spots.

(37) 38. Tergites $\mathrm{I}-4$ black, with yellow lateral spots.

laterimacula Handl.

laterimacula var. euteles Handl.

(2) 39. Sides of the epinotum compressed, the lateral margins of the declivity not excised but nevertheless ending below in a tooth. Antennae moderately clavate.

(rhopalocerus group)

(4I) 40. Mesonotum with two clavate yellow streaks on each side of the middle. Abdomen black and yellow, neither ferruginous nor with rufescent edges to the yellow markings.

quadristrigatus Arnold

(40) 4r. Mesonotum without median yellow streaks, at the most with two small ferruginous spots in front.

(45) 42. Interocular distance on the vertex two and two-thirds greater than across the base of the clypeus.

(44) 43. Tergites $I-3$ ferruginous, with narrow, pale yellow, apical bands, barely dilated laterally.

rhopaloceroides Brauns

(43) 44. Tergites $1-5$ black, with yellowish red apical bands widely dilated laterally on the first, fourth and fifth. mutabilis Arnold

(42) 45. Interocular distance on the vertex twice or two and a quarter times greater than across the base of the clypeus.

47) 46. Tergites I-5 ferruginous, narrowly black at the extreme base. Io-r I $\mathrm{mm}$. long.

hyperocrus Brauns

46) 47. Tergites $I-5$ pale yellowish white apically, reddish basally, the first to fourth with a median black area at the base. I3-14 mm. long. rhopalocerus Handl.

(I) 48. Two longitudinal veins emitted from the apex of the medial cell of the hind wing; the anal lobe ends far beyond the origin of the cubital vein. Sides of the epinotum not compressed, the declivity not concave and not excised at the sides.

(72) 49. Scutellum without a pubescent fovea in the middle.

(55) 50. Black, excepting sometimes the clypeus, face and antennae. Thorax, excepting the pronotum and sometimes the mesonotum, very strongly and closely punctured, the punctures round and deep. Eyes moderately convergent below, slightly so above. Wings usually in greater part fuscous. Face with a median longitudinal carina between the antennae.

(tridentatus group)

(52) 5I. Dorsum of the epinotum with a dense, silvery pilosity, the declivity with two teeth at the apex of the lateral margins; the first tergite with a dense, silvery and decumbent pubescence on its basal half.

(51) 52. Epinotum without silvery pilosity.

fenestratus Smith

(54) 53. Antennae black; sides of the epinotum punctate and rugose. 25-27 $\mathrm{mm}$. long.

niger Radosz.

(53) 54. Antennae ferruginous; sides of the epinotum reticulate-punctate, without rugae. $17 \mathrm{~mm}$. long.

funebris Handl.

(50) 55. Thorax not very strongly punctured and never closely or very coarsely sculptured at the sides; thorax and abdomen, with one exception, never entirely black. Eyes almost parallel, or only very slightly convergent below. 
(57) 56. Pronotal collar not discoid, the anterior face long and oblique; second sternite subcarinate longitudinally in the middle; sixth tergite with a marginate pygidial area extending almost to the base of the segment. (scoliaeformis group) scoliaeformis Arnold

(56) 57. Pronotal collar discoid; second sternite unarmed; sixth tergite very rarely with a marginate pygidial area.

(fasciatus group)

(59) 58. Wings entirely fuscous, with a violaceous lustre; abdomen and the greater part of the head and thorax, black.

atrox Smith

(58) 59. Wings hyaline, sometimes slightly tinged with yellow. Abdomen with yellow markings.

(61) 6o. Sixth tergite ferruginous and with a marginate pygidial area; the other tergites black, with yellow marking on the first three.

melanurus Handl.

(6o) 6I. Sixth tergite without a marginate pygidial area.

(69) 62. Second joint of the flagellum more than three-fourths longer than the third.

(68) 63. Mesonotum black, the lateral margins ferruginous or yellow.

(65) 64. Second joint of the flagellum four-fifths longer than the third.

chrysorrhoeus Handl.

(64) 65. Second joint of the flagellum nearly twice as long as the third.

(67) 66. First tergite, excepting the yellow lateral maculae, black.

Neavei Turner

(66) 67. First tergite, excepting the yellow lateral maculae, ferruginous.

(63) 68. Mesonotum ferruginous. multicolor Turner

(62) 69. Second joint of the flagellum not more than three-fourths longer than the third.

(7I) 70. Second joint of the flagellum three-fourths longer than the third; mesonotum ferruginous; tergites ferruginous, with yellow apical bands.

rubellus Turner

(70) $7 x$. Second joint of the flagellum half as long again as the third; mesonotum black, with the lateral margins and a lanceolate spot on each side of the middle in front, yellow; tergites black and yellow.

imperialis Handl.

(49) 72. Scutellum with a pubescent fovea in the middle. (ruficornis group)

(74) 73. Wings fuscous, the apical margins paler; tergites $x-4$ black, the first three with yellow lateral spots which do not cover one-third of the width of the segment.

fuscipennis Smith

(73) 74. Wings hyaline, tinged with yellow.

(76) 75. Tergites I and 2 black, without yellow spots.

Baumanni Handl.

(75) 76. Tergites black or ferruginous, with yellow spots.

(78) 77. Abdomen ferruginous, with yellow spots.

ferrugineus Smith

(77) 78. Abdomen black, with yellow spots.

(80) 79. Scutellum and sides of mesonotum ferruginous; $23 \mathrm{~mm}$. long.

Dewitzii Handl.

(79) 80. Scutellum black, the posterior margin yellow; sides of the mesonotum yellow. $15 \mathrm{~mm}$. long.

Ellenbergeri Arnold

\section{KEY TO THE SPECIES, 0}

(52) I. Only one longitudinal vein emitted from the apex of the medial cell of the hind wing; the anal lobe ends a little beyond the origin of the cubital vein.

(47) 2. Sides of the epinotum compressed, forming with the concave declivity a more or less secant edge which is excised at or below the middle. (If only very slightly excised, then the antennae are clavate and the second sternite is armed with a large, curved tooth, cinguliger Smith.) 
(38) 3. Flagellum filiform, the tenth joint produced into a spine at the apex, the eleventh deeply excised below, the twelfth thin, curved and more or less unciform.

(5) 4. Sixth sternite with two longitudinal tori. Eyes nearly parallel.

(4) 5. Sixth sternite without longitudinal tori.

(loriculatus group) loriculatus Smith

(29) 6. Sternites unarmed, without any tubercles or teeth.

(28) 7. Eyes strongly convergent from above towards the base of the clypeus, thence divergent; ventral flaps of the seventh tergite not visible between the sixth and seventh sternites; the interocular distance on the vertex is at least twice as great as across the base of the clypeus, if not, then the seventh tergite is very widely rounded at the apex or semicircular.

(Ir) 8. Interocular distance on the vertex less than twice as great as across the base of the clypeus; seventh tergite very widely rounded at the apex.

(I0) 9. Seventh tergite semicircular, with a small semicircular excision at the apex; interocular distance on the vertex three-fourths greater than across the base of the clypeus.

laticaudatus Arnold

(9) Io. Seventh tergite widely rounded at the apex, slightly sinuate at the sides; interocular distance on the vertex one and a half times greater than across the base of the clypeus. witzenbergensis Arnold

(8) II. Interocular distance on the vertex fully twice as great as across the base of the clypeus, rarely less than two and a half times.

(13) I2. Abdomen ferruginous, the base of the segments narrowly black, the second and third with yellow apical bands. polychromus Handl.

(I2) I3. Abdomen black, with yellow or ivory white bands.

(19) I4. Seventh tergite ferruginous.

(16) 15. Femora and tibiae in greater part black. haemorrhoidalis Handl.

(15) r6. Femora and tibiae more or less ferruginous.

(18) 17. Seventh tergite shallowly, angularly emarginate at the apex; last joint of the flagellum, measured across the curvature below, not much shorter than the preceding joint. boer Handl. var. rufipes Arnold

(I7) I8. Seventh tergite rounded at the apex; last joint of the flagellum distinctly shorter than the preceding joint.

(I4) r9. Seventh tergite black.

(2I) 20. Tergites with deep chrome yellow bands.

(20) 2I. Tergites with pale yellow or ivory white bands.

Buyssoni Brauns

(23) 22. Interocular distance on the vertex twice as great as across the base of the clypeus. (Scapes subtriangular, twice as long as wide at the apex.)

fraterculus Arnold

(22) 23. Interocular distance on the vertex more than twice as great as across the base of the clypeus.

(25) 24. Scapes nearly twice as long as wide at the apex. mitulus Arnold

(24) 25. Scapes fully three times as long as wide at the apex.

(27) 26. Dorsum of the epinotum with round and not very shallow punctures. boer Handl.

(26) 27. Dorsum of the epinotum with very shallow and oblique punctures.

Braunsi Handl.

(7) 28. Eyes moderately convergent towards the base of the clypeus, less divergent below that point than in the tridens group; ventral flaps of the seventh tergite large and clearly exposed between the sixth and seventh sternites. (discolor group), nyasae Turner

(6) 29. Second or third sternites armed with a median tooth or tubercle.

(peregrinus group)

(35) 30. Second sternite armed with a tooth truncated at the apex. 
(32) 31. Sixth sternite simple.

Herbsti Brauns

(31) 32. Sixth sternite with a prominence.

(34) 33. Sixth sternite with a semi-elliptical platform in the middle, extending over the basal half of the segment and highest posteriorly.

dentriventris Handl.

(33) 34. Sixth sternite with a median longitudinal carina which is raised to a point at its termination at about the second third of the segment.

hoplites Handl. var. minor Arnold

(30) 35. Third sternite armed with a tooth.

(37) 36. Seventh sternite with a triangular platform, raised towards the apex which lies near the posterior margin of the segment. (The tooth on the third sternite is very large in the larger and almost entirely yellow form, varying from small to obsolete in the smaller and more typical forms which have black on the thorax and abdomen.)

proteus Arnold

(36) 37. Seventh sternite simple.

laticinctus Arnold

(3) 38. Tenth joint of the flagellum without an apical spine, the eleventh not excised below, the apical joint not strongly curved, at least not unciform.

(42) 39. Flagellum strongly clavate; clypeus unusually long, about as long as wide in front.

(41) 40. Second sternite with a very large curved tooth, longer than wide at the base.

(40) 4I. Second sternite unarmed. (oxydorcus group), oxydorcus Handl.

(39) 42. Flagellum filiform, attenuated towards the apex; clypeus much wider than long.

(caffer group)

(44) 43. Abdomen ferruginous, with yellow maculae. laterimacula Handl.

(43) 44. Abdomen black, with yellow maculae.

(46) 45. Interocular distance on the vertex three-fourths greater than across the base of the clypeus; second joint of the flagellum nearly one-third longer than the third joint.

haplocerus Handl.

(45) 46. Interocular distance on the vertex one-half greater than across the base of the clypeus; second joint of the flagellum hardly longer than the third.

laterimacula var. euteles Handl.

(2) 47. Sides of the epinotum compressed, the declivity only slightly concave, its lateral margins not excised, but ending in a tooth below. Flagellum moderately clavate.

(rhopalocerus group)

(49) 48. At least the first three tergites ferruginous, with narrow yellowish white apical bands, narrowly black at the base and with two black spots in the middle just behind the apical margin; seventh tergite subcarinate longitudinally in the middle; second joint of the flagellum half as long again as the third.

rhopaloceroides Brauns

(48) 49. Abdomen otherwise coloured; second joint of the flagellum two-thirds longer than the third joint.

(5 I) 50. Apical joint of the flagellum curved and slightly hooked; seventh tergite trapezoidal, its apical margin obtusely and angularly excised in the middle.

mutabilis Arnold

(50) 5I. Apical joint of the flagellum not hooked; seventh tergite triangular, the apex broadly rounded.

rhopalocerus Handl.

(I) 52. Two longitudinal veins emitted from the apex of the medial cell of the hind wing; the anal lobe ends a good distance beyond the origin of the cubital vein.

(58) 53. Sculpture of the thorax and abdomen strong, consisting of round punctures, and so close, at least on the mesopleurae, as to be reticulatepunctate; body black; wings in greater part fuscous; abdomen lanceolate-cylindrical.

(tridentatus group) 
(57) 54. Sides of the epinotum punctate and rugose.

(56) 55. Dorsum of the epinotum with a dense silvery pilosity; the first tergite with a decumbent silvery pubescence on the basal half.

fenestratus Smith

(55) 56. Epinotum and first tergite without silvery pilosity and pubescence.

(54) 57. Sides of the epinotum closely reticulate-punctate. $\begin{array}{r}\text { niger Radosz. } \\ \text { funebris Handl. }\end{array}$

(53) 58. Sculpture of the thorax and abdomen fine, very shallow, and usually composed of oblique punctures; the mesopleurae never coarsely reticulate-punctate, the sides of the epinotum not rugose nor closely reticulate-punctate.

(60) 59. Pronotal collar not discoid, the anterior face long and oblique; second sternite subcarinate longitudinally in the middle.

(scoliaeformis group), scoliaeformis Arnold

(59) 6o. Pronotal collar discoid, the second sternite unarmed.

(62) 6I. Antennae very long, extending back as far as the middle of the first tergite; abdomen with a rather coarse, dense, exserted and black pubescence. (group ?), pubescens Arnold

(61) 62. Antennae shorter; abdomen with a fine inconspicuous pubescence.

(76) 63. First transverse cubital vein with a slight curve towards the apex of the wing.

(fasciatus group)

(65) 64. Wings entirely fuscous. Abdomen black, with a curved, pyriform yellow spot on each side of the third tergite, sometimes absent.

atrox Smith

(64) 65. Wings hyaline, tinged with yellow.

(67) 66. First tergite ferruginous at the base, yellow beyond, the apical margin black; the rest of the tergites black except the apical one which is fusco-ferruginous; the second has a large transverse yellow spot on each side, the third to fifth with smaller spots of the same colour.

melanurus Handl.

(66) 67. Abdomen otherwise coloured.

(7I) 68. Scutellum yellow or black and yellow.

(70) 69. Mesonotum with two longitudinal yellow streaks in front on each side of the middle; tergites chiefly yellow, the black areas confined to a narrow median longitudinal line and narrow apical margins. Second joint of the flagellum two-thirds longer than the third.

imperialis Handl.

(69) 70. Mesonotum without yellow streaks in front or with only very small and indistinct ones; tergites with basal and apical black bands, the yellow bands on the second to fifth narrowed but not entirely interrupted in the middle; second joint of the flagellum one-third longer than the third.

Neavei Turner

(68) 71. Scutellum ferruginous.

(75) 72. Interocular distance on the vertex one-third greater than across the base of the clypeus.

(74) 73. Second joint of the flagellum two-thirds longer than the third joint.

chrysorrhoeus Handl.

(73) 74. Second joint of the flagellum a little more than one-half longer than the third.

aurifluus Turner

(72) 75. Interocular distance on the vertex nearly one-fourth greater than across the base of the clypeus. multicolor Turner

(63) 76. First transverse cubital vein straight.

(ruficornis group)

(8o) 77. First three and basal half of the fourth tergite, or first five tergites in greater part black, the rest fusco-ferruginous.

(79) 78. Tergites without yellow lateral spots; wings pale flavo-hyaline.

Baumanni Handl. 
(78) 79. First three tergites with yellow spots; wings fuscous, paler at the apical margin.

fuscipennis Smith

(77) 80. Last two or three tergites not fusco-ferruginous, the basal tergites excepting the first mainly yellow, the black being confined to the apical margins and a narrow median longitudinal line between the yellow maculae.

(82) 81. Abdomen ferruginous, with yellow maculae.

(81) 82. Abdomen black, with yellow maculae.

(84) 83 . Scutellum and sides of the mesonotum ferruginous. $16-18 \mathrm{~mm}$. long. Dewitzii Handl.

(83) 84. Scutellum black, the posterior margin yellow, sides of the mesonotum yellow. $14 \mathrm{~mm}$. long.

Ellenbergeri Arnold

\section{TRIDENS Group}

Eyes strongly convergent below in both sexes. Head wide, the height about two-thirds of the width. Antennae in the of fairly short and feebly clavate, long and cylindrical in the $\hat{\delta}$, the tenth joint of the flagellum in the $\delta$ produced into a spine at the apex, the eleventh deeply excised below, the apical joint thin, curved and hamate. Epinotum compressed at the sides, so that the declivity, which is obliquely concave, has its lateral margins prominent and more or less secant. Anal lobe of the hind wing ending nearly behind the origin of the cubitus; the medial cell emits only one longitudinal vein at its apex. Sternites in both sexes simple. Temples moderately developed, generally about onethird as wide as the eyes when viewed from the side. In most of the species the sculpture of the thorax and abdomen consists of a semi-puncturation, i.e. only the anterior half or less of the puncture has any depth, so that the posterior part is barely defined. Large round punctures are never present on the sides of the epinotum.

S. Braunsii Handl. (figs. 25, 25a-c, 28). Ann. K.K.N.H.Mus. Wien, rx, p. 287, ơ, ‥ 1894 .

S. pruinosus Cam. Sjöstedt's Kilimandjaro-Meru Exped. viII, p. 293, rgro.

S. pulchritinctus Cam. Ann. Soc. Ent. Belg. LvI, p. 400, ô. I912.

ㅇ. 5.5-9 $\mathrm{mm}$. long. Black, the abdomen with a slight steely blue lustre. Labrum, clypeus excepting a black spot in the middle, upper margin of the pronotal collar, pronotal tubercles, a narrow streak at the sides of the mesonotum, the posterior corners of the same, a spot on the outer side of the tegulae and axillary sclerite, a triangular spot on each side of the scutellum, the greater part of the metanotum, the lateral margins of the declivity as far as the excision, a broad band on the apical half of the first tergite, narrower bisinuate apical bands on the second to fifth tergites, pale yellow. On the fifth tergite the band is very often broken into three spots, of which the middle one is sometimes very small or obsolete. Sternites $2-5$ with very narrow yellow bands on the apical margin. Mandibles pale yellow, the apex piceous. Antennae yellow below, fuscous above at the base and becoming gradually paler or brownish towards the apex. Legs yellow, the base of the anterior and middle coxae and trochanters, a streak on the underside of the anterior femora and the greater part of their upper sides, a spot on the outside of the anterior tibiae, the middle femora on the basal half below and the greater part above, the hind coxae, trochanters and femora, a spot on the inside of the hind tibiae at the apex, and the upper side of the basal joint of the hind tarsus, black. Wings hyaline, the veins brown. Clypeus and face with a sparse silvery 
pubescence, the mesopleurae with similar pubescence, but long and dense. Vertex, back of the head, thorax and abdomen with a very fine decumbent pubescence and also a thin whitish pilosity which is inconspicuous. Head and thorax fairly dull, the sculpture very shallow, consisting of sparse, oblique punctures, with a suggestion of transverse rugulosity. Anterior margin of the clypeus concave. Interocular distance on the vertex two and a third times greater than across the base of the clypeus, and equal to the length of the first eight joints of the flagellum. Posterior ocelli slightly nearer to each other than to the eyes. Second joint of the flagellum one-quarter longer than the third. Lateral margins of the epinotum declivity deeply excised, the angles of the excision acute. Cilia of the tarsal comb pale ochreous. Second cubital cell with a very short stalk on the radius, the first and second transverse cubital veins meeting just below the radius.
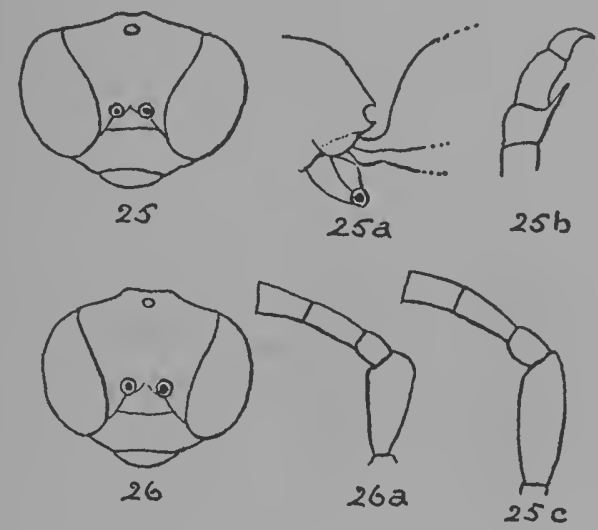

Fig. 25. Stizus Braunsii, $q$, head; $a$, $q$, epinotum, lateral view; $b$, 0 , apical joints of the flagellum; $c$, $q$, scape and base of flagellum.

Fig. 26. Stizus fraterculus, $q$, head; $a$,, , scape and base of flagellum.

3. 5.5-7 mm. long. Clypeus immaculate, the first two joints of the flagellum lemon yellow below. Eyes more convergent below than in the $q$, the interocular distance on the vertex being fully three times as great as across the base of the clypeus. Second joint of the flagellum not quite one-third longer than the following joint, the tenth joint produced into a spine at the apex, the eleventh arcuately emarginate below, the apical joint rostrate, only half as long as the preceding joint. Seventh tergite very shallowly excised at the apex, the angles of the excision rounded. Otherwise like the $q$.

Widely distributed from Cape Lopez on the west to Delagoa Bay on the east, and as far south as the Cape. One of the commonest species of the genus. In size this species varies within rather wide limits. Specimens from the Karroo have the mesonotum more shining than in Rhodesian examples, owing to the transverse rugulosity being almost obsolete. They are also more deeply excised on the margins of the declivity and are somewhat less brightly coloured. The transverse apical band on the fifth tergite is frequently absent or broken up into spots. In specimens from Durban the interocular distance on the vertex in the $q$ is greater than in Rhodesian specimens, being two and a half times greater than across the base of the clypeus, and two and three-quarter times greater in the $\sigma^{*}$; the yellow bands on the abdomen of the $\sigma^{t}$ are also much wider and of a brighter yellow. 
This species is synonymised in the British Museum collection with flavipes Smith. This appears to me to be incorrect, since Smith's species is described as having the legs yellow, the venation and the apex of the abdomen ferruginous.

\section{S. Braunsii var. corpulentus n.v. (figs. $27,27 a$ ).}

․ 9-10 mm. long. Mesonotum, metanotum and epinotum entirely black; the scutellum with a roundish spot of yellow on each side, usually very small. Labrum dark brown, sometimes yellow on the anterior half. Clypeus yellow, or black at the base and yellow in front, or with a median black spot. First tergite with a transverse yellow macula on each side, leaving the middle third black. Second and fourth tergites with a bisinuate apical band of yellow, the third usually immaculate, or sometimes with two or three spots. Fifth tergite with a large median yellow spot. Upper half of the face at the sides with a fine, sparse but distinct puncturation; median area of the epinotum dull, with only a microscopic puncturation which is barely distinct with a magnification of 16 diameters. First two tergites rather more strongly punctured than in

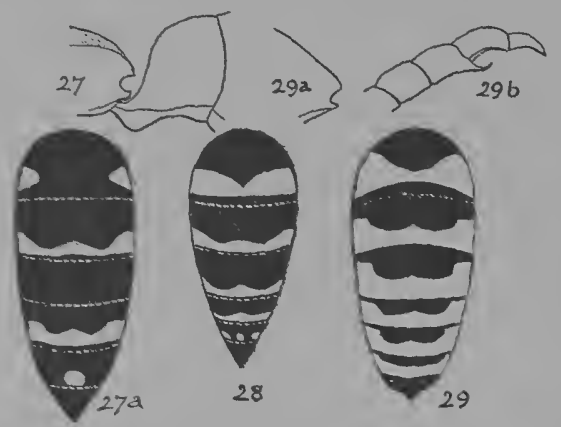

Fig. 27. Stizus Braunsii var. corpulentus, 9 , lateral view of epinotum; $a$, var. corpulentus \%, abdomen.

Fig. 28. Stizus Braunsii, $\circ$, abdomen.

Fig. 29. Stizus sipapomae, $\hat{\sigma}$, abdomen; $a, \sigma^{\star}$, lateral view of epinotum; $b, 0^{\star}$, apical joints of flagellum.

the type of the species. Vertex wider than in the latter, being equal to the length of the first nine joints of the flagellum. Lateral margins of the epinotal declivity more deeply excised.

o. 8-10 mm. long. Labrum, tibiae and tarsi, excepting the apical joint of the hind tarsus, entirely lemon yellow; the spots on the scutellum are usually absent, otherwise like the $q$ in sculpture and colour. Interocular distance on the vertex from two and a third to two and a half times greater than across the base of the clypeus. Otherwise like the of the type of the species.

Types in R.M. coll.

A distinctly stouter insect with deeper yellow colour and thicker legs than the type of the species. The genitalia of the o do not differ in the slightest degree from those of the type species.

S. Braunsii var. aemulus Handl. (as species). Sitzungsber. K. Akad. Wiss. Wien, CIV, p. 974, 우, ơ. I895.

"Very much like and allied to S. Braunsii. Second cubital cell not petiolate. Lateral margins of the epinotal declivity distinctly, deeply excised, the upper angle of the incision less prominent than in Braunsii. Legs not thicker than 
usual. Body distinctly more strongly punctured than in Braunsii and more pilose.

"Black. Anterior orbits, sides of the clypeus, labrum, margin of the pronotum with the tubercles, posterior angles of the mesonotum, spots on the sides of the scutellum, a band on the metanotum, bands interrupted in the middle on the first five tergites and spots on the sides of the sternites, pale yellow. Antennae black, yellow below. Legs black, the apices of the femora, the tibiae and tarsi variegated with yellow. 8-9 $\mathrm{mm}$. long. Cape Province."

Thanks to the kindness of Dr Maidl of the Vienna Museum I have been able to examine a pair of cotypes bearing Handlirsch's labels, and in consequence sink this form to varietal rank. The puncturation is certainly a little stronger and less close on the abdomen, but the differences in pilosity and in the shape of the excision on the margins of the epinotal declivity which are noted in Handlirsch's description do not justify the separation of this form as a distinct species.

S. major Handl. Loc. cit. p. 975, ㅇ.

"Very much like and allied to aemulus but larger and stouter. Second cubital cell very shortly petiolate. Lateral margins of the epinotal declivity deeply excised. Legs of the usual form. Body hardly pubescent but distinctly pilose, thorax fairly closely and not strongly punctured, tergites less sharply but more closely punctured than in aemulus. Black. Anterior orbits, lower part of the face, clypeus except a large median spot, labrum, margin of the pronotum with the tubercles, sides of the mesonotum and scutellum, a band on the metanotum, the lateral angles of the epinotum, a broad interrupted band on the first tergite, undulating bands on the second to fifth tergites and lateral spots on the sternites, yellow. Antennae black, yellow below; legs yellow, the base and the femora and tibiae variegated with black. Wings barely infuscated. $12 \mathrm{~mm}$. long. South Africa."

\section{S. flavipes Smith. Cat. Hymen. B.M. rv, p. 343 , ㅇ. 1856 .}

" $\%$. Length $4 \frac{1}{2}$ lines $(=9.5 \mathrm{~mm}$.). Black: the antennae in front, the clypeus, labrum and mandibles, yellow. Thorax: the anterior and posterior margins of the prothorax, the tubercles, a spot beneath the wings, the tegulae and an epaulet over them, a spot on each side of the scutellum, the postscutellum, the lateral posterior angles of the metathorax, and the legs, yellow; the metathorax truncated and hollowed out behind; the wings hyaline, their nervures ferruginous. Abdomen: the basal segment has on each side a large angular yellow spot, the two uniting in the middle of the segment; the four following segments have a bisinuated fascia on their apical margins; the sixth ferruginous at its apex. Hab. The Gambia."

Three specimens, a $o^{*}$ and two 우, from S. Rhodesia which I have before me agree fairly well with this description, although the postscutellum and lateral margins of the epinotum declivity are immaculate, and the if small yellow spot on each side of the scutellum and the yellow spots on the first tergite do not meet in the middle. The 우 have the apical segment of the abdomen ferruginous, and the middle and hind femora are also more or less reddish. The excision of the lateral margins of the declivity and the shape of the last three joints of the antennae in the ${ }^{\wedge}$ do not differ from those of Braunsii. Failing a comparison with Smith's type, these three specimens may be provisionally assigned to flavipes, but if this identification is correct Braunsii will have to be considered a variety of Smith's species. 


\section{S. fraterculus n.sp. (figs. $26,26 a$ ).}

․ $6.5 \mathrm{~mm}$. long. Closely allied to Braunsii, from which it differs as follows. Sculpture of the mesonotum distinctly finer. Clypeus black, with the anterior margin and a median basal spot yellow. Lateral margins of the mesonotum in front of the tegulae without a yellow streak. Yellow markings on the abdomen paler, more yellowish white than yellow. The third and fifth tergites have only a median transverse spot, and the apical band on the second tergite is sometimes widely interrupted in the middle. Eyes less convergent below, the interocular distance on the vertex being only two-thirds greater than across the base of the clypeus; the latter therefore appears wider and shorter. Scapes strongly incrassate apically, including the pedicel, as long as the first two joints of the flagellum and only a little more than twice as long as wide at the apex (in Braunsii it is only slightly clavate and longer, being as long as the first two joints of the flagellum plus half of the third, and three times longer than its greatest width). The tarsi are more slender, and the second to fourth joints are more attenuated towards the base. The sixth tergite is more strongly punctured, and the apex is not rounded and entire as in Braunsii but minutely excised, the angles of the excision fairly acute. The second cubital cell is not stalked on the radius.

o. Clypeus and labrum entirely yellow, otherwise coloured like the $q$. Interocular distance on the vertex only twice as great as across the base of the clypeus. Seventh tergite narrowly and arcuately emarginate at the apex, the angles of the excision dentiform and acute. Wings as in the + . Otherwise like the of of Braunsii.

Bulawayo, September-November. $30^{\star} 0^{\star}, 6$ of . Types in R.M. coll.

\section{S. sipapomae n.sp. (figs. 29, 29a, 29b).}

o. $9 \mathrm{~mm}$. long. Labrum, clypeus, face below the antennal sockets and the lateral margins half way up, the mandibles excepting their ferruginous apices, yellow; the rest of the head black. Scapes excepting a thin black streak behind and the underside of the first two joints of the flagellum, yellow; the rest of the flagellum ochreous below, black above.

Pronotum excepting a narrow band of black below the posterior margin, pronotal tubercles, the greater part of the mesopleurae, a spot on the sternum in front of the middle coxae, lateral margins of the mesonotum, tegulae, a large spot narrowed inwardly on each side of the scutellum, a broad band on the metanotum and the posterior half of the lateral margins of the epinotum, bright chrome yellow. Legs yellow, the upper side of the coxae, trochanters and basal third or more of the femora, black. Abdomen black, with broad apical yellow bands on the first six tergites, that on the first narrowed in the middle, on the others somewhat angularly dilated at the sides and more or less bisinuate over the middle third. Second to fifth sternites with yellow maculae at the sides, those of the second long and wide. Wings hyaline, the veins dark brown. Pubescence finer and more abundant than in Braunsii, the abdomen without the long whitish hairs which are present in that species. Sculpture much finer than in Braunsii, especially on the mesonotum and abdomen, which are therefore less shining. The mesonotum and scutellum have a dense and microscopic semi-puncturation without any larger punctures intermixed. The epinotum is fairly closely punctured, the punctures deeper than in Braunsii and almost round. Seventh tergite closely and fairly strongly punctured, the punctures slightly elongated. Joints of the flagellum somewhat longer than in Braunsii, the seventh and eighth as long as wide, the ninth a 
little longer than wide, the tenth, measured on the upper side, nearly half as long again as wide at the base, the apical joint longer and more gradually acuminate. Interocular distance on the vertex two and two-thirds greater than across the base of the clypeus. Excision of the lateral margins of the epinotal declivity wider but much shallower than in Braunsii, the upper angle of the excision less acute. Spines of the eighth sternite ochreous, not dark brown as in Braunsii.

ㅇ. 8-9 $\mathrm{mm}$. long. Seventh joint of the flagellum as wide as long, the eighth to tenth wider than long. Femora pale reddish at the base. The yellow bands on the second and following tergites are narrower in the middle and obliquely dilated at the sides. Apical tergite pale ferruginous or flavo-ferruginous. Eyes less convergent below. Otherwise like the $\delta$.

Sawmills (native name Sipapoma), S. R. $2 \widehat{\sigma^{\lambda}}, 2$ 우. Types in the Rhodesian Museum.

Allied to Braunsii and to gracilis Schult., to judge by the description of the latter in Handlirsch's monograph. The yellow pattern of the abdomen is, however, different. The yellow colour is of a much deeper tint than in Braunsii.

\section{S. haemorrhoidalis Handl. Verh. Zool. Bot. Ges. Wien, L. p. 472, ô. 1900.}

․ 9.5-10 mm. long. Black, the abdomen with a slight steely blue lustre. Anterior margins of the labrum and clypeus, sometimes the frontal triangle, the scapes in front, the lower half of the sides of the face, the upper margin of the pronotal collar, pronotal tubercles, a small spot in front of the tegulae, sometimes the extreme posterior angles of the mesonotum, an oblong spot on each side of the scutellum, a streak on the lateral margins of the epinotal declivity, a transverse bar on each side of the apical margin of the first tergite, and bisinuate apical bands widest at the sides on the second and fourth tergites, pale lemon yellow. Sixth tergite and sternite and the apical margin of the fifth tergite, ferruginous. Second sternite with a transverse pale yellow spot on each side of the apical margin. Palpi yellow. Mandibles black. Flagellum black above, ochreous below. Legs in greater part black, the fore and middle tibiae in front, and a streak near the apex of the fore and middle femora, yellow; the last four joints of the tarsi pale ferruginous. Wings hyaline, the veins blackish brown. Pubescence, sculpture and pilosity very much like that of Braunsii, but the pilosity on the abdomen is longer and a little less sparse, and the puncturation is a little closer and deeper, especially on the epinotum, apical tergite and on the sternites. Anterior margin of the clypeus almost straight. Eyes less convergent below than in Braunsii, the interocular distance on the vertex being not quite twice as great as across the base of the clypeus. Second joint of the flagellum nearly half as long again as the third. The excision on the lateral margins of the epinotal declivity is not so wide or so deep as in Braunsii, and the upper angle of the excision is less acute. The second cubital cell has a short stalk on the radius as in Braunsii.

o. $7-8.5 \mathrm{~mm}$. long. Lateral margins of the epinotal declivity usually without the yellow streak which is present in the $q$; second to fourth tarsal joints pale yellow, the fifth ferruginous. Eyes more convergent below, the interocular distance on the vertex being a little more than twice as great as across the base of the clypeus. Apical joints of the flagellum as in Braunsii. Apex of seventh tergite not emarginate. Otherwise like the $q$.

Bothaville, O. F. S. and Algoa Bay; S. Rhodesia, widely distributed but not common.

There is a slight variety from Sawmills, S. R., which hardly merits a distinct varietal name. It differs from the type of the species as follows. 
9. Apical margin of the fifth tergite and the whole of the sixth, black. Posterior tibiae with the basal half or more, excepting the extreme base, pale yellow or yellowish white. Posterior tarsi straw yellow outwardly, black inwardly.

S. boer Handl. (figs. 30, 30a-c). Verh. Zool. Bot. Ges. Wien, L. p. 471, ㅇ, ô. I900.

ㅇ. 9-10 mm. long. Black, the abdomen with a slight steely blue lustre. Labrum, clypeus, front of the scapes, inner orbits narrowly to about the level of the middle of the face, posterior margin of the pronotal collar, pronotal tubercles, tegulae and axillary sclerite, posterior angles of the mesonotum, a subtriangular spot on each side of the scutellum, the metanotum, more or less triangular spots on each side of the first four tergites, pale yellow. Sometimes the third and fourth tergites have a bisinuate apical band of yellow, and the fifth has a transverse median apical spot of the same colour. Apical margins of the segments narrowly reddish brown, the sternites and apical tergite not deep black, but brownish black. First two
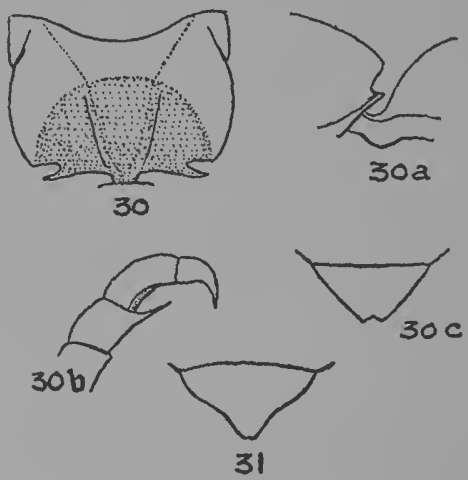

Figs. 30,30 a. Stizus boer,, , epinotum; $b$, $\delta$, apical joints of the flagellum; $c$, $\widehat{A}$, seventh tergite. joints of the flagellum black above, the Fig.3r. Stizus mitulus, ô, seventh tergite.
rest reddish brown above, ochreous below. Apex and outer margin of the anterior femora, apices of the middle and hind femora and the tibiae, dark yellow; the anterior and middle tibiae with a blackish spot on the inside at the apex, the hind tibiae more or less ferruginous at that point; tarsi reddish ochreous. Wings hyaline, the costa and subcosta blackish, the rest of the veins brownish ochreous.

Face and clypeus with a sparse silvery pubescence, the rest of the body with a greyish pubescence. The vertex and clypeus have a thin greyish pilosity and the apical half of the abdomen a brownish one. Sculpture like that of Braunsii but distinctly stronger, consisting of a round puncturation on the epinotum and a deeper semi-puncturation on the abdomen. Scapes moderately clavate, three times longer than wide at the apex, and as long as the second and third joints of the flagellum. Interocular distance on the vertex nearly two and a half times greater than across the base of the clypeus. The lateral margins of the epinotal declivity are excised very low down, the upper angle of the excision is rounded, the lower one acute. Sixth tergite rounded at the apex. Second cubital cell not stalked, but the second and third transverse cubital veins are very close together on the radius.

o. $8 \mathrm{~mm}$. long. Apical joint of the flagellum rostrate, but more gradually attenuated and longer than in Braunsii, measured across the arc below nearly as long as the preceding joint. The spine on the tenth joint is longer and thinner than in Braunsii. The apical tergite is shallowly and angularly emarginate at its apex. Otherwise like the ?.

Bothaville, O. F. S. and Lichtenburg, Transvaal.

The description given above is based on the types in the Braunsian collection. 
S. boer var. rufipes, n.v.

o. $9 \mathrm{~mm}$. long. Lateral margins of the mesonotum, tegulae, extreme lateral margins of the tergites, apical margin of the fifth, apical half of the sixth and the whole of the seventh abdominal segment, ferruginous. Legs, excepting the coxae, trochanters and basal half of the femora, ferruginous. First four tergites and the second to fourth sternites with apical yellow bands, those of the sternites widely interrupted in the middle. Otherwise like the type of the species.

Museum.

S. mitulus n.sp. (fig. 3I).

. $10 \mathrm{~mm}$. long. Black. Labrum, clypeus, front of the scapes, posterior margin of the pronotum, metanotum and narrow apical bands on the first four tergites, yellow. The bands on the first three are only slightly widened at the sides and in the middle, that on the fourth extends over only the middle third of the apical margin. Apical margins of the fourth and fifth tergites and the sides of the sixth diffusely, fusco-ferruginous. Second and third sternites with transverse yellow streaks on each side. Undersurface of the flagellum, pronotal tubercles, tegulae, posterior angles of the mesonotum, apices of the femora, tibiae and tarsi ferruginous. Wings hyaline, the veins dark brown. Lower half of the face and the clypeus with a thin silvery pubescence, intermixed with longer, outstanding white hairs on the clypeus. Vertex with a sparse, erect brownish pilosity and a decumbent, very fine and brownish golden pubescence, not conspicuous but clearly visible in some lights; it is also present on the mesonotum. Sides of the thorax and apical half of the abdomen with a thin, scanty and white pilosity. Face and vertex with shallow, round punctures, fairly close on the face, scanty on the vertex. Dorsum of the epinotum fairly shining, with a close and fine puncturation, consisting of round punctures, deeper than in $S$. boer Handl. Abdomen with as strong a semi-puncturation as in that species. Scapes nearly twice as long as wide at the apex. Posterior margin of the clypeus not defined. Interocular distance on the vertex two and a third times greater than across the base of the clypeus. The excision of the lateral margins of the epinotal declivity like that of boer, but the upper angle is less blunt. Venation as in boer.

0 . Io $\mathrm{mm}$. long. Colour, sculpture and pubescence as in the $q$, but the apical margin of the fourth tergite is also pale ferruginous. Interocular distance on the vertex two and a half times greater than across the base of the clypeus. Scapes a little shorter than in the $q$. The seventh tergite differs from that of boer in having a fairly close and fine puncturation and in having the apical half of the sides feebly concave. The apical joint of the flagellum is not so strongly curved as in boer.

Mossel Bay, C. P. December. $2 \delta^{x}, I$ o (R. E. Turner). Types in the British Museum.

\section{S. witzenbergensis n.sp. (figs. $32,32 a-c$ ).}

‡. $9.5 \mathrm{~mm}$. long. Black. Labrum, clypeus, mandibles excepting the apex, face below the antennal sockets, the sides of the face nearly as far as the level of the anterior ocellus, scapes in front, a narrow streak on the temples, posterior margin of the pronotal collar, the pronotal tubercles, a transverse elliptical spot on each side of the first tergite, and apical bands abruptly narrowed over the middle third on the second and fourth tergites, yellow. The yellow on the 
head is deeper than on the abdomen. Flagellum ochreous below, brown above. Anterior femora reddish brown above, yellow below but somewhat brownish at the base; anterior tibiae and tarsi ochreous. Middle and hind femora blackish, the middle tibiae yellow on the outside, fusco-ferruginous on the inside, the tarsi fusco-ferruginous. Tegulae ferruginous. Wings hyaline and faintly smoky, the veins dark brown. Head and thorax dull, with a microscopic fundamental puncturation except on the epinotum; vertex and scutellum with a larger, sparse and shallow puncturation superimposed. Metanotum and dorsum of the epinotum fairly closely and shallowly punctured, the punc-

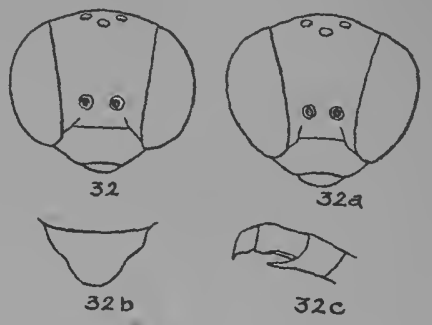

Fig. 32. Stizus witzenbergensis, q; $a, 0 ; b, \hat{o}$, seventh tergite; $c$, 0 , apical joints of the flagellum. tures round. Abdomen with a slight steely blue lustre, and a fine, close puncturation on the first five tergites, the last two with elongate and relatively coarse punctures.

Face wide, the interocular distance on the vertex being only half as great again as across the base of the clypeus. The posterior margin of the latter is clearly defined. Apical joint of the flagellum short, abruptly acuminate at the apex, only half as long as the penultimate joint. Excision of the lateral margins of the epinotal declivity shallow, the upper angle obtuse. Seventh tergite very broadly rounded at the apex, the sides feebly sinuate. Second cubital cell not petiolate, the space between the first and second transverse cubital veins on the radius about half as long as the distance between the recurrent veins on the cubitus.

․ $8.5 \mathrm{~mm}$. long. Basal half of the clypeus black. Flagellum black above, pale ochreous below. Legs ferruginous, the coxae and trochanters blackish, the hind femora suffused with black at the base, the first joint of the hind tarsi fuscous above. Second tergite with a transverse streak of yellow on each side. Otherwise like the $\hat{o}$ in colour and sculpture. Interocular distance on the vertex only half as great again as across the base of the clypeus, as in the $\hat{o}$, but the eyes are less convergent below than in that sex.

Witzenberg Valley, S.W. Cape Province. 3,000 feet. January. 2 ô $0^{\wedge}$ : Ceres, C. P. I o (R. E. Turner). Types in the British Museum.

\section{S. laticaudatus n.sp. (figs. 33, 33a).}

o. 7.5-8 mm. long. Black. The posterior margin of the clypeus and the lower half of the sides of the face, pale yellow. Posterior margin of the pronotum, pronotal tubercles, a small spot on each side of the scutellum, a transverse streak on the metanotum which may be absent, a transverse spot on each side of the first tergite, narrow apical bands widened laterally on the second and third tergites and an apical streak across the middle of the fourth tergite, ivory white. Anterior tibiae and apex of the anterior femora in front, yellow; a streak on the outside of the anterior femora, the basal third of the middle tibiae and basal half above of the hind tibiae, ivory white. The tarsi brown, the basal joint darker. Flagellum pale brown below, black above. Wings hyaline, faintly smoky, the veins black. Pubescence whitish and scanty, the abdomen with a short, exserted black pilosity, fairly conspicuous on the apical half. Sculpture like that of Braunsii, but the puncturation of the epinotal dorsum is shallow and round. Apical joints of the flagellum and excision of the declivity as in Braunsii. Scapes twice as long as wide at the apex. Inter- 
ocular distance on the vertex about three-quarters greater than across the base of the clypeus. Seventh tergite short and wide, its posterior margin moderately convex, with a semicircular excision in the middle, the angles of the excision

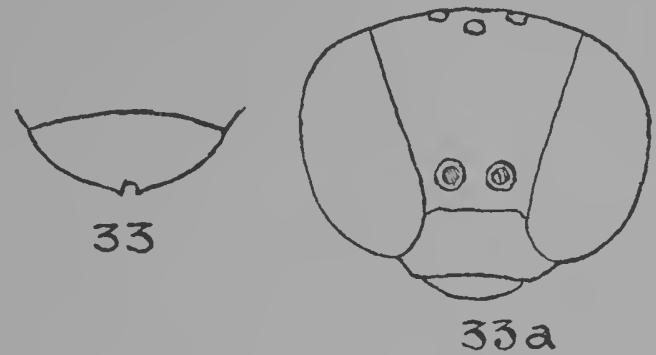

Fig. 33. Stizus laticaudatus, ô, seventh tergite; $a, \hat{o}$, head.

acute. The first and second transverse cubital veins are contiguous at their junction with the radius.

Ceres, C. P. November. 2 ôt (R. E. Turner). Types in the British Museum.

\section{S. Buyssoni Brauns. Brauns in litt.}

․ 7·5-9 mm. long. Black. Labrum, clypeus, face below the antennae and on the lower half of its lateral margins, scapes in front, pronotal tubercles and posterior margin of the pronotum, a more or less triangular spot on each side of the scutellum, middle of the metanotum, a broad band on the first tergite often widely interrupted in the middle, feebly bisinuate apical bands on the three following tergites, sometimes a median apical spot on the fifth tergite, and lateral streaks on the apical margins of the second and third sternites, chrome yellow. Tegulae, lateral margins of the mesonotum, fifth and sixth tergites and extreme lateral margins of the other tergites, sternites and legs, pale ferruginous. The sternites are sometimes more or less blackish at the base and in the middle; the anterior tarsi yellowish. Mandibles yellow, fuscoferruginous at the apex. Flagellum blackish above, ferruginous below. Wings hyaline, the costa and subcosta dark brown, the rest of the veins ferruginous. Clypeus and face with a thin silvery pubescence intermixed with a whitish pilosity. On the rest of the body there is a grey pubescence, and a sparse whitish pilosity on the epinotum. Clypeus, face and median area of the epinotal dorsum with a shallow, not dense, and round puncturation; on the rest of the body the sculpture consists of the semi-puncturation usually present in the tridens group. Eyes strongly convergent below, the interocular distance on the vertex being nearly two and a half times greater than across the base of the clypeus. Posterior ocelli nearer to each other than to the eyes. Second joint of the flagellum one-third longer than the following joint. The excision of the lateral margins of the epinotal declivity is similar to that of $S$. boer. Sixth tergite conical, the apex narrowly rounded. First and second transverse cubital veins separated on the radius by a distance equal to about one-fourth of the first abscissa of the radius, but sometimes almost contiguous.

. 8-9 mm. long. Second joint of the flagellum hardly longer than the third. The shape of the seventh tergite is like that of $S$. mitulus and the apical joints of the flagellum are like those of Braunsii. Otherwise like the $q$. colls.)

Bulawayo and Khami, S. R. November to January. (R.M. and T.M. 


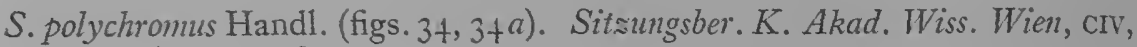
p. 976,, , 7 . $1 \$ 95$.

f. $12 \mathrm{~mm}$. long. Labrum, clypeus, lower half of the sides of the face, and scapes in front, yellow; the rest of the head black. Nandibles yellow at the base outwardly, the rest ferruginous. Flagellum ferruginous, the apical joints blackish abore. Thorax black, the pronotum, a spot on the mesopleurae below the wings, lateral margins of the mesonotum, tegulae, scutellum and sides of the epinotum, ferruginous. Abdomen ferruginous, the base of the first tergite black, the second and third tergites with sinuous apical yellow bands. Legs ferruginous. Wings hyaline, the veins

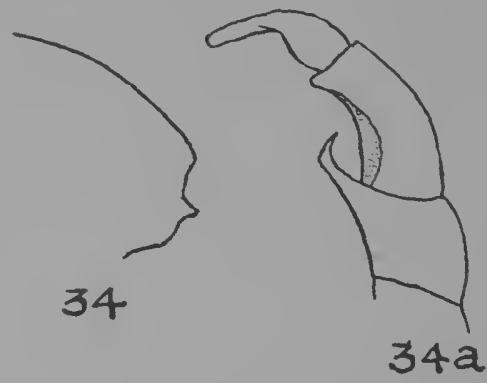

ferruginous. Clypeus and lower half Fig. 34. Stizus polychromus, o, lateral of the face with silvery pubescence, elsewhere the pubescence is brownish view of epinotum; $a$, $\hat{o}$, apical joints of the flagellum. yellow, decumbent and not dense. Pilosity white and sparse. Clypeus, face and dorsum of the epinotum with a shallow, round puncturation, fairly dense on the epinotum. Elsewhere the sculpture is a semi-puncturation, very fine on the abdomen. Posterior margin of the clypeus well-defined. Interocular distance on the vertex two and a third times greater than across the base of the clypeus. Second joint of the flagellum two-fifths longer than the third, the flagellum fairly short and thick. Median area of the epinotal dorsum with a shallow impressed line in the middle. The excision of the lateral margins of the epinotal declivity shallow and placed low down, the upper angle of the excision broadly rounded. Pygidium conical, the apex rounded. The first and second transverse cubital veins are fairly widely separated on the radius, the distance between them being usually fully half as long as the first abscissa of the radius.

O. $12 \mathrm{~mm}$. long. Second joint of the flagellum very little longer than the third. Apical spine of the tenth joint slightly curved at the apex, the eleventh joint deeply emarginate below, the apical joint subglobose at the base, then curved, the apical half slightly flattened, and rounded at the apex. Apical tergite very broadly rounded, almost semicircular in outline. Otherwise like the $q$.

Springvale, Khami and Bulawayo, S. R. October to November. (R.M. and T.M. colls.)

In a slight variety which is found at Sawmills, S. R., the second, third and fourth tergites have apical bands of yellow which are somewhat abruptly widened at the outer third. Sometimes, however, only the second tergite has a yellow band.

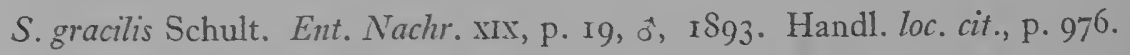

" $\hat{o}$. Allied to $S$. tridens Fab. but more slender, the body less pubescent. The head a little wider than the thorax. The thorax sparsely and more finely punctured, with but few large punctures. Epinotum fairly deeply excavated posteriorly, shining, the median area well-defined. Wings hyaline, the second cubital cell not petiolate, but the first and second transverse cubital veins are contiguous on the radius. Abdomen fairly densely punctured, the sternites unarmed. Black, very slightly aeneous. Clypeus, labrum, base of the mandibles, 
lower part of the face, the anterior orbits, the underside of the antennae, margin of the pronotum and the pronotal tubercles, sides of the pronotum, tegulae, the scutellum posteriorly, metanotum, lateral angles of the epinotum and a spot on its disc, spots on the mesopleurae, broad bands on all the abdominal segments, that of the first trisinuate, of the second dilated at the sides, of the rest bisinuate, and narrow bands widened laterally on the ventral segments, pale lemon yellow. Legs lemon yellow.

"Io mm. long. Webi Valley, East Africa."

\section{LORICULATUS Group}

Allied to the tridens group. Inner margins of the eyes parallel or nearly so. Head narrower, the height being about four-fifths of the width. Antennae slender, the last three joints in the $\hat{\sigma}$ built on the tridens model, but the penultimate joint is swollen in its apical half. Lateral margins of the epinotal declivity with two excisions. Sixth sternite with two longitudinal carinae at the base and with a dense fimbria of curved hairs on its apical margin. The sculpture of the thorax consists of a true puncturation, but on the mesonotum it is mixed with a semi-puncturation. The sides of the epinotum are sparsely, coarsely punctured.

S. loriculatus Smith (figs. $35,35 a-d$ ). Cat. Hymen. B.M. Iv, p. 345 , o. 1856 .

o. I 5-17 mm. long. Labrum, clypeus, the face below the antennal sockets and an elongate triangle between them, a wide band on the sides of the face almost to the level of the anterior ocellus, a triangular macula below the latter, and the posterior orbits, yellow; the rest of the head black, here and there reddish brown. Mandibles yellow, their apices fusco-ferruginous. Scape and first two joints of the flagellum underneath yellow, the upper side of the scapes and the rest of the flagellum ferruginous. Pronotum ferruginous, the
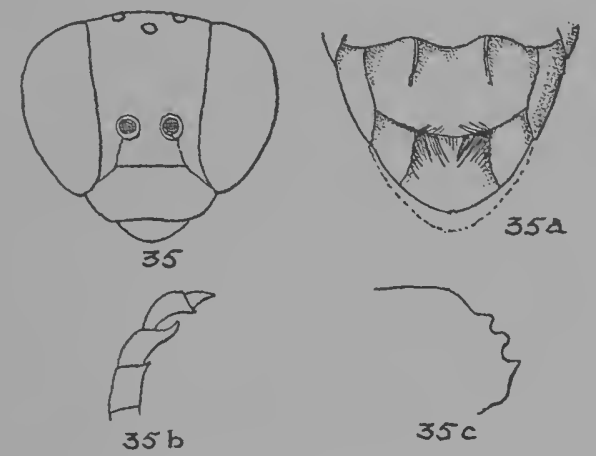

Fig. 35. Stizus loriculatus, $\hat{\sigma}$, head; $a$, $\hat{0}$, apical sternites; $b, \hat{o}$, apical joints of flagellum; $c, 0$, lateral view of epinotum.

posterior margin and the tubercles, yellow. The rest of the thorax black, with the following parts ferruginous, or yellow and margined with ferruginous: the lateral margins of the mesonotum, two longitudinal streaks on each side of its middle in front, a large spot on the mesopleurae above, a large spot on each side of the scutellum, the metanotum and the lateral margins of the epinotum. Abdomen black, each tergite with a small semicircular spot in the middle and transverse spots on each side yellow; the apical tergite yellow in the middle and at the apex, ferruginous at the sides. These spots are 
usually connected by a narrow band in front of the apical margin, but sometimes they are separated by the tongue of black extending from the base to the apical margin. The extreme apical margin of all the segments is reddish brown or blackish. Sternites $2-5$ with a yellow spot on each side, the apical half of the sixth and the whole of the seventh ferruginous. Legs ferruginous, the anterior tibiae with the apical third yellowish below. Wings hyaline, the veins ochreous, the costa brown. Pubescence whitish, fine and scanty. The sculpture of the head is microscopic, but the face has a ferv very shallow, small, round punctures, The mesonotum, scutellum and metanotum are dull, closely and fairly strongly punctured, the punctures mostly round. Mesopleurae and sides of the epinotum microscopically alutaceous, with large, round and fairly deep punctures superimposed, scanty on the slightly shining sides of the epinotum. Dorsum and declivity of the epinotum dull, closely reticulate-punctate. Abdomen fairly dull, closely punctured, the punctures deep and elongated. Inner margins of the eyes for the greater part parallel, slightly divergent above and below, the interocular distance on the vertex being only a little more than one-fifth greater than across the base of the clypeus, and equal to the length of the second and third joints of the flagellum. Anterior margin of the clypeus concave, the posterior margin well-defined. The antennal sockets are farther from the clypeus than from the eyes. Second joint of the flagellum about one-fourth longer than the third. Posterior ocelli twice as far from each other as they are from the eyes. Tenth jointh of the flagellum produced into a spine below which is curved at its tip, the eleventh joint arcuately emarginate below and wider at the apex than at the base; the apical joint is claw-like, hardly longer than wide at the base. Lateral margins of the epinotal declivity with two semicircular excisions, thereby forming three teeth, of which the lowest is acute, the other two rounded. Sixth sternite with a longitudinal carina on each side of the middle; the ventral flaps of the seventh tergite are very large and lie between the sixth and seventh sternites, their apical margins are fringed with stiff reddish hairs which curve backwards over the sixth sternite and appear to proceed from the apical margin of that segment. Seventh tergite conical, the apex moderately rounded. First and second transverse cubital veins separated on the radius by a space equal to about half the first abscissa of the radius.

․ $15-16 \mathrm{~mm}$. long. Face a little wider than in the ${ }^{*}$. First joint of the anterior tarsi rather short, a little more

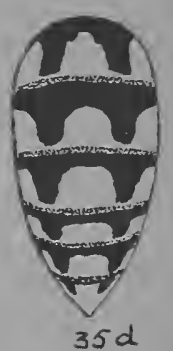

Fig. 35d. Stizus loriculatus, 오, abdomen. than twice as long as wide, the outer margin with seven spines. The mesopleurae are usually entirely black. Otherwise like the $\sigma^{*}$.

Inhambane, Portuguese E. Africa; Gambia; Sawmills, S. R., Zululand. (R.M. and T.M. colls.)

\section{CAFFER Group.}

Apical joints of the flagellum in the simple, the tenth without an apical spine, the eleventh not, or barely excised below, the apical joint attenuated but not drawn to a sharp point as in the tridens group. Lateral margins of the epinotal declivity moderately excised. Sternites unarmed. Abdomen lanceolate-ovate.

This group includes three very closely allied species: caffer Sauss., laterimacula Handl. and hoplocerus Handl. 
S. caffer Sauss. Mélanges Hymenop. p. 28, ․ 1855. Turner, Ann. Mag. N.H. Ix, p. 339, ô. I912. Handlirsch, Sitzungsber. K. Akad. Wiss. Wien CIV, p. 980 , 9.1895 .

"?. Eyes distinctly convergent towards the clypeus; face very wide. Epinotum excavated behind, the lateral margins of the declivity compressed and excised. Wings deeply infuscated, with a violet lustre; the second cubital cell with a short petiole; in the hind wing only one vein is emitted from the end of the medial cell. A pical tergite without a pygidial area, the sternites unarmed. Antennae fairly stout but hardly clavate. Legs moderately stout, the anterior metatarsus fairly wide, bearing long cilia like the following joints. Body very densely and moderately coarsely punctured, hardly pilose but fairly distinctly pubescent, black with violet reflections. Head, excepting black maculae on the face, pronotum and the pronotal tubercles, sides of the mesonotum, scutellum, metanotum, sides of the thorax, epinotum excepting the median area, lateral margins of the first and second abdominal segments, the first two sternites in front, apex of the fifth segments above and below, and the whole of the apical segment, more or less dark ferruginous. Large angular maculae on the first four tergites, yellow. Antennae and legs entirely ferruginous. I6 $\mathrm{mm}$. long.

Vertex noticeably wide, the antennae inserted close together, hardly farther from the clypeus than from the eyes. The posterior ocelli lie on the level of the line joining the posterior margins of the eyes, and are barely farther from each other than from the eyes. Otherwise the head resembles that of loriculatus. The lateral margins of the epinotal declivity have only one excision, which is wide and deep... The puncturation is smaller than in loriculatus, very dense, and finer on the dorsum of the thorax than on the abdomen. The pubescence is fairly abundant and brownish grey."

The description given above is that of Handlirsch, based on the type of Saussure, from Natal.

\section{S. laterimacula Handl. Loc. cit. p. 980, .}

o. $15 \mathrm{~mm}$. long. Ferruginous. Labrum, clypeus and lower part of the face yellow. The face on each side of the middle and the vertex between ocelli and the eyes have diffuse black patches of variable extent. On the thorax, the mesonotum excepting the lateral margins, the lower half of the mesopleurae, the mesosternum, metapleurae, median area of the epinotum and the middle part of its declivity, are black. Posterior margin of the pronotum yellow. The colour of the abdomen is mainly ferruginous, and the yellow maculae on each side are smaller than in the variety euteles. Sculpture like that of euteles but the puncturation on the dorsum of the epinotum is somewhat closer and smaller. The eyes are slightly more divergent above and below than in euteles and the width of the vertex relatively greater, the interocular distance there being three-fifths greater than across the base of the clypeus. The temples are as feebly developed as in euteles. Flagellum as in that species. The slight sinus above the excision of the lateral margins of the declivity is deeper than in euteles, but not so deep as in haplocerus. Sternites and apical tergite as in euteles.

f. $15 \mathrm{~mm}$. long. Interocular distance on the vertex somewhat less than half as great again as across the base of the clypeus. Colour,sculpture etc. as in the ${ }^{+}$.

Victoria Falls, Sanyati Valley, Sawmills and Umtali, S. R.; Delagoa Bay.

In the course of writing this description, which was done after that of euteles, it became apparent that the latter cannot be separated as a distinct 
species, but must be considered as a variety of laterimacula. The latter has precedence, having been described two pages earlier in Handlirsch's monograph. The specific characters of the var. euteles, other than the differences enumerated above, apply therefore to laterimacula.

S. laterimacula, var. euteles Handl. (figs. 36, 36a-e). Loc. cit. p. 982, o. $^{\text {. }}$

o. $\mathrm{r}_{5} \mathrm{~mm}$. long. Black. Mandibles excepting the ferruginous apex, labrum, clypeus, face below the antennae and narrow streaks at the sides of the face and in the middle almost to the level of the anterior ocellus, posterior orbits and a line joining them on the vertex, yellow. Margins of the pronotum yellow, the rest reddish yellow excepting a transverse black band on the collar. Sides of the mesonotum, upper half of the mesopleurae, tegulae, scutellum, metanotum, sides of the epinotum posteriorly, the lateral areas of its dorsum, lateral margins of the tergites, the greater part of the sternites, the whole of the apical segment, the legs and the antennae, pale ferruginous, in parts almost yellowish red. Scapes below, tibiae at the apex inwardly and apices of the scapes, yellowish. First six tergites with large, more or less
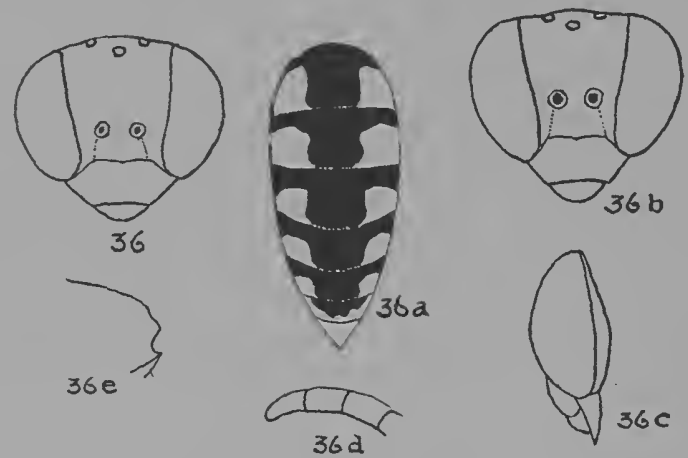

Fig. 36. Stizus laterimacula, var. euteles, $\uparrow$, head; $a, \hat{o}$, abdomen; $b, \hat{\jmath}$, head; $c, \hat{o}$, head; $d, \hat{\delta}$, apical joints of flagellum; $e, \hat{\sigma}$, lateral view of epinotum.

triangular, yellow maculae on each side; the median black portion of the tergite with a slight violet tinge. Wings pale fusco-hyaline, the veins blackish. Pubescence very fine, silvery on the clypeus and face, greyish elsewhere. Upper half of the face with a sparse and not large puncturation. Mesonotum, scutellum and metanotum with a semi-puncturation, very fine and close on the mesonotum. Mesopleurae with a few large, round punctures in addition to the fundamental microscopic sculpture. The dorsum of the epinotum has a large and fairly close puncturation, composed of round punctures near its base. Sculpture of the abdomen fairly distinct, not very close on the tergites, and composed of oblique punctures. Face wide, the eyes only moderately convergent below. The interocular distance on the vertex is only half as great again as across the base of the clypeus. Antennal sockets twice as far from the clypeus as from the eyes. Head vertically truncate behind, the temples very feebly developed, not as wide at their widest as the base of the mandibles. All the joints of the flagellum, excepting the first, much longer than wide, the second barely longer than the third, the apical joint slightly curved, rounded at the apex, and as long as the preceding joint. Posterior ocelli slightly nearer to the eyes than to each other. Lateral margins of the epinotal declivity excised below, with a very shallow sinus above the upper angle of the excision. 
Sternites unarmed; seventh tergite broadly triangular, the apex rounded. Second cubital cell not petiolate.

This description is based on a specimen from Ligombwe, S. Africa, in the Braunsian collection, bearing a label "det. Handlirsch." The shape of the lateral margin of the epinotal declivity does not conform to Handlirsch's figure 16 on Plate II.

ㅇ. I attribute to this species 3 우 from IO-I $2 \mathrm{~mm}$. long which agree with the $o^{-1}$ in the feeble development of the temples and in the shape of the epinotum. The yellow on the face and clypeus is more ochreous than in the $\hat{0}$, and the rest of the head, excepting the occiput and two maculae above the antennae, is ferruginous. The greater part of the epinotum is ferruginous, only the median area, middle of the declivity and anterior margin of the sides being black. In one specimen the greater part of the mesonotum is ferruginous. Apical margins of the tergites narrowly, the middle of the fifth and the whole of the sixth tergite, ferruginous. Apical third of the sixth tergite smooth and shining, with a few large round punctures.

Victoria Falls and Gwaai, S. R. December to January.

S. haplocerus Handl. (figs. $37,37 a-c$ ). Loc. cit. p. 984, ot.

o. I2-I $4 \mathrm{~mm}$. long. Very much like euteles from which it differs as follows. Scutellum and metanotum black, the sides of the epinotal dorsum yellow, but sometimes the epinotum is entirely black. Mesopleurae entirely black. First five and basal half of the sixth sternite black, their apical margins narrowly flavo-testaceous. Yellow maculae on the tergites wider. The semipuncturation on the mesonotum, scutellum and metanotum larger, deeper and

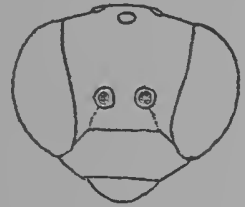

37

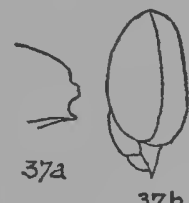

376

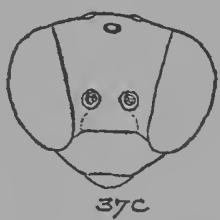

Fig. 37. Stizus haplocerus, 오, head; $a, \hat{\jmath}$, lateral view of epinotum; $b$ and $c$, $\hat{o}$, head.

not so close, so that the surface is more shining. Dorsum of the epinotum with round punctures. Temples more developed than in euteles, seen from the side about half as wide as the eyes. Face and clypeus relatively wider, but the eyes are more convergent below, the interocular distance on the vertex being three-fourths greater than across the base of the clypeus. Second joint of the flagellum nearly one-third longer than the third joint, the apical joint thinner and less blunt at the apex. Posterior ocelli as far from the eyes as from each other. Lateral margins of the epinotal declivity almost twice excised, the sinus above the excision being much more pronounced than in euteles. Seventh tergite much broader, almost semicircular, its ventral flaps covered with a dense, exserted and ferruginous pilosity.

․ I $4 \mathrm{~mm}$. long. Colour like that of euteles 9 , but the sides of the epinotum posteriorly are sometimes lemon yellow instead of ferruginous, and the first four sternites are black as in the $\delta$. Interocular distance on the vertex nearly one-third greater than across the base of the clypeus. Second joint of the flagellum half as long again as the third (one-third longer in euteles). The sinus above the excision of the epinotum is less distinct than in the 0 .

Salisbury, Matopos and Rusapi, S. R.; Johannesburg. 


\section{DISCOLOR Group.}

Like the loriculatus group, but the sixth sternite is without longitudinal carinae. The ventral flaps of the seventh tergite are large and densely fringed with long hairs. The mesopleurae have a fine, scattered and round puncturation. The apical spine of the tenth joint of the flagellum is long and angulated near its end; the apical joint is also long, thin and acuminate.

S. nyasae Turner (figs. $\left.38,3^{8} a, b\right)$. Ann. Mag. N.H. Ix, p. $33^{8}$, ơ ㅇ․ I912.

o. I4 $\mathrm{mm}$. long. Colour pattern of the head and of the greater part of the thorax like that of loriculatus, but of a bright lemon yellow. The mesopleurae are for the greater part also of that colour, only the periphery and a large patch below being black. The posterior half of the scutellum is yellow and the metanotum is entirely black. A wide $V$-shaped yellow band covers the greater part of the median area of the epinotum. The sides of the epinotum from the stigma to the upper angle of the lateral excision are yellow, and there is a small spot of yellow in front of

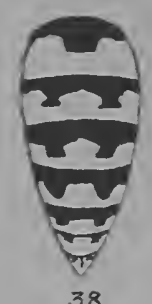

38

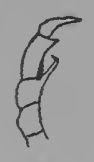

$38 a$

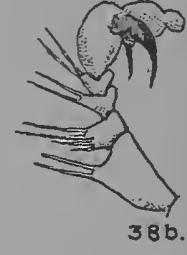

Fig. 38 . Stizus nyasae, $\hat{0}$, abdomen; $a, \hat{o}$, apical joints of flagellum; $b$, + , anterior tarsus.

the stigma and just behind the base of the hind wing. Abdomen black and yellow, the yellow markings on the second to fifth tergites being wider than in loriculatus, connected by a wider yellow band on the apical margin, and with the median spot more angular anteriorly. The first tergite is black on the declivous face, the black extending as a tongue medially over half the length of the dorsal face. The sixth tergite is black only at the extreme base, and the seventh is yellow at the base with a black spot on each side and flavo-ferruginous at the apex. Sternites $2-5$ with apical bands of yellow, widely and abruptly dilated at the sides and slightly interrupted in the middle. Sixth sternite yellow at the sides, black at the base and ferruginous at the apex. Seventh sternite and the ventral flaps of the seventh tergite ferruginous. Flagellum reddish ochreous below, reddish brown above. Legs yellow, the femora pale reddish above. Pubescence whitish and sparse, on the clypeus and lower part of the face, silvery. Upper part of the face with a round, shallow and sparse puncturation. The sculpture of the thorax and tergites consists of a very fine semi-puncturation, but the mesopleurae have a sparse and true puncturation superimposed. The sternites and seventh tergite are shining, fairly strongly and closely punctured with round punctures. All the joints of the flagellum, excepting the first and tenth, longer than wide; the apical spine on the tenth is hooked at the apex and more than half as long as the following joint. The latter has its apex angularly produced below, and the apical joint is long, curved and acute at the apex. The second joint is about one-fifth longer than the third. Posterior ocelli half as far again from each other as from the eyes. Interocular distance on the vertex nearly twice as great as across the base of the clypeus, and equal to the length of the second to fourth joints of the flagellum, or even a little more. The inner margins of the eyes are moderately divergent above and below. Lateral margins of the epinotal declivity with one shallow excision, of which the upper angle is widely rounded. Seventh tergite triangular, narrowly truncated at the apex, its ventral flaps with a dense row of long reddish hairs on the posterior margin. 
Second cubital cell not petiolate, the second abscissa of the radius being nearly half as long as the first.

․ If $\mathrm{mm}$. long. The yellow on the labrum, clypeus and face is darker than in the $\hat{o}$, ochreous or reddish yellow. The yellow apical bands on the sternites are often obsolete or very much reduced. Face wider, the eyes less convergent in the middle than in the $\sigma^{t}$. The interocular distance on the vertex is only half as great again as across the base of the clypeus. First joint of the anterior tarsi subtriangular, the second, third and fourth strongly asymmetrical, the fifth unusually swollen, the pulvillus very large and vesicular. Sixth tergite triangular, rounded at the apex and fairly closely covered with elongate punctures.

Lower Luangwa River, N.E. Rhodesia; Karonga, Lake Nyasa; Victoria Falls, Sarmills, Bulawayo and Sanyati River, S. R. (R.MI. and T.M. colls.)

\section{PEREGRINUS Group.}

Epinotal declivity less concave than in the tridens group; second or third sternite with a dentiform tubercle; sometimes the sixth is also armed. Otherwise like the tridens group. The sculpture on the mesonotum and abdomen consists of a semi-puncturation, but usually the mesopleurae and epinotum have a true puncturation as well.

S. dentiventris Handl. (figs. $39,39 a-c$ ). Loc. cit. p. 983 , o.

o. II $5^{-1} 3 \mathrm{~mm}$. long. Black. Labrum, clypeus, base of the mandibles on the outside, face below the antennae and the lower half of its lateral margins, front of the scapes, posterior margin of the pronotal collar and the pronotal

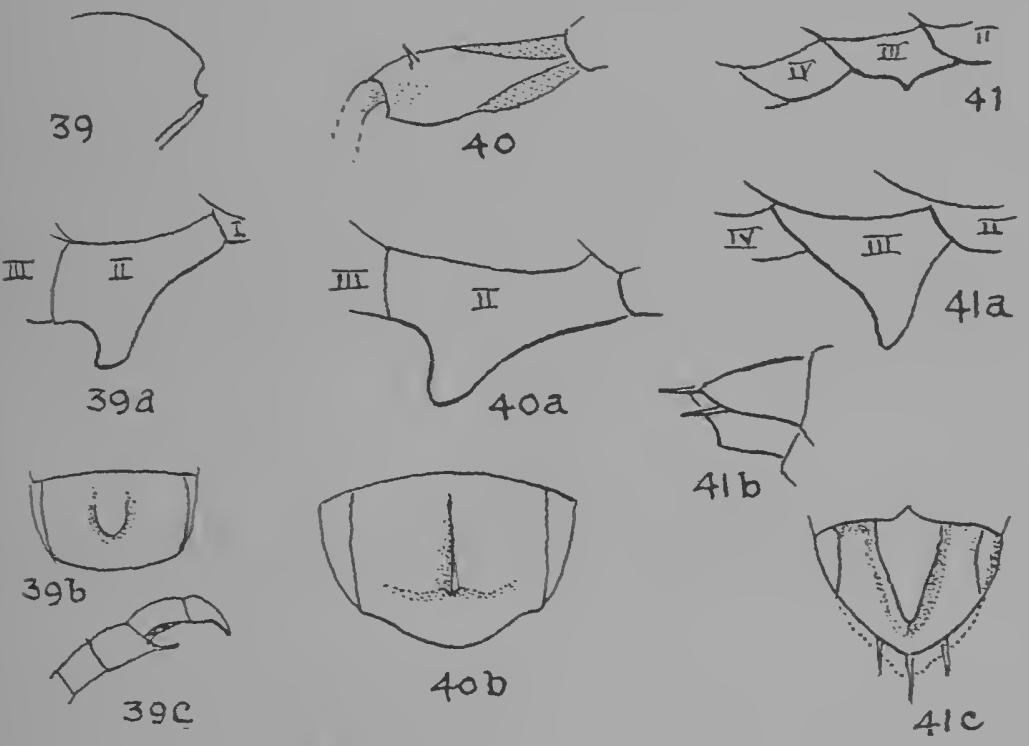

Fig. 39. Stizus dentiventris, $\hat{o}$, lateral view of epinotum; $a, \hat{o}$, second sternite; $b, \hat{o}$, sixth sternite; $c, \hat{o}$, apical joints of flagellum.

Fig. 40. Stizus hoplites, var. minor, ox, posterior femur seen from below; $a$, second sternite; $b$, sixth sternite.

Fig. $4 \mathrm{I}$. Stizus protetus, $\hat{\jmath}$, second sternite, normal form; $a$, $\hat{o}$, second sternite, extreme development; $b$ and $c, \hat{o}$, seventh sternite. 
tubercles and apical transverse bands on the first four or five tergites, dark yellow. The yellow bands on the tergite are more or less suffused with red in front and behind. Posterior angles of the mesonotum, tegulae, a small spot on each side of the scutellum, the last two tergites and sternites, the apical margins of sternites $2-5$, and the legs, pale ferruginous. Coxae, trochanters and base of the femora above, blackish. Flagellum pale ferruginous. Wings pale hyaline, the veins brown.

Pubescence on the clypeus and lower part of the face silvery, elsewhere grey and fairly abundant. The vertex, mesopleurae, sides of the epinotum and apical segments of the abdomen have also a sparse, greyish pilosity. Puncturation on the face, mesopleurae and epinotum round and shallow, sparse on the face, fairly dense on the other parts. On the mesopleurae there is only a fine, close semi-puncturation, and on the abdomen a fairly close sculpture of the same kind, on the first tergite intermixed with round punctures. Sides of epinotum and the abdomen nitidulous, the rest of the body dull. Interocular distance on the vertex slightly more than twice as great as across the base of the clypeus. Posterior ocelli as far from the eyes as from each other. Second joint of the flagellum nearly half as long again as the third. Apical joints of the flagellum formed as in the tridens group. Lateral margins of the epinotal declivity arcuately excised, the upper angle obtuse, the lower very short and acute. Second sternite with a large tubercle in the middle, its apex rounded. Sixth sternite with a more or less semicircular raised platform in the middle; the apical tergite broadly triangular, its apical margin entire. Second cubital cell not petiolate, the second abscissa of the radius being twothirds as long as the first.

De Vlagt, Aventuur, C. P. (Dr H. Brauns).

S. hoplites Handl. Sitzungsber. K. Akad. Wiss. Wien, CI, p. 84, ô. I892.

" ${ }^{\circ}$. Closely allied to $S$. peregrinus Smith and like it. The posterior femora are moderately excavated behind as in peregrinus, but in place of a series of spines have a single and fairly long spine close to the apex. Second sternite with a large, curved, compressed tooth, blunt at the apex, the sixth with a distinct triangular tubercle, the seventh with a median carina. Black, a little more distinctly punctured on the thorax than peregrinus, moderately pilose and pubescent; the clypeus, posterior margin of the pronotum and the pronotal tubercles, and very narrow bands on the first four tergites, pale yellow. Antennae black, scapes yellow below, the flagellum testaceous below; legs fuscous, the tarsi paler. I3 mm. long."

Caffraria.

\section{S. hoplites, var. minor n.v. (figs. $40,40 a, b$ ).}

A $\delta$ and $o$ from Ceres in the British Museum's collection agree fairly closely with the description given above, but are smaller and differ also in other features.

o. Io $\mathrm{mm}$. long. Sixth sternite with a median longitudinal carina which is raised to a point at its termination at about the second third of the segment. Seventh sternite without a carina. Otherwise this variety agrees fairly closely with Handlirsch's rather short description of hoplites. The interocular distance on the vertex is two and a third times greater than across the base of the clypeus. The excision of the lateral margins of the epinotal declivity is like that of dentiventris. The labrum is brown and there is a small blackish spot on the middle of the clypeus. The mesonotum is slightly shining, with a microscopic 
fundamental sculpture on which is superimposed a scattered and rather sharply defined semi-puncturation. ㅇ. ro $\mathrm{mm}$. long. Like the $\hat{o}$.

In both sexes the transverse yellow band on the fourth tergite is short, covering only the middle part of the segment. The band on the first tergite is of even width throughout, on the second and third slightly dilated in the middle and at the sides.

Ceres, C. P. (R. E. Turner), types in the British Museum.

S. monodon Handl. Sitzungsber. K. Akad. Wiss. Wien, cIv, p. 984, ㅊ, ․ I 895 .

"Allied to and like $S$. Gazagnairei. The head a little wider and the eyes a little more convergent below. Antennae about the same as in Gazagnairei. Sides of the epinotum compressed, distinctly excised below, not angularly prominent above. Wings slightly smoky, the second cubital cell not petiolate. Posterior femora in the of scarcely excavated in the apical half, armed with a distinct tooth a little before the middle. Abdomen similar to that of Gazagnairei, the seventh tergite in the o narrower, almost triangular, the second sternite with a compressed and truncate tooth, the sixth and seventh unarmed. Sternites simple in the of, the sixth segment almost conical, without a pygidial area above. Body less finely and evenly punctured than in Gazagnairei, moderately pilose, black, the anterior orbits, clypeus, labrum, pronotal tubercles and in the $\hat{\sigma} \mathrm{a}$ band on the pronotum, a band on the metanotum, and in the $\delta$ complete bands on the first four tergites and a median spot on the fifth, in the o a band interrupted in the middle on the first, complete on the second, almost obsolete on the third, a median spot on the fourth, pale yellow; the margins of the segments more or less ferruginous. Antennae black, testaceous below, the scapes yellow below. Legs in the ${ }^{*}$ ferruginous, black at the base, in the of black with the tibiae and tarsi more or less testaceous. 9-1o mm. long. I ot and I 9 . South Africa."

Types in the Berlin Museum.

S. proteus n.sp. (figs. 4I, 4I $a-f$ ).

This species is characterised by the wide range of variation in the $\sigma^{t}$ in size, colour and length of the tooth on the third sternite.

․ $9 \mathrm{~mm}$. long. Black. The inner orbits narrowly and sometimes a streak on each side of the base of the clypeus, yellow. Posterior margin of the pronotal collar, pronotal tubercles, a triangular spot behind them on the mesopleurae, the outer half of the tegulae and the axillary sclerite, a very thin
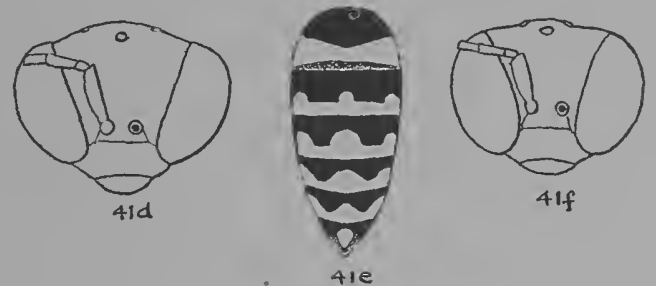

Fig. 4I $d$. Stizus proteus,, , head; $e, \rho$, abdomen; $f, \hat{o}$, head.

streak on the mesonotum opposite the tegulae, posterior corners of the mesonotum, a large spot on each side of the scutellum, the metanotum except in front, a broad band on each side of the epinotum, apical bands on the first five tergites and a large median spot on the fusco-ferruginous sixth tergite, lemon yellow. The band on the first is narrowed in the middle, those of the 
second to fifth abruptly and more or less roundly dilated in the middle and at the sides. Sternites $2-5$ with very narrow fuscous yellow apical bands, slightly dilated laterally. Legs yellow, the femora more or less black above, a spot on the outside of the anterior tibiae and on the inside of the middle and hind tibiae at the apex, fuscous. Antennae brownish black above, dirty yellow below. Pubescence silvery on the clypeus and face, yellowish grey, decumbent and very fine and sparse on the dorsum of the thorax and on the abdomen, longer and whitish on the mesopleurae. Pilosity almost absent. Sculpture like that of Braunsii, but the face has a sparse, fairly fine and round puncturation. Clypeus about three times wider than long. Eyes not strongly convergent below, the interocular distance on the vertex being hardly twice as great as across the base of the clypeus. Excision of the lateral margins of the epinotal declivity small, low down and with subacute angles. Sixth tergite conical, the apex narrowly rounded. Second cubital cell distinctly petiolate.

o. $9 \mathrm{~mm}$. long (typical form). I regard those examples which most closely resemble the $q$ in colour and size as the typical form. Labrum, clypeus, mandibles except at the apex, face below the antennae and half way up the sides, scapes and flagellum below, pale lemon yellow. Pronotum yellow, with a transverse streak of black across the neck. Mesonotum black, the lateral margins and two short longitudinal lines on each side of the middle in front, lemon yellow. Mesopleurae, the outer portion of the mesosternum, a large spot on each side of the scutellum, metanotum and epinotum excepting the sides in front, the base of the dorsum and the middle part of the declivity, lemon yellow. Abdomen mainly lemon yellow; on the second and third tergites the black forms a bisinuate band occupying not more than the basal third of the segment, on the fourth to sixth it is as extensive as in the $q$, but the dilated part of the yellow band is more angular; the seventh yellow with two small lateral and one median black spot. The first sternite and median basal spots on the other sternites are black. Pubescence on the upper part of the face and of the vertex with a golden tinge. Eyes more convergent below than in the $q$, the interocular distance on the vertex being two and a third times greater than across the base of the clypeus. Scapes broader than in the . . Apical joint of the flagellum as in Braunsii ot. Excision of the lateral margins of the epinotal declivity as in dentiventris. Third sternite with a low and acute prominence in the middle, or with none at all. Seventh sternite with a triangular platform in the middle, raised towards its apex which lies near the apical margin of the segment. Otherwise like the + .

In this sex there is a wide range of variation which proceeds on the following lines. With an increase in size, up to a maximum of $12 \mathrm{~mm}$., there is a concurrent increase of the yellow colour and enlargement of the tubercle on the third sternite. The change, as represented in the material before me, is a gradual one, but at its extreme development the whole body is yellow, excepting only the vertex, the upper surface of the flagellum, apices of the mandibles and two narrow streaks on the posterior half of the mesonotum, which are black. At the same time the prominence on the third tergite increases in size till at its greatest development it forms a curved tooth, longer than wide at the base.

Sawmills, Gwaai and Victoria Falls, S. R. October to December. Types in the Rhodesia Museum. (R.M. and T.M. colls.)

This species furnishes a striking illustration of the danger of erecting new species in this genus on the strength of a single character, or even a combination of two or three characters, in the absence of the opposite sex. In the absence of the $q$ and the intermediate forms of the $\hat{o}$ (all taken together on each 
occasion at the same time and place), no one would suppose that the small form of the $\sigma^{A}$ with female colour pattern and small sternal process could be the same species as the large and almost entirely yellow $\sigma^{\star}$, with a large tooth on the third sternite.

\section{S. laticinctus n.sp. (figs. $42,42 a, b)$.}

3. Io mm. long. Black. Labrum, clypeus, base of the mandibles, face below the antennae and half way up the sides, scapes excepting a black mark above, pronotal tubercles and posterior margin of the pronotum, a transverse macula on the middle of the mesopleurae, lateral margins of the mesonotum, outer half of the tegulae and the axillary sclerites, the whole of the scutellum and metanotum, and transverse bands on the apical half of the first six tergites, chrome yellow (in one specimen the bands on the fourth to sixth are angularly bisinuate). Apical third of seventh tergite yellowish red. Sternites 2-6 with small yellow spots at

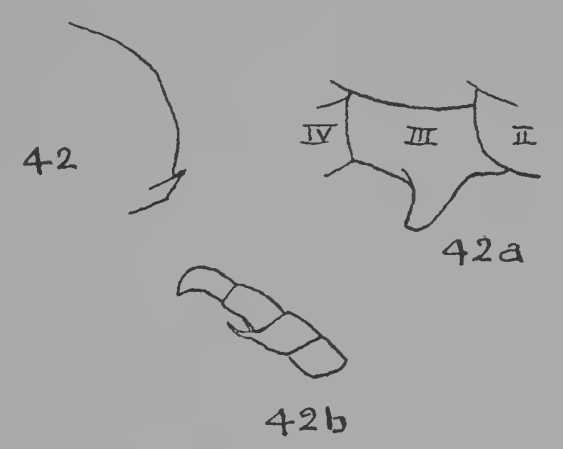

Fig. 42. Stizus laticinctus, ô, epinotum; $a, \hat{o}$, third sternite; $b, \hat{o}$, apical joints of flagellum. the sides. Legs dark yellow, the coxae and trochanters blackish above, the upper side of the femora reddish. Wings hyaline, the veins black. Pubescence very scanty everywhere, the vertex and apical margins of the sternites with a few long hairs. Face and vertex nitidulous, sparsely, finely and shallowly punctured. Mesonotum fairly dull, closely and finely punctured, the punctures on the anterior half round, merging into a semipuncturation behind. Scutellum, metanotum, dorsum and declivity of the epinotum dull, closely and finely punctured with round punctures. Mesopleurae very finely punctured, with a few larger and shallow punctures here and there. Sides of the epinotum shining, the upper part of the posterior half with a close and round puncturation. The abdomen has a fine semi-puncturation. Clypeus not twice as wide as long in the middle. Antennal sockets twice as far from the clypeus as from the eyes. Scapes short, barely twice as long as wide at the apex. Tenth joint of the flagellum with an apical spine, the apical joint moderately curved, fully as long as the preceding joint. Interocular distance on the vertex twice as great as across the base of the clypeus. Lateral margins of the epinotal declivity not excised, but furnished with a short tooth below. Third sternite with a curved tooth which is as long as wide at the base. Sixth and seventh sternites simple. Apical tergite subtriangular, the apex narrowly rounded. Second cubital cell not petiolate, but in one specimen the first two transverse cubital veins are almost contiguous on the radius.

Montagu, C. P. October, 2 ô (R. E. Turner). Type in the British Museum.

\section{S. Herbsti Brauns (figs. $43,43 a, b)$. Brauns in litt.}

f. I I mm. long. Black. Labrum, clypeus, face below the antennae and half way up the sides, scapes in front, posterior margin of the pronotum and the pronotal tubercles, the metanotum and transverse pre-apical bands on the first four tergites, pale yellow. The fifth tergite with a median yellow spot. The apical margins of the first four tergites, the apex of the seventh tergite and the whole of the seventh sternite, reddish brown. Flagellum black above, ochreous 
below. Tegulae ferruginous. Legs ferruginous, the coxae, trochanters and the extreme base of the femora above, black. Anterior and middle tibiae yellow on the inside. Wings hyaline, the veins dark brown. Pubescence whitish on the head, pale brown and very fine on the mesonotum, white on the rest of the thorax, long, decumbent and pale yellowish on the abdomen. The sculpture is a semi-puncturation, very fine and close on the mesonotum, stronger and less oblique on the mesopleurae, rather coarse on the abdomen. On the upper half of the face there is a round, fairly strong and close puncturation, and also on the dorsum of epinotum which is moderately shining, like the sides of that segment. The rest of the thorax is dull; the abdomen slightly shining above. Anterior margin of the clypeus nearly straight. Interocular distance on the vertex two and a third times greater than across the base of the clypeus. Posterior ocelli slightly nearer to the eyes than to each other. Apical joints of
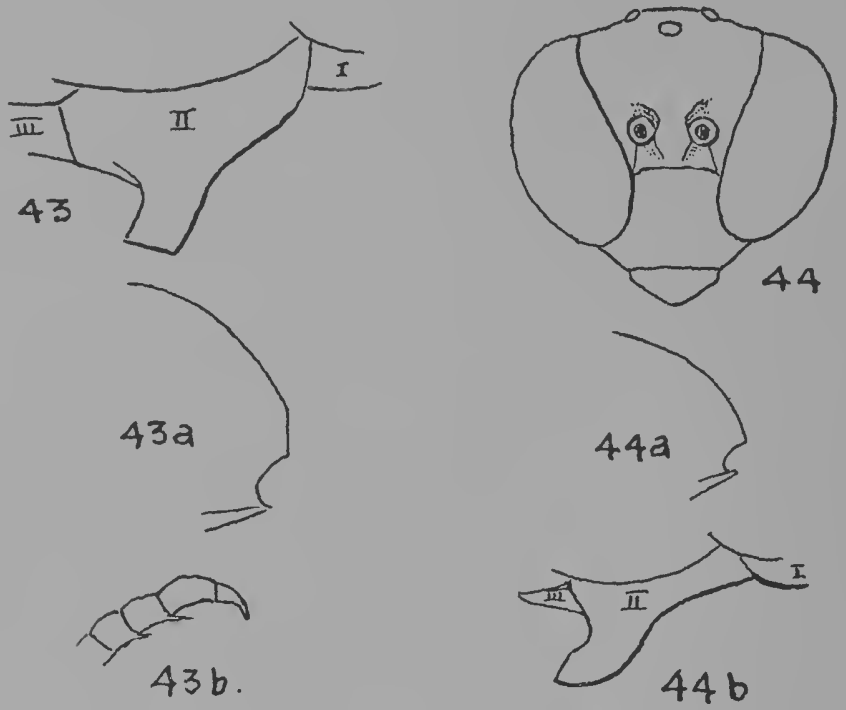

Fig. 43. Stizus Herbsti, $\hat{\sigma}$, second sternite; $a, \hat{o}$, epinotum, lateral view; $b$, $\delta^{\star}$, apical joints of the flagellum.

Fig. 44. Stizus cinguliger, + , head; $a$, + , epinotum; $b, \hat{b}$, second sternite.

the flagellum as in the tridens group, but the ninth joint has a minute apical spine below, and the apical joint is only a little more than half as long as the penultimate joint. Lateral margins of the epinotal declivity excised below, the upper angle of the excision truncate, the lower acute. Second sternite with a large, curved and transversely compressed tooth which is broadly truncate at its apex. Seventh sternite acutely angular at the apex, the seventh tergite broadly triangular and rounded at the apex. Second cubital cell not petiolate.

․ Io mm. long. Clypeus and labrum fuscous, only their anterior margins yellow. Face with only a very narrow yellow streak on the lateral margins, also yellow below the antennae. Second sternite with a transverse yellow streak on each side near the apical margin. Interocular distance on the vertex nearly two and a half times greater than across the base of the clypeus. Sternites simple.

Lichtenburg, Transvaal, January (Dr H. Brauns). Type in coll. Brauns. 


\section{CINGULIGER Group.}

Antennae clavate in both sexes, the apical joints simple. Second sternite in the ormed with a very large curved tooth. Lateral margins of the epinotal declivity excised. Clypeus high, reaching half way up the head. Sculpture composed chiefly of a semi-puncturation.

S. cinguliger Smith (fig. 44, 44a, b). Cat. Hymen. B.M. IV, p. 34I, ․ 1856. S. clavicornis Handl. Sitzungsber. K. Akad. Wiss. Wien, CI, p. 95, f. o. i 1892.

․ I I-I $3 \mathrm{~mm}$. long. Black. Labrum, clypeus, sides of the face at the base, pronotal tubercles and posterior margin of the pronotum, pale yellow. Apical margins of all the tergites broadly reddish brown; tergites $\mathrm{I}-5$ with narrow pre-apical pale yellowish bands, slightiy dilated at the sides. Sternites 2-5 with dull whitish apical bands, dilated at the sides and in the middle. Mandibles ferruginous, black at the base and apex. Scapes ochreous below, flagellum fusco-ferruginous above, pale reddish below. 'Tegulae ferruginous. Legs ferruginous, the anterior femora black above, ochreous below; the anterior tibiae also ochreous below. Wings hyaline, slightly smoky, the veins brown. Pubescence on the clypeus, temples and mesopleurae silvery, brown on the mesonotum, elsewhere grey. The vertex has a short testaceous pilosity. Dull; the sculpture consists of a fine and close semi-puncturation, almost microscopic on the abdomen. The median area of the epinotum is slightly shining, and has a sparse, large and round puncturation; the lateral areas of the epinotal dorsum also have round punctures, smaller and more abundant than on the median area. Clypeus distinctly convex, the anterior margin straight. Eyes divergent above and below, nearest together at the base of the clypeus where they are separated by nearly half the interocular distance on the vertex. Flagellum strongly clavate, the seventh to tenth joints fully twice as wide as long; the second joint is longer than in any of the preceding species, being four times longer than wide at the apex and nearly three-quarters longer than the third. Posterior ocelli half as far again from each other as from the eyes. Temples well-developed. Lateral margins of the epinotal declivity deeply and widely excised, both angles of the excision acute. Sixth tergite shallowly and angularly excised at the apex. Second cubital cell not petiolate, the second abscissa of the radius about one-third as long as the first.

o. II $-13 \mathrm{~mm}$. long. Anterior tibiae, tarsi and apical half of the anterior femora below, yellow. The pre-apical yellow bands on the first four tergites are wider than in the $q$; apical margin of the third and fourth tergites and the whole of the following tergites fulvous, their sternites somewhat darker. Anterior margin of the clypeus concave. Antennal sockets farther from the clypeus than in the $q$. The eyes are nearest together a little below the base of the clypeus, the interocular distance on the vertex is two and a half times greater than at that point. Second sternite with a long, curved and compressed tooth. Ventral flaps of the seventh tergite raised and dentiform at their apex. Seventh tergite very broadly rounded, not excised at the apex. Otherwise like the ?.

Willowmore, C. P. December. (R.M. and T.M. colls.)

\section{OXYDORCUS Group.}

Like the preceding group, but the sternites are unarmed. The ventral flaps of the seventh tergite are very large, plicate and end in a tooth. Flagellum clavate, the second joint not so long as in cinguliger. Lateral margins of the epinotal declivity distinctly excised. The sculpture is a semi-puncturation, but there are some round punctures on the epinotum. Clypeus very long. 
S. oxydorcus Handl. (figs. 45, 45a-d). Verh.Zool. Bot. Ges. Wien, L, p. 472, প. 1900.

S. Fohannis Cameron. Rec. Albany Mus. I, p. 323, ․ 1905.

․ IO-I I mm. long. Black. Labrum excepting a black spot in the middle, clypeus, sides of the face as far as the level of the antennal sockets, scapes in front, posterior margin of the pronotum and the pronotal tubercles, a spot on the front of the tegulae, a streak on the sides of the mesonotum from the tegulae to the posterior angle, two large spots on the scutellum, metanotum, a spot on the upper part of the mesopleurae, the posterior lateral margins of the epinotum, pre-apical bands on the first five tergites dilated laterally on the first three, apical bands on the second to fifth sternites and two spots on the sixth tergite, pale lemon yellow. Flagellum black above, ochreous below, the first two joints black below. Legs yellow, the basal third or more of the femora black. Mandibles piceous, with a yellow spot on the outside at the base. Wings hyaline, the veins dark brown. Clypeus, face, vertex, temples and

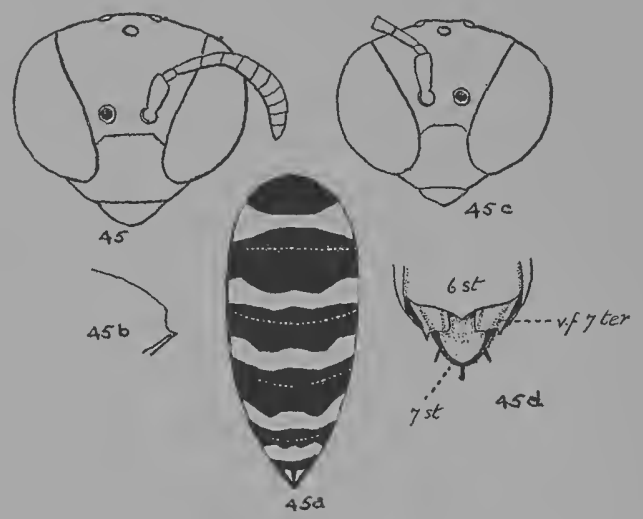

Fig. 45. Stizus oxydorcus, 우, head; $a$, 우 abdomen; $b$, 우, epinotum; $c$, $\hat{o}$, head; $d, \delta$, apical sternites ( $v . f .7$ ter $=$ ventral flaps of seventh tergite).

mesopleurae with silvery pubescence, elsewhere the pubescence is grey and very fine. Dull, the sculpture consists of a fine and close semi-puncturation, except on the dorsum of the epinotum where the punctures are larger and more separated, intermixed with some round punctures. Clypeus long, only one and a half times wider than long. Eyes strongly divergent above, less so below, nearest together at about the base of the clypeus. Interocular distance on the vertex as long as the whole flagellum and two and a third times greater than across the base of the clypeus. Flagellum clavate, the fifth to eleventh joints wider than long, the second half as long again as the third. Posterior ocelli as far from the eyes as from each other. Temples well-developed. Median area of the epinotal dorsum convex and gibbous; lateral margins of the declivity excised below and less compressed than in the tridens group, the declivity is therefore much less concave transversely. Apex of the sixth tergite narrowly truncate. Posterior tibiae with a row of short spines on the upper margin. Anterior tarsi without a comb of long cilia; the basal joint, however, has a dense row of very short and fine spines on the outer margin. Second cubital cell not petiolate, the second abscissa of the radius being about half as long as the first. 
o. 9-10 mm. long. The lateral marginal streaks of yellow on the mesonotum are much reduced, the sides of the epinotum immaculate. Yellow bands on the tergites paler than in the + , more yellowish white, the apical margins of all the tergites widely rufo-testaceous. Otherwise like the $q$ in colour and sculpture. Interocular distance on the vertex three and a half times greater than across the base of the clypeus. Apical margin of the sixth sternite obtusely angular. Ventral flaps of the seventh tergite large, plicate on the outer margin which ends in a tooth. Apical tergite broadly triangular, the apex narrowly rounded. Otherwise like the o. colls.)

Willowmore, C. P.; Bothaville, O. F. S.; Bulawayo. (R.M. and T.M.

\section{RHOPALOCERUS Group.}

Eyes strongly divergent above and below as in the preceding group. Flagellum moderately clavate, the second joint long and slender, especially in the $t$, which sometimes has the apical joint curved. Lateral margins of the epinotal declivity only slightly compressed, not excised, but having a short tooth below. Abdomen cylindrical, the sternites flattened and unarmed. Ventral flaps of the seventh tergite in the $o^{*}$ very large, meeting in the middle. Temples only moderately developed. Mesonotum, or at least the epinotum with a round puncturation. Claws long and slender, the pulvillus welldeveloped on the anterior tarsi, very feeble on the other tarsi. Second cubital cell not petiolate.

S. rhopalocerus Handl. (figs. 46, $46 a-d$ ). Sitzungsber. K. Akad. Wiss. Wien, CIV, p. 986, ㅇ. 1895 .

․ I $3^{-I} 4 \mathrm{~mm}$. long. Labrum, clypeus, mandibles excepting the black apex, face below the antennae and half way up the sides, the greater part of the temples and the mouth-parts, yellowish white; the rest of the head black, with a diffuse reddish border on the inside of the whitish margins of the face.
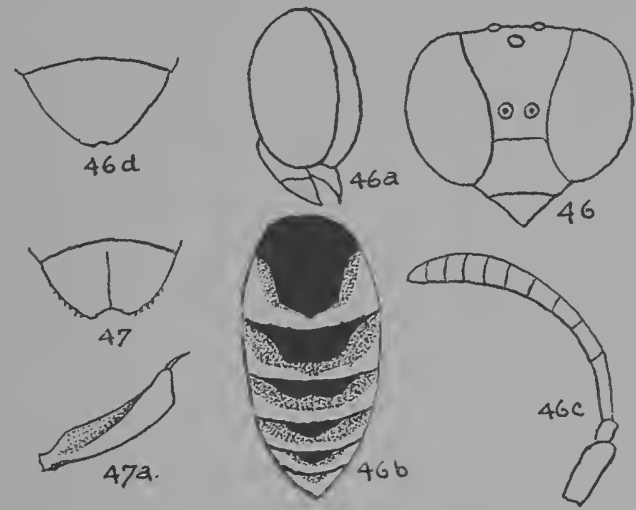

Figs. 46 and $46 a$. Stizus rhopalocerus, + , head; $b$, + , abdomen; $c$, 우 , antenna; $d, \hat{o}$, seventh tergite.

Fig. 47. Stizus rhopaloceroides, $\hat{\sigma}$, seventh tergite; $a, \hat{\sigma}$, right tibia viewed from above.

The temples in the upper part are also rufescent. Thorax black; the posterior margin of the pronotal collar, the pronotal tubercles, two large spots on the scutellum, posterior margin of the metanotum, the mesopleurae, the anterior half or more of the sides of the epinotum, the whole of the underside of the thorax and the lateral margins of the epinotal declivity, pale ochreous white. 
The sides of the mesonotum and two small spots on its anterior half, the tegulae and occasionally two small spots on the upper half of the declivity, ferruginous. Sternites yellowish white, tergites with yellowish white apical and lateral margins, the first four black at the base and with a diffuse reddish area between the black and the yellowish white, the fifth and sixth tergites merely reddish at the base. Legs pale reddish above and on the inside, yellowish white below. Scapes yellowish white below, black above; flagellum ochreous below, ferruginous above, the apical joints darker. Wings hyaline, the veins black. Clypeus and lower half of the face densely covered with silvery pubescence, the upper half of the face and the mesopleurae more sparsely so.

Vertex, occiput and epinotum with a thin, whitish pilosity; on the rest of the body there is a greyish, inconspicuous pubescence. Labrum shining, with a few large punctures. Face and vertex dull, with a shallow and round puncturation superimposed on the fundamental sculpture. Dorsum of the thorax, excepting the pronotal collar, dull, closely and fairly strongly punctured with round punctures, on the scutellum, metanotum and epinotum almost reticulate-punctate. Pronotal collar, metapleurae and sides of the epinotum smooth, nitidulous and very sparsely finely punctured. Abdomen slightly shining, the tergites with a close and very fine semi-puncturation, the sternites microscopically and closely punctured, except the first which is sparsely and coarsely punctured. Head in front, including the labrum, wider than long. Clypeus tivice as wide as long, the labrum triangular, almost as long as wide at the base. Antennal sockets twice as far from the clypeus as from each other. Eyes large, their facets on the inner half enlarged, divergent above and below, nearest together at the level of the antennal sockets, the interocular distance on the vertex slightly more than twice as great as across the base of the clypeus. Posterior ocelli nearer to the eyes than to each other. Flagellum clavate, the second joint long, nearly five times longer than wide and twice as long as the third, the sixth to eleventh joints wider than long. Declivity of the epinotum with a short tooth below, not excised. First tergite fully as long as wide at the apical margin, the sixth triangular, rounded at the apex. Sternites rather flat. Anterior tarsi with long golden cilia at the apices of the joints and four shorter cilia on the outer margin of the basal joint. Second transverse cubital vein strongly curved outwards in its lower half. The second abscissa of the radius about one-third as long as the first. Posterior tibiae with only a few short spines on the outside.

o. If $\mathrm{mm}$. long. The parts which are yellowish white in the $o$ are yellow in this sex. The puncturation is stronger than in the o, especially on the vertex and occiput. Second joint of the flagellum two-thirds longer than the third joint. Apical tergite wide, subtriangular, the apex very shallowly emarginate. Otherwise like the 우.

Willowmore, C. P. (Dr H. Brauns).

\section{S. rhopaloceroides Brauns (figs. 47,47 a). Brauns in litt.}

․ Io-II mm. long. Head and thorax black, abdomen ferruginous. Mandibles except at the apex, labrum, clypeus, face below the antennae and half way up the sides, scapes below, posterior orbits narrowly, posterior margin of the pronotum and the tubercles, a large pentagonal spot on the mesopleurae, a spot on the tegulae, a spot on each side of the scutellum, posterior half of the metanotum, a spot on the posterior corners of the epinotal dorsum, narrow apical bands on tergites $\mathrm{I}-5$, and a median spot on the sixth tergite, pale yellow. The declivous face of the first tergite and the fourth to sixth tergites, black. Sometimes the extreme base of the second and third 
tergites and a transverse streak on each side of the middle near the apical margin are also black. Flagellum ferruginous below, fuscous above. Anterior and middle legs yellow, the hind legs flavo-ferruginous, all the femora more or less black above. Wings hyaline, the veins blackish. Pubescence as in rhopalocerus, the sculpture also much the same as in that species but relatively finer, shallower and less close. Interocular distance on the vertex two and two-thirds greater than across the base of the clypeus. Eyes divergent above and below, nearest together at about the level of the antennal sockets. Labrum triangular, nearly as long as wide, subcarinate lengthwise in the middle. Temples wider than in rhopalocerus. Second joint of the flagellum two-thirds longer than the third joint. Posterior ocelli about as far from each other as from the eyes. First tergite at the apical margin one-fourth wider than long. Otherwise like rhopalocerus.

o. $12 \mathrm{~mm}$. long. Sculpture stronger than in the ? , especially on the vertex and mesonotum. Second joint of the flagellum half as long again as the third. Anterior tibiae broad, the inner face obliquely excavated. Seventh tergite semicircular, subcarinate lengthwise in the middle, the apex widely and shallowly emarginate. Otherwise like the o.

Willowmore, C. P. (Dr H. Brauns).

\section{S. hyperocrus Brauns. Brauns in litt.}

ㅇ. II mm. long. Head and thorax black, abdomen ferruginous. Labrum, anterior two-thirds of the clypeus, sides of the lower half of the face, scapes in front, and the posterior orbits, yellow. Posterior margin of the pronotum and the tubercles, tegulae, lateral margins of the mesonotum, a transverse streak on each side of the posterior margin of the scutellum and metanotum, a spot on each side of the epinotal dorsum, yellowish red. The declivous face of the first tergite, the extreme base of the second to fifth tergites, the sixth tergite excepting the apex, and the greater part of the third to sixth sternites, black. Flagellum black above, ochreous below. Legs ferruginous, the anterior pair paler. Wings hyaline, the veins brown, the costa and subcosta black. Labrum shining, with a few large punctures, subtriangular, nearly as long as wide. Face and vertex dull, fairly closely and moderately finely punctured. Thorax, excepting the pronotum, metapleurae and sides of the epinotum, dull, closely and fairly strongly punctured with round punctures, those on the dorsum of the epinotum twice as large as those on the vertex. Pronotum, metapleurae and sides of the epinotum nitidulous, microscopically punctured, the sides of the epinotum also with a few large punctures. Abdomen nitidulous, closely, shallowly and finely punctured, the punctures round. The first two sternites rather coarsely and not closely punctured. Interocular distance on the vertex two and a quarter times greater than across the base of the clypeus. Flagellum a little more strongly clavate than in the two preceding species, the seventh to eleventh joints wider than long; the second joint three-quarters longer than the third. Posterior ocelli about as far from the eyes as from each other. Anterior tarsi and the venation as in rhopalocerus. Sixth tergite triangular, rounded at the apex, the lateral margins with a row of very short, black spines.

Willowmore, C. P. (Dr H. Brauns).

S. mutabilis n.sp. (figs. $48,48 a, b)$.

7. II $5 \mathrm{~mm}$. long. Black. Mandibles except at the apex, labrum, clypeus, face below the antennae, scapes and flagellum underneath, a streak behind the posterior margin of the eyes, posterior margin of the pronotum, pronotal 
tubercles, lateral margins of the mesonotum, a spot on the tegulae and a spot on the middle of the mesopleurae, lemon yellow. A spot on each side of the scutellum, posterior margin of the metanotum, lateral margins of the epinotal dorsum, apical bands on the first five tergites and a median spot on the sixth, yellowish red. The band on the first tergite is abruptly narrowed in the middle, those on the second and third occupy more than half the segments, those on the fourth and fifth are dilated at the sides and in the middle. Legs dark yellow, the femora blackish above, the anterior and middle femora on the outside and the anterior tarsi, pale yellow. Wings hyaline, the veins black. Clypeus and face with silvery pubescence, elsewhere the pubescence is very short, grey and scanty. The epinotum has a sparse, whitish pilosity. Labrum broadly rounded in front, a little wider than long, shining, sparsely and finely punctured. Vertex and sides of the upper half of the face finely punctured. Mesopleurae dull, closely and finely punctured. Mesonotum, scutellum and metanotum slightly shining, shallowly and not closely punctured. Epinotum more strongly punctured than the mesonotum, the punctures shallow and round. Sides of the epinotum and the metapleurae smooth and shining. Abdomen not closely punctured, the punctures shallow and oblique. Head

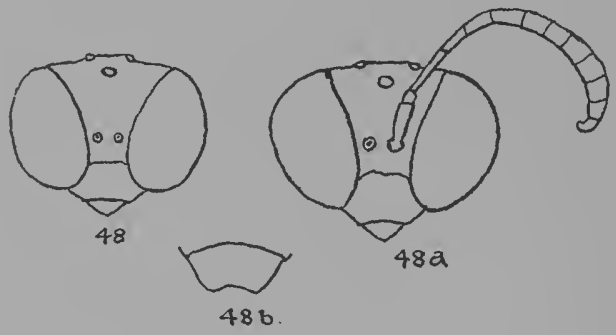

Fig. 48. Stizus mutabilis,, , head; $a, \hat{o}$, head; $b, \hat{o}$, apical tergite.

very wide, one-third wider than long, measured from the vertex to the anterior margin of the clypeus. Interocular distance on the vertex two and two-thirds greater than across the base of the clypeus. Flagellum strongly clavate, the second joint two-thirds longer than the following joint, the seventh to tenth wider than long, the apical joint as long as wide at the base. Temples narrow, about one-third as wide as the eyes. Posterior ocelli nearer to the eyes than to each other. Sixth tergite triangular, the apex narrowly rounded. Anterior tarsi like those of rhopalocerus. Second abscissa of the radius two-thirds as long as the first.

o. I I-I $2 \mathrm{~mm}$. long. Colour and pattern of the abdomen variable. In two specimens the pale bands have the same colour, yellowish red, as in the $q$, in a third specimen they are lemon yellow. In the latter the bands on the second and third tergites are roundly dilated at the sides and angularly in the middle as in $S$. nyasae. In the other two the fourth and fifth or fifth and sixth are dilated. All the legs are yellow, and the spot on the mesopleurae may be either much reduced or absent. A thin and long whitish pilosity is rather conspicuous on the vertex and on the dorsum of the thorax. The puncturation is scantier on the mesonotum and stronger on the vertex and first tergite than in the क. Head wider than in the o. Flagellum not so strongly clavate, the second joint is two-thirds longer than the third joint, the ninth to eleventh are as long as wide, all the rest longer than wide, and the apical joint is curved 
and slightly hooked at the end. Seventh tergite trapezoidal, its apical margin widely but shallowly concave. Otherwise like the ?.

Montagu, C. P. October (R. E. Turner). I f and $30 \hat{o}$. Types in the British Museum.

\section{S. quadristrigatus n.sp. (figs. 49, 49 a).}

f. I I-I $4 \mathrm{~mm}$. long. Black. Mandibles except at the apex, labrum, clypeus, face below the antennae and half-way up the sides and the scapes below, yellowish white. Temples and a sinuous line connecting them behind the vertex, pronotum excepting a transverse black streak across the base of the neck, mesopleurae, tegulae, sides of the mesonotum and two clavate streaks on each side of its middle, scutellum excepting a basal triangular area, the greater part of the metanotum, sides of the epinotum excepting a black band on their posterior margins, the lateral areas of the epinotal dorsum and a triangular mark on the middle of the declivity, yellow. Tergites with yellow apical bands widely dilated at the sides on the first two and covering more than half the length of those segments, on the third to fifth less widely dilated at the sides

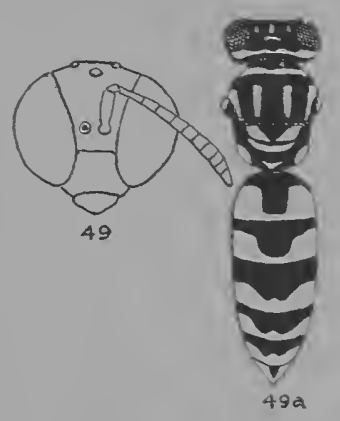

Figs. $49,49 a$. Stizus quadristrigatus, ㅇ. and bisinuate in the middle; the sixth with a median basal black spot. Sternites in greater part yellow, the second and sixth black at the base. Legs yellow, the coxae, trochanters and femora on their inner sides black. Flagellum reddish yellow below, ferruginous above, the first two joints black above. Wings hyaline, the veins dark brown. Clypeus and lower half of the face with silvery pubescence, on the rest of the body the pubescence is whitish and exceedingly fine. There is a short, scanty and white pilosity on the vertex and epinotum. Labrum roundly triangular, wider than long, shining, sparsely and coarsely punctured. Face and vertex finely and fairly closely punctured. Mesonotum, mesopleurae, scutellum, metanotum and the epinotum excepting the sides dull, closely punctured with shallow and round punctures. The sides of the epinotum are rather sparsely punctured. Abdomen slightly shining, with a very fine semi-puncturation which is very close, almost reticulaterugulose. Interocular distance on the vertex two and one-fifth times greater than across the base of the clypeus. Temples narrow above, one-third as wide as the eyes below. Flagellum moderately clavate, the second joint four-fifths longer than the third, the sixth to tenth wider than long, the apical joint as wide as long. Posterior ocelli nearer to the eyes than to each other. First tergite about one-quarter wider at the apex than long, and one-third longer than the second. Apical tergite triangular, the apex narrowly rounded. Second abscissa of the radius about two-thirds as long as the first.

Kamanyab, S.W. Africa. 3 우. Type in the South African Museum.

\section{FASCIATUS Group.}

Usually large species, with stout hornet-like bodies. Labrum elliptical or forming a narrow segment of a circle, not triangular as in the preceding group, usually coarsely punctured. Antennae filiform, only slightly widened towards the end, the apical joint usually curved in the $\sigma^{x}$. Temples very narrow, the head being almost vertically truncate behind. Sternites simple in both sexes. First transverse cubital vein slightly curved outwards towards the apex 
of the wing. Two longitudinal veins are emitted from the apex of the medial cell in the hind wing; the anal lobe ends far behind the origin of the cubitus. Eyes almost parallel, only feebly convergent below. Sculpture of the thorax close and usually fine, consisting of round punctures, that of the tergites is a semi-puncturation mixed with some round punctures. In some species the $q$ has a distinct, i.e. marginate, pygidial area on the apical tergite, which, however, does not extend beyond the apical third of the segment. The hind tibiae and tarsi in the of are densely pubescent.

This group comprises a number of closely allied forms, most of which have the same or a very similar livery, which, however, is somewhat variable within the species. For this reason the descriptions of many species is unsatisfactory, too much importance having been attached by some authors to the colour. In the of the chief diagnostic characters, and almost the only reliable ones, are the width of the face and the comparative lengths of the second and third joints of the flagellum, and of the last two joints. These have not been taken into account by Handlirsch in his monograph, so that some of his African species are difficult to recognise, especially as some of his descriptions are largely based on comparisons with non-Ethiopian species.

S. imperialis Handl. (figs. 50, 50a-c). Sitzungsber. K. Akad. Wiss. Wien, CI, p. 141 , ‥ 1892 .

․ I $\mathrm{S}-20 \mathrm{~mm}$. long. Lemon yellow. The following parts are black: apex of the mandibles, posterior margin of the clypeus, two large maculae above the antennal sockets, a band across the vertex enclosing the ocellar area, occiput, neck of the pronotum, mesonotum excepting the sides and two clavate streaks near the middle, extreme anterior margins of the scutellum and metanotum, mesopleurae excepting the anterior and posterior margins and the lower third, mesosternum, lower half of the metapleurae, base of the epinotal dorsum, the margins of its median area as far as the bottom of the declivity, the lateral areas of the epinotal dorsum anteriorly, the extreme base and apical fourth of the first four tergites and a longitudinal bar down their middle. Last two tergites ochreous. Flagellum ferruginous. Intermediate and hind coxae and trochanters diffusely ferruginous. Wings hyaline, slightly tinged with yellow, the veins ochreous, the radial and the

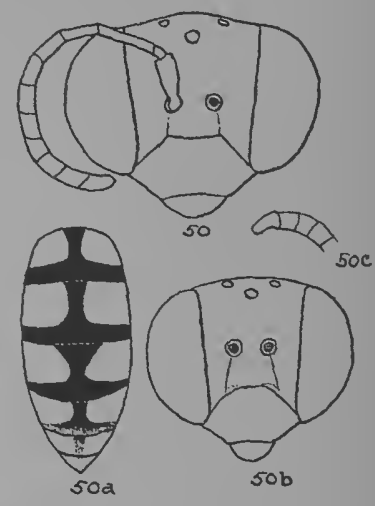

Fig. 5o. Stizus imperialis, head; $a, q$, abdomen; $b, \hat{o}$, head; $c$, $\delta$, apical joints of the flagellum. upper half of the second and third cubital cells faintly fuscous.

Pubescence and pilosity whitish, the latter confined chiefly to the epinotum and first tergite, the apical abdominal segment with a sparse yellowish pilosity. Labrum and anterior half of the clypeus fairly coarsely, the vertex finely and closely, punctured; the labrum dull, the anterior margin convex. Thorax with a fine, shallow and round puncturation, fairly close except on the epinotum. Abdomen with a sparse semi-puncturation. Eyes feebly convergent below, the interocular distance on the vertex being slightly more than one-fourth greater than across the middle of the clypeus. Antennal sockets as far from the eyes as from the base of the clypeus. Posterior ocelli half as far again from each other as from the eyes. Second joint of the flagellum half as long again as the third, the apical joint slightly longer than the tenth. Apical 
tergite elongate triangular, more strongly punctured than the other tergites, the apex narrowly rounded. Tarsal comb composed of long, stiff spines. Second abscissa of the radius half as long as the first.

o. I4-I7 mm. long. Interocular distance on the vertex about one-third greater than across the middle of the clypeus. Second joint of the flagellum two-thirds longer than the third, the apical joint slightly curved, shallowly excised below, rounded at the apex and a little longer than the eleventh joint. Apical tergite broadly triangular, widely rounded at the apex. Otherwise like the ?.

Willowmore, C. P. (Dr H. Brauns). (R.M. and T.M. colls.)

S. chrysorrhoeus Handl. (figs. 51, 5I $a-d$ ). Loc. cit. p. 122, ơ, ㅇ. 1892.

"Closely allied to and similar to sexfasciatus Fab. (an Indian species). Median area of the sixth tergite like that of $S$. terminalis Evers. and distinctly narrower than in fasciatus Fab. Antennae in the $\sigma^{*}$ a little stouter than in those species, the last joint distinctly curved and very distinctly obliquely truncate at the apex. Wings distinctly yellowish, but less so than in fasciatus, the radial cell distinctly fuscous. Body black, anterior and posterior orbits, the face below the antennae, clypeus, labrum, mandibles except at the apex, posterior margin of the pronotum and the pronotal tubercles, sides of the mesonotum, scutellum either entirely or only on the posterior margin, the metanotum often wide, and interrupted bands on the tergites, Fig. 51. Stizus chrysorrhoeus, ?, pale yellow; sixth segment and in the $\delta$, also the seventh, ochreous, the markings on the thorax nearly always more or less rufescent. Sternites without yellow markings. Legs ferruginous, coxae and trochanters ferruginous and black. Antennae ferruginous, the flagellum in the of more or less infuscated above near the middle. Sixth

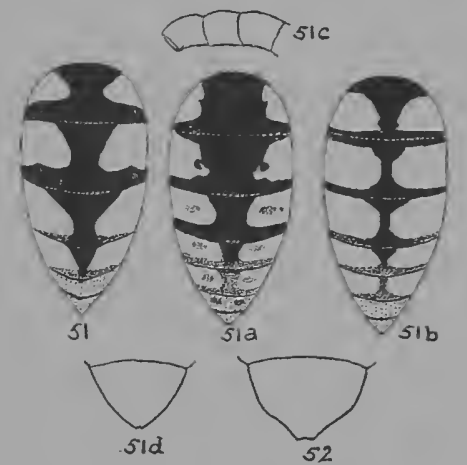
abdomen; $a$, $\hat{a}$, abdomen, semimelanic form; $b, \hat{o}$, abdomen, normal form (closely dotted parts $=$ ferruginous; sparsely dotted parts $=$ ochreous); $c, 0$, apical joints of flagellum; $d, \hat{\sigma}$, seventh tergite.

Fig. 52. Stizus aurifluus, $\widehat{\delta}$, seventh tergite. tergite in the $q$ densely clothed with golden pubescence. $18-25 \mathrm{~mm}$. long."

" $S$. chrysorrhoeus agrees in the shape of the sixth tergite in the of with terminalis, in the colour of the wings with rufiventris, and in the colour pattern of the abdomen and the unspotted sternites with fasciatus. The puncturation of the thorax and tergites is somewhat finer and more regular than in fasciatus. The apical joint of the antennae in the $\sigma^{t}$ is not so distinctly attenuated as in the preceding species...."

Of the six examples, $5 \hat{0} \sigma^{\hat{0}}$ and I $\circ$, seen by Handlirsch, only one, a male, was of African origin. It is possible that the single $q$ was not correctly assigned to this species. On the strength of the figure of the antennae in the $\delta$ in Plate II of Handlirsch's work, I identify with this species a male and female taken together at Springvale, S. R. and several st ô in the South African Museum's collection. The structure of the apical joint of the antennae in the of renders this identification quite certain, and supplementary notes, based on the pair from Springvale, are appended herewith. 
f. I $8 \mathrm{~mm}$. long. A spot somewhat rufescent below on the mesopleurae, the epinotum excepting the anterior two-thirds of the sides, base and lateral margins of the median area, pale yellow. The parts of the head which are not indicated as yellow in Handlirsch's description are ferruginous, not black. First sternite and base of the second ferruginous, the rest dark yellow, the second and third blackish in the middle. Inner margins of the eyes almost parallel, the interocular distance on the vertex being only a trifle more than across the base of the clypeus. Second joint of the flagellum four-fifths longer than the third joint; apical joint slightly longer than the preceding joint. Sixth tergite triangular, as long as wide at the base, narrowly rounded at the apex, densely punctured, the punctures larger than any on the rest of the body excepting those of the labrum, covered with long yellowish hairs and yellowish pubescence. Comb of the anterior tarsi composed of long and straight spines.

3 . I $8 \mathrm{~mm}$. long. Lateral margins of the mesonotum and the whole of the scutellum ferruginous, the rest of the thorax, excepting the pronotum, black. Pronotum ferruginous, its posterior margin yellow. Second joint of the flagellum three-fourths longer than the third joint. Interocular distance on the vertex one-fourth greater than across the base of the clypeus. The puncturation of the tergites becomes progressively stronger from segment to segment, the first and second have moderately fine and oblique punctures, whereas the serenth is closely and strongly punctured. Sternites $\mathrm{I}-4$ fusco-ferruginous, the rest reddish ochreous, all strongly and closely punctured. Seventh tergite triangular, the apex rounded.

The colour is somewhat variable, the thorax in this sex being sometimes marked with yellow on the scutellum, mesopleurae and epinotum as in the $?$. There is also a slight variation in the apical joint of the flagellum. In the example from Springvale on which the above description is based, it is no longer than the penultimate joint, as shown in Handlirsch's figure, but in some specimens it is a little longer. The colour pattern of the abdomen is also variable. As a rule the black markings are less extensive than in the $q$, but in a specimen from Hex River, in the South African Museum, the whole of the first tergite is black, and the yellow maculae on the three following segments are much reduced. The commoner and the intermediate patterns are illustrated in figs, $5 \mathrm{I}, 5 \mathrm{I} a$. Specimens from Zesfontein, S.W. Africa, in the South African IIuseum, differ from the pair from Springvale by the greater size, $720 \mathrm{~mm}$., of $17-20 \mathrm{~mm}$., by the paler yellow of the abdomen, slightly longer second joint of the flagellum in the $q$, which is five-sixths longer than the third joint, and the colour of the wings which show no yellowish tint. The genitalia of the $\widehat{o} \sigma^{t}$, however, show no appreciable difference.

A male and female from Marsabit, British East Africa, in the British Museum collection, have the colour of the clypeus, face and tergites eren paler than in the examples from Zesfontein, being almost ivory white, and the first tergite is ferruginous on the brow of its declivous face.

Springrale and Bulawayo, S. R. Hex River, C. P.; Zesfontein, S. W. A. Marsabit, B. E. A. (R.MI. coll.)

S. Saussurei Handl. Sitæungsber. K. Akad. Wiss. Wien, cIV, p. 990. I 895.

" $\hat{0}^{-}$. I $7-\mathrm{I} S \mathrm{~mm}$. long. Allied to and like $S$. chrysorrhoeus. Last joint of the antennae distinctly longer than the preceding joint, curved and rounded at the apex. Wings yellowish basally, the middle and the radial area distinctly fuscous, the venation like that of chrysorrhoeus. Puncturation and pilosity almost like that of chrysorrhoeus; black, the orbits in front and behind widely, the face below the antennae, clypeus, labrum, the greater part of the prothorax 
together with the pronotal tubercles, sides of the mesonotum, a large spot on the mesopleurae, bands on the scutellum, metanotum, epinotum, large spots on the sides of the epinotum, broad bands widely interrupted in the middle on the first five tergites, a band slightly interrupted on the sixth and large lateral spots on the sternites, bright yellow. The margins of the fifth and sixth sternites, the last tergite and sternite, the yellow maculae excepted, ferruginous. Antennae ferruginous, the scape yellow below, the flagellum fuscous above. Legs ferruginous, streaked with yellow. The frontal area below the antennae is almost quadrate, the first transverse cubital vein curved, so that the species belongs without doubt to the fasciatus group. By the longer and not truncate apical joint of the antennae and by the colour this species is easily distinguished from chrysorrhoeus. Cape Province."

\section{S. melanurus Handl. (fig. 55). Sitzungsber. K. Akad. Wiss. Wien, cI, p. I38, o. I $S 92$.}

․ $22 \mathrm{~mm}$. long. Mandibles at the base, labrum, clypeus, scapes below, face below the antennae and half-way up the sides, also sometimes a median line extending to and enclosing the anterior ocellus, and the temples, yellow; the rest of the head including the antennae, ferruginous. Pronotum ferruginous, the upper half of the collar and the tubercles, yellow. Mesonotum black, the lateral margins widely yellow. Mesosternum and lower half of the mesopleurae black, the upper half of the latter ferruginous, with a diffuse yellow spot above. Tegulae and scutellum ferruginous, the latter with a transverse band of yellow, narrowed in the middle, in front of the posterior margin. Metanotum yellow. Metapleurae in the middle and the sides of the epinotum ferruginous. Dorsum and declivity of the epinotum yellow, the base of the median area and a narrow border outside it black or fusco-ferruginous. Tergites $\mathrm{I}-5$ black with a steely blue lustre, inclining to fusco-ferruginous torvards the apical margin, the sixth tergite ferruginous. The first tergite is ferruginous at the base and has a transverse band of yellow in the middle; the second has a large yellow spot on each side nearer to the base than to the apex, and the third has a smaller yellow spot on each side. Sternites and legs ferruginous. Head and thorax dull, very finely and closely punctured, the mesonotum and scutellum with a shallow and larger puncturation interspersed. The puncturation of the dorsum of the epinotum is stronger than on the rest of the thorax. Abdomen shining, sparsely and fairly strongly punctured, the sixth tergite dull, closely and finely punctured; the puncturation of the sternites is almost coarse, much stronger than that of the tergites, and composed of round punctures. Clypeus and face with silvery, the mesonotum with brownish yellow pubescence. Epinotum and base of the first tergite with a short white pilosity, the last three abdominal segments with a fulvous pilosity which is fairly dense on the sixth where it is mixed with a pubescence of the same colour. Clypeus distinctly convex lengthwise, three times wider than long. Eyes almost parallel. Antennal sockets as far from each other and from the eyes as from the base of the clypeus. Second joint of the flagellum threefourths longer than the third, the apical joint slightly curved, distinctly longer than the penultimate joint. Posterior ocelli nearly twice as far from each other as from the eyes. Sixth tergite with a distinctly marginate pygidial area extending over the apical third of its length, rounded at the apex. Anterior tarsi without a regular comb, the basal joint has numerous short stiff spines, which are much shorter than the curved ones on the succeeding joints. Middle and posterior tibiae strongly spinose. 
J. $18 \mathrm{~mm}$. long. Apical joint of the flagellum very slightly curved, round at the apex, distinctly longer than the penultimate joint. The epinotum is usually without yellow markings. Otherwise like the o.

Senegal; Caia, Zambesi; Tsintsabis, S.W. Africa.

S. aurifluus Turner (fig. 52). Ann. Mag. N.H. xvII, p. 442, ․ I916.

" + . Black; clypeus, labrum, base of the mandibles, face below the antennae, posterior margin of the pronotum, a large transverse macula on each side of the first tergite and broad interrupted bands on the second to fifth tergites, yellow; head, antennae, pronotum, sides of the mesonotum, scutellum, epinotum, pygidium and legs, ferruginous; apex of the pygidium with a dense, golden pubescence; wings hyaline, the veins fuscous; the costal margin widely fuscous. $25 \mathrm{~mm}$. long. Clypeus broadly emarginate, the emargination slightly angular in the middle; inner margin of the eyes almost parallel; apical joint of the antennae conical, as long as the penultimate. Thorax finely and very closely punctured, scutellum without a median depression; pubescence long and greyish, more dense on the median segment than elsewhere. Abdomen closely and very distinctly punctured; sixth dorsal segment more closely punctured, clothed with ferruginous pubescence at the base, with shining golden pubescence at the apex. Basal joint of the fore tarsi with eight stout but not very long spines. Second abscissa of the radius shorter than the first; the costa thickened and forming a very distinct rounded stigma at the base of the radial cell. Hab. Yapi, Gold Coast (Simpson).

"This is very near chrysorrhoeus Handl. but differs from South African specimens sent by Dr Brauns under that name in the much broader pygidial area, the much stronger puncturation of the abdomen, the colour of the nervures, and the costal infuscation, which in chrysorrhoeus is confined to the radial and second and third cubital cells, the more clearly defined stigma, and the more deeply emarginate clypeus. The spines of the basal joint of the fore tarsus are shorter and more numerous than in chrysorrhoeus."

o. $21 \mathrm{~mm}$. long. Sides of the face above the antennal sockets ochreous yellow as far as the level of the anterior ocellus. Only the lateral margins of the median area of the epinotal dorsum are ferruginous, the rest of that segment is black. Otherwise like the $q$ in colour. The interocular distance on the vertex is very nearly one-third greater than across the base of the clypeus; the second joint of the flagellum is slightly more than half as long again as the third. The seventh tergite has the apical half of the sides feebly sinuate, and the yellow maculae are a little smaller than in chrysorrhoeus, the apical joints of the flagellum are the same as in that species, and, apart from the slight differences indicated, this insect is like chrysorrhoeus ${ }^{2}$, of which it probably represents a race. I have not seen the $q$, but the description of the $\sigma^{\circ}$ is based on a specimen from the same locality as the type and determined by Turner.

\section{S. rubroflavus Turner (fig. 53). Loc. cit. p. 44r, f. rgr6.}

․ $2 \mathrm{I} \mathrm{mm}$. long. Ferruginous. Labrum, anterior half of the clypeus, face below the antennae and half-way up the sides, scapes below, temples, pronotal tubercles and posterior margin of the pronotum, ill-defined spots on the mesopleurae, sides of the epinotum posteriorly, a small spot on each side of the first tergite, and large spots on the following tergites, yellow. The second to sixth tergites are ferruginous only at the extreme base, apical margin and in the middle. Sternites $2-5$ with large, diffuse and pale yellow spots on each side. Anterior tarsi, and the anterior and middle tibiae on the outside, yellow. Wings hyaline, the veins and the radial cell ochreous. Face and clypeus with 
silvery pubescence, elsewhere the pubescence is very scanty and whitish; the epinotum is without a long pilosity. Clypeus and labrum coarsely, shallowly punctured, face sparsely and finely punctured. The mesonotum anteriorly, mesopleurae and epinotum very finely and closely punctured. Elsewhere the sculpture is microscopic, except on the sixth tergite where it is close and stronger than that of the thorax. Mesonotum and scutellum moderately, the abdomen distinctly shining.

Clypeus prominent, the anterior margin strongly concave, the anterior half Fig. 53. Stizus rubroflavus,, , head. deflexed, the posterior half subcarinate Fig. 54. Stizus multicolor, , head; $a$, in the middle. Inner margins of the

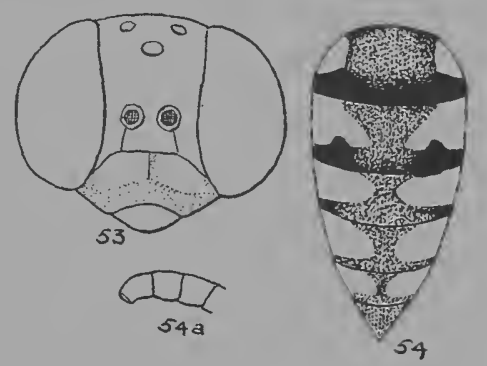

$\hat{0}$, apical joints of flagellum. eyes slightly divergent above and below, nearest together at the level of the antennal sockets, the interocular distance on the vertex very little greater than across the base of the clypeus. Posterior ocelli placed well in front of the line joining the upper margins of the eyes, almost twice as far from each other as from the eyes. Second joint of the flagellum very nearly twice as long as the third, the apical joint a trifle longer than the preceding joint. Sixth tergite elongate triangular, the apex narrowly rounded. Legs rather strongly spinose, the tarsal comb of the fore legs composed of long yellowish spines.

Gambia. Type in the British Museum.

Turner says of the type that the second abscissa of the radius is much shorter than the first, but in the specimen before me (det. Turner), also from Gambia, it is a little longer. This fact furnishes another instance of the unreliability of the venation as a specific distinction.

S. multicolor Turner (figs. 54, 54a). Loc. cit. p. 440, ô, o. I 1916.

․ 2I mm. long. Ferruginous. Closely allied to rubroflavus from which it differs as follows. Mesosternum and mesonotum excepting the sides, black. Posterior lateral angles of the mesonotum, metanotum and posterior half of the median area of the epinotum, yellow. Basal half of the epinotal dorsum black. Sternites without yellow maculae. Apical tergite ferruginous, with a small yellow spot on each side near the base. Wings hyaline, tinged with yellow, the radial and second and third cubital cells fusco-flavous. Anterior tarsi and middle tibiae entirely ferruginous. Mesonotum, scutellum and metanotum dull, very closely and very finely punctured. Sixth tergite less elongate than in rubroflavus, more closely punctured, the apex more broadly rounded. Clypeus less distinctly deflexed in the anterior half, and hardly subcarinate basally. Face slightly wider than in rubroflavus. Apical joint of the flagellum curved and blunter than in rubroflavus. Otherwise like that species.

f. $18 \mathrm{~mm}$. long. Mandibles ferruginous. The median area of the epinotum is black with narrow lateral yellow margins. Clypeus very convex but not deflexed anteriorly. Interocular distance on the vertex nearly one-fourth greater than across the base of the clypeus. Antennae inserted higher up than in the $q$, being twice as far from the base of the clypeus as from the eyes. Second joint of the flagellum about two-thirds longer than the third joint, the apical joint very similar to that of chrysorrhoeus of, not longer than the penultimate, curved, and truncate at the apex. Puncturation stronger than in 
the 9 , especially on the dorsum of the epinotum and on the abdomen. Seventh tergite broadly triangular, the apex narrowly rounded.

Uganda.

A + specimen from Sawmills, S. R., which I associate with this species, differs from it only in its smaller size, $16 \mathrm{~mm}$. long, and in the more distinctly deflexed anterior half of the clypeus.

\section{S. mbellus Turner. Ann. Mag. N.H. Ix, p. 342, ‥ 1912.}

ㅇ. $19 \mathrm{~mm}$. long. Ferruginous. Labrum, clypeus, face below the antennae and half-way up the sides, scapes below, temples, posterior margin of the pronotum and the pronotal tubercles, a spot on the upper part of the mesopleurae, tegulae, posterior half of the scutellum, metanotum, posterior half of the median area of the epinotum, transverse bands, not sharply defined but confluent with the ferruginous ground, on the fourth and fifth tergites, and sometimes on the second and third, yellow. Tergites $I-3$ blackish at the apical margins. Legs ferruginous, the tibiae outwardly yellow. Flagellum reddish ochreous. Wings pale flavo-hyaline, the veins flavo-ferruginous, the radial and upper half of the second and third cubital cells, pale fuscous. Head and thorax dull, abdomen shining. Labrum sparsely and coarsely punctured, clypeus finely punctured, with a few larger punctures in the anterior half. Face and vertex finely and not closely punctured. Thorax very finely, closely and shallowly punctured, but a little less finely on the epinotum and mesopleurae. Tergites I-5 with a fine, close and shallow puncturation, the sixth tergite fairly strongly and closely punctured, and rounded at the apex. Inner margins of the eyes nearly parallel, the interocular distance on the vertex being only one-sixth greater than across the base of the clypeus. Second joint of the flagellum three-fourths longer than the third joint, the apical joint a little longer than the penultimate. Antennal sockets as far from the eyes as from the base of the clypeus. Posterior ocelli twice as far from each other as from the eyes. Tarsal comb composed of long, curved ferruginous spines.

Domira Bay, Nyasaland; Fort Jameson, N.W. Rhodesia.

\section{S. Marshalli Turner. Loc. cit. p. 344, ㅇ․ 1912.}

"ㅇ. $23 \mathrm{~mm}$. long. Black; head, pronotum, sides of the mesothorax, tegulae, scutellum, metanotum, first tergite except at the apex, the apex of the fifth, the whole of the sixth and almost the whole of the sternites, and the legs, ferruginous; clypeus, labrum, scapes below, two small spots below the ocelli, the posterior margin of the pronotum narrowly, a small spot on each side of the first tergite and large spots on each side of the second to fifth tergites, yellow; wings flavo-hyaline, the radial cell infuscated, the veins ferruginous. Clypeus widely emarginate at the apex, nearly three times as broad as long, almost smooth; the labrum short and strongly punctured. Eyes not convergent towards the clypeus; posterior ocelli nearly twice as far from each other as from the eyes. Antennae gradually thickened towards the apex, second joint of the flagellum twice as long as the third. Scutellum without a distinct fovea. Very minutely punctured; median segment finely rugulose; sixth dorsal segment more coarsely punctured, especially towards the apex, which is narrowly rounded. Second abscissa of the radius longer than the first, but only half as long as the third; submedian cell of the hind wing terminating far beyond the origin of the cubitus. The fuscous mark on the radial area of the fore wing spreads over the greater part of the second 
and third cubital cells. Pubescence on the thorax short and greyish. The black portion of the abdomen shows a faint iridescent flush."

Salisbury, S. R.

S. Neavei Turner. Loc cit. p. 343, ơ, ㅇ. 1912.

d. I6-18 $\mathrm{mm}$. long. Black. Labrum, clypeus, base of the mandibles, scapes, face below the antennae and at the sides almost as far as the level of the anterior ocellus, posterior orbits, pronotum, tegulae, a spot below them on the mesopleurae, lateral margins of the mesonotum, a band narrowed in the middle on the posterior margin of the scutellum, posterior margin of the metanotum, lateral margins of the median area of the epinotum and of its sides and declivity, transverse bands interrupted on the first tergite, slightly so and covering more than half of the segments on the second to fourth tergites, the fifth and sixth tergites, a large spot on each side of the second sternite and wide bands slightly narrowed medially on the third to sixth sternites, yellow. Posterior third of the sides of the epinotum, first and second sternites, the base of the third and fourth and the whole of the apical segment, pale ferruginous. Legs pale ferruginous, the tibiae outwardly, basal joints of the tarsi and apices of the femora, pale yellow. Flagellum ferruginous. Wings hyaline, the veins ferruginous, the radial cell and greater part of the second and third cubital cells, pale brown. Clypeus and lower half of the face with silvery pubescence. A fairly abundant, short and whitish pilosity on the vertex, thorax and first tergite. Head and thorax dull, face shallowly and sparsely punctured, the punctures mostly oblique, the sides of the epinotum slightly shining and with a very sparse puncturation. Abdomen shining, the sculpture a semi-puncturation, stronger and less close on the sternites than on the tergites, on the latter finer on the basal than on the apical segments. Anterior margin of the labrum obtusely angular. Eyes distinctly convergent below, the interocular distance on the vertex a little more than one-third greater than across the base of the clypeus. Antennal sockets nearer to the eyes than to the base of the clypeus. Second joint of the flagellum one-third longer than the third joint, the apical joint curved, roundly truncate at the apex, not longer than the penultimate. Seventh tergite subtriangular, widely rounded at the apex.

․ I7-19 mm. long. Upper part of the face, vertex and occiput, metapleurae and sides of the epinotum, ferruginous. 'The mesonotum sometimes has two short longitudinal streaks of yellow on the anterior half, and the base of the first and second tergites are sometimes ferruginous. Anterior margin of the labrum convex. Clypeus strongly convex, the anterior half slightly deflexed, but not so distinctly as in rubroflavus. Eyes slightly less convergent below than in the $\sigma^{*}$. Posterior ocelli half as far again from each other as from the eyes. Antennal sockets as far from the clypeus as from the eyes; second joint of the flagellum nearly twice as long as the third, the last joint broadly rounded at the apex, a little longer than the penultimate joint. Sixth tergite coarsely and fairly closely punctured, the apex broadly rounded, in some specimens almost transversely truncate. Tarsal comb composed of long, straight and yellowish white spines.

Northern Rhodesia and Nyasaland; Sanyati Valley, S. R. (R. H. R. Stevenson).

The specimens from the Sanyati Valley are deceptively like some $S$. chrysorrhoeus from the same locality, the colouring being exactly the same; they are, however, to be distinguished by the long stiff spines of the tarsal comb and the more broadly rounded apical abdominal segment. 
S. Marnonis Handl. Sitzungsber. K. Akad. Wiss. Wien, cI, p. I45, ㅇ. I892.

"ㅇ‥ Allied to, and much like the preceding species (succineus Klug) but the whole body is ferruginous, neither black nor variegated with yellow, the legs and antennae ferruginous, the flagellum slightly infuscated above. $21 \mathrm{~mm}$. long. Central Africa."

Handlirsch's description of succineus, with which this species is compared, is as follows.

"Frontal area below the antennae almost quadrate in the $\hat{\sigma}$, transverse and wide in the $q$. Labrum rounded and distinctly longer than in fasciatus. Wings almost hyaline, without a fuscous cloud on the radial cell, the first transverse cubital vein slightly curved. Last antennal joint in the not longer than usual, hardly curved, rounded at the apex. Metatarsus of the fore legs in the $q$ with long cilia; sixth tergite rounded at the apex and marginate, not pubescent, coarsely and irregularly punctured. Thorax and tergites very closely and exceedingly finely punctured, with a few large punctures intermixed. Body and face with silvery pubescence. Head ferruginous, the face more or less yellow; thorax ferruginous, the mesonotum, epinotum and sternum more or less blackish. Abdomen yellow above, two oblique spots on the base of the first tergite and the apical margins of that and the following tergites more or less dark ferruginous. Apical segment ferruginous. Sternites ferruginous, and spotted with yellow. Legs ferruginous. Antennae ferruginous, the flagellum fuscous above. $2 \mathrm{I}-27 \mathrm{~mm}$. long."

S. basalis Guérin. Iconog. du Règne anim. p. 438 , ơ, + . 1844 . Handlirsch,
loc. cit. p. I 48 .
"Similar to, and closely allied to $S$. vespiformis Fab. (an East Indian species). Wings fuscous violaceous, the first transverse cubital vein distinctly curved. Body black, the head ferruginous, in the of black behind and with two black spots on the face; pronotum, sides of the mesonotum and very often also the scutellum, metanotum, greater part of the epinotum and sternum and first abdominal segment (partially in the $o^{*}$, wholly in the $q$, together with the base of the second segment), ferruginous. Legs dark, antennae pale ferruginous. I $8-2,5 \mathrm{~mm}$. long."

Egypt and Senegal.

S. atrox Smith. Cat. Hymen. B.M. IV, p. 339, ㅇ. I 856 .

S. flavomaculatus Smith, Ann. Mag. N.H. IV, p. 404, o. 1873.

S. pentheres Handl., Sitzungsber. K. Akad. Wiss. Wien, cIV, p. 995, o. 1895.

ㅇ. $23 \mathrm{~mm}$. long. Black. Labrum, clypeus, face below the antennal sockets and widely at the sides as far as the level of the anterior ocellus, a small spot on each side of the latter, posterior orbits and the antennae, yellow. The posterior margin and anterior face of the pronotal collar sometimes yellow or reddish yellow. The lateral margins of the mesonotum, very rarely also the scutellum and two longitudinal streaks on the disc of the mesonotum, tibiae, tarsi and apices of the femora, ferruginous. The anterior tibiae below, and sometimes the posterior tibiae and tarsi are black. Wings dark brown, with a violaceous lustre.

Face and clypeus with a short greyish pubescence, the thorax with a scanty, very short and brownish pubescence, the epinotum also with some longer, greyish hairs. The sixth tergite with decumbent fulvous setae, the scutellum sometimes with a short, fulvous pubescence. Head and thorax dull. Head, mesonotum, scutellum and metanotum very closely, shallowly and finely punctured. The mesopleurae have a semi-puncturation, larger 
and not so close as on the mesonotum. Dorsum and declivity of the epinotum with round punctures, much stronger than on the mesonotum, the sides of the epinotum very shallowly punctulate and rugulose. Tergites I -5 fairly shining, with a shallow and not close semi-puncturation, the sixth tergite closely and more strongly punctured. Sternites dull, microscopically punctured. Clypeus two and a half times wider than long. Second joint of the flagellum two-thirds longer than the third joint, the apical joint not longer than the penultimate. The spines on the basal joint of the anterior tarsi are short, barely longer than the apical width of the joint.

o. I $5^{-20} \mathrm{~mm}$. long. Middle of the face below the antennal sockets and basal two-thirds of the clypeus, black. Third tergite with a curved, pyriform, yellow macula on each side, the second tergite sometimes with a small yellow spot on each side. Puncturation stronger than in the 9 . Second joint of the flagellum nearly half as long again as the third, the apical joint not attenuated, barely longer than the penultimate, rounded at the apex. Posterior ocelli twice as far from each other as from the eyes. Seventh tergite broadly triangular, the lateral margins slightly sinuate over the apical half. Otherwise like the \%.

Angola; Hoarusib Otshu, S.W. Africa; Uitenhage and Willowmore, C. P.

In the the yellow markings on the abdomen are sometimes entirely absent and the clypeus is ferruginous except the middle of the basal margin (three examples from Hoarusib Otshu in the South African Museum).

S. tuberculiventris Turner. Ann. Mag. N.H. Ix, p. 345, ô, ㅇ. I912.

" $\mathrm{t}$. $13 \mathrm{~mm}$. long. Black; clypeus, a broad band on the first tergite, and bisinuate bands on the second to sixth tergites, yellow; labrum, antennae excepting the last five joints, pronotum posteriorly, tegulae, sides of the mesonotum narrowly, legs, first tergite in the middle, the rest on the apical margin, the whole of the seventh, and the sternites more or less, ferruginous; wings dirty hyaline, the apical margin infuscated; anal lobe of the hind wing terminating far beyond the origin of the cubital vein; third sternite armed with a large tooth. Eyes slightly converging towards the clypeus; labrumalmost as long as the clypeus, rounded at the apex; clypeus less than twice as broad as long. Antennae separated from the base of the clypeus by a distance almost equal to the length of the scape, second joint of the flagellum nearly twice as long as the third. Posterior ocelli nearly twice as far from each other as from the eyes. Thorax very closely punctured rugose; abdomen more finely punctured; the convergent sulci on the median segment very distinctly marked. Third ventral segment with a strong slightly curved tubercle near the middle; sixth ventral segment with a minute tubercle near the middle, seventh with a low longitudinal carina in the middle. Second abscissa of the radius a little shorter than the first, third cubital cell almost as long on the radius as on the cubitus. Median cell of the hind wing emitting two nervures from the apex, cubitus originating far before the termination of the submedial cell. Anterior and intermediate tarsi longer than the tibiae.

"ㅇ. I $5 \mathrm{~mm}$. long. As in the male, but the ventral surface of the abdomen is unarmed; the sixth dorsal segment narrowly truncate at the apex. The apical joint of the antennae. is truncate at the apex, not curved; the anterior tarsi with very long spines. The yellow marks on the abdomen are more extensive than in the male, and there is no ferruginous colour on the two basal segments; the apical segment is yellow in the middle. There is no fovea on the scutellum. The general build of both sexes is slender, as in pentheres Handl, , or even more slender. 
"Hab. Salisbury, Mashonaland (G. A. K. Marshall), ox, ㅇ, April I900; Simba, British East Africa, $335^{\circ}$ feet, April I9I I (S. A. Neave), I ơ; Harar, Abyssinia ( $\mathrm{G}$. Kristensen), I \%.

"This is a very distinct species, approaching most nearly to the fasciatus group, but distinguished by the armature of the ventral segments of the abdomen of the male, also by the coarse sculpture of the thorax and median segment in both sexes. The first transverse cubital nervure is almost straight, only very feebly bent near the cubitus. The antennae are considerably thickened towards the apex. In the specimen from Abyssinia the wings are fuscous."

\section{RUFICORNIS Group.}

Closely allied to the fasciatus group, from which it differs only in a few minor characters. The o has a shallow pubescent fovea on the scutellum; the apical joint of the flagellum in the $\sigma$ is more attenuated and more curved than in the fasciatus group and the first transverse cubital vein is nearly always straight. The vertex, occiput, thorax and base of the first tergite in the $q$ are rather densely pilose, at least much more so than in the fasciatus group. The puncturation on the mesothorax is fine and shallow and on the epinotum it is stronger and close, almost reticulate-punctate, the punctures round. The puncturation of the tergites, except the apical one, is oblique. The sternites are shining, very sparsely and finely punctured, with a few larger punctures interspersed. In the female, the second joint of the flagellum is usually twice as long as the third and the apical joint is very little longer than the penultimate joint. Eyes parallel or nearly so. Posterior ocelli about twice as far from each other as they are from the eyes. Basal joint of the fore tarsi about three to four times longer than wide at the apex, longer than the three following joints united. The tarsal comb is composed of long thick spines.

S. Dewitzii Handl. (figs. 56, $5^{6 a-c)}$. Sitzungsber. K. Akad. Wiss. Wien, CI, p. 156, ㅇ, o. 1892 .

S. erythraspis Cameron. Ann. Trans. Mus. p. I44, ㅇ. I9ro.

\%. $23 \mathrm{~mm}$. long. Very much like chrysorrhoeus in colour, the pattern on the abdomen being exactly the same. On the head, however, the temples and occiput are entirely ferruginous, and the thorax, excepting the pronotum, is somewhat different. The meso- and metathorax and epinotum are black, excepting the lateral margins of the mesonotum, scutellum and the metanotum posteriorly, which are ferruginous. Occasionally the median area of the epinotal dorsum is margined with yellow as in chrysorrhoeus. Antennae ferruginous, the scapes yellow below. Wings coloured like those of chrysorrhoeus. Head, thorax and first tergite with fairly abundant pubescence and pilosity, yellowish grey on the mesonotum, white elsewhere. Pubescence and pilosity on the abdomen reddish yellow. Middle and hind femora with long whitish pilosity. Puncturation similar to that of chrysorrhoeus but the labrum is more coarsely punctured and shining, and the apical tergite is more finely and more closely punctured. Labrum and clypeus strongly convex transversely, the anterior margin of the clypeus very concave. Inner margins of the eyes nearly parallel, only very feebly convergent below; the eyes do not reach the base of the mandibles, being separated therefrom by short cheeks. Interocular distance on the vertex equal to the length of the first three joints of the flagellum. The antennal sockets are as far from the eyes as from the base of the clypeus, and the frontal area below the antennae is much wider than long: Second joint of the flagellum fully twice as long as the third. Posterior ocelli 
nearly twice as far from each other as they are from the eyes. Comb of the anterior tarsi composed of long reddish spines. The basal joint of the fore tarsi is long, nearly four times longer than wide and longer than the three following joints united. Sixth tergite widely rounded at the apex.

o. $16-18 \mathrm{~mm}$. long. Eyes a little more convergent below than in the 9 . Anterior margin of the clypeus less concave. Antennal sockets nearer to the eyes than to the base of the clypeus; the frontal area below them very little

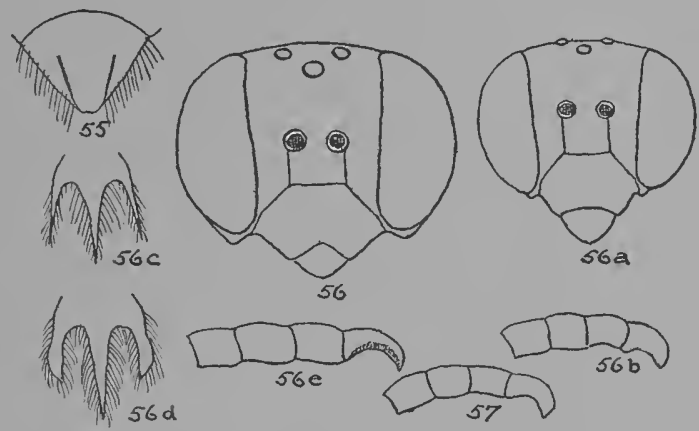

Fig. 55. Stizus melanurus, 9 , pygidium.

Fig. 56. Stizus Dewitzii, + , head; $a$, $\hat{0}$, head; $b$, ô, apical joints of flagellum; $c$, ô, eighth ventral plate; $d$, var. hamatus, $\hat{0}$, eighth ventral plate; $e$, var. hamatus, 0 , apical joints of flagellum.

Fig. 57. Stizus Ellenbergeri, $\hat{0}$, apical joints of flagellum.

wider than long. Apical joint of the flagellum slightly longer than the preceding joint, strongly curved, rounded at the apex. Seventh tergite very widely rounded at the apex, almost semicircular. Otherwise like the $q$.

Cape Province; Bulawayo, S. R. July to October. R.M. and T.M. colls.

The form with a yellow margin to the median area of the epinotum has been quite unnecessarily separated by Bischoff as a subspecies, propodealis (Mitt. Zool. Mus. Berlin, p. 473, 1915). It is only a colour variety which I have taken flying with the typical form.

\section{S. Dewitzii var. hamatus n.v. (figs. $56 d, 56 e$ ).}

f. $2 \mathrm{Imm}$. long. Apart from its greater size and ferruginous clypeus this variety differs from the type of the species only in two important characters. The apical joint of the flagellum is much more curved, deeply excavated below and narrower and more acute at the apex. The outer rami of the eighth ventral plate are thicker than the median one and are not sharply aculeate as in the type of the species. I can see no appreciable differences in the form of the genitalia.

Bulawayo. Taken flying at the same time and place as the typical form. Type in R.M. coll.

\section{S. Ellenbergeri n.sp. (fig. 57).}

o. $14 \mathrm{~mm}$. long. Black. Mandibles except at the apex, labrum, clypeus, face below the antennae and at the sides almost as far as the level of the anterior ocellus, posterior orbits, scapes below, pronotal collar above and the tubercles, yellow. Sides of the mesonotum, tegulae and posterior margin of the scutellum, reddish yellow. Colour pattern on the abdomen like that of Dewitzii but the yellow is distinctly brighter, lemon yellow instead of orange yellow. First 
and second sternites and the third excepting the sides, black; the second sternite has a small yellow spot on each side; the remaining sternites yellow, somewhat infuscated at the base. Femora ferruginous, the middle pair at the base and the hind pair above, fuscous. Tibiae and tarsi yellow, the former somewhat reddish underneath. Flagellum pale ferruginous below, darker above, the seventh to tenth joints blackish above. Wings hyaline, tinged with yellow, the veins ferruginous, the radial cell fuscous. Face and clypeus with white pubescence, the rest of the head, the thorax and first tergite with yellowish grey pilosity. Pubescence on the abdomen yellow and decumbent. Puncturation like that of Dewitzii but a little larger and less close, especially on the mesonotum and abdomen. Labrum very convex transversely, distinctly tumid in the middle at the base, narrower than in Dewitzii. Anterior margin of the clypeus almost straight. Antennal sockets farther from the clypeus than from the eyes, the frontal area below them as long as wide. Eyes feebly convergent below, the interocular distance on the vertex being only a little more than one-third greater than across the middle of the clypeus. Second joint of the flagellum nearly twice as long as the third, the apical joint is much more narrowed towards the apex, longer and more curved than in Dewitzii, and has the apex obliquely truncate, which is not the case in Dewitzii or its variety hamatus. Otherwise like Dewitzii s.

9. $15 \mathrm{~mm}$. long. Median area of the epinotum narrowly yellow at the sides. The second sternite is black with a large yellow spot on each side which reaches the apical margin; third sternite with a small black patch in the middle. Otherwise like the $\sigma^{*}$ in colour. Anterior margin of the clypeus fairly concave. Eyes nearly parallel. Frontal area below the antennae a little wider than long. Second joint of the flagellum twice as long as the third, the apical joint a little longer than the penultimate, moderately narrowed towards the apex and slightly curved. Scutellum with a fovea covered with fulvous pubescence. Sixth tergite like that of Dewitzii.

Leribe, Basutoland, $x \hat{o}, x+$. (R. Ellenberger). Types in the Museum National d'Histoire Naturelle, Paris.

\section{S. ferrugineus Smith. Cat. Hymen. B.M. Iv, p. $34^{2}$, o. $185^{6}$.}

․ $21-23 \mathrm{~mm}$. long. Ferruginous. Labrum, clypeus more or less, base of the mandibles, face below the antennae and round the anterior ocellus, posterior orbits, occiput above, posterior margin of the pronotum, pronotal tubercles, a spot on the posterior half of the tegulae, sometimes the metanotum and the posterior margin of the median area of the epinotum, yellow. Vertex between the posterior ocelli, mesonotum, mesopleurae excepting a ferruginous spot above, metapleurae and base of the epinotal dorsum, black. Abdomen ferruginous, a small spot on each side of the first, a larger spot narrowed inwardly on the second, and transverse bands narrowly interrupted in the middle on the third to fifth tergites, yellow. Sternites three and four yellow, the rest ferruginous. Legs and antennae ferruginous. Wings hyaline, the veins ferruginous, the costal margin of the radial cell faintly fuscous. Head and thorax with white pubescence and a long whitish pilosity, the pilosity on the last three abdominal segments greyish. Puncturation finer than in Dewitzii, on the first two tergites microscopic; the apical tergite is, however, more coarsely punctured than in that species. Sternites, clypeus and labrum as in Dewitzii. The eyes are very slightly convergent below. Interocular distance on the vertex equal to the length of the first two joints of the flagellum plus half of the third. The second joint of the flagellum is twice as long as the third. 
The median area of the epinotal dorsum is almost level with the lateral areas, not gibbous posteriorly as in Dervitzii. Otherwise like that species.

o. $18-20 \mathrm{~mm}$. long. Colour like that of the $q$. Apical joint of the flagellum not longer than the preceding joint, slightly more excavated below than in Deritzii, the apex somewhat acute. Otherwise like Dewitzii in structural characters.

Gambia; Egypt; Togoland.

S. Baumanni Handl. (fig. 58). Verh. Zool. Bot. Ges. Wien, LI, p. 508, ô. 1901.

ㅇ. I9 $\mathrm{mm}$. long. Black. Labrum, clypeus, base of the mandibles, face below the antennae and half-way up the sides, scapes below and posterior margin of the pronotum, yellow. Antennae, upper part of the face, vertex, temples and occiput, pronotal tubercles, lateral margins of the mesonotum, tegulae, a spot below them on the mesopleurae, scutellum and metanotum, sternites and the legs, ferruginous. Tergites 3-6 yellowish red. Wings pale flavohyaline, the veins ferruginous, the radial and upper half of the second and third cubital cells fuscous. Abdomen shining below, moderately so above on the first two segments, the rest of the body dull. Labrum closely and coarsely punctured, the clypeus sparsely and a little more finely. The puncturation of the mesonotum and scutellum is not very close, that of the first tergite micro-

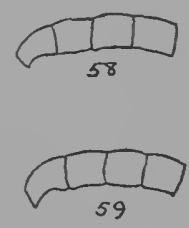

Fig. 58. Stizus Baumanni, $\hat{0}$, apical joints of flagellum.

Fig. 59. Stizus fuscipennis, ô, apical joints of flagellum. scopic. The sixth tergite is closely and finely punctured. Clypeus and face with silvery pubescence, the thorax and first tergite with long, whitish pilosity. The shape of the head, length of the antennal joints, etc. is the same as in the preceding species of this group.

o. I $5 \mathrm{~mm}$. long. First three abdominal segments and basal half or less of the fourth, black; the apical and lateral margins of the first three tergites and the middle of the second sternite more or less fusco-ferruginous, the rest of the abdominal segments reddish yellow, otherwise like the $q$ in colour. Tergites I-3 have a rather conspicuous yellowish-grey pubescence. The puncturation of the tergites is somewhat stronger than in the $q$, especially on the first. The sternites have a fairly strong but not close puncturation. Second joint of the flagellum three-fourths longer than the third, the apical joint hardly longer than the preceding, moderately curved and broadly truncate at the apex. Interocular distance on the vertex equal to the length of the first three joints of the flagellum. Seventh tergite broadly rounded at the apex.

Loangwa Valley, N. Rhodesia; Harar, Abyssinia.

\section{S.fuscipennis Smith (fig. 59). Cat. Hymen. B.M. Iv, p. 344, ơ, ㅇ. 1856.}

ㅇ. $16-20 \mathrm{~mm}$. long. Black, the abdomen with a very distinct violaceous lustre. Labrum, clypeus, base of the mandibles, scapes below, face below the antennae and half-way up the sides, a small spot on each side of the first tergite and larger spots on the second and third tergites, yellow. Upper part of the face, rertex, temples, antennae, posterior margin of the pronotum and the pronotal tubercles, sides of the mesonotum, a spot on the mesopleurae below the tegulae, scutellum, last two abdominal segments, first two sternites and the legs, ferruginous. Clypeus suffused with red over the basal half. Wings pale brown, paler on the apical and hind margins, the veins black. The sculpture is of the kind usual to the ruficornis group but distinctly stronger on the mesonotum and tergites than in the preceding species. Second joint of the 
flagellum a little less than twice as long as the third. Inner margins of the eyes almost parallel. Antennal sockets as far from the eyes as from the base of the clypeus.

o. I 5-18 mm. long. Fifth abdominal segment fusco-ferruginous, at least over its apical half, the sixth and seventh ferruginous. Otherwise coloured like the \%. Puncturation stronger and less close than in the , especially on the abdomen; the sternites almost coarsely punctured in comparison with the tergites. Second joint of the flagellum not quite twice as long as the third; the apical joint very much the same as in Baumanni but a little more excavated below. Eyes slightly more convergent below than in the ?. The antennal sockets are farther from the clypeus than from the eyes. Otherwise like the + .

Durban; Scottsburgh, Natal. (R. H. R. Stevenson.)

S. apicalis Guérin. Iconog. du Règne anim. III, p. 439, ․ I844. Smith, Cat. Hymen. B.M. IV, p. 339, Аิ. 1856 .

"Head, thorax, legs ventral surface and apex of the abdomen, ferruginous; face, clypeus and labrum yellow. A yellow band on the margin of the prothorax. The first five abdominal segments reddish, with black apical margins and a broad yellow band in the middle which is narrowed medially and interrupted by a very thin reddish streak. Wings hyaline, lightly tinged with yellow, and with a fuscous spot near the apex. $20 \mathrm{~mm}$. long, o. Senegal."

" $o$. Length 9 lines ( $9 \mathrm{~mm}$.). Ferruginous; the scape in front, the apical joint of the flagellum, the labrum, clypeus, the face above as high as the insertion of the antennae, the sides and two spots before the posterior stemmata, yellow; the mesothorax fuscous; the postscutellum and a curved line on the metathorax yellow; the wings and abdomen as in the other sex."

This species is also found in Abyssinia.

S. fuliginosus Klug. Symb. physicae. Plate 46, fig. II, o๋. I845. Handl. Sitzungsber. K. Akad. Wiss. Wien, c1, p. 142, ㅇ, o. 1892.

"Wings dark fusco-violaceous, the apical margin almost as far as the third cubital and second discoidal cells, hyaline. The first transverse cubital vein not curved, the second slightly so. Labrum fairly long. Frontal area below the antennae quadrate in the $\hat{s}$, the apical joint of the antennae fairly thick, slightly curved and indistinctly truncate at the apex. Scutellum in the + with a distinct median fovea, the sixth tergite rounded at the apex and marginate. Face with a dense silvery pubescence, head and thorax with a moderate greyish pilosity and pubescence. Mesonotum and scutellum moderately densely and moderately coarsely punctured. Body black, face, prothorax, lateral margins of the mesonotum, sometimes also the sides of the thorax and epinotum, first abdominal segment and also the base of the second, more or less dark fusco-ferruginous. Legs and antennae more or less fusco-ferruginous, sometimes almost black. 2I-27 mm. long."

Egypt and Gambia.

S. tenuicornis Smith. Cat. Hymen. B.M. IV, p. $35^{\text {I }}$, ‥ $185^{6}$.

" $\sigma$. Length 7 lines ( $5 \mathrm{~mm}$.). Black: the face below the insertion of the antennae, and a narrow line at the inner orbits of the eyes, not running upwards so high as the anterior stemma, the scape in front, clypeus, labrum and outer orbit of the eyes, yellow; a narrow black line runs from the antennae to the base of the clypeus, which has a black spot; the mandibles and antennae fulvous; the first joint of the flagellum very slender, its apex as well as that of the two following produced beneath. Thorax: the prothorax, the meso- 
thorax on each side, the tubercles, tegulae, scutellum and legs, ferruginous; the tibiae have a yellow stain above; the wings fusco-ferruginous, the nervures ferruginous. Abdomen: the basal segment has a yellow macula on each side, the three following a broad interrupted band; the fifth and sixth segments yellow, with a central longitudinal ferruginous line; the apical segment ferruginous; beneath, the two basal segments have a large ferruginous macula." Gambia.

S. lughensis Magr. Ann. Mus. Civ. Genova, xxxIx, p. 6o6. I898. Turner. Ann. Mag. N.H. xvir, p. 439, ㅇ. I9I6.

The following description is Turner's.

"q. Black; base of the mandibles, labrum, clypeus in the apical half, anterior and posterior orbits widely, face below the antennae, scapes below, posterior margin of the pronotum, metanotum, a transverse and small spot on each side of the first tergite and a wide band interrupted in the middle on the second, yellow; basal half of the clypeus, antennae, pronotum, sides of the mesonotum, tegulae, scutellum, sternites, first tergite, fifth and sixth and base of the second, and the legs, ferruginous; wings fusco-hyaline, the apical margin widely hyaline, the radial cell fuscous, the veins black. $24 \mathrm{~mm}$. long.

Apical joint of the flagellum conical, fully as long as the penultimate; clypeus with a few shallow punctures on the apical half, the basal half with closer and smaller piligerous punctures. Inner margins of the eyes almost parallel. Scutellum with a large puncture or depression near the middle, as in $S$. ruficornis; thorax finely and closely punctured. First dorsal segment much more finely punctured than the rest of the abdomen; sixth dorsal segment very finely and not very closely punctured, rather narrowly rounded at the apex. First transverse cubital nervure straight.

$H a b$. Bohotle, Somaliland."

S. Ritzemae Handl. Sitzungsber. K. Akad. Wiss. Wien, cIV, p. I000, ․ 1895.

"Allied to $S$. ruficornis. Wings yellowish, very distinctly infuscated over the radial area, the first transverse cubital vein almost straight. Face almost the same as in ruficornis. Scutellum with a distinct median pubescent fovea. Sixth tergite fairly widely rounded at the apex and distinctly marginate. Head and thorax with a greyish pilosity, the face with silvery pubescence. Dorsum of the thorax punctured like that of ruficornis. The whole body ferruginous, the face and large angular maculae on the sides of the first five tergites yellow, the antennae and legs ferruginous. $25 \mathrm{~mm}$. long. Remarkable for its splendid colour, and easily distinguished from all the other species of the ruficornis group. The maculae on the tergites are almost straightly truncate on the inside and lie quite at the sides of the segments, as in S. caffer. The wings are distinctly darker than in the allied species. I f. Leiden Museum, with the label "Nagtglas d'Elmina."

To judge by the description this form does not differ in any way from $S$. ferrugineus Smith except in having the mesonotum ferruginous instead of black.

S. Franzi Turner. Turner (emend. nec. Neavei Turner). Ann. Mag. N.H. XVII, p. 443. I9I6.

S. Neavei Kohl. Rev. Zool. Afric. III, p. 209, ㅇ. I9I3.

"o. $17 \mathrm{~mm}$. long. Black. Legs, and here and there the head and thorax, red. Clypeus, labrum, base of the mandibles and lower part of the face, yellow. Wings yellowish brown, the radial cell not infuscated. The apex of the 
abdomen obscurely rufescent. Eyes subparallel, slightly convergent towards the clypeus, separated there by about the length of the first two joints of the flagellum. Scutellum with a distinct median fovea. Basal joint of the anterior tarsi with seven spines. Abdomen black, the apical segment rufescent. Posterior orbits, the greater part of the pronotum, the lateral margins of the mesonotum widely, and all the legs, red. The inner orbits and a median line from the antennal sockets to the anterior ocellus, yellow."

Kayambo-Dikulwe, Belgian Congo. I + . Type in the Congo Museum, Tervueren.

\section{TRIDENTATUS Group.}

Slender, the abdomen cylindrical-lanceolate. Eyes distinctly convergent below. Antennae slightly clavate, the eleventh joint of the flagellum in the $\sigma^{*}$ without an apical spine, the apical joint not strongly curved. Scutellum in the o without a fovea. Wings usually dark; the anal lobe of the hind wing ends far behind the origin of the cubitus, and the medial cell emits two longitudinal veins at its apex. Sternites simple. Temples usually poorly developed, the head being often truncate just behind the eyes. Thorax, excepting the pronotum and sometimes the mesonotum, very strongly punctured with round punctures.

S. niger Radosz. (figs. 6o, 60 $a, b$ ). Fourn. Lisboa, xxxI, p. 208, ㅇ. 1881. Turner, Ann. Mag. N.H. Ix, p. 346, o. I9I2.

․ 25-27 mm. long. Black. Wings dark brown, with a very strong violaceous and green lustre, the apical margin very narrowly hyaline. Clypeus and face with a thin greyish pubescence, the epinotum and base of the first tergite with black pubescence, the second sternite with a patch of velvety pile near the base. Elsewhere the body is almost glabrous. Mesopleurae and tergites moderately, the sternites distinctly shining; the rest of the body dull. Head very finely and closely punctured, with a few larger punctures here and there. Mesonotum, scutellum, metanotum and epinotum above and on the declivity closely and strongly punctured, the punctures round; mesopleurae

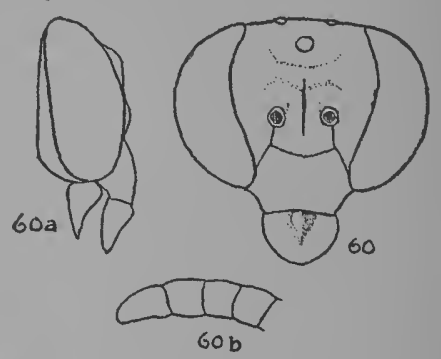

Fig. 60 and $60 a$. Stizus niger, $q$, head; $b$, $\hat{0}$, apical joints of flagellum. coarsely punctured, less closely below than above. Sides of the epinotum reticulate-rugose and finely punctured between the rugae. Tergites I-5 finely and closely punctured, except the middle and apical third of the first which are almost impunctate. Sixth tergite triangular, coarsely, obliquely and not closely punctured, the apex narrowly rounded. Sternites finely and closely punctured at the sides, and with a few larger punctures here and there. Eyes convergent above and below, the interocular distance on the vertex not quite one-fourth greater than across the middle of the clypeus, and equal to the length of the first four joints of the flagellum. Labrum semicircular, as long as the clypeus, strongly convex transversely, with a rounded boss at the base. Face swollen in the middle below the anterior ocellus and with a median longitudinal carina which does not reach the base of the clypeus or the anterior ocellus. Second joint of the flagellum more than twice as long as the third, nearly as long as the third, fourth and half of the fifth; the last joint moderately narrowed towards the apex and longer than the penultimate joint. Posterior 
ocelli separated from the eyes by a distance one-third less than the distance between each other. Anterior tarsi with a comb of stiff black spines, of which there are six on the basal joint. Middle and hind tibiae moderately spinose. First abscissa of the radius as long as the second.

5. $22 \mathrm{~mm}$. long. Flagellum gradually and moderately thickened towards the apex, the second joint nearly two and a half times longer than the third, the apical joint one-third longer than the penultimate, slightly narrowed apically and not so blunt as in the +. Puncturation of the abdomen distinctly coarser than in the $q$. Apical tergite broadly triangular, the apex rounded. Otherwise like the ?.

Angola; Entebbe, Uganda.

\section{S. fenestratus Smith. Cat. Hymen. B.M. Iv, p. $34^{2}$, ô. $188_{5}^{6}$.}

ㅇ. I9-2I mm. long. Black. The front wing from the base as far as the origin of the basal vein, and a narrow apical margin not reaching the radial and third cubital cells, and the basal half of the hind wing, hyaline; the rest of the wings fusco-violaceous. Face with a thin greyish pubescence. Dorsum of the epinotum with a dense, greyish silvery and oblique pilosity, hiding the sculpture. Basal two-thirds of the first tergite with a dense decumbent silvery pubescence, the rest of the tergites and sternites with a scanty cinereous pubescence. The second sternite has a dull patch at the base covered with a microscopic black pile. Head dull, microscopically and closely punctured, with a few larger punctures scattered here and there on the clypeus and face. Mesonotum, scutellum and metanotum dull, very closely, obliquely and rather strongly punctured; the mesopleurae more coarsely and less closely punctured than the mesonotum, the sides of the epinotum dull, reticulate-rugose. Tergites fairly dull, closely punctured, the first five finely so. Sternites shining, finely and closely punctured at the sides, sparsely and more coarsely in the middle. Labrum like that of $S$. niger. Face with a short median longitudinal carina as in that species. Second joint of the flagellum two and a half times longer than the third. Interocular distance on the vertex half as great again as across the middle of the clypeus.

o. I6-20 mm. long. The greyish pubescence on the abdomen longer and more abundant than in the 9 . Sculpture of the thorax and abdomen distinctly coarser than in the 9 . The flagellum is rather abruptly narrowed after the sixth joint and the last joint is one-third longer than the penultimate and rounded at the apex. Seventh tergite broadly rounded at the apex. Otherwise like the ?.

Gambia; Congo; Southern Rhodesia, Natal and Zululand.

This species cannot be confused with any other of the genus on account of the pilosity of the epinotum and the pubescence on the first tergite. (R.M. and T.M. colls.)

\section{S. Simpsoni Turner. Ann. Mag. N.H. xvII, p. 443, ㅇ. I9I6.}

"o. 2 I mm. long. Black; clypeus, labrum, antennae, face below the antennae, pronotum, tegulae, mesopleurae, sides of the mesonotum, scutellum, metanotum, epinotum and the legs, fusco-ferruginous; the front wing fuscoviolaceous, its base as far as the first discoidal cell hyaline, its apical margin hyaline, but not as far as the third cubital cell; the basal half of the hind wing hyaline; epinotum with black pilosity.

Eyes converging towards the clypeus, separated at the base of the clypeus by a distance almost equal to the combined length of the second and third joints of the flagellum. Thorax very closely punctured; median segment more 
deeply punctured than the thorax, without an impressed median line, clothed with short, erect, black hairs. First dorsal segment finely and rather closely punctured, the four following segments more closely punctured; sixth dorsal segment with very sparse and large setigerous punctures, narrowly truncate at the apex, the lateral margins near the apex distinctly carinate. Basal joint of the fore tarsus with seven spines."

Hab. Yapi, Gold Coast (Simpson).

S. amoenus Smith. Cat. Hymen. B.M. IV, p. 338, ․ 1856.

S. bicolor Tasch. Zeitschr.f.d.ges. Nat. p. 361, o. 1875 .

"ㅇ. Length 5-6 lines (I I-I3 mm.). Black; the mandibles, clypeus, scape, and five basal joints of the flagellum, ferruginous; the following joints fuscous; the extreme apex ferruginous. Thorax strongly and very closely punctured; the tegulae and legs ferruginous; the coxae and trochanters black; the wings reddish brown, their base hyaline. Abdomen smooth, shining, and very delicately and closely punctured; the basal segment ferruginous, its extreme base, as well as its apical margin, black; the three apical segments pale ferruginous; the apical margins of the second and third segments obscurely rufo-testaceous; beneath, the basal segment has a central longitudinal carina; the three apical segments pale ferruginous."

West Africa.

S. Mionii Guérin. Iconog. du Règne Anim. p. 438, ㅇ․ I844. Handlirsch, Sitzungsber. K. Akad. Wiss. Wien, CI, p. 109. I892.

"Similar to and closely allied to $S$. fenestratus. Abdomen distinctly less densely punctured, but the first tergite with distinct punctures. Head black, the clypeus a little paler. Thorax dark ferruginous, the epinotum concolorous. Abdomen black, the first segment and base of the second dark ferruginous. Antennae fuscous, paler at the base, the legs dark ferruginous. Wings coloured very much as in fenestratus, the hyaline apical margin not extending to the third cubital cell. Epinotum with a dense long and pale pilosity. I 7-20 mm. long."

Senegal.

S. funebris Handl. Verh. Zool. Bot. Ges. Wien, L, p. 473, ㅇ. 1900.

ㅇ. $17 \mathrm{~mm}$. long. Black. Labrum, clypeus, mandibles and frontal area below the antennae, ferruginous. Antennae pale ferruginous, becoming darker towards the apex. Anterior femora, tibiae and tarsi ferruginous, the femora blackish below at the base. Wings fusco-violaceous, the apical margin beyond the cells very narrowly hyaline. Clypeus, face and temples with a greyish silvery pubescence, the abdomen with a scanty cinereous pubescence and the epinotum with a short, sparse and grey pilosity. Head and thorax dull, the abdomen very nearly so. Head closely and microscopically punctured. Thorax strongly punctured, reticulate-punctate, the punctures larger on the mesopleurae than elsewhere. Abdomen with a very close and fine puncturation, the punctures round and shallow; the sixth tergite more strongly punctured than the rest, even coarsely so at the base. Labrum gibbous at the base as in the rest of this group. Second joint of the flagellum about twice as long as the third, the last joint longer than the penultimate. Eyes moderately convergent below, the interocular distance on the vertex being only one-third greater than across the middle of the clypeus. The anterior margin of the clypeus is shallowly concave. Posterior ocelli a little farther from each other than from the eyes. Face with a short median carina extending from the level 
of the antennal sockets to half way up to the anterior ocellus. Median area of the epinotum with a thin median longitudinal raised line. Basal joint of the anterior tarsi with five short ferruginous spines.

o. I4-I7 mm. long. Fore legs fusco-ferruginous or black. Head entirely black. Antennae ferruginous, the scapes darker above, the ninth to twelfth joints of the flagellum black above. Sculpture stronger than in the $q$, especially on the abdomen. Otherwise like the ?.

Victoria Falls and Sawmills, S. R.

A species easily recognised by the very dense and coarse puncturation of the thorax.

\section{S. persimilis Turner. Ann. Mag. N.H. (9) I, p. 9I, f. I9I8.}

"․ Black; clypeus, labrum, mandibles, palpi, antennae, posterior margin of the pronotum narrowly in the middle and widely at the sides, pronotal tubercles, lateral margins of the mesonotum in front of the tegulae, anterior femora, middle and hind femora at the apex, tibiae and the tarsi, orange yellow; second tergite with a small spot on each side at the apical angles, the third and fourth with a broad longitudinal fascia on each side, the greater part of the fifth and the whole of the sixth, yellow; wings bluish black. $16 \mathrm{~mm}$. long. The first tergite closely punctured, the sixth sparsely and more finely punctured."

Magadi Junction, British East Africa.

\section{SCOLIAEFORMIS Group.}

Eyes parallel. Pronotal collar not discoid as in the other groups, the anterior face being oblique instead of vertical; this makes the pronotum appear much longer. Sides of the epinotum transversely compressed, so that the declivity is moderately concave; the lateral margins of the declivity are, however, not excised below. First sternite with a median longitudinal carina and a carina on each side (this is also the case in some of the tridentatus group); second sternite longitudinally carinate in the middle. Sixth tergite with a distinctly defined pygidial area, marginate at the sides, covering the greater part of the segment. Antennae slender, filiform. First transverse cubital vein slightly curved; the medial cell of the hind wing emits two longitudinal veins. Abdomen very convex transversely.

\section{S. scoliaeformis n.sp. (figs. 6I, 6I $a-c$ ).}

. $12.5 \mathrm{~mm}$. long. Face at the sides and below the antennae, and the clypeus, yellow; labrum, mandibles excepting the black apex, vertex, temples, pronotum excepting the black middle portion of the sides, mesonotum, tegulae, scutellum, metanotum and a spot on the mesopleuraebelow the tegulae, very pale ferruginous; the rest of the thorax black. Abdomen black, the first two tergites with a large spot on each side covering the greater part of the segment, and the third to fifth almost entirely, brownish orange; the base of the sixth tergite with a spot of the same colour on each side at the base. Antennae and legs ferruginous. Wings fusco-hyaline, the veins black. Face, clypeus and labrum with silvery pubescence. Thorax and legs with a dense, microscopic and whitish pubescence, having a pruinose appearance on the mesopleurae. Abdomen with a sparse yellow pubescence and a scanty pilosity of the same colour on the last three segments. Head and thorax dull. Head closely, the pronotum closely and microscopically punctured, the mesonotum, scutellum and metanotum a little more strongly punctured than the pronotum, 
the sides of the thorax very finely and closely punctured, the mesopleurae with a few large and round punctures here and there. Dorsum of the epinotum with a close and fairly strong oblique puncturation; the median area is clearly defined at the sides by impressed lines and has an apical sulcus margined by carinae which extend to the bottom of the declivity. Abdomen fairly closely punctured, more so on the sternites than on the tergites, the punctures nearly round, and on the first two tergites nearly as large as those on the epinotum. Pygidial area triangular, about as long as wide at the base, coarsely and not closely punctured, the apex narrowly rounded. Interocular distance on the vertex not greater than across the base of the clypeus, and equal to the length of the second and third joints of the flagellum. Posterior ocelli nearly twice as far from each other as from the eyes. Second joint of

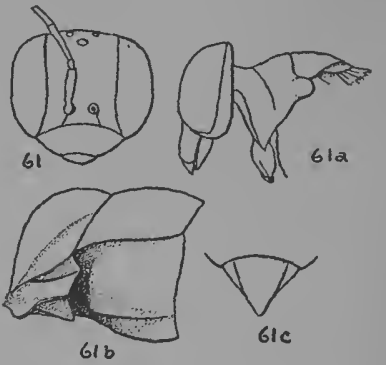

Fig. 6r. Stizus scoliaeformis, ㅇ, head; $a$, o, head and pronotum $; b$,, , first two sternites viewed obliquely from below; $c, \uparrow$, pygidium. the flagellum one-fourth longer than the third, all the joints much longer than wide, the last joint narrowed towards the apex and as long as the penultimate. Clypeus wide and not very convex. Frontal area below the antennae triangular; the antennal sockets nearer to the clypeus than to the eyes. Basal joint of the anterior tarsi with seven short spines; the middle and hind tibiae with a few long spines. First abscissa of the radius nearly twice as long as the second. For the rest, the characters of the group, $q . v$.

o. $12.5 \mathrm{~mm}$. long. Legs and antennae paler than in the of the anterior coxae and the pronotal tubercles pale yellow. Mesopleurae yellow in front, becoming gradually reddish behind. Sternites castaneous. Mesopleurae, sides of the epinotum and the abdomen more strongly punctured than in the $q$. Face narrower than in the . Second joint of the flagellum one-fourth longer than the third. Flagellum long and slender as in the $o$, all the joints simple, and all, except the first, longer than wide. Seventh tergite triangular, rounded at the apex, closely punctured with large, elongated and shallow punctures. Second sternite subcarinate longitudinally as in the $q$, shallowly impressed on each side of the carina, the sixth and seventh sternites simple. Otherwise like the o.

Kaross, S.W. Africa I + , type; Warmbad Koakoveld, S.W. Africa, 3 ôt (type) and $\mathrm{I}$ \%. Types in the South African Museum.

Quite unlike any other species of the genus and perhaps deserving to rank as the type of a subgenus. The shape and colour of the abdomen recalls that of Scolia chrysotricha Burm.

\section{S. pubescens n.sp. (fig. 62).}

o. 2 I mm. long. Black. Labrum, clypeus and face below the antennal sockets and half way up the sides, yellow or reddish yellow. The upper half of the face, vertex, posterior orbits, posterior margin of the pronotum, pronotal tubercles, lateral margins of the mesonotum, tegulae and the legs, ferruginous. Sixth and seventh abdominal segments fusco-ferruginous. Antennae pale ferruginous. Fore wing: apical margin, second discoidal and second submedial cells and the inner margin below them, hyaline; the rest of the wing fuscoviolaceous. Hind wing hyaline, the veins black. Face and clypeus with yellowish pubescence, the rest of the head and the thorax with a pale brownish grey, long and exserted pilosity. Abdomen with an abundant, blackish and 
outstanding pubescence, somewhat more sparse on the first three and the apical sternites than elsewhere. Head dull, microscopically punctured, the face and vertex with a few larger, shallow punctures in addition. Thorax slightly shining, with a shallow, fine and fairly dense semi-puncturation, stronger on the lateral areas of the epinotal dorsum than elsewhere, very fine on the mesopleurae and on the sides of the epinotum. Abdomen with a fairly strong and close semipuncturation, sparser on the second sternite than elsewhere. The first sternite is

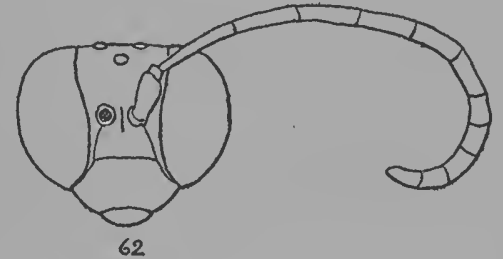

Fig. 62. Stizus pubescens, ơ, head. not carinate, but the second is feebly so lengthwise in the middle. Head much narrower than the thorax. Antennae very long and slender, extending back as far as the middle of the first tergite, the second to seventh joints much longer than wide, the second two-fifths longer than the third, the last joint attenuated towards the apex and slightly longer than the preceding one. Eyes slightly convergent below; the interocular distance on the vertex equal to the length of the first two joints of the flagellum, and one-fourth greater than across the base of the clypeus. Posterior ocelli farther from each other than from the eyes. Temples narrow above. Labrum transversely elliptical. Median area of the epinotum with a smooth median longitudinal line. Seventh tergite very broadly rounded at the apex.

Kaoko Otavi, S.W. Africa. 2 of. March. Types in the South African Museum.

In the absence of the I am unable to determine the group to which this species belongs. It is very distinctly characterised by the unusual colour pattern of the wings, the long antennae and the dense pubescence of the tergites. 


\title{
THE SPHEGIDAE OF SOUTH AFRICA
}

\author{
BY GEORGE ARNOLD, D.Sc., A.R.C.Sc., F.E.S. \\ Curator of the Rhodesia Museum, Bulawayo
}

With I Plate and 42 Text-figures

\section{PART XIII}

Genus Bembex Fab.

(Bembyx) Syst. Ent. p. 36r. 1775.

General Characters. Head wide, wider than the thorax, vertically truncate behind or nearly so, the upper occipital margin lying just behind the eyes. The temples are therefore very narrow or obsolete above, but become wider below. Cheeks obsolete, the eyes almost touching the base of the mandibles. Face usually carinate between the antennal sockets. Inner margins of the eyes parallel, or divergent below, or slightly divergent both above and below, rarely convergent below. Anterior ocellus transversely arcuate, flattened and linear; the posterior ocelli elongate and flattened, somewhat sunk below the surface. The ocellar area, except in a few species, is raised or subtuberculate in the middle and is separated from the sides of the vertex by a more or less deep depression on each side. Mandibles not excised on the outer margin, with one or two teeth on the inner, the apex simple. Maxillae very long, their palpi 4-jointed; the labial palpi 2 -jointed. Tongue and paraglossae very long. Labrum exserted, snout-shaped, much longer than wide, the apex angularly excised. Clypeus very convex, wider than long. Antennae filiform in the $q$; in the $\sigma^{t}$ some of the apical joints are nearly always abnormal, being widened and excavated below or armed with one or two minute teeth or spines on the posterior margin below. Pronotum discoid, linear above, sunk below the level of the mesonotum. The mesopleurae lack an epicnemium and the episternal suture is obsolete. The epimerum of the mesopleurae is nearly always distinctly defined all round. Epinotum short, roundly truncate behind, the median triangular area of the dorsum welldefined, wide and continued far over on to the declivity. Six abdominal segments in the $q$, the sixth tergite more or less triangular, fringed at the sides with very short setae, without a marginate pygidial area. In the ot seven dorsal and ventral segments are visible, the second and sixth sternites often armed with carinae or tubercles, the seventh simple or carinate, often largely hidden by the ventral flaps of the seventh tergite, the eighth sternite always hidden by the seventh and nearly always ending in a single spine. Middle coxae separated. Trochanters small. The anterior tarsi with a distinct comb, composed of long spines which are sometimes flattened or lanceolate. Middle tibiae with one or two spurs, sometimes produced on the outside at the apex into a stout point. The fore and middle femora, more especially the latter, are sometimes dentate or serrate on the posterior lower margin. Tibiae and tarsi spinose. Wings usually rather short. 
Fore wing: three cubital cells present, the second receiving both recurrent veins, the first as large as the second and third united; the second narrowed above and never stalked on the radius; radial cell long, rounded at the apex, the basal vein arises just before the end of the submedial cell or is interstitial with the cross-vein and meets the subcosta at a considerable distance from the pterostigma; the latter is small.

Hind wing: the retinaculum is complete and arises near the origin of the radius; the latter is long and nearly reaches the apical margin of the wing; the cubitus arises beyond the end of the submedial cell; the submedial vein extends to the anal sinus; the basal lobe is elongate and oval.

Distribution. Both hemispheres.

The prey consists of Diptera and in many species, if not in all, the nests are kept open, the larvae being provided with fresh food day by day. The nests are nearly always made in soft ground, chiefly loose sand.

The sculpture generally consists of an even and shallow semi-puncturation on the thorax and tergites, whereas the punctures on the sternites are usually round. The nature of the puncturation on the dorsum of the thorax and on the sternites is of some diagnostic value, but that of the face and vertex, usually very fine and close, and of the tergites is too uniform, and therefore not taken very much into consideration in the following descriptions. The coloration conforms to a particular pattern in each species but is liable to a certain amount of variation, more particularly on the dorsum of the thorax and on the abdomen. It is not easy to give a concise and at the same time an accurate description of the colour pattern of the tergites, and I have therefore, whenever possible, figured the commonest or average pattern in Plate VI.

The genus was monographed by Handlirsch in the Sitzungsber. K. Akad. Wiss. Wien, CII, 1893 . This work is of fundamental importance, since previously the descriptions of other authors were based chiefly on colour, instead of structural characters. Valuable as it is, Handlirsch's work would have been more helpful to the student if it had been arranged in a different form. In his diagnoses of groups and descriptions of species the tabulation of structural characters which are not present is as unnecessary as it is confusing. It may reasonably be assumed that, unless there is a statement to the contrary, the reader will understand that the structure of the femora, tibiae and tarsi is normal, i.e. not characterised by the dilatation of the tarsi or by the presence of teeth or serrations on the femora. A comparison of Handlirsch's diagnoses for the fuscipennis and oculata groups suffices to illustrate this point. It will be seen that the one is merely a repetition of the other, with only this difference, that in the former there is the statement that the basal joint of the middle tarsi is dilated. In the following pages I have endeavoured to avoid such superfluous repetition.

Handlirsch divided the genus into numerous species-groups, based on combinations of several characters, but chiefly and somewhat arbitrarily on resemblances in the structure of the male genitalia. If the separation of groups is based only on the shape of the genitalia, then we should have to place within the same group such dissimilar species as cinctella and diversipennis or chlorotica and monedula. If, however, other characters are brought into consideration we shall find that many of them are common to two or more groups. Such overlapping of characters not only emphasises the artificial nature of some groups but also makes them of little value in the identification of species, since their boundaries become so ill-defined. On the other hand, a narrow interpretation of the limits of a group leads to the undesirable multiplication of groups, since many new species will not fit in with the old groups. I am 
of the opinion that the arrangement of the species into groups does not represent in the majority of cases the natural affinities of the species, but nevertheless, such an arrangement in this large genus is to a certain extent helpful in the identification of species and I have therefore adopted Handlirsch's scheme. At the same time it has been found necessary to erect a few more groups for some new species which are sharply defined, but others which are less so have been attached provisionally to the old groups.

A character which has been used by Handlirsch and other authors, the presence of either one or two longitudinal veins at the apex of the medial cell of the hind wing, appears to me to be of doubtful value and has not been relied on to any great extent in this work. In those species supposed to have only one such vein, it will be seen that the other is present as a vena spuria, and the presence of the second or lower one depends on its degree of chitinisation. This is certainly variable, for in some species described as having two such veins only the extreme base of the lower one shows a distinct chitinisation.

\section{KEY TO THE SPECIES, $\widehat{0} \delta^{*}$.}

(זо) I. First four joints, or at least the basal joint, of the anterior tarsi dilated.

(5) 2. First four joints of the anterior tarsi dilated.

(4) 3. Seventh tergite semicircular, seventh sternite with a short carina on each side near the lateral margin; middle femora unarmed. I $6 \mathrm{~mm}$. long.

Cameronis Handl.

(3) 4. Seventh tergite triangular, the apex emarginate, seventh sternite with one median and two feeble lateral carinae; middle femora with two teeth near the base. $22 \mathrm{~mm}$. long.

bubalus Handl.

(2) 5. First and second, or only the first joint of the anterior tarsi dilated.

(7) 6. First joint of the anterior tarsi strongly dilated, the second a little less so, the first with six black lanceolate spines. anomalipes Arnold

(6) 7. First joint of the anterior tarsi moderately dilated, with thin short spines which are unevenly spaced and inserted towards the middle of the joint and not on its edge (figs. $6,10 b$ ).

(9) 8. Six spines on the first joint of the anterior tarsi, two near the apex and four close together in the basal half; eighth to twelfth joints of the flagellum strongly dilated and excavated below; middle femora with four spines on the posterior margin. scaura Arnold

(8) 9. Eight spines on the first joint, two at the apex and six in the basal half; joints of the flagellum not dilated, the seventh and eighth feebly spinose posteriorly; middle femora dentate-serrate along the whole of the posterior margin.

atrospinosa Turner

(I) Io. Joints of the anterior tarsi simple.

(I2) II. Middle tibiae produced into a broad spine at the apex outwardly; seventh tergite not semi-elliptical.

afra Handl.

(I I) 12. Middle tibiae not produced at the apex, or if so, then the seventh tergite is semi-elliptical.

(I8) I3. Seventh tergite with a small tooth on each side near the base.

(I5) I4. Second sternite with a carina which ends posteriorly in a short curved tooth; seventh tergite orange yellow; $16-20 \mathrm{~mm}$. long.

Moebii Handl.

(I4) I5. Second sternite with at the most a slightly raised and shining line down the middle; seventh tergite black, with a yellow spot on each side.

(I7) 16. Thorax, excepting the posterior margin and a part of the sides of the epinotum, black; tergite with dark chrome yellow bands. $19 \mathrm{~mm}$. long. odontopyga Turner 
(16) 17. Thorax mainly lemon yellow at the sides and with lemon yellow bands on the scutellum, metanotum and epinotum; tergites with lemon yellow bands. $16 \mathrm{~mm}$. long.

(I3) IS. Seventh tergite not toothed at the sides.

Scotti Turner

(20) 19. Apical half of the seventh tergite flattened, semi-elliptical and fuscoferruginous. (Seventh sternite tricarinate, the median carina low and not reaching the base; bands on the tergites lemon yellow; seventh to tenth joints of the flagellum feebly spinose.)

(19) 20. Seventh tergite varying from triangular to semicircular.

(40) 2I. Large species I $\delta-25 \mathrm{~mm}$. long.

(23) 22. Pale markings on the head, the prothorax and tegulae ferruginous; middle femora bluntly angular in the middle behind, the apical half much narrower than the basal. 24-25 $\mathrm{mm}$. long. diversipennis Smith

(22) 23. Pale markings on the head not ferruginous, prothorax black, or black and yellow; middle femora not subangular in the middle.

(29) 24. Pale colour of the tergites whitish, yellowish white or glaucous white, not distinctly yellow.

(26) 25. None of the joints of the flagellum spinose. (Middle femora strongly dentate-serrate on the posterior margin; the first six tergites with whitish bands, the seventh ferruginous; $15^{-1} 8 \mathrm{~mm}$. long.)

cultrifera Arnold

(25) 26. The sixth to eighth or the eighth and ninth joints of the flagellum spinose.

(2S) 27. Tergites $x-6$ with white bands; second joint of the flagellum threefifths longer than the third, the sixth to eighth spinose; sixth sternite with a scutate platform, the seventh with a carina on each side. I $8 \mathrm{~mm}$. long.

albofasciata Snith

(27) $2 S$. Tergites $1-4$ with yellowish white maculae, narrowed inwardly, on each side, the fifth with a bisinuate band of the same colour, the sixth with a yellowish white spot on each side; second joint of the flagellum two and a quarter times longer than the third; sixth sternite with a triangular platform, the seventh without carinae. $24 \mathrm{~mm}$. long.

(24) 29. Pale colour of the tergites distinctly yellow.

albidula Turner

(33) 30. Mesonotum with a large U-shaped yellow mark in the middle.

(32) 31. Posterior margin of the middle femora distinctly dentate-serrate over the greater part of its length; tergites $\mathrm{I}-6$ lemon yellow, the apical margins narrowly black, the first, second and third enclosing black maculae; second sternite unarmed. $20-23 \mathrm{~mm}$. long. flavicincta Turner

(3I) 32. Posterior margin of the middle femora smooth; tergites chrome yellow, the first five enclosing indistinct, linear, transverse and blackish streaks; second sternite with a median carina ending in a small and acute tooth. $23 \mathrm{~mm}$. long.

Bequaerti Arnold

(30) 33. Mesonotum without a U-shaped yellow mark.

(35) 34 . Outer paramera of the genitalia very broad and transverse at the apex (fig. I9).

(34) 35. Outer paramera of the genitalia differently formed.

(37) 36 . Fourth and following tergites black, the pale colour on the first three is whitish yellow.

ugandensis Turner

(36) 37. All the tergites yellow, with black markings.

(39) 3 S. Flagellum black, the eighth joint feebly spined posteriorly; mesopleurae with a large yellow mark, the sides of the thorax in greater part yellow. $23 \mathrm{~mm}$. long.

Bequaerti var, dira Arnold

(3) 39. Flagellum ferruginous, the seventh to ninth joints distinctly spined; mesopleurae with a yellow mark, the sides of the thorax in greater part black. $24 \mathrm{~mm}$. long.

venusta Arnold

(2I) 40. Small or medium-sized species, less than IS $\mathrm{mm}$. long. 
(48) 4I. Basal joint of the middle tarsi more or less dilated.

(43) 42. Seventh tergite narrow and truncate at the apex, the sides feebly trisinuate; sixth sternite with a semicircular platform.

compedita Turner

(42) 43. Seventh tergite not trisinuate at the sides; the sixth sternite with a triangular platform.

(45) 44. Wings usually deep brown in the middle; seventh tergite triangular, rounded at the apex. Flagellum, excepting the last four joints, ferruginous.

fuscipennis Lep.

(44) 45. Wings hyaline or only faintly tinged with brown; flagellum black above, dirty yellow below.

(47) 46. Wings faintly tinged with brown in the basal half; pale bands on the tergites yellowish white, the seventh entirely black. Interocular distance on the vertex equal to the length of the first six joints of the flagellum, the second joint three times longer than wide at the apex.

sibilans Handl.

(46) 47. Wings hyaline; pale bands on the tergites yellowish white in the middle, pale lemon yellow at the sides, the apical half of the seventh reddish yellow. Interocular distance on the vertex equal to the length of the first five joints of the flagellum, the second joint four and a half times longer than wide at the apex.

capensis Lep.

(4I) 48. Basal joint of the middle tarsi not dilated.

(58) 49. Second to fifth or sixth sternites dull, finely and closely punctured all over.

(53) 50. Flagellum filiform, all the joints cylindrical, and not spinose. Head, thorax and first tergite with a dense whitish or greyish pilosity. Seventh sternite with a median carina.

(52) $5 \mathrm{r}$. Abdomen entirely black. Sternites two and six not armed nor carinate. $14 \mathrm{~mm}$. long.

Arnoldi Brauns

(5I) 52. Tergites lemon yellow, the first two widely, the third to sixth narrowly black at the base; second sternite with a low tooth, the sixth somewhat tumid in the middle. $14 \mathrm{~mm}$. long.

albopilosa Arnold

(50) 53. At least the seventh joint of the flagellum angularly produced behind; seventh sternite tricarinate.

(57) 54. Posterior femora with two or three teeth behind near the apex; sixth sternite with a low, indistinct and triangular tubercle.

(56) 55. Second joint of the flagellum one-third longer than the third; outer paramera of the genitalia bifurcate at the apex, the inner ramus thin, cylindrical and longer than the outer. ulula Arnold

(55) 56 . Second joint of the flagellum one-fifth longer than the third; the outer paramera of the genitalia not bifurcate.

Junodi Arnold

(54) 57. Posterior femora indistinctly serrate; sixth sternite with a semielliptical and high platform. (Second joint of the flagellum one-third longer than the third; outer paramera of the genitalia bifurcate, the outer ramus longer than the inner.)

Stevensoni Arnold

(49) 58. Sternites not entirely dull, and not finely, closely punctured all over.

(62) 59. Posterior margin of the middle femora smooth, without teeth or serration.

(6I) 6o. Tergites $\mathrm{I}-6$ lemon yellow, black at the extreme base and apex, the second and third enclosing transverse black maculae; seventh joint of the flagellum feebly spined, the second joint three-fourths longer than the third. $17 \mathrm{~mm}$. long.

capicola Handl.

(60) 6r. Tergites $\mathrm{I}-6$ pale whitish yellow, the apical margins widely black; all the joints of the flagellum simple, the second joint half as long again as the third. I4-15 mm. long. Kriechbaumeri Handl.

(59) 62. Posterior margin of the middle femora more or less dentate or serrate.

(70) 63. Seventh sternite tricarinate. 
(65) 64. Mesonotum without yellow streaks on each side of the middle in front; tergites $I-6$ pale chrome yellow, the declivous basal half of the first and the bases of the rest, narrowly black; seventh and eighth joints of the flagellum spined posteriorly; sixth sternite with a high semicircular platform. $16 \mathrm{~mm}$. long.

ochracea Handl.

(64) 65. Tergites with dirty white bands, or if the bands are partially yellow, then the mesonotum has two longitudinal yellow streaks in front.

(67) 66. Sixth sternite without a distinct platform or tubercle, merely tumid in the middle; second joint of the flagellum two-thirds longer than the third; posterior margin of the middle femora very distinctly serrate. (Pale bands on the tergites glaucous white, the mesonotum with two yellow streaks near the middle in front.)

harenarum Brauns

(66) 67. Sixth sternite with a high semicircular platform; second joint of the flagellum twice as long as the third.

(69) 68. Mesonotum without two yellow streaks in front; sides of the thorax mostly black; tergites with narrow dirty white bands. I7 $\mathrm{mm}$. long.

liturata Turner

(68) 69. Mesonotum with two yellow longitudinal streaks in front, sides of the thorax mostly yellow; bands on the tergites glaucous white, those on the first three or four yellowish anteriorly. $17 \mathrm{~mm}$. long.

liturata, race flavopicta Arnold

(63) 70. Seventh sternite with only a median carina.

(74) 7 r. Clypeus and the labrum, excepting only the lateral margins and apex, blackish; middle femora with two or three teeth behind at the apex.

(73) 72. Pilosity of the head and thorax greyish white.

(72) 73. Pilosity of the head and thorax yellowish grey.

melanopa, race litoralis Arnold

(7I) 74. Labrum and greater part of the clypeus not black.

(80) 75. Bands on the tergites glaucous white, those on the first two sometimes yellowish in front.

(77) 76. Labrum, clypeus and all the markings on the thorax glaucous white. (Middle femora feebly serrate; seventh joint of the flagellum spined, the second joint nearly three-quarters longer than the third; interocular distance on the vertex nearly equal to the length of the first five joints of the flagellum; $x 7 \mathrm{~mm}$. long.) massaica Cameron

(76) 77. Labrum, clypeus and pale markings on the thorax lemon yellow.

(79) 78. Seventh tergite considerably narrowed over the apical third, the apex narrowly rounded (fig. $23 a$ ). intermedia Dahlbom

(78) 79. Seventh tergite not much narrowed apically, the apex fairly widely truncate (fig. 24).

Baumanni Handl.

(75) 80. Bands on the tergites distinctly yellow.

(84) 8I. Fifth to ninth joints of the flagellum spined posteriorly.

(83) 82. Second joint of the flagellum nearly half as long again as the third. I 5-I $7 \mathrm{~mm}$. long.

labidura Handl.

(82) 83. Second joint of the flagellum two-thirds longer than the third. $15 \mathrm{~mm}$. long. modesta Handl.

(8x) 84. Fifth joint of the flagellum not spined.

(86) 85. Seventh tergite black.

a. Sixth to eighth joints of the flagellum spined.

b. Seventh joint of the flagellum spined.

c. Eighth and ninth joints of the flagellum spined.

d. Sixth to ninth joints of the flagellum spined.

(85) 86. Seventh tergite yellow.

carinata Smith

Braunsii Handl. velox Handl.

Stadelmanni Handl. fraudulenta Arnold

B. obtusa Turner and forcipata Handl. being unknown to me in nature have been omitted from the key. 


\section{KEY TO THE SPECIES, ㅇ.}

(I0) I. Sternites 2-5 very finely and closely punctured, dull or nearly so.

(5) 2. Sides of the thorax in greater part yellow.

(4) 3. Sixth sternite ferruginous, sharply carinate in the middle over its whole length. $19 \mathrm{~mm}$. long.

speciosa Arnold

(3) 4. Sixth sternite black, convex and not carinate. $15 \mathrm{~mm}$. long.

(2) 5. Sides of the thorax more black than yellow.

ulula Arnold

(9) 6. Tergites with lemon or chrome yellow bands.

(8) 7. Face narrow, the eyes distinctly divergent below; tergites I-5 with chrome yellow bands, the sixth black with a yellow apical spot. Interocular distance on the vertex equal to the length of the first three joints of the flagellum plus half of the fourth. Second joint of the flagellum two and a third times longer than the third.

scaura Arnold

(7) 8. Face wide, the eyes nearly parallel; tergites I-5 with lemon yellow bands, the sixth ferruginous at the base and reddish ochreous in the middle. Interocular distance on the vertex equal to the length of the first four joints of the flagellum; second joint of the flagellum twice as long as the third.

bubalus Handl.

(6) 9. Tergites $1-5$ with creamy white bands, the sixth black, with a ferruginous apical spot. (Second joint of the flagellum two and a half times longer than the third; interocular distance on the vertex equal to the length of the first three joints of the flagellum.) atrospinosa Turner

(I) IO. Sternites 2-5 not finely and closely punctured all over.

(I4) II. Second sternite dull, finely and closely punctured over the greater part, but with a narrow longitudinal strip in the middle which is impunctate or only microscopically punctured, the part adjoining this strip with a few punctures larger than those on the rest of the segment.

(13) I2. Sixth sternite ferruginous; mesopleurae with a large yellow spot in front.

cultrifera Arnold

(I2) I3. Sixth sternite black; mesopleurae entirely black. albofasciata Smith

(II) I4. Second sternite sparsely, coarsely punctured and shining in the middle, more closely and more finely punctured at the sides.

(30) I 5. Large species, 22-24 mm. long, or if less than $22 \mathrm{~mm}$. (small specimens of Moebii) then the second and third sternites are distinctly subcarinate lengthwise in the middle and the apical abdominal segment is reddish yellow.

(19) I6. Basal two-thirds of the fore wing and nearly all the hind wing deeply tinged with brown.

(18) I7. Tergites I-5 with large pale yellow maculae on each side, face, pronotum and sixth abdominal segment ferruginous, scutellum, metanotum and median area of the epinotal dorsum entirely black; second joint of the flagellum four and a half times longer than wide at the apex.

diversipennis Smith

(I7) IS. First tergite mainly yellow, black at the base and narrowly black in the middle and on the apical margin, tergites $2-5$ with deeply bisinuate lemon yellow bands which are sometimes narrowly interrupted in the middle, scutellum, metanotum and epinotum with wide lemon yellow bands, sixth tergite black at the base and ferruginous on the apical half; second joint of the flagellum nearly five and a half times longer than wide at the apex.

venusta Arnold

(I6) I9. Wings hyaline.

(2I) 20. Abdomen black with a violaceous lustre, and pale yellow spots on each side. monedula Handl. 
(20) 2 I. Abdomen with yellow bands on at least some of the tergites, or in greater part yellow.

(23) 22. Last three abdominal segments entirely black, the first two with wide, the third with narrow bisinuate lemon yellow bands, that on the second enclosing two black spots.

(22) 23. Last three abdominal segments not entirely black.

(27) 24. Sixth tergite yellow or reddish yellow.

(26) 25. Mesonotum with a large U-shaped yellow mark on its disc, the greater part of the thorax yellow. First five tergites pale lemon yellow, black on the apical margins, the first three each enclosing two black spots.

flavicincta Turner

(25) 26. Mesonotum black, occasionally with two narrow longitudinal yellow streaks near the middle in front; sixth sternite flavo-ferruginous, abdomen black, with fairly narrow yellow bands on the first five tergites, that on the first sometimes interrupted in the middle, on the second to fifth deeply bisinuate. I7-2I mm. long. IMoebii Handl.

(24) 27. Sixth tergite black.

(29) 28. Tergites $I-5$ with chrome yellow bands, the second and third enclosing two black spots on each side of the middle; mesonotum with two longitudinal chrome yellow streaks in front. Bequaerti Arnold

(28) 29. The chrome yellow bands on tergites $\mathbf{I}-5$ widely interrupted in the middle; mesonotum entirely black. Bequaerti, var. dira Arnold

(I5) 30. Small or medium-sized species less than $20 \mathrm{~mm}$. long.

(34) 3I. Basal half of the wings tinged with brown.

(33) 32. The clypeus in greater part, flagellum excepting the last four joints and the sixth abdominal segment, ferruginous; second joint of the fiagellum nearly twice as long as the third, and four and a half times longer than wide at the apex.

fuscipennis Lep.

(32) 33. Clypeus in greater part, flagellum and sixth abdominal segment, black; second joint of the flagellum two-thirds longer than the third, and three and a half times longer than wide at the apex.

(3I) 34. Wings hyaline.

sibilans Handl.

(42) 35. Pale markings on the tergites dirty white, glaucous white or yellowish white, but not distinctly yellow; the sixth tergite entirely black.

(37) 36. Clypeus and the labrum excepting the lateral margins, black.

melanopa Handl.

(36) 37. Clypeus and labrum yellow, the former with the basal half blackish or with two black spots at the base.

(4r) 38. Dorsum and greater part of the sides of the thorax black, the scutellum with a pale pre-apical margin in liturata; sixth sternite subcarinate lengthwise over the apical half.

(40) 39. Legs reddish yellow, the femora marked with black; second joint of the flagellum twice as long as the third.

liturata Turner

(39) 40. Legs lemon yellow, the femora in greater part black; second joint of the flagellum half as long again as the third. harenarum Brauns

(38) 4r. Thorax with yellowish white transverse bands on the scutellum, metanotum and epinotum and longitudinal streaks of the same colour near the middle of the mesonotum, the sides of the thorax largely variegated with the same colour; sixth sternite distinctly carinate from base to apex.

massaica Cam.

(35) 42. Tergite with yellow or reddish yellow markings, but if inclining to whitish yellow then the sixth tergite has an ochreous spot on each side (= intermedia).

(46) 43. Mesonotum, excepting a streak at the sides near the tegulae, black; the posterior half of the thorax without yellow bands. 
(45) 44. Pale markings on the head and thorax reddish ochreous; second joint of the flagellum twice as long as the third. compedita Turner

(44) 45. Pale markings on the thorax lemon yellow; head, excepting the sides of the labrum, anterior angles of the clypeus and the posterior orbits, black; second joint of the flagellum three-fourths longer than the third.

Arnoldi Brauns

(43) 46. Yellow bands on the scutellum, mesonotum and epinotum, or on at least one of those segments.

(48) 47. Mesonotum with a U-shaped yellow mark in the middle, the lateral arms sometimes not joining the basal part; sides of the thorax mostly yellow.

a. Second joint of the flagellum fully twice as long as the third; sixth tergite yellow, black at the base.

Scotti Turner

b. Second joint of the flagellum nearly one-half longer than the third; sixth tergite black, with an ochreous spot on each side.

intermedia Dahlbom

c. Second joint of the flagellum one-third longer than the third; sixth tergite black.

Braunsii Handl.

d. Second joint of the flagellum one-half longer than the third, sixth tergite black. Kriechbaumeri Handl. and var. scitula Arnold

e. As in d. but the sixth tergite yellow.

lobatifrons Turner

(47) 48. Mesonotum without a U-shaped yellow mark.

(54) 49. Sixth tergite yellow or reddish yellow.

(5I) 50. Second joint of the flagellum short, only two-fifths longer than the third. (Sternites black, the sixth not carinate.) fraudulenta Arnold

(50) $5 \mathrm{I}$. Second joint of the flagellum long, more than twice as long as the third; apical half of the sixth sternite subcarinate.

(53) 52. Greater part of the second and the whole of the third to fifth sternites chrome yellow, the sixth black at the base, yellow apically; clypeus yellow. ochracea Handl.

(52) 53. Sternites pale ferruginous, black at the base, yellow at the sides; basal half of the clypeus blackish.

capensis Lep.

(49) 54. Sixth tergite black.

(56) 55. Sixth sternite distinctly carinate medially from base to apex.

(55) 56. Sixth sternite not carinate, or only subcarinate on the apical half.

(58) 57. Clypeus and labrum, excepting the lateral margins, black; interocular distance on the vertex equal to the length of the first five joints of the flagellum.

melanopa, race litoralis Arnold

(57) 58. Clypeus and labrum not mainly black.

(6o) 59. Sides of the thorax black; second joint of the flagellum three-fourths longer than the third. carinata Smith

(59) 6o. Sides of the thorax mainly yellow; second joint of the flagellum half as long again as the third.

labidura Handl.

B. Cameronis Handl. has been omitted from the above key, being unknown to $\mathrm{me}$ in nature.

\section{INTEGRA Group.}

Face wide, eyes parallel or feebly divergent below. Wings noticeably short in the $q$. Sixth tergite in the $q$ with lateral carinae towards the apex, enclosing a flattened pygidial area. In the male the anterior tarsi are dilated, especially the second to fourth joints, the middle femora are often dentate posteriorly, the middle tibiae are usually produced into a point at the apex, the middle tarsi are not normal, the second sternite is armed with a carina or tubercle, the 
sixth with a tubercle, the seventh wide, with two longitudinal carinae. Second sternite in the $q$ evenly and finely punctured, with some shallow and larger punctures.

Including B. Cameronis Handl.

B. Cameronis Handl. (figs. I, I $a-f$, Plate VI, fig. 34). Sitzungsber. K. Akad. Wiss. Wien, cII, p. 7I5, +, ô. I 893 .

"Inner margins of the eyes distinctly divergent below, the face carinate between the antennae. Eleventh joint of the antennae in the $\hat{\sigma}$ excavated below, the seventh, eighth and ninth very distinctly spined behind. Wings almost hyaline, the veins brown, in the of almost twice as long as the width of the thorax. Hind wing with only one longitudinal vein emitted from the apex of the medial cell. Basal joint of the anterior tarsi with seven or eight spines, which are dilated in the $\sigma$. The three intermediate joints are widely dilated outwardly, almost quadrate, their inner angles armed with short, straight spines. The middle femora in the of are hardly excavated below, not distinctly dentate but crenulate, the middle tibiae not produced at the apex, the first joint of the middle tarsus

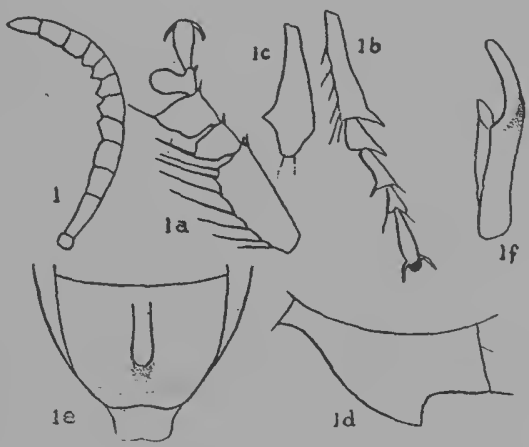

Fig. I. Bembex Cameronis, ô, flagellum; $a, \hat{o}$, left anterior tarsus; $b, \hat{o}$, middle tibia and tarsus; $c, \hat{\sigma}$, middle tibia, dorsal aspect; $d, \hat{o}$, second sternite; $e, \hat{a}$, sixth and seventh sternites; $f$, ô, genitalia.

dilated near the apex, excavated and having a dentiform carina in the middle. The $q$ has a less distinct pygidial area on the sixth tergite than in $B$. integra. Seventh tergite in the ${ }^{t}$ widely rounded at the apex, the second sternite has a median dentiform tubercle and the sixth also has a small one. Head and thorax densely covered with a grey pilosity. Sculpture similar to that of integra. (Head with a dense and fine fundamental puncturation and scattered coarse punctures on the labrum and clypeus. Dorsum of the thorax and the mesopleurae densely covered with coarse and fine punctures. Tergites with a very even, fairly fine and moderately dense puncturation, the apical segment in the $\delta$ with numerous coarse punctures, in the $q$ with a very dense, moderately coarse and in the middle almost rugose, puncturation. Sternites in the o dull, with a very fine and dense puncturation and a few larger punctures here and there; in the $\sigma^{\hat{\alpha}}$ more shining, with a coarser puncturation.)

Black. Anterior and posterior orbits, clypeus, labrum, the margin of the pronotum narrowly, the pronotal tubercles, sides of the prothorax, large spots on the mesopleurae, metapleurae and sides of the epinotum, a very narrow line sometimes obsolete on the scutellum, complete fasciae, barely sinuate and moderately dilated laterally on the first five tergites, a cordiform spot on the sixth tergite in the $q$, and a transverse spot on the sixth tergite in the $\hat{o}$, lateral maculae on the sternites in the $q$, of which the first three are joined in the middle and almost the whole of the sternites in the $\delta$, yellow. Scapes yellow, the flagellum in the ${ }^{t}$ fuscous above, brown below, entirely brown in the 9 . Legs yellow; coxae, trochanters, femora and in the $\hat{o}$ also the tibiae, more or less marked with black. I 5 -19 mm. long.

Cape Province. Types in the Berlin Museum." 
A o specimen, $16 \mathrm{~mm}$. long, from Tradouw Pass, Swellendam, C. P., and in the South African Museum, which I attribute to this species, has the bands on the abdomen lacteous rather than yellow; the structure of the legs and antennae agree with the figures of those parts in Handlirsch's monograph, but the genitalia are slightly different. The figures given herewith are drawn from this specimen. In addition it should be noted that the interocular distance on the vertex is equal to the length of the first six joints of the flagellum, and that the second joint is three-quarters longer than the third.

\section{ULULA Group.}

Face wide. Eyes feebly divergent below. Wings fairly short.

o. Anterior tarsi simple. Middle femora dentate near the apex behind. Basal joint of the middle tarsi slightly enlarged near the apex. Second sternite with a longitudinal carina, the sixth tergite with a tubercle or platform, the seventh with a median and lateral carinae.

q. Second sternite dull, closely and finely punctured. Vertex only shallowly depressed on each side of the ocellar area. Allied to the cinctella group of the Palaearctic region, but the $q$ has no pygidial area.

Including ulula Arnold and Stevensoni Arnold.

B. ulula n.sp. (figs. 2, $2 a, b$ ); Plate VI, figs. 3 and 43 ).

o. I $5 \mathrm{~mm}$. long. Black. Mandibles excepting the apex, labrum, clypeus, anterior orbits, the face at the base and a sinuous line below the anterior ocellus, temples, posterior margin and sides of the pronotum, the mesopleurae excepting a black spot below the tegulae and two black spots on the posterior margin, the metapleurae excepting their posterior margins, sides of the epinotum, narrow streaks on the sides of the mesonotum, narrow transverse bands on the posterior margins of the scutellum and metanotum, an arcuate band on the epinotum, continuous transverse bands, abruptly dilated at the sides, on the first six tergites, the underside of the thorax, first two sternites excepting four black spots on the second, and apical bands, dilated at the sides, on the third to fifth sternites, lemon yellow. Legs lemon yellow, with narrow black streaks on the upper side of the femora. Tegulae yellow in front. Wings

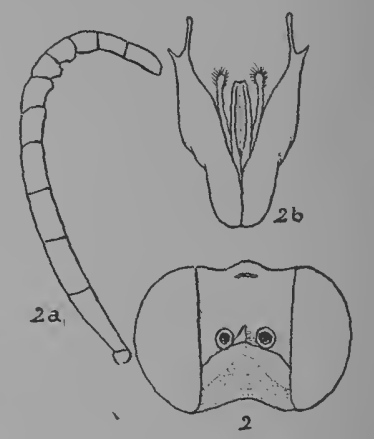

Fig. 2. Bembex ulula, + , head; $a, \sigma^{\prime}$, flagellum; $b, \hat{0}$, genitalia. hyaline, the veins ochreous, the subcosta black as far as its junction with the basal vein. Flagellum ochreous below, fuscous above. Pilosity white and very sparse. Puncturation of the mesonotum exceedingly fine, very close and shallow; that of the scutellum much larger, oblique and not very close. Dorsum of the epinotum very finely reticulate-punctate. Tergites closely punctured, the seventh shining, coarsely and not closely punctured. Sternites $2-4$ closely and finely punctured all over, the second dull, the rest almost so. The second sternite has a low median longitudinal carina which does not reach the apical margin; the sixth is very slightly raised in the middle and has an indistinct carina over its apical half; the seventh is distinctly tricarinate. Seventh tergite triangular, broadly rounded at the apex, the sides not sinuate. Clypeus moderately convex, somewhat flattened in the middle in front. Inner margins of the eyes parallel. Face carinate below between the antennae. Vertex 
less deeply impressed on each side of the ocellar area than in the majority of our species. Antennae long and slender. Second joint of the flagellum not quite one-third longer than the third, the seventh to ninth slightly and bluntly produced on the outer margin, the apical joint cylindrical, about onethird longer than the penultimate, none of the joints excavated below. Interocular distance on the vertex equal to the length of the first three joints of the flagellum plus one-third of the fourth joint. Basal joint of the anterior tarsi with seven whitish spines. Middle femora with two or three small teeth near the apex behind. Middle tibiae with one spur, not produced at the apex outwardly. The basal joint of the middle tarsi is slightly dilated near the apex. The genitalia are unlike those of any other member of the genus excepting Stevensoni. The outer paramera are bifurcate at the apex, the inner ramus long and thin and much longer than the outer ramus.

o. ${ }_{5} \mathrm{~mm}$. long. Base of the clypeus with a transverse black spot on each side. The yellow bands margining the posterior orbits sometimes meet in the middle behind the ocellar area. Mesonotum with two clavate yellow streaks in the middle and a sinuous one near the base, these are sometimes united to form a $U$-shaped mark. Sixth tergite ochreous on the apical half. Second sternite yellow, with a large black macula in the middle which is connected by a thin band at the base to two small black maculae at the sides. Sternites 3-5 with triangular yellow maculae at the sides, sometimes connected by a band of the same colour on the margin. Otherwise like the $\delta$ in colour and sculpture. Clypeus very distinctly flattened on the apical half. Interocular distance on the vertex equal to the length of the first four joints of the flagellum. The second joint of the latter is almost three-fourths longer than the third. Second sternite a little more closely punctured than in the $\delta$, the sixth very closely and microscopically punctured. Sixth tergite triangular, narrowly rounded at the apex, the lateral margins with black and rather long setae. Otherwise like the $\hat{o}$.

Victoria Falls, Gwaai, Sawmills and Springvale, S. R. January. Taken visiting the flowers of a small leguminous, clover-like plant, and very noticeable on account of its shrill hum, more like that of a bee than a Sphegid.

(R.M. and T.M. colls.) Types in the Rhodesia Museum.

B. Stevensoni n.sp. (figs. $3,3 a$ and $b$, Plate VI, fig. 48).

o. I4 mm. long. Black. Labrum, clypeus, mandibles except at the apex, scapes excepting a narrow black streak above, sides of the face widely, a triangular area between the antennal sockets, a V-shaped mark and a spot on each side of same below the anterior ocellus, temples, pronotum excepting the neck and a streak in front of the tubercles, prosternum in the middle, sides of the mesothorax excepting the margins of the epimerum and a black patch on the lower posterior angle of the mesopleurae, the metapleurae, sides of the epinotum excepting their margins, sides of the mesonotum, a transverse band on the posterior margin of the scutellum, transverse bands on the anterior and posterior margins of the metanotum and a line margining the sides of the epinotal median area, pale lemon yellow. Fairly wide bisinuate bands on the first six tergites dull white. Sternites I-3 lemon yellow; spots on their basal angles, the carina on the second and two spots on each side of the same and the base of the third, black, The fourth and fifth sternites with narrow apical bands of lemon yellow, broadly dilated at the sides. Legs lemon yellow, a streak on the upper side of the femora, the basal halves of the trochanters and an irregular mark on the inside of the tibiae, black. Tegulae pale yellow in front, brownish behind. Wings hyaline, the veins brown. 
Pilosity white and scanty. Clypeus not flattened anteriorly. Inner margins of the eyes almost parallel. Second joint of the flagellum about one-third longer than the third, the eighth to eleventh excavated belorr, the seventh to tenth slightly dilated but not spinose, the apical joint slightly curved, cylindrical and barely longer than the penultimate joint. Interocular distance on the vertex equal to the length of the first four joints of the flagellum, plus onethird of the fifth joint. Puncturation of the thorax close, very fine, oblique and shallow. Fifth and sixth tergites sparsely punctured, the seventh shining, with a few scattered and large punctures. Sternites $\mathrm{I}-5$ closely and finely punctured and dull, the sixth shining and more strongly punctured on its apical half. Second sternite with a

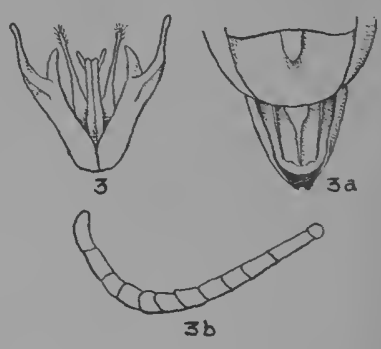

Fig. 3. Bembex Stevensoni, $\hat{0}$, genitalia; $a, 0$, sixth and seventh sternites; $\vec{b}, \hat{a}$, flagellum.

median longitudinal carina which is raised posteriorly and ends in a sharp angle some distance from the hind margin. Sixth tergite with a semi-elliptical platform at the base; seventh tergite with three carinae, the middle one broadened towards the base into a convex triangular area. Outer paramera of the genitalia bifurcate, the outer ramus long and narrow, the inner one triangular and lamelliform. Basal joint of the anterior tarsi with seven whitish spines. The apical half of the middle femora indistinctly serrate below.

Bulawayo (Arnold); Sawmills, S. R. (R. H. R. Stevenson). January to February. Type in the Rhodesia Museum.

\section{BUBALUS Group.}

of. All the joints of the anterior tarsi dilated. Middle femora dentate behind, middle tibiae with a short apical point and a distinct spur. Middle tarsi abnormal. Second sternite with a longitudinal tubercle, the sixth armed, the seventh wide and with two convergent longitudinal carinae.

o. Second sternite finely punctured all over.

Closely allied to the integra group. Including B. bubalus Handl.

\section{B. bubalus Handl. (figs. 4, $4 a-c$ ). Loc. cit. p. 719, ô,}

o. $22 \mathrm{~mm}$. long. Black. Labrum, clypeus, mandibles except at the apex, scapes, sides of the face, a triangular area at the base of same, posterior orbits narrowly, pronotal tubercles and the margins of the pronotum below them and the lower anterior angle of the mesopleurae, lemon yellow. Flagellum reddish ochreous. Tegulae brown. The first six tergites have transverse, bisinuate and lacteous bands. Sternites $\mathrm{I}-6$ lemon yellow, the first and second black at the base, the third to fifth in the middle with a short transverse black spot at the base and apex. Sixth sternite with a black spot on each side of the median carina and a black spot on the basal angles. Legs lemon yellow, the coxae and femora above and the whole of the middle and hind trochanters, black. Wings hyaline, slightly tinged with brown, the veins dark brown. Pilosity long and abundant, greyish brown on the vertex and mesonotum, white elsewhere. The sixth and seventh sternites densely pilose in the middle. Puncturation of the thorax and tergites fine, close and shallow, the tergites fairly dull, the sternites shining, shallowly, finely and not closely punctured except the second. Clypeus very convex transversely, not flattened in front, almost three times wider than long. Inner margins of the eyes almost 
parallel. Scapes thick, about twice as long as wide at the apex. Second joint of the flagellum rather short, three-quarters longer than the third, the sixth to ninth spined at the base, the tenth to twelfth deeply excavated below, the ninth to eleventh dilated, the twelfth twisted. Interocular distance on the vertex equal to the length of the first five joints of the flagellum plus half of the sixth joint. Vertex not deeply depressed at the sides of the ocellar area. Second sternite with an acute, triangular and transversely compressed tooth. Sixth sternite with a similar tooth extending over its basal twothirds. Seventh sternite with a median carina and a faint carina on each side. Seventh tergite triangular, shining, finely punctured at the base, Fig. 4. Bembex bubalus, ô, sparsely and coarsely at the sides, the apex deeply and angularly emarginate. The eighth sternite has the apical process bluntly trilobate. The ventral flaps of the seventh tergite are very large

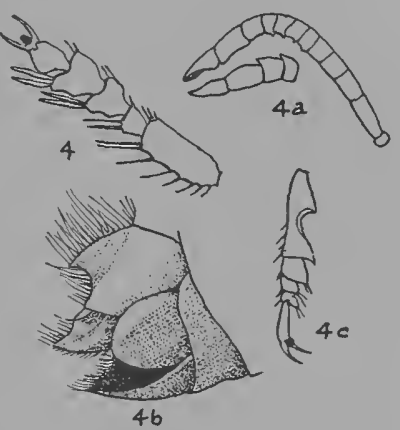
and broadly ovate. The joints of the anterior tarsi are all dilated, especially the last three; the basal joint has seven or eight white spines on the outer margin, and the third and fourth have two flattened white spines at the apex. Middle femora with two teeth on the posterior margin near the base; middle tibiae not distinctly produced at the apex; basal joint of the middle tarsi dilated at the apex, bidentate on the inside and excavated between the teeth, the second joint is also moderately dilated.

o. $18 \mathrm{~mm}$. long. Clypeus with two black spots at the base. Flagellum pale ferruginous. The pale bands on the tergites are lemon yellow, not lacteous as in the $\hat{0}$. Sixth sternite and apical margin of the fifth tergite ferruginous. The sixth tergite is yellow, except at the base where it is ferruginous. Femora ferruginous above and in front, the posterior femora black behind. Otherwise like the $\delta$ in colour. Fifth and sixth tergites with a sparse fulvous pilosity. Sternites very closely and finely punctured, and with a few large shallow punctures. Clypeus sparsely and fairly strongly punctured. Scapes much more slender than in the $\hat{\sigma}$, three times longer than wide at the apex. Second joint of the flagellum nearly twice as long as the third. Interocular distance on the vertex equal to the length of the first four joints of the flagellum plus half of the fifth. On the tarsal comb the two apical spines on the basal joint and the two on the second joint are long and ferruginous, the other spines are pale yellow and shorter. Sixth tergite narrowly rounded at the apex, the sides slightly sinuate.

Willowmore, C. P.

\section{ANOMALIPES Group.}

o. Eyes very slightly divergent below. Basal joint of the fore tarsi greatly dilated, the second slightly so. Middle tibiae with only one spur and not produced outwardly at the apex; the basal joint of the middle tarsi slightly dilated and produced into a point at the apex. Second sternite carinate; sixth sternite with an oblong platform on the apical half; the seventh with a median carina which is flattened at the base. Seventh tergite broadly rounded at the apex, the sides slightly sinuate and with distinct lateral carinae on its apical half.

Including anomalipes Arn. 


\section{B. anomalipes n.sp. (figs. 5, 5 a-e; Plate VI, fig. 5).}

o. I9 $\mathrm{mm}$. long. Black. Extreme apex of the labrum and the posterior orbits pale ochreous. A spot on the sides of the pronotum lemon yellow. First six tergites with transverse bands of lemon yellow, that on the first narrowed medially and slightly interrupted, that of the second abruptly trisinuate. Seventh tergite black. Sternites I-5 with triangular yellow marks at the sides of the apical margins. Legs lemon yellow, the anterior femora above, the outer half of the anterior tibiae and the base of the anterior tarsal joints, black. A broad streak on the upper side of the middle and hind femora, a narrow one on the tibiae and the apical tarsal joint, black. Tegulae with a small yellow spot in front. Wings hyaline, the veins dark brown. Clypeus with a long and dense whitish pubescence. Pilosity of the head and thorax

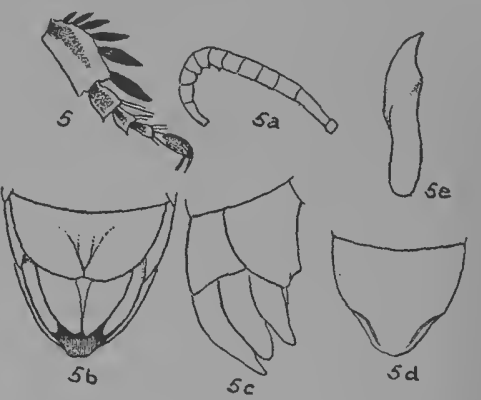

Fig. 5. Bembex anomalipes, $\hat{o}$, anterior tarsus; $a, \hat{o}$, flagellum; $b$ and $c, \hat{0}$, sixth and seventh sternites; $d$, 0 , seventh tergite; $e, \hat{o}$, paramera of the genitalia, right half from above.

fairly long, dense and white, that of the vertex and mesonotum shorter and pale fulvous. Thorax closely, finely and shallowly punctured, the punctures round. Second sternite closely punctured except in the middle near the apex, fairly shining, the other sternites shining, coarsely and sparsely punctured at the sides. Seventh tergite closely, finely punctured at the base, sparsely and more coarsely on the apical third, which is shining. Labrum with a fine median longitudinal carina which is expanded over the apical third into a low tubercle which is slightly hollowed out. Clypeus strongly convex, not flattened in front. Eyes slightly divergent below. Interocular distance on the vertex equal to the length of the first six joints of the flagellum. Vertex fairly deeply impressed at the sides of the ocellar area. Second joint of the flagellum threequarters longer than the third, the seventh and eighth feebly spined at the base, the ninth to eleventh excavated below, the apical joint compressed and narrowed apically, its apex truncate. Scapes thick, barely twice as long as wide. Second sternite with a median longitudinal carina, raised posteriorly and ending in an acute tooth some distance from the posterior margin. Sixth sternite with an oblong platform in the apical half; seventh sternite with a median longitudinal carina which is flattened at the base. Seventh tergite broadly rounded at the apex, its sides slightly sinuate and distinctly carinate on each side of the apical half. The ventral flaps of the seventh tergite are long and narrow. Outer paramera of the genitalia acute at the apex, subrostrate. Basal joint of the anterior tarsi dilated, less than twice as long as wide, the outer margin with six flattened lanceolate black spines, the second joint slightly dilated. Femora simple. Basal joint of the middle tarsi dilated and produced into a tooth at the apex outwardly.

Penkridge, near the eastern border of S. Rhodesia, I $t$, October, type (R. R. R. Stevenson): Thysville, Congo (J. Bequaert).

The specimen from Thysville in the Congo Museum, Tervueren, has the posterior margin of the scutellum dark yellow. Type in coll. Stevenson.

A very distinct species, easily recognised by the shape of the fore tarsi and the seventh tergite. 


\section{ATROSPINOSA Group.}

Eyes almost parallel, only feebly divergent below.

0 . Basal joint of the anterior tarsi slightly dilated, the basal spines of the joint inserted on the middle line below and not on the outer margin. Middle femora strongly serrate along the whole of the hind margin; middle tibiae slightly swollen near the apex, with only one spur and not produced into a point outwardly at the apex. Second sternite closely punctured, armed with a large, compressed and rounded tooth; sixth sternite armed, the seventh with a median longitudinal carina.

9. Second sternite closely and finely punctured.

Including atrospinosa Turner.

B. atrospinosa Turner (figs. 6, 6a-e). Ann. Mag. N.H.xx, p. 289, ô, ․ 1917.

o. $18 \mathrm{~mm}$. long. Black. Mandibles except at the base, clypeus, labrum, sides of the face and its base between the antennae, a curved bilobed streak below the anterior ocellus, posterior orbits, scapes below, sides of the pronotum and a rectangular macula on the mesopleurae in front, pale straw yellow. Wide transverse bands on the first six tergites and triangular lateral marks on the second to fifth sternites, lacteous. Legs pale yellow, the anterior femora above, and the anterior tibiae on the outside, black; middle and hind
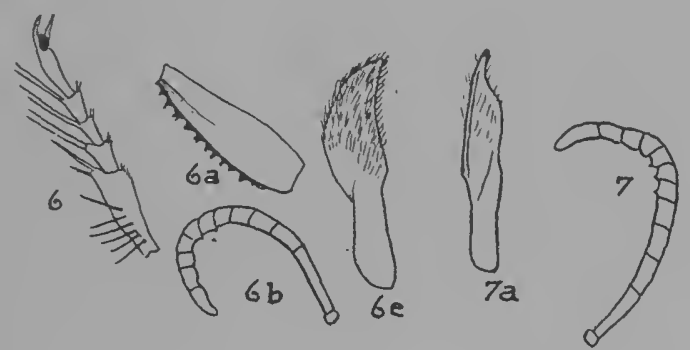

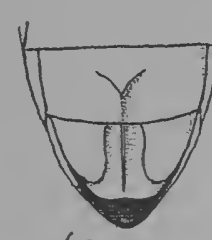

$6 c$
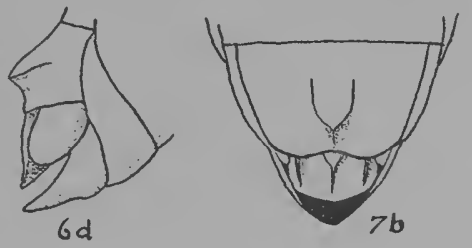

Fig. 6. Bembex atrospinosa, $\hat{o}$, anterior tarsus, ventral view; $a, \hat{o}$, left middle femur; $b$, $\delta$, flagellum; $c$ and $d, \hat{\delta}$, sixth and seventh sternites; $e, \delta$, outer paramera, right half from above.

Fig. 7. Bembex albofasciata, $\hat{0}$, flagellum; $a, \hat{\sigma}$, outer paramera, right half; $b, \hat{\sigma}$, sixth and seventh sternites.

femora rufescent and streaked with black above, the middle and hind tibiae with a narrow black line on the outside. Tegulae fuscous, with a yellow spot in front. Wings hyaline, the veins black. Pilosity and pubescence whitish, the former fairly long and dense on the vertex and epinotum. Mesonotum, mesopleurae and scutellum closely and microscopically punctured, the epinotum a little more strongly but still finely punctured. Tergites $x-6$ finely and shallowly punctured, moderately shining, the seventh with a sparse and fairly strong puncturation. Second sternite very finely, shallowly and closely 
punctured and dull at the base, somewhat rugulose near the apical margin, the other sternites shining, with a sparse and shallow puncturation. Eyes almost parallel. Clypeus convex, not flattened in front, about twice as wide in front as long. Second joint of the flagellum slender, four and a half times longer than wide at the apex, two and a half times longer than the third; seventh and eighth joints with a very small spine at the base, the apical joint curved, attenuated apically and longer than the penultimate joint. Interocular distance on the vertex equal to the length of the first three joints of the flagellum plus half of the fourth joint. Vertex fairly deeply impressed on each side of the ocellar area. Second sternite with a very high and broad, compressed tooth, rounded at its apex. Sixth sternite with a triangular platform, which is acute at the apex. Seventh sternite with a median longitudinal carina. Seventh tergite narrowly truncate at the apex, its ventral flaps large and wide. Basal joint of the anterior tarsi slightly dilated outwardly at the apex, where it has two yellowish spines; a large space separates the latter from six black spines on the basal half which are inserted on the middle line of the joint and not on the outer margin as usual. Middle femora serrate along the whole of their posterior margin, the teeth black. Outer paramera of the genitalia wider on the apical half than on the basal, rostrate and finely pilose.

. $17 \mathrm{~mm}$. long. Yellow markings on the head and thorax deeper than in the $\delta$, lemon yellow. Posterior margin of the pronotum and scutellum yellow. Legs pale ferruginous above, ochreous below. Clypeus with two small black spots at the base, the flagellum ferruginous below, brownish above. The bands on the first five tergites not quite so pale as in the $\hat{\sigma}$, having a tinge of yellow. First sternite ferruginous, sixth tergite black at the base, reddish yellow apically. Second joint of the flagellum slender as in the $\delta^{*}$. Interocular distance on the vertex equal to the length of the first three joints of the flagellum. Sternites $I-5$ microscopically and closely rugulose and dull; the sixth shining, except at the base, and with a sparse, coarse puncturation. Sixth tergite narrowly rounded at the apex. Basal joint of the anterior tarsi with eight long spines on the outer margin, the basal three ferruginous and shorter than the others, which are black. Vertex shallowly impressed at the sides of the ocellar area.

Willowmore, C. P. (Dr H. Brauns).

\section{ALBOFASCIATA Group.}

Face wide. Eyes feebly divergent below.

o. Middle femora dentate, middle tibiae with one spur, middle tarsi normal. Second sternite with a tooth, the sixth with a platform, the seventh with a carina on each side.

․ Second sternite with fine and coarse puncturation.

Closely allied to the atrospinosa group, from which it differs chiefly by the puncturation of the second sternite in the $q$ and by the shape of the genitalia in the $\hat{o}$.

Including albofasciata Smith. The two species speciosa Arn. and cultrifera Arn. may be provisionally attached to this group.

B. albofasciata Smith (figs. 7, $7 a$ and b, Plate VI, figs. I, 2). Ann. Mag. N.H. XII, p. 296, ơ. 1873 .

B. Karschii Handl. Loc. cit. p. 742, 7 , ㅇ.

๙. I $8 \mathrm{~mm}$. long. Very similar in colour to atrospinosa, but differing therein as follows. The clypeus has a large, rhomboid black spot on each side of the base. All the femora are black above, the middle in the basal half and the 
hind femora excepting the apex are black also below. Tibiae black on the inside, the anterior pair also with a short black streak on the outside. The bands on the abdomen are lacteous as in atrospinosa, but are more dilated at the sides. The puncturation of the thorax is stronger than in that species, but still fairly fine. The sternites are much more strongly punctured, and moderately shining, the punctures largest on the second sternite. Eyes as in atrospinosa, the interocular distance on the vertex the same as in that species. Vertex not deeply impressed at the sides of the ocellar area. Second joint of the flagellum three and a half times longer than wide at the apex, three-fifths longer than the third; sixth to eighth joints feebly spined at the base, the ninth to eleventh moderately excavated below, the apical joint slightly curved and longer than in atrospinosa, being nearly twice as long as the penultimate. Second sternite with a compressed tooth, not so high as in atrospinosa, and ending in a blunt right angle. Sixth sternite with a semi-elliptical platform in the middle, the seventh with a carina on each side and a small triangular platform in the middle at the base. Seventh tergite semi-elliptical, coarsely punctured and shining, its ventral flaps small and not covering the seventh sternite. Spines of the tarsal comb whitish, the basal joint with six spines on the outer margin. Middle femora serrate along the whole of their posterior margin. Outer paramera not so wide in the apical half as in atrospinosa.

f. $19 \mathrm{~mm}$. long. The pale colour on the face and legs is chrome yellow, and the whole of the scape is of that colour. Posterior margin of the pronotum, sides of the mesonotum, narrow transverse bands on the posterior margin of the scutellum and metanotum, the lateral margins of the median area of the epinotum and the pale bands on the abdomen, chrome yellow. Sixth tergite black at the base, ochreous elsewhere, its sides with blackish setae. Pubescence and pilosity on the vertex and mesonotum pale fulvous. Labrum and clypeus sparsely and rather strongly punctured. Second joint of the flagellum three-fourths longer than the third. Interocular distance on the vertex equal to the length of the first four joints of the flagellum. Second sternite dull, with a close and fine puncturation intermixed with larger, shallow and oblique punctures, a narrow median longitudinal line impunctate. Third to sixth sternites dull, more closely and more finely punctured than the second, the sixth with a scattered and larger puncturation in addition. Sixth tergite triangular, closely striato-punctate, the apex narrowly rounded. Basal joint of the anterior tarsi with seven spines on the outer margin, the basal spine short and thin.

De La Rey and Johannesburg, Transvaal: Cape Province.

\section{$B$. speciosa n.sp. (figs. 8, $8 a-e$ ).}

1. $19 \mathrm{~mm}$. long. Closely allied to albofasciata, the sculpture, pilosity and shape of the abdominal fasciae being as in that species. Black. Mandibles except at the apex, labrum, clypeus and the rest of the head with markings like those of albofasciata but of a lemon yellow colour. Scapes yellow excepting a small black spot at the apex above. Flagellum fusco-ferruginous above, ochreous below excepting the second joint which is pale lemon yellow. Pronotum, excepting a broken black band in front, and the greater part of the sides and lower surface of the thorax, lemon yellow; the hind margin of the mesopleurae, a spot at their middle, the margins of the epimerum and the anterior margin of the sides of the epinotum, more or less black. Sides of the mesonotum and two clavate streaks on its anterior half, posterior margin of the scutellum, anterior and posterior margins of the metanotum and the median area of the epinotum excepting the base, pale lemon yellow. Abdominal 
bands lemon yellow, but paler in the middle, more abruptly dilated at the sides than in albofasciata. Apical margin of the sixth tergite and sternite, seventh tergite except in the middle, and apical half of the seventh sternite, ferruginous. Genitalia ferruginous, the apical fourth of the outer paramera pale yellow. Legs chrome yellow with small black spots or streaks above on the femora and base of the tibiae. Sculpture very much like that of albofasciata but the mesonotum is closely and obliquely punctured and somewhat transversely rugulose. Clypeus slightly flattened in front. Scapes two and a half times longer than wide, much thicker than in albofasciata in which they are nearly three and a half times longer than wide. Second joint of the flagellum nearly three times longer than wide at the apex and about one-half longer than the third, seventh to tenth joints feebly dentate on the posterior margin, the tenth and eleventh excavated below, the apical joint excavated at the base below, curved and obliquely truncate at the apex. Eyes slightly divergent below. Interocular distance on the vertex nearly equal to the length of the first four joints of the flagellum. Second sternite with a high compressed tooth, rounded
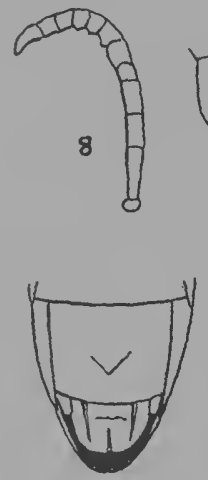

$8 b$

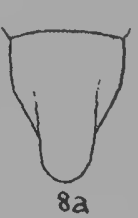

82
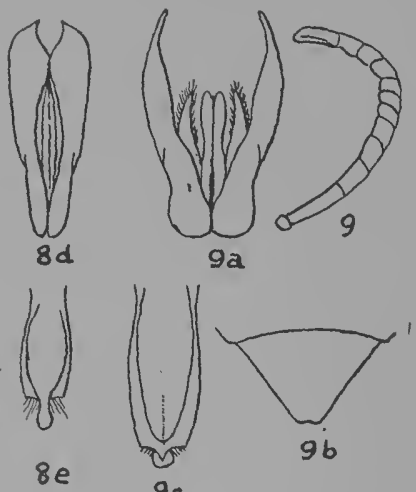

$9 c$

Fig. 8. Bembex specios $a, \hat{\sigma}$, flagellum; $a, \hat{o}$, seventh tergite; $b$ and $c, \hat{o}$, sixth and seventh sternites; $d, \hat{o}$, genitalia; $e, \hat{o}$, eighth sternite seen from above.

Fig. 9. Bembex cultrifera, $\hat{\sigma}$, flagellum; $a, \hat{o}$, genitalia; $b$, $\hat{o}$, seventh tergite; $c, \hat{o}$, eighth sternite from above.

at the apex; sixth sternite with a very low triangular platform, the seventh with widely separated lateral carinae and a low median carina on the apical half, and transversely impressed at the base. Seventh tergite like that of albofasciata, semi-elliptical, but narrower and more parallel-sided, coarsely but not closely punctured. Anterior tarsi simple, the basal joint with seven whitish spines on the outer margin and a very thin short one at the base. Middle femora strongly and irregularly serrate behind, the teeth yellow; middle tibiae with one spur, slightly swollen near the middle and produced outwardly into a point at the apex. Outer paramera of the genitalia only slightly widened over the apical half, rapidly acuminate towards the apex.

․ $19 \mathrm{~mm}$. long. Very much like albofasciata $\circ$ and with the same colour pattern on the abdomen, excepting the sixth tergite which is ferruginous. The coloration of the head and thorax is similar to that of the $\sigma^{*}$, but the clypeus is black at the base, the flagellum black above, ochreous below excepting the lemon yellow second joint, and the yellow colour of the thorax is deeper or chrome yellow. The mesonotum has a clavate yellow streak on each side near the middle and a transverse one at the base; these may be very small 
or absent and are never so greatly developed as to unite to form a $\mathbf{U}$-shaped mark. The yellow on the epinotum is more extensive than in the $\delta$, the declivity being all yellow except for a $\mathbf{V}$-shaped black mark outside the median area. The black markings on the legs are more extensive than in the $\delta$. The superficial resemblance to albofasciata is very great, but the colour of the sixth tergite and the sides of the thorax which are mostly yellow and the carinate sixth sternite suffice to distinguish the species on closer examination. Eyes distinctly divergent below. Second joint of the flagellum three-fifths longer than the third. Interocular distance on the vertex equal to the length of the second, third and fourth joints of the flagellum or nearly equal to the length of the first four. Second sternite closely punctured all over, finely so at the base, the apical half slightly shining and with a larger but still fairly fine puncturation. Sixth sternite with a distinct median longitudinal carina. Sixth tergite coarsely and closely punctured, distinctly narrower in the apical half than in albofasciata ․ Basal joint of the anterior tarsi with seven long yellowish spines on the outer margin, not including the thin and short one at the base. Otherwise like the $\sigma^{*}$.

Gwaai, Victoria Falls and Matopos, S. R. January to February (G.Arnold); Sanyati Valley and Bulawayo (R. H. R. Stevenson). Types in the Rhodesia Museum.

By the structure of the genitalia this species falls within the albofasciata group, but it is an aberrant member on account of the closely punctured second sternite of the ?.

\section{B. cultrifera n.sp. (figs. 9, $9 a-c$; Plate VI, figs. 4, 44).}

o. I 5-I $8 \mathrm{~mm}$. long. Colour pattern very much like that of speciosa but the pale bands on the abdomen are dirty lacteous as in albofasciata, and the seventh tergite is ferruginous only at the sides and apex. The sides of the thorax are mainly black, the mesopleurae have a $Y$-shaped yellow mark only on the anterior lower angle. The pale bands on the scutellum and metanotum are wider than in speciosa, that of the scutellum nearly always interrupted in the middle. The epinotum is entirely black. Legs yellow except for a small black spot at the base of the middle and hind tibiae, and the upper side of the hind femora which is very pale reddish. Flagellum brownish red above, ochreous below. Wings hyaline, the veins blackish. Sculpture of the mesonotum stronger than in either albofasciata or speciosa, without transverse rugulosity, the punctures larger and nearly round. Sternites punctured in the same way as in speciosa. Seventh tergite with a shallow, irregular and large puncturation. Second joint of the flagellum a little more than three times longer than wide at the apex, half as long again as the third; fifth to eleventh joints slightly excavated below, the joints simple or without distinct spines on the posterior margin, the twelfth joint curved, not attenuated, blunt at the apex and nearly twice as long as the preceding joint. Interocular distance on the vertex equal to the length of the first four joints of the flagellum. Second sternite with a strong median carina which ends in a sharp tooth a little before the hind margin. Sixth and seventh sternites as in speciosa, but the triangular platform on the sixth is narrower and more acute at the apex. The eighth sternite has an apical process not unlike that of speciosa. Seventh tergite broadly triangular, narrowly truncate at the apex. Genitalia quite different from those of speciosa, the outer paramera being cultrate, gradually narrowed from the middle towards the apex, where they are thin and acute. Basal joint of the anterior tarsi with seven yellow spines on the outer margin; the middle femora dentate along the whole of the hind margin, the teeth 
yellow; the middle tibiae with one spur and not produced into a point on the outside.

ㅇ․ $\mathrm{r}^{8} \mathrm{-r} 9 \mathrm{~mm}$. long. Very much like speciosa 우, from which it may be distinguished as follows. Flagellum brownish red above. Anterior femora with a black streak above, the middle and hind pair pale reddish above. Mesonotum without yellow streaks on the disc. Mesopleurae, metapleurae and sides of the epinotum black, the mesopleurae with a reversed cuneiform yellow macula on its upper half. Declivity of the epinotum entirely black. Yellow bands on tergites $x-5$ not shallowly bisinuate on their anterior margins as in speciosa, but abruptly bi-emarginate. Sixth tergite ferruginous at the sides and apex, yellow in the middle and with a black spot on each side of the base. Second sternite with the middle part shining, coarsely and sparsely punctured, dull, closely and finely punctured at the sides. Sixth sternite subcarinate only over the apical half. Eyes less divergent below than in speciosa. Second joint of the flagellum three-fourths longer than the third. Interocular distance on the vertex equal to a little more than the length of the first four joints of the flagellum. Puncturation of the mesonotum coarser, and of the median area of the epinotum finer than in speciosa. Otherwise like the $q$ of that species.

Bulawayo. December (R. H. R. Stevenson). Types in coll. Stevenson. (R.M. coll.)

\section{SCAURA Group.}

Eyes distinctly divergent below; the face rather narrow.

o. Basal joint of the anterior tarsi dilated, the spines inserted not on the outer margin but between the latter and the middle line of the joint. Middle femora dentate on the posterior margin; middle tibiae with one spur. Second and sixth sternites armed, the seventh with a median carina. Genitalia quite unlike those of any other member of the genus, the apical half of the outer paramera very broad. Apical joint of the flagellum very long and strongly twisted.

ㅇ. All the sternites dull, very finely and closely punctured. Including scaura Arn., a large, robust species allied to the atrospinosa group by the structure of the anterior tarsi in the $\sigma^{*}$.

\section{B. scaura n.sp. (figs. Io, Io $a-e$; Plate VI, fig. $5^{\mathrm{I}}$ ).}

o. 2 I mm. long. Black. Mandibles except at the apex, labrum, clypeus, sides of the face, a triangular area between the antennal sockets extending to, and uniting with a transverse sinuate bar below the ocelli, posterior orbits, posterior margin and sides of the pronotum, posterior half of the tegulae and a large macula below them on the mesopleurae, pale lemon yellow. (In one specimen there are two black spots at the base of the clypeus.) Scapes and flagellum ochreous, the two basal joints of the latter and a streak on the upper side of the scapes, black. First five tergites with moderately sinuate lacteous bands, narrowed in the middle, the sixth tergite, except at the base, chrome yellow; the seventh with a large apical spot of the same colour. (In one specimen the sixth tergite has a yellow band interrupted in the middle.) Legs pale yellow, the upper side of the femora and narrow streaks on the tibiae, black. Wings hyaline, the veins dark brown. Pubescence and pilosity white. Labrum and clypeus with silvery pubescence. The shape of the pale bands on the tergite are like those of atrospinosa. Puncturation of the thorax very fine and close, but not so fine as in atrospinosa. Tergites $I-6$ finely and very shallowly punctured, the seventh coarsely and closely punctured except at the 
apex. Sternites moderately shining, the second to fourth and the sixth with a shallow and fairly large puncturation, the fifth closely and very finely punctured. Clypeus and labrum impunctate. Clypeus convex, slightly flattened in the middle in front, about twice as wide as long. Exes distinctly divergent below. Face unusually narrow. Interocular distance on the rertex equal to the length of the first four joints of the flagellum; the vertex fairly deeply impressed at the sides of the ocellar area. Second joint of the flagellum nearly two and twothird times longer than the third, and three times longer than wide at the apex; serenth to trelfth joints deeply excavated below, the eighth to tenth with two small spines on the lower hind margin, the eighth to eleventh strongly produced in front apically, the twelfth strongly twisted and about twice as long as the penultimate. Second sternite with a large, compressed and rounded

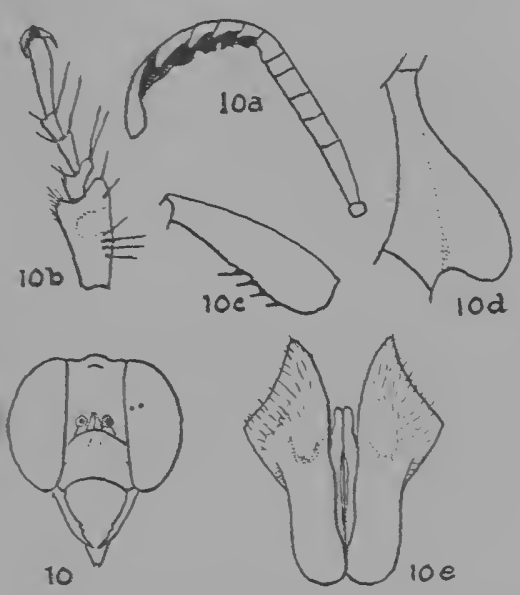

Fig. Io. Bembex scaura, $\hat{o}$, head; $a, \hat{o}$, flagellum; $b, \hat{a}$, anterior tarsus; $c, \hat{o}$, middle femur; $d, \hat{o}$, second sternite; $e, \hat{o}$, genitalia. tooth like that of atrospinosa. The sixth and seventh sternites also as in that species. Seventh tergite wide, rounded at the apex, the sides feebly sinuate. Anterior tarsi similar to those of atrospinosa; the basal joint is distinctly dilated apically, the apex has two short black spines which are separated by a wide space from four slightly longer black spines on the basal half. As in atrospinosa these are not inserted on the outer margin but between the latter and the middle line. Between the two sets of spines there is a whitish, translucent and somerrhat swollen area. Middle femora with four black spines on the posterior margin. Niddle tibiae with one spur, not produced into a point outwardly. Outer paramera of the genitalia very wide, angular at the apex and at the sides in front.

. 2I mm. long. Clypeus with two black spots at the base. Pronotum more extensively yellow than in the $\hat{\jmath}$. Sides of the mesonotum, transverse bands on the posterior margins of the scutellum and metanotum, lateral margins of the median area of the epinotum and median transverse bands on the first fire tergites, chrome yellow. Sixth tergite with a small chrome yellow spot at the apex. The bands on the tergites are more widely dilated at the sides than in the $\hat{o}$. All the sternites dull, very closely and finely punctured. Sixth tergite triangular, closely and fairly strongly punctured, the apex narrowly rounded. Face not quite so narrow as in the $\hat{o}^{\text {. }}$. Interocular distance on the rertex equal to the length of the first three joints of the flagellum plus half of the fourth; the second joint of the flagellum two and a third times longer than the third. Tarsal comb composed of long ferruginous spines, the basal joint broad, about twice as long as wide at the apex, the outer margin with six spines. Otherwise like the 0 .

Sawmills, S. R. I to, April (G. Arnold); I ô also from Sawmills, and I $q$ from Sanyati Valley, S. R. (R. H. R. Stevenson).

Type of $\sigma$ from Sawmills in the Rhodesia Museum, of the $q$ in coll. Stevenson. 


\section{AFRA Group.}

Face wide. Eyes barely divergent below.

${ }_{0}$. Middle femora dentate, middle tibiae with one spur and produced into a point at the apex, middle tarsi simple. Second and sixth sternites with a longitudinal tubercle, the seventh sternite tectiform, with a median carina and short lateral ridges near the base. Seventh tergite widely rounded.

Including afra Handl.

B. afra Handl. (figs. II, II $a$ and $b$; Plate VI, fig. 6). Loc. cit. p. 74I, $o^{t}$.

5. ${ }^{1} 5^{-18} \mathrm{~mm}$. long. Black. Lateral margins of the labrum and clypeus, posterior orbits very narrowly, a thin line on the scapes in front, the upper margin of the pronotum, pronotal tubercles, transverse bands on the first six tergites, that of the first widely, of the following narrowly interrupted in the middle, and very narrow apical bands, widely dilated at the sides, on the second to fourth sternites, pale yellow. Legs yellow, the femora above and a thin line on the outside of the tibiae, black. Wings hyaline, the veins brown. Thorax with a shallow, and not very close semi-puncturation. Sternites coarsely and not closely punctured. Puncturation of the thorax and tergites fairly fine, oblique and close. Eyes nearly parallel. Interocular distance on the vertex equal to the length of the first five joints of the flagellum. The second joint of the latter four-fifths longer than the third, the fifth and sixth slightly dilated on the outer margin, the seventh and eighth feebly spined below, the ninth to eleventh excavated below, the apical joint gradually

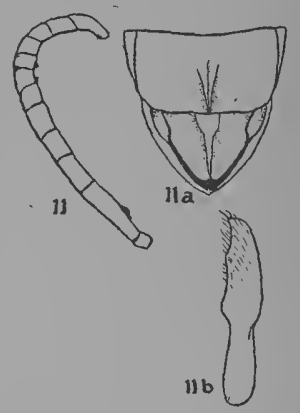

Fig. I1. Bembex afra, $\hat{o}$, flagellum; $a$, sixth and seventh sternites; $b$, outer paramera, left half from above.

narrowed towards its end, transversely compressed and longer than the eleventh. Second sternite with a low median longitudinal carina which is depressed before reaching the apical margin; the sixth with a small median spine, the seventh with a median carina which is flattened at the base. Middle femora distinctly serrate along the whole of the hind margin, the teeth black and acute. Middle tibiae produced into a point at the apex on the outside, and with one spur. Seventh tergite wide, almost semicircular, shining, sparsely and not coarsely punctured.

The description given above is based on a specimen from the Vienna Museum bearing a label "afra m. det. Handlirsch." The seventh sternite does not show the lateral ridges near the base mentioned in Handlirsch's description.

Cape Province.

\section{BIDENTATA Group.}

Eyes distinctly divergent below. Face moderately wide. Wings long.

o. Middle femora sometimes dentate on the hind margin. Middle tibiae without an apical point, with one spur. Second and sixth sternites unarmed, or with small tubercles, the seventh unarmed. The seventh tergite with a welldeveloped tooth on each side near the base.

o. Second sternite usually finely punctured in the middle.

Including Moebii Handl., odontopyga Turner and Scotti Turner. 
B. Moebii Handl. (figs. ${ }^{3} 3, \mathrm{r}_{3}$ a; Plate VI, fig. 7). Loc. cit. p. 775, ơ,.+ B. testaceicauda Cam., Ann. Trans. Mus. II, p. I44. Igro.

t. 16-20 mm. long. Black. Labrum, clypeus, scapes, mandibles excepting the apex, sides of the face and a triangular area between the antennal sockets, two small spots below the ocelli, posterior orbits, sides and posterior margin of the pronotum, the sides of the mesonotum adjacent to the tegulae, a more or less triangular mark on the mesopleurae in front of the epimerum, and the legs, chrome yellow. A streak above and below on the hind femora and the extreme base of the hind tibiae, black. Tergites $\mathrm{x}-5$ with bands across the middle, varying from pale whitish yellow to lemon yellow in colour, that on the first always widely interrupted in the middle, those on the second to fourth bisinuate and usually narrowly interrupted in the middle, that of the fifth usually entire. The apical margin of the sixth tergite, and sometimes also of the fifth, ferruginous. Seventh tergite deep chrome yellow, blackish at the base. Sternites $2-5$ with yellow apical bands narrowed and infuscated in the middle, the sixth and following sternites flavo-ferruginous. Flagellum brownish black above, flavo-ferruginous below. Wings hyaline, faintly tinged with brownish yellow, more particularly the upper margin of the radial and the lower margin of the cubital cells; veins dark brown. Pilosity whitish, fairly long and abundant,

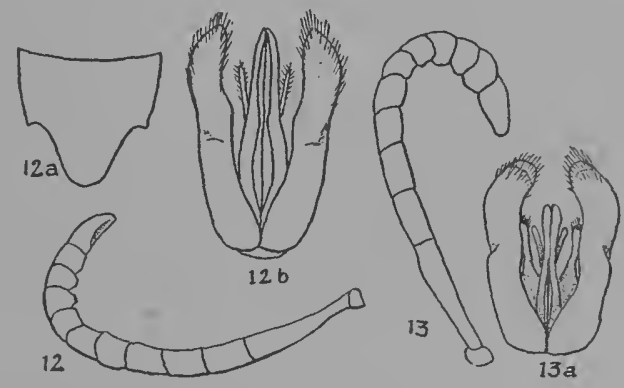

Fig. 12. Bembex odontopyga, $\hat{0}$, flagellum; $a, \hat{o}$, seventh tergite; $b, \hat{o}$, genitalia.

Fig. I3. Bembex Moebii, ô, flagellum; $a$, ô, genitalia.

yellowish on the mesonotum. Sternites with fulvous pubescence and small tufts of long hairs of the same colour in the middle of the fourth and fifth, the sixth with fulvous pilosity all over. Thorax very closely and finely punctured, the tergites less closely. Second sternite closely and fairly finely punctured, only the median carina, which ends in a low and acute tooth, being shining and impunctate. Third and following sternites sparsely and not coarsely punctured. Clypeus very convex transversely, usually subcarinate at the base. Eyes moderately divergent below. Scapes short and thick, subovate, less than twice as long as wide. Second joint of the flagellum five and a half times longer than wide at the apex and nearly twice as long as the third, the sixth to twelfth joints excavated below, the eighth to eleventh slightly dilated, the apical joint short, about half as long again as the preceding joint and not much narrowed apically. Interocular distance on the vertex equal to the length of the first three joints of the flagellum. Sixth sternite with a low, small and triangular platform, often obsolete or nearly so. Seventh tergite triangular, widely rounded at the apex, with a rectangular tooth on each side at the base. Tarsal comb long, composed of stiff yellow spines, of which there are seven on the basal joint. Middle femora excised at the apex of the hind margin, the lower 
angle of the excision forming a distinct tooth. The outer paramera of the genitalia are very distinctly curved inwards apically, blunt at the apex, the apical half clearly convex on the dorsal face.

․ $17-21 \mathrm{~mm}$. long. Basal half of the clypeus often rufescent or with two reddish brown spots. Scapes reddish yellow above. The mesonotum has two longitudinal streaks of yellow near the middle in front and a transverse one, often broken into two, at the base. Posterior margins of the scutellum, metanotum and epinotal dorsum with narrow yellow bands. The sides of the thorax are in greater part yellow, only the epimerum and base of the mesopleurae, posterior margin of the metapleurae and posterior margin of the sides of the epinotum being black. The bands on the tergites are wider and paler than in the $\vec{t}$, distinctly bisinuate and entire. Sixth abdominal segment flavo-ferruginous, blackish at the base. Tibiae more or less suffused with ferruginous colour on the outside. Otherwise coloured like the $\hat{\sigma}$. Mesonotum more strongly punctured than in the $\sigma^{*}$, fairly closely so in front but less so on the posterior half and on the scutellum, which are slightly shining. Sternites shining, the second and third sparsely and coarsely punctured in the middle, closely and fairly finely at the sides, the fourth, fifth and sixth finely so at the base, fairly coarsely and sparsely punctured elsewhere. Sixth tergite triangular, widely rounded at the apex, without lateral teeth at the base, closely punctured, the punctures large at the base and becoming smaller and fairly shallow towards the apex. Labrum very distinctly and sparsely punctured. Clypeus subcarinate at the base, slightly flattened in the middle in front. Eyes not so strongly divergent below as in the $\sigma^{x}$. Second joint of the flagellum nearly six times longer than wide at the apex and nearly two and a third times longer than the third. Interocular distance on the vertex equal to the length of the first three joints of the flagellum. Scapes thick as in the $\sigma^{t}$, but clavate rather than ovate. As in the $o^{A}$ the ocellar area is rather flat. Tarsal comb composed of reddish yellow spines, of which there are seven on the basal joint. Otherwise like the $t$.

Delagoa Bay: Victoria Falls, Sawmills, Sanyati Valley and Umtali, S. R. September to December.

Two specimens from the Sanyati Valley and Sawmills (coll. Stevenson) are very much dwarfed, one a $\delta^{t}$, measuring only $13 \mathrm{~mm}$. long, and a $q$ I $5 \mathrm{~mm}$. This species is partial to shady situations for its nests, such as ant-bear holes and the sandy ground under dwellings built on piles. (R.M. and T.M. colls.)

B. odontopyga Turner (figs. 12, I2 $a$ and $b$; Plate VI, fig. 8). Ann.Mag. N.H. XIX, p. 439 , o. 1917 .

o. I $9 \mathrm{~mm}$. long. Black. Base of the mandibles, labrum, clypeus excepting two black spots at the base, scapes below, sides of the lower half of the face, and the temples, pale ochreous yellow. Transverse maculae, narrowed inwardly, on the sides of the second to fourth tergites, a bisinuate band on the apical half of the fifth, a band on the sixth and a small spot on each side of the seventh, chrome yellow. The extreme apical margins of the tergites fuscoferruginous. The apical margins of the second to fifth sternites with chrome yellow bands which are dilated at the sides. Apex of the seventh sternite reddish brown. Legs yellow, the middle and hind femora below and the tibiae outwardly, black. The hind femora are also black above. Wings hyaline, the veins black. Head and thorax with whitish pilosity and pubescence, the mesonotum and abdomen with short brownish pubescence. Thorax very finely and closely punctured, more closely on the mesopleurae than elsewhere, most finely on the mesonotum and scutellum which are slightly shining. Tergites closely and finely punctured; sternites slightly shining, fairly closely, obliquely 
and not coarsely punctured. The second sternite is not carinate but has a median longitudinal and shining line, widening towards the base. Seventh tergite strongly punctured, closely so on the basal half. Eyes divergent below. Interocular distance on the vertex equal to the length of the first three joints of the flagellum plus half of the fourth. Second joint two and a half times longer than the third, the ninth and tenth joints truncate on the outer margin and excavated below like the eleventh and twelfth; the latter is slightly curved, rounded at the apex and three-fourths longer than the penultimate joint. Seventh tergite with a short tooth on each side near the middle, the apical half beyond the teeth narrowed, broadly rounded at the apex. Sixth and seventh sternites unarmed. The genitalia differ from those of Moebii by the flatter outer, and the longer inner paramera. Anterior tarsi normal, the basal joint with seven reddish yellow spines; fore and middle femora not serrate.

Ngara and Fort Jameson, Nyasaland; Sanyati Valley, Penkridge and Mutambara, S. R. (R. H. R. Stevenson).

\section{B. Scotti Turner (Plate VI, fig. 9). Ann. Mag. N.H. IX, p. 371, ô. I9I2.}

. $16 \mathrm{~mm}$. long. Black. Labrum, clypeus excepting two black spots at the base, sides of the face and two spots below the anterior ocellus, yellowish white. Basal half of the mandibles, the carina between the antennae, temples, pronotum, sides of the mesonotum and a $U$-shaped mark on the middle of same, sides and ventral surface of the thorax, posterior half of the scutellum, the metanotum and an arcuate band on the epinotum, lemon yellow. A spot on the lower part of the mesopleurae and narrow lines margining the sclerites of the pleura are black. Tergites $1-5$ with lemon yellow bands, wider at the sides than in the middle and bisinuate except on the first. Sixth tergite yellow, black at the extreme base, the apical margin slightly ferruginous. Sternites yellow, black at the extreme base, the second with a median black spot. Legs yellow. Wings hyaline, the veins fusco-ferruginous. Face and clypeus with a thin silvery pubescence. Pilosity of the head and thorax white, scanty and short. Mesonotum and scutellum shining, very sparsely and finely punctured, the epinotum a little more closely punctured. Sixth tergite strongly punctured. Sternites shining, fairly strongly and sparsely punctured, especially in the middle. Eyes nearly parallel. Interocular distance on the vertex equal to the length of the first four joints of the flagellum plus half of the fifth joint. Clypeus subcarinate at the base, the apical half flattened in the middle. There is a short carina between the antennal sockets. Second joint of the flagellum a little more than twice as long as the third, the apical joint blunt and hardly longer than the preceding joint. Tarsal comb long, the basal joint with seven spines.

5. $16 \mathrm{~mm}$. long. Seventh tergite with a yellow spot at the base. The colour pattern is like that of the of but the yellow is paler, or olive yellow. Tarsi, tibiae and femora simple. The four apical joints of the flagellum are excavated below, the twelfth joint is a little longer than the eleventh, curved, rounded at the apex; ninth to eleventh joints produced below at the apex, the sixth joint at the apex and the seventh at the base, thickened. Second sternite simple, the sixth feebly carinate on the apical half, the apex emarginate, the seventh simple. Seventh tergite with a tooth on each side near the base. Otherwise like the $q$.

Zungeru, Nigeria.

A small species with the livery of $B$. ulula Arn., for which at a first glance it might be mistaken. 


\section{Io. DIVERSIPENNIS Group.}

Face narrow, the eyes strongly divergent below. Wings fairly long.

o. Second sternite with a small longitudinal tubercle, the sixth armed, the seventh with two parallel and widely separated longitudinal carinae.

q. Second sternite smooth and shining in the middle, without fine puncturation.

Including diversipennis Smith, ugandensis Turner, Bequaerti Arn., and venusta Arn.

B. diversipennis Smith (Plate II, fig. 4, vol. XI, part I; figs. I4, I4 $a-c$ ). Ann. Mag. N.H. xII, p. 297, ô, ‥ 1873 .

B. Fohnstoni Turner. Ann. Mag. N.H. x, p. 372, ô. 1912. Turner, Ann. Mag. N.H. XIX, p. 437. I9I7.

o. 24-25 mm. long. Black. Labrum, mandibles excepting the apex, anterior third of the clypeus and sides of the face narrowly, pale whitish yellow; the temples chrome yellow. Ocellar area black, the rest of the head including the eyes, ferruginous. Antennae pale ferruginous, the scapes blackish in front. Pronotum, tegulae, sides of the mesonotum and a mark on the sides of the epinotum anteriorly, ferruginous. Pronotal tubercles yellow behind. Tergites $\mathrm{I}-6$ with large chrome yellow maculae on each side, the apical margin of the fifth, the sixth excepting the lateral maculae and the whole of the seventh, ferruginous. Apical half of the sixth and all the seventh sternite, ferruginous. The black areas of the tergites have a distinct steely blue lustre. Legs ferruginous, the middle and hind femora yellowish above at the apex, the anterior

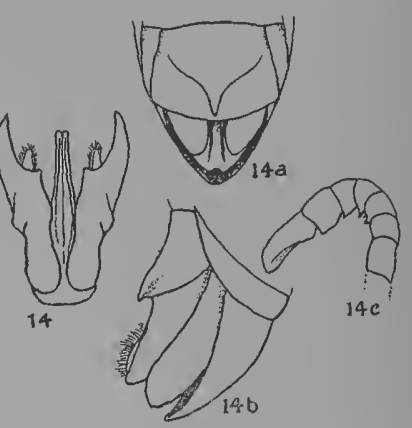

Fig. 14. Bembex diversipennis, 0 , genitalia; $a$ and $b$, $\hat{\sigma}$, sixth and seventh sternites; $c$, $\sigma^{7}$, apical joints of the flagellum. coxae lemon yellow below, the apical joint of the anterior tarsi black above, of the other tarsi black over the apical half; claws black. Wings hyaline, the veins fusco-ferruginous. Pilosity and pubescence white, short and scanty, except on the temples, anterior coxae, posterior margin of the anterior femora and sides of the thorax, where it is long. Mesopleurae fairly strongly and closely punctured, the mesonotum very finely and closely punctured. Sternites shining, the second coarsely and not closely punctured at the sides, a narrow median area at the base almost impunctate. The following sternites are very sparsely punctured in the middle, fairly closely at the sides. Clypeus convex, not flattened in front, subcarinate at the base. Eyes moderately divergent below. Scapes a little more than twice as long as wide. Second joint of the flagellum a little more than twice as long as the third and about four times longer than wide at the apex; seventh to twelfth joints dilated, the sixth to ninth slightly, and the tenth to twelfth deeply excavated below, the seventh to ninth feebly dentate behind, the apical joint moderately curved, bluntly pointed at the apex and twice as long as the penultimate joint. Interocular distance on the vertex equal to the length of the second and third joints of the flagellum. Second sternite with an acute curved spine in its apical half; sixth sternite with a low triangular platform which is acute at the apex and projects slightly beyond the posterior margin of the segment; seventh sternite with a curved carina on each side. Seventh tergite broad, narrowly rounded 
at the apex, fairly closely and strongly punctured. Basal joint of the anterior tarsi with seven or eight ferruginous spines. Anterior femora excavated below over the basal half, middle femora excavated below over the apical two-thirds, middle tibiae flattened below, without a large spur and not produced to a point at the apex. The basal joint of the middle tarsi is feebly and angularly dilated close to the base. Outer paramera of the genitalia acute at the apex, strongly angulated on the outside at about the middle. (The figure 6, Plate II, in Handlirsch's monograph is inaccurate and misleading, the apical portion of the paramera having been drawn too slender and too abruptly narrowed from the basal portion.)

9. $22-24 \mathrm{~mm}$. long. Face entirely ferruginous, somewhat paler at the sides and on two spots below the ocellar area, but not whitish yellow as in the $\hat{c}^{\text {. }}$. Scapes without a black mark below. Pronotal tubercles entirely ferruginous. Lateral maculae on the tergites paler than in the $\hat{\delta}$, pale lemon yellow or whitish yellow; sixth abdominal segment and apical margin of the fifth tergite, ferruginous. Basal two-thirds of the fore wing and nearly the whole of the hind wing strongly tinged with dark brown. Sternites shining, very coarsely and sparsely punctured in the middle, more finely and more closely at the sides. Otherwise like the $\hat{o}$ in colour and sculpture. Eyes very slightly divergent below. Second joint of the flagellum nearly twice as long as the third, and four and a half times longer than wide at the apex. Interocular distance on the vertex equal to the length of the first three joints of the flagellum. Sixth tergite triangular, narrowly rounded at the apex. Middle femora and tibiae not excavated below. Otherwise like the $o_{0}^{t}$.

Central Africa from Angola to Uganda, and southwards as far as the Transvaal and S.W. Africa (Tsumeb). (R.M. and T.M. colls.)

$B$. venusta $\mathrm{n} . \mathrm{sp}$. (figs. $\mathrm{r}_{5}, \mathrm{r}_{5} a-d$; Plate VI, figs. 35,47 ).

o. $24 \mathrm{~mm}$. long. Black. Mandibles excepting the apex, labrum, clypeus, the whole of the scapes, face, vertex excepting the ocellar area and a bilobed macula below it, temples, pronotum excepting a ferruginous band in front,

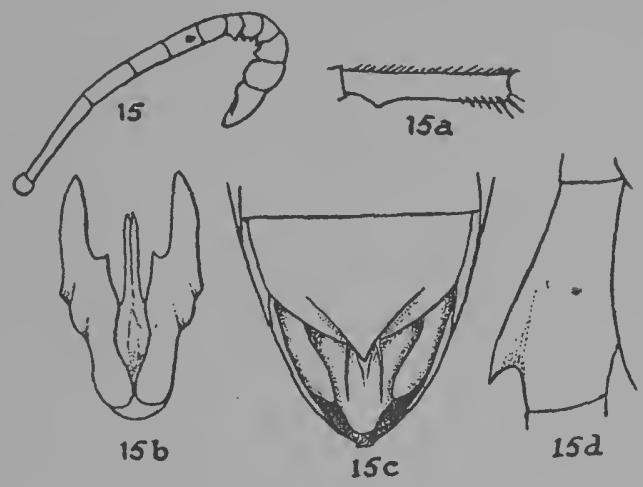

Fig. I5. Bembex venusta, $\hat{0}$, flagellum; $a, \hat{o}$, middle tarsus, basal joint; $b, \hat{o}$, genitalia; $c$, $\sigma^{*}$, sixth and seventh sternites; $d, \hat{o}$, second sternite.

sides of the mesonotum opposite the tegulae, posterior two-thirds of the scutellum, metanotum excepting the extreme posterior margin, the dorsum of the epinotum excepting the base and an arcuate black band outside the median area, chrome yellow. Flagellum pale ferruginous. Tergites $\mathrm{I}-6$ chrome yellow, the first four with apical black bands angularly dilated in the middle, 
the fifth and sixth with narrow ferruginous apical bands, the first black on the declivous face and with two round black spots on the brow, the second and third each enclosing black maculae. Seventh tergite black at the extreme base, ferruginous in the middle and yellow at the apex. Sternites black, the apical third of the sixth sternite ferruginous. Legs yellow, the anterior femora above, the middle femora except on the posterior margin and the hind femora, ferruginous. The hind femora are somewhat blackish below and the apical joint of all the tarsi is in greater part black. Wings hyaline, the veins ferruginous. Pilosity of the head and thorax whitish, noticeably dense on the lower half of the temples, on the anterior coxae and on the posterior margin of the anterior femora. Mesonotum finely, closely and shallowly punctured. Sternites $2-6$ coarsely and sparsely punctured, more coarsely in the middle than at the sides. Seventh tergite closely and fairly strongly punctured basally, the apical half sparsely punctured. Clypeus slightly flattened in the middle in front. Inner margins of the eyes distinctly divergent below. Face sharply carinate between the antennal sockets. Second joint of the flagellum five and a half times longer than wide at the apex and nearly twice as long as the third, the sixth emarginate behind apically, the seventh and ninth spinose, the eighth bispinose posteriorly, the seventh to twelfth dilated, especially the tenth, eleventh and twelfth, the last six excavated below; the apical joint subtriangular, half as long again as the penultimate. Interocular distance on the vertex nearly equal to the length of the second and third joints of the flagellum, or to that of the first and second plus half of the third. Second, sixth and seventh sternites like those of diversipennis but the triangular platform on the sixth is wider. The genitalia are similar to those of diversipennis but the apical portion of the outer paramera is broader and less acute at the apex. The structure of the legs is the same as in diversipennis.

․ $23 \mathrm{~mm}$. long. Labrum and anterior half of the clypeus yellowish white, the basal half of the latter pale ochreous. Scapes ochreous. Face and vertex, excepting the black ocellar area, posterior orbits and anterior half of the pronotal collar, reddish or brownish ochreous. Tergites I-5 with the black at the base and apex more extensive than in the ${ }^{x}$, so that the yellow bands are more deeply sinuate, those of the fourth and fifth more or less interrupted in the middle; sometimes the black indentations at the base of the second and third are separated from the extreme base, forming discrete maculae on each side of the middle. Sixth tergite black at the base, ferruginous at the apex. Wings as in diversipennis o, but the brown cloud is not quite so dark as in that species. Eyes less divergent below than in the $\delta$. Interocular distance on the vertex equal to the length of the first three joints of the flagellum. The second joint of the flagellum is nearly five and a half times longer than wide at the apex. Sixth tergite closely punctured, more finely so than in the $\hat{o}$, the basal half also somewhat striolate lengthwise. Basal joint of the anterior tarsi with six ferruginous spines. Otherwise like the $\hat{o}$.

Kamanyab, S.W. Africa, I $\sigma^{\top}$, type; Ombombo, S.W. Africa, I of $^{-}$Ongandjera, Otjimbumbe and Erickson's Drift, S.W. Africa, I $\sigma^{t}, 8$ $\rho$. Type of $q$ from Ongandjera. Types in the South African Museum.

B. ugandensis Turner (figs. I6, I6 a-c; Plate VI, figs. 10, 50). Trans. Ent. Soc. London, p. 746, ò, ๆ. 1912.

o. $23 \mathrm{~mm}$. long. Black. Basal half of the mandibles, labrum, lateral and anterior margins of the clypeus, sides of the face, two spots below the ocellar area, scapes below, temples, sides of the pronotum, a spot on the mesopleurae above, an arcuate band on the epinotal dorsum, sides of the epinotal dorsum 
posteriorly and transverse bands on the first three tergites, lemon yellow. The band on the first tergite narrowed medially, the second with an oblong black spot on each side of the middle, the third narrow, widest in the middle. Legs yellow, the anterior tibiae outwardly, the femora above and below basally, black; tarsi reddish yellow. Wings hyaline. Clypeus with a few large punctures on the anterior half. Puncturation of the thorax close and oblique, of the tergites also oblique, finer and less close than on the mesonotum. Second sternite sparsely and coarsely punctured and shining, the lateral margins more closely punctured, the remaining sternites similarly punctured but less coarsely than the second in the middle, excepting the sixth. Pubescence and pilosity brownish grey, the fourth to sixth tergites with black pubescence. Clypeus subcarinate at the base. Eyes moderately divergent below. Interocular distance on the rertex equal to the length of the first four joints of the flagellum. Second joint of the flagellum twice as long as the third, the apical joint two-thirds longer than the preceding joint. Extreme apex of the sixth tergite smooth and rounded. Tarsal comb composed of long ferruginous spines, of which there are six on

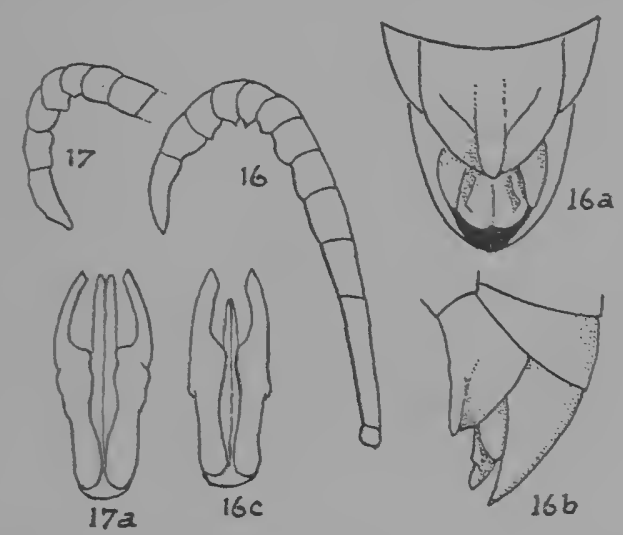

Fig. 16. Bembex ugandensis, $\hat{\jmath}$, flagellum; $a$ and $b$, $\hat{b}$, sixth and seventh sternites; $c, \hat{o}$, genitalia.

Fig. 17. Bembex Bequaerti, $\hat{o}$, flagellum; $a$, $\hat{o}$, genitalia.

the basal joint; the latter is black on the outer half and two and a half times longer than wide at the apex.

o. $23 \mathrm{~mm}$. long. Colour pattern like that of the $q$, but the yellow on the tergites is much paler, more of an olive yellow. The yellow lateral streaks of the face are wider. Second joint of the flagellum two and a quarter times longer than the third, the eighth and ninth with a spine below on the outer margin, the tenth and eleventh concave below, the apical joint twice as long as the penultimate, slightly curved, narrowed to the apex and moderately concave below at the base. Interocular distance on the vertex as in the $q$. Second sternite with a low median carina which ends before the apical margin in a small angular tubercle. Sixth sternite raised in the middle to form an oblong, smooth platform, highest at the apex, which is rounded. Seventh sternite with a low longitudinal carina on each side, widely separated and slightly divergent apically. Seventh tergite rather long, the sides and apex shining and sparsely punctured, the lateral margins convex and rather suddenly narrowed just before the apex which is widely rounded. Middle femora with two or three denticles near the apex. Otherwise like the $q$. 
Uganda, Mbale district (S. A. Neave); Entebbe (G. C. Gowdey); Mayolo, Beni, Belgian Congo (J. Bequaert). Types in the British Museum.

\section{B. Bequaerti n.sp. (figs. 17, I 7 a ; Plate VI, figs. 36,37 ).}

o. $23 \mathrm{~mm}$. long. Dull chrome yellow. Mandibles excepting the apex, labrum, clypeus, and the scapes excepting a narrow black streak above, yellow; the sides of the face and the temples brownish yellow. Flagellum black, brownish yellow below. Mesonotum with a longitudinal black bar on each side, widest in the middle, and extending from the anterior to the posterior margin; in the middle there is another black bar, roundly dilated posteriorly, and not reaching the posterior margin. Anterior half of the scutellum black, and the base of the median area of the epinotum also black. The declivous face of the first tergite black at the base and in the middle, the brow of the declivity with two small black spots. The apical margins of the first six tergites with a very narrow dark reddish brown band, the second and third tergites each with two ill-defined, transverse and brownish maculae; the first sternite, base and apical margin of the second, apical halves of the third, fourth and fifth sternites stained with pale brownish yellow. The fourth, fifth and sixth sternites have median black spots at the base, the tubercle of the sixth is also black, and the seventh excepting its apex. Legs yellow, the femora with a pale reddish tinge. Wings hyaline, with a faintly smoky tint, the veins ferruginous excepting the costa and subcosta which are black. Pilosity on the head, thorax and first tergite yellowish grey, short on the mesonotum, fairly long and dense on the temples, anterior coxae and mesosternum. Dorsum of the thorax very finely and very closely punctured, almost reticulate-punctate, the mesopleurae even more finely punctured than the mesonotum. Sternites $2-4$ shining, coarsely and fairly sparsely punctured in the middle, closely and rather finely at the sides, the fifth and sixth nearly dull, finely and closely punctured except near the apical margin where there are a few large punctures. Tergites $I-6$ with a very fine, short and black pubescence, and rery finely punctured. The seventh tergite fairly closely punctured at the sides. Clypeus slightly flattened in the middle in front, subcarinate at the base. The face is very distinctly carinate between the antennal sockets. Eyes strongly divergent below. Second joint of the flagellum four times longer than wide at the apex and two and a third times longer than the third joint, the eighth to eleventh moderately dilated and also excavated below, the apical joint moderately curved, twice as long as the eleventh, acute at the apex. Interocular distance on the vertex equal to the length of the first three joints of the flagellum plus half of the fourth. Second sternite with a feeble carina which ends in a small tooth some distance from the apical margin. Sixth sternite with a narrow triangular platform ending in an acute point, not much raised above the rest of the segment, like that of ugandensis but more acute. Seventh sternite with a longitudinal carina on each side and a trace of a median one, the lateral carinae are nearer together than in ugandensis and less divergent apically. Seventh tergite elongate triangular, not sinuate at the sides, the apex rather narrowly rounded. Basal joint of the anterior tarsi with six yellow spines. The middle femora are somewhat concave below, so that their cross-section is triangular, the posterior margin trenchant but not serrate or dentate.

ㅇ. $24 \mathrm{~mm}$. long. Chrome yellow. Apex of the mandibles, two round spots at the base of the clypeus, face excepting the sides, the base and a triangular spot below the ocellar area, the vertex and occiput, black. A transverse band across the front of the pronotal collar, the mesonotum excepting the lateral 
margins and two narrow longitudinal streaks extending over the anterior two-thirds, the anterior and posterior margins of the scutellum and of the post-scutellum, the base of the median area of the epinotum and an arcuate band on the outside of it and an arrow-shaped mark on the mesosternum, black. Tergites $\mathrm{I}-5$ chrome yellow, with a black apical band which is widest in the middle, the first black at the base, the black joining the apical band in the middle, the second and third each enclosing two transverse and fairly large black maculae, the fourth and fifth with a bilobed black band at the base, the sixth black and with a thin yellow streak on each side. Sternites yellow, the second with the middle third black, yellow at the sides, the third to sixth black, the third to fifth also with triangular yellow maculae at the sides. Legs yellow, a streak on the anterior and middle femora above, and the extreme base of the tibiae above, black. Second sternite shining, coarsely and very sparsely punctured in the middle, moderately closely and much more finely at the sides. Sternites 3-5 finely but not very closely punctured, moderately shining, with a few larger punctures on their apical halves. Sixth sternite dull, very finely and closely punctured, with a median longitudinal carina on its apical half. Sixth tergite closely and fairly strongly punctured, triangular, the sides slightly sinuate, the apex narrowly rounded. Eyes not quite so strongly divergent below as in the $x$. Second joint of the flagellum nearly four and a half times longer than wide at the apex and twice as long as the third joint. Interocular distance on the vertex as in the $\hat{o}$. Tarsal comb composed of long, thick reddish yellow spines, of which there are six on the basal joint. Otherwise like the $\hat{o}$.

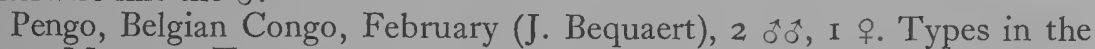
Congo Museum, Tervueren.

In spite of the considerable difference in the colour patterns, this species is closely allied to ugandensis. The flagellum is very similar, but the eighth and ninth joints are not clearly spinose, and the outer paramera of the genitalia have their apical portion narrower and more arcuate than in ugandensis.

\section{B. Bequaerti, var. dira n.v. (Plate VI, figs. 38, 39).}

0 . Of the same size and robust build as the type of the species, but with the yellow colour less pronounced. The clypeus has a black spot on each side at the base, the sides of the face are chrome yellow, the scapes are black above, the whole of the mesonotum excepting the lateral margins is black and the transverse black bands on the scutellum, metanotum and epinotum are much wider. The mesopleurae are black in front below the pronotal tubercles, and round the margins of the epimerum. The mesosternum is black. The apical black bands on the first six tergites are wider than in the type of the species, and all enclose two sharply defined transverse black maculae. The seventh tergite has the apical margin and sides black. The yellow markings on the sternites are much reduced. The apical joints of the tarsi are black above as well as below. The median carina of the seventh sternite is more distinct than in the type of the species.

q. The melanism in this sex is more marked than in the $\mathrm{o}$. The mesonotum lacks the two longitudinal median streaks of yellow which are present in the type of the species and the scutellum has only a short triangular yellow mark on each side. The difference between this variety and the type of the species is made clear by a comparison of the figs. 36,37 and 38,39 in Plate VI.

Stanleyville, Belgian Congo. I $\delta^{x}$, I + , March (J. Bequaert). Types in the Congo Museum, Tervueren. 


\section{MONEDULA Group.}

Face wide. Eyes distinctly divergent below. Wings long.

ot. Middle femora not dentate on the hind margin. Second and sixth sternites with small longitudinal tubercles, the seventh without a distinct carina.

ㅇ. Second sternite shining in the middle, only coarsely punctured.

Including monedula Handl., and albidula Turner.

B. albidula Turner (figs. I8, I8 $a$; Plate VI, fig. I2). Ann. Mag. N.H. xrx, p. 438,0 . 1917 .

o. $24 \mathrm{~mm}$. long. Black. Basal half of the mandibles, labrum, clypeus at the sides, in front and narrowly in the middle, scapes below, sides of the face as far as two spots of the same colour below the anterior ocellus, temples, prosternum, sides of pronotum including the posterior margin of the pronotal tubercles, the posterior angles of the epinotum and a spot on the upper margin of the declivity, yellowish white. Abdomen black, with a distinct violaceous tint. The first four tergites with yellowish white maculae on each side, narrowed outwardly and abruptly so inwardly, the fifth tergite with maculae of the same colour narrowed inwardly and meeting in the middle, the sixth with a transverse spot of whitish yellow on each side.

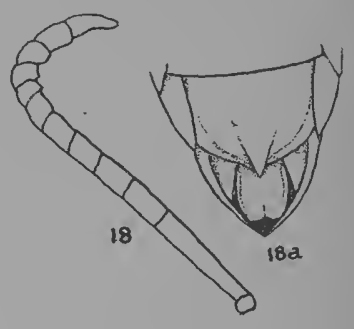

Fig. 18. Bembex albidula, $\widehat{o}$, flagellum; $a$, $\hat{o}$, sixth and seventh sternites.

The second and third sternites with a small yellowish white spot on each side. Anterior coxae and apical half of the middle coxae yellowish white, the tibiae and anterior femora of the same colour, the former with black streaks above and below and the latter black at the base; middle and hind femora in greater part black. Tarsi dirty white above, fuscous below, the apical joints and the outer margins of all the tarsal joints of the fore legs black. Wings hyaline, the veins black. Pilosity on the head white and fairly long. Eyes divergent below. Clypeus subcarinate at the base. Interocular distance on the vertex equal to the length of the first three joints of the flagellum. The second joint of the flagellum is two and a quarter times longer than the third, the eighth and ninth with a slight tooth at the base, the tenth and eleventh feebly concave below, the twelfth half as long again as the eleventh. Second to fifth sternites shining, sparsely, coarsely punctured in the middle, more finely and closely at the sides. Sixth sternite fairly dull and finely punctured, with a few large punctures on the apical half. Second sternite like that of ugandensis, the sixth with a triangular platform acute at the apex. Seventh sternite without distinct carinae, but the lateral margins are slightly swollen. Seventh tergite triangular, narrowly rounded at the apex, closely punctured at the base, sparsely so at the apex. Femora unarmed.

Mussaia, Sierra Leone.

B. monedula Handl. (fig I9; Plate VI, fig. I I). Loc. cit. p. 789, ๙, o.

"Eyes distinctly divergent below, the face distinctly carinate between the antennae, the clypeus fairly convex, slightly flattened in front. Antennae about as far from each other as from the eyes, almost cylindrical in both sexes, the antepenultimate joints in the $\sigma$ not spinose and not excavated. Wings distinctly infuscated, the veins blackish, two and a half times longer than the width of the thorax in front, the medial cell in the hind wing emitting 
two longitudinal veins at the apex. Legs robust, anterior tarsi normal, the basal joint with six spines on the outer margin, middle femora not dentate below, the middle tibiae in the $\vec{o}$ without a large anterior spur. Abdomen fairly long,...the sixth tergite in the $q$ without a pygidial area, widely rounded at the apex, the seventh tergite in the of wide, almost truncate at the apex, the sides sinuate. Second and sixth sternites in the $\hat{j}$ armed with small and acute tubercles, the seventh indistinctly carinate, the eighth with a long and acute apical spine. Genitalia of a singular shape. Thorax with a short and dense brown pilosity, fairly coarsely and irregularly punctured.

Body black, with a violaceous lustre on the abdomen; the anterior orbits narrowly and the posterior widely, the labrum, anterior margin and sides

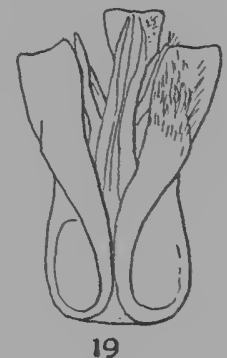

Fig. I9. Bembex monedula, $\hat{o}$, genitalia (after Handlirsch).

of the clypeus and large lateral spots on the first four or five tergites, yellow. Antennae black, the scapes more or less pale below. Legs black. 22-27 mm. long. Delagoa Bay."

The only example which I have seen is a from the British Museum. I have copied Handlirsch's figure of the genitalia, which are quite distinct from those of any other African species.

\section{ARNOLDI Group.}

Eyes parallel. Face wide. Head, thorax and first tergite densely pilose.

0 . Antennae filiform, all the joints of the flagellum cylindrical. Legs normal, the middle tibiae with a large spur. Sternites $x-6$ simple and very finely punctured, the seventh with a median carina.

f. Second sternite shining, sparsely and coarsely punctured in the middle, finely and fairly closely at the sides.

Including Arnoldi Brauns.

\section{B. Amoldi Brauns (figs. 20, $20 a$; Plate VI, fig. I 5).}

o. If mm. long. Black. Mandibles except at the apex, labrum, clypeus, scapes below, sides of the face and the temples in front, pale lemon yellow. The aper of the femora below, the tibiae below and the tarsi pale lemon yellow, the last joint of the tarsi ochreous. Flagellum pale brown below. Wings hyaline, the veins ferruginous. Head, excepting the labrum and clypeus, thorax and first tergite densely clothed with a white pilosity; the remaining tergites with a fairly conspicuous whitish pubescence. Thorax and tergites finely and closely punctured, except the seventh tergite which is coarsely so. Sternites dull, finely and closely punctured, all of them simple except the

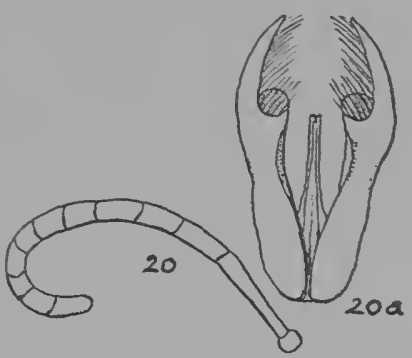

Fig. 20. Bembex Arnoldi, ô, flagellum; $a$, ô, genitalia. seventh which has a fine median longitudinal carina. Clypeus very convex and prominent. Scapes slightly clavate, fully three times longer than wide. Second joint of the flagellum twice as long as the third, all the joints cylindrical, the apical joint bluntly rounded at the apex, about half as long again as the 
penultimate. Vertex very wide, the interocular distance there being equal to the length of the first five joints of the flagellum plus half of the sixth. Basal joint of the anterior tarsi with six whitish spines on the outer margin. Seventh tergite broadly rounded at the apex, the sides very distinctly sinuate. Outer paramera of the genitalia abruptly narrowed at about the apical third, acute at the apex, the narrow portion fringed with long hairs on the inner margin. The genitalia strongly resemble those of the Palaearctic cinctella group, with which, however, this species has no relationship.

․ I $5 \mathrm{~mm}$. long. Black. The sides of the clypeus and labrum suffused with dirty yellow. There are two ochreous spots below the ocelli, and the temples are narrowly lemon yellow in front. Posterior margin of the pronotum at the sides and the lateral margins of the mesonotum opposite the tegulae, yellow. First tergite with a yellow streak on each side, narrowed inwardly; tergites $2-5$ with bisinuate lemon yellow bands. Femora black, with the anterior margin yellow, but only on the apical half on the hind femora. Tibiae black below and on the outer margins, yellow elsewhere, tarsi dirty yellow, suffused with brown underneath. Pilosity and pubescence on the head, thorax and first tergite abundant as in the $\delta$, but of a brownish white colour, on the vertex and mesonotum pale brown. Sternites fairly shining, coarsely and sparsely punctured in the middle, finely and fairly closely at the sides, the sixth rather sparsely and not very finely punctured. Sixth tergite triangular, narrowly rounded at the apex, shining, closely and fairly finely punctured. The sixth sternite is subcarinate lengthwise in the middle. Second joint of the flagellum three-quarters longer than the third. Interocular distance on the vertex equal to the length of the first four joints of the flagellum, plus two-thirds of the fifth. The vertex is deeply depressed on each side of the ocellar area. Tarsal comb composed of long blackish spines, of which there are six on the basal joint.

Zwartkops and Jeffery's Bay, C. P. November (Dr H. Brauns). Types in coll. Brauns.

According to Dr Brauns's observations this species is confined to sand dunes on the seashore. The $q$ is exceedingly like carinata ?.

\section{I3. MELANOPA Group.}

Face wide, the eyes barely divergent below. Wings fairly long.

o. Middle femora dentate behind, often indistinctly or only near the apex; middle tibiae with a spur. Second and sixth sternites with longitudinal carinae or tubercles, the seventh with a carina.

. Second sternite shining in the middle, with coarse puncturation only.

Including melanopa Handl., forcipata Handl., labidura Handl. and carinata Smith.

B. melanopa Handl. (figs. 2I, 2 I $a-c$; Plate VI, figs. I6, I7). Loc. cit.p. 797, ơ, + .

. I $5-17 \mathrm{~mm}$. long. Black. Sides of the labrum occasionally, and the middle of the mandibles, dirty yellow, two spots below the ocelli ochreous, the posterior orbits narrowly lemon yellow. A triangular mark on each side of the first tergite and bisinuate bands on the second to fifth tergites lemon yellow, that on the fifth usually interrupted in the middle. Legs yellow, the anterior tibiae and tarsi on the outside, the anterior femora on the outside and below, the middle femora above and at the base below, the middle tibiae behind, the hind femora above and below, the hind tibiae on the inside and a narrow line above, black. The apical joints of all the tarsi blackish. Wings 
hyaline, the veins brown. Last three or four joints of the flagellum brownish yellow below. Pilosity on the head and thorax whitish and fairly dense, the clypeus with a dense white pubescence. Mesonotum shallowly and fairly closely punctured, slightly shining. Sternites fairly coarsely punctured, sparsely so in the middle, much more closely at the sides, especially on the second sternite. Clypeus very convex and prominent, subcarinate at the base, slightly flattened in the middle in front. Face feebly carinate between the antennal sockets. Eyes parallel or nearly so. Vertex wide, deeply impressed on each side of the ocellar area. Interocular distance on the vertex equal to the length of the first five joints of the flagellum. Scapes thick. Second joint of the flagellum about one-half longer than the third, the fifth feebly, the sixth to ninth distinctly spinose on the posterior margin, the ninth to eleventh dilated and also excavated below, the apical joint curved, gradually narrowed towards the blunt apex and longer than the penultimate. Second sternite with a median longitudinal carina, slightly rising posteriorly and ending in a rounded angle. Sixth sternite with a narrow triangular platform, the seventh longitudinally carinate orer its apical third. Seventh tergite strongly and closely punctured, very widely rounded at the apex. Basal joint of the anterior tarsi with six

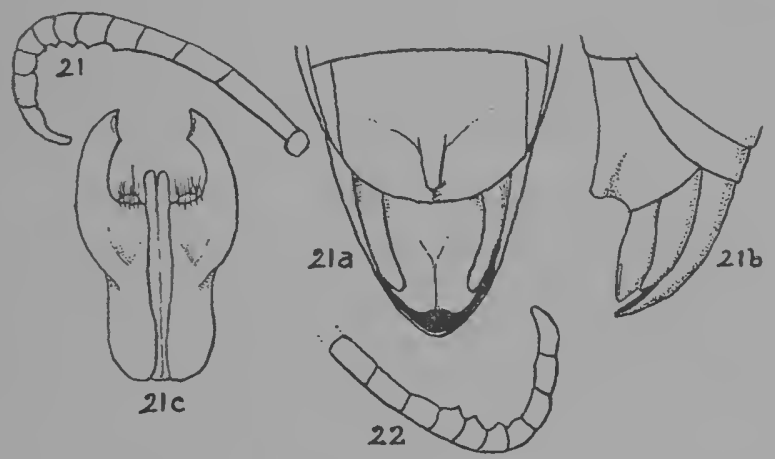

Fig. 21. Bembex melanopa, $\hat{0}$, flagellum; $a$ and $b, \hat{\sigma}$, sixth and seventh sternites; $c, \hat{\sigma}$, genitalia.

Fig. 22. Bembex carinata, $\hat{0}$, flagellum.

black spines. Middle femora with two or three teeth on the posterior margin near the apex. The shape of the yellow fasciae on the abdomen is decidedly variable. The commonest pattern is shown in fig. I7, Plate $\mathrm{I}$, but sometimes the bands are wider and much less deeply bi-emarginate in front.

o. $16 \mathrm{~mm}$. long. Posterior margin of the sides of the pronotum sometimes narrowly yellow. A very narrow line on the posterior margin of the scutellum and an arcuate one on the posterior margin of the median area of the epinotum, pale yellow. Basal joint of the middle and hind tarsi fuscous on the inside, the apical joint of all the tarsi brownish. Tergites $\mathrm{I}-5$ with dull whitish bands, not yellow as in the ${ }_{0}$. Those on the first and fifth usually reduced to a triangular mark on each side, that of the second enclosing a transverse black spot on each side. Puncturation like that of the 0 , but the second sternite has shallow and very large punctures in the middle. Apical half of the sixth sternite subcarinate longitudinally in the middle. Sixth tergite closely punctured except near the apex, where it is shining and more sparsely punctured. Second joint of the flagellum three-quarters longer than the third. Interocular distance on the vertex as in the $\delta^{*}$. Basal joint of the anterior tarsi with seven black spines, the basal spine shorter than the others. 
Natal, Delagoa Bay and S. Rhodesia. (R.M. and T.M. colls.)

Some specimens from Algoa Bay (C. B. Krüger), in the Stevenson coll. appear to be sufficiently distinct to be separated as a race, and to furnish such a direct link between melanopa and forcipata Handl., as to reduce the latter also to the rank of a subspecies.

\section{B. melanopa race litoralis n.r.}

This differs from the type of the species as follows.

In both sexes the pilosity on the head and thorax is yellowish grey or pale fulvous as in forcipata, but unlike the latter the sides of the thorax are black as in melanopa. The mesonotum is quite dull and the puncturation on it closer and finer than in melanopa.

o. Labrum, sides and anterior margin of the clypeus and the scapes below, lemon yellow. The pale bands on the abdomen are distinctly yellow, not yellowish white as in the type of the species, and the bands on the second and third tergites do not enclose oblong black spots, although they are deeply emarginate in front. The yellow of the legs is also deeper than in the type of the species.

0. Spines of the tarsal comb pale yellow. Apical joint of the flagellum less narrowed, rounded at the apex, not truncate as in the type of the species. Second sternite much more finely punctured, the median longitudinal carina much less dereloped. Sixth sternite with the median platform much narrower, hardly triangular. The genitalia are exactly like those of the type of the species.

B. melanopa race forcipata Handl. Loc. cit. p. 798, ot, o.

"Very much like and related to melanopa, the thorax a little less strongly punctured, distinguished by the yellowish grey pilosity and by the colour of the head and thorax. Black; the anterior and posterior orbits broadly, the face between the antennae, clypeus excepting often two small spots in the $\sigma^{t}$ and a large median spot in the $q$, labrum excepting a median line in the $q$, margins of the pronotum and the pronotal tubercles, large spots on the sides of the prothorax, mesothorax and epinotum, often the posterior angles of the mesonotum, a narrow band on the scutellum in the of (more rarely in the of), the greater part of the epinotum in the $q$, maculae on the first segment, fasciae on the second and third segments and often enclosing black spots, sinuate fasciae on the fourth and fifth, and lateral spots on the sixth in the $\alpha$, pale yellow. Antennae black. Scapes yellow in front; legs pale yellow, more or less variegated with black towards the base. I 5-20 mm. long. This form agrees so closely with the preceding (melanopa) in all structural characters and even in the genitalia that I would not venture to separate them if the slight difference in the puncturation of the thoracic dorsum and the more yellowish grey pilosity were not considered in conjunction with the constant colour differences and the different geographical distribution. Possibly one is dealing only with a local race."

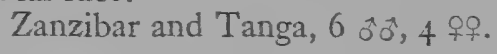

B. carinata Smith (fig. 22; Plate VI, figs. I3, I4). Cat. Hymen. B.M. Iv, p. 323 , ‥ 1856 .

B. venator Smith. Cat. Hymen. B.M. Iv, p. 323 , o. 1856 .

o. $16 \mathrm{~mm}$. long. Black. Labrum, mandibles excepting the apex, clypeus, scapes below, sides of the face and the temples narrowly, posterior margin of the pronotal tubercles, sometimes a very narrow band on the scutellum, yellow. The clypeus has two small black spots at the base. A transverse macula 
on each side of the first tergite, transverse bisinuate bands on the second to sixth tergites, those of the second and third sometimes narrowly interrupted in the middle, lemon yellow. Legs yellow, the femora black except at the apex, the tibiae with small spots of black on the outside, the basal joint of the fore tarsi black outwardly. Last four joints of the flagellum pale yellow below. Pilosity and pubescence white, the former rather long and abundant on the head and thorax. Dorsum of the thorax dull, closely and finely punctured. Tergites more strongly punctured than the thorax. Second sternite evenly, closely and strongly punctured, the third and fourth very sparsely, the fifth and sixth more closely so, but not as closely as the second. Labrum flattened. Clypeus very convex, not flattened in the middle in front. Eyes parallel. Interocular distance on the vertex equal to the length of the first five joints of the flagellum. The second joint of the latter is about three-fourths longer than the third, the fifth slightly, the sixth to eighth distinctly spined below, the ninth to eleventh dilated, the tenth and eleventh excavated below, the twelfth narrowed to the apex, curved and a little longer than the eleventh. Second sternite with a median longitudinal carina which extends from the base to the apex of the segment; the sixth sternite with a low raised angle in its apical half. The seventh sternite has a feeble median longitudinal carina and is shallowly emarginate at the apex. Seventh tergite coarsely and fairly closely punctured, rounded at the apex. Anterior femora with a very indistinct denticulation at the apex, the middle femora very distinctly dentate along the whole of the posterior margin.

. I $5 \mathrm{~mm}$. long. Labrum often with a black spot at the base. Clypeus with only the sides and anterior margin yellow. Sides of the face almost entirely black. Outer halves of the femora, anterior tibiae and basal joint of the tarsus and inner half of the posterior tibiae, black. Posterior tarsi fuscous on the inside. The yellow bands on the second to fourth tergites are much narrower than in the $\delta$, and much reduced on the first and fifth, on the first sometimes nearly obsolete. Third to fifth sternites, sides of the second and base of the sixth fairly finely and not very sparsely punctured. Otherwise like the $\sigma^{*}$ in colour, sculpture and pilosity. Interocular distance on the vertex equal to the length of the first four joints of the flagellum plus half of the fifth. The second joint is three-fourths longer than the third. Tarsal comb long and black, the basal joint with six spines. Sixth tergite triangular, widely rounded at the apex.

Mossel Bay, C. P.

\section{B. labidura Hand1. Loc. cit. p. 799, ô.}

The following description is based on a cotype "det. Handlirsch" from the Vienna Museum.

o. This differs from melanopa as follows.

Labrum, clypeus, face at the sides and below the antennae, two spots below the anterior ocellus and the scapes excepting a black streak above, yellow. Legs in greater part yellow; fore and middle femora with a black streak above, the hind tibiae with a black streak on the inside. The second to fifth sternites have apical yellow bands, widened laterally and interrupted in the middle. Pronotum, sides of the mesonotum, posterior margin of the scutellum, posterior margin of the epinotal dorsum, mesopleurae excepting the anterior and posterior margins, metapleurae and sides of the epinotum excepting a streak in the middle, yellow. Puncturation of the thorax and abdomen finer and closer than in melanopa. Face narrower than in that species; interocular distance on the vertex equal to the length of the first five 
joints of the flagellum plus half of the sixth. Second joint of the flagellum not quite half as long again as the third, the apical joint two-thirds longer than the eleventh. The triangular dentiform tubercle on the sixth sternite is less acute and less prominent.

․ I 5-17 mm. long. Clypeus and labrum black in the middle, yellow at the margins, face yellow at the sides as in the $\sigma^{7}$. Legs more variegated with yellow than in melanopa. Pale markings on the abdomen distinctly yellow, not yellowish white as in melanopa \%. Metanotum and epinotal dorsum with transverse yellow bands. Inner margins of the eyes parallel, not divergent above and below as in melanopa. Sixth tergite much more closely punctured than in that species. Interocular distance on the vertex equal to the length of a little more than the first four joints of the flagellum. Second joint of the flagellum half as long again as the third. Tarsal comb fusco-ferruginous.

Central Africa; British East Africa, Mombasa and Lake Mpeketoni. Specimens in the Paris Museum from Basutoland (Leg. Ellenberger) which I attribute to this species have the whole head, excepting the posterior orbits and the lateral margins of the labrum, black; the sternites are also black, only the second to fourth having small yellow spots at the sides.

\section{I4. MEDITERRANEA Group.}

Face fairly wide, the eyes feebly divergent below. Wings long.

o. Middle femora usually dentate, middle tibiae with a spur. Second and sixth sternites with tubercles or often only feebly carinate, the seventh with a longitudinal carina.

The characters of this group are very much the same as in the melanopa group, the difference lying chiefly in the shape of the genitalia.

Including, internedia Dahl., Baumanni Handl., capicola Handl., Braunsii Handl., Kriechbaumeri Handl., velox Handl., modesta Handl., massaica Cam. and fraudulenta Arn.

B. intermedia Dahl. (figs. 23, $23 a$ and $b$; Plate VI, fig. I9). Hymen. Eur. I, p. 49 I, No. 27 , 9 . I 845 .

B. olivata Dahl. Hymen. Eur. I, p. 49r, No. 29, ․ 1845 .

o. I $5 \mathrm{~mm}$. long. In greater part yellow and whitish. Head lemon yellow, the apex of the mandibles ferruginous; the ocellar area, the middle of the face excepting a transverse band below the ocellar area and a triangular area behind the clypeus, the back of the scapes and the occiput, black. Flagellum black or dark brown above, pale dull yellow below. Pronotum, excepting a black spot of variable size at the sides, lemon yellow. Mesonotum black, the lateral margins and three streaks in the middle which form a more or less $U$-shaped mark, often incomplete, lemon yellow. Sides of the thorax lemon yellow, the anterior margin of the mesopleurae narrowly, the anterior and posterior margins of the metapleurae, the mesosternum and two spots on the sides of the epinotum, black. Scutellum and metanotum black in front, lemon yellow behind. Epinotal dorsum and declivity black, with arcuate yellow bands of very variable extent across the brow and the base of the declivity. Tergites $I-6$ pale glaucous white, the declivous face of the first and the bases of the second to sixth narrowly black, the apical margins of the first five tergites with a blackish brown band, somewhat dilated in the middle. Seventh tergite black, usually with two pale yellowish spots behind the apex. Sternites black, the apical margins very narrowly, and triangular marks at the sides, pale lemon yellow. The black area on the base of the first tergite sometimes has two or more 
yellow spots in the middle, and on the sternites the yellow sometimes covers the apical half of the segments. Legs yellow, the femora black at the extreme base and with blackish streaks above. A spot on the underside of the anterior tibiae and the apical halves of the anterior tarsal joints, black. Wings hyaline, the veins brown. Face, vertex, thorax and first tergite with a long, dense and yellowish white pilosity. Mesonotum not very closely punctured; seventh tergite fairly strongly punctured at the sides. Second sternite closely, shallowly and largely punctured, almost rugulose-punctate, the punctures being confluent; the remaining sternites shining, very sparsely and fairly finely punctured. Clypeus slightly flattened in the middle in front. Eyes very feebly divergent below. Scapes thick, subtriangular, about twice as long as wide at the apex. Second joint of the flagellum half as long again as the third, and only three times longer than wide at the apex, the eighth to eleventh joints dilated, angular in the middle and also excavated below, the apical joint curved, narrowed slightly towards the apex which is bluntly truncate. Interocular distance on the vertex equal to the length of the first five joints of the flagellum. Second sternite with a low longitudinal carina which does not end in a tooth. Sixth sternite unarmed, the seventh carinate longitudinally in the middle. Seventh tergite triangular, narrowed from the middle to the apex, which is narrowly rounded. Tarsal comb composed of whitish spines, of which there are six on the basal joint. Middle femora dentate along their whole length behind, the teeth small.

f. $15^{-16} \mathrm{~mm}$. long. Clypeus usually with a black spot on each side of the middle. The pale bands on the first five tergites are distinctly pale lemon yellow, not glaucous white as in the $\sigma^{1}$; the second and third usually enclose two transverse black spots near the base. Sixth tergite black, with a large ochreous spot on each side at the base. Otherwise like the of in colour.

Sternites shining, the second very sparsely and largely punctured in the middle, more finely and more closely at the sides, the other sternites finely and sparsely punctured. Scapes cylindrical or moderately clavate, about three times longer than wide at the apex. Second joint of the flagellum four and a half times longer than wide at the apex, not quite half as long again as the third, the apical joint moderately curved, rounded at the apex and twice as long as the penultimate joint. Interocular distance on the vertex as in the $\overrightarrow{0}$. Sixth sternite with a trace of a median carina in its apical half. Sixth tergite triangular, closely and strongly punctured, narrowly rounded at the apex. Otherwise like the $\sigma^{t}$.

Natal, Transvaal, Cape Province and Tanganyika; Sawmills and Sanyati Valley, S. R.; Windhuk, S.W. Africa. (R.M. and T.M: colls.)

Handlirsch rightly synonymised Dahlbom's olivata with this species, but as he does not appear to have seen the type of either, it is difficult to understand why he should have preferred the latter name. The name intermedia has priority since its description in Dahlbom's work precedes that of olivata by a few lines.

Dahlbom's descriptions are exceedingly short and based entirely on colour, and it is not out of the question that they were based not only on this species but also on Baumanni.

\section{B. Baumanni Handl. (figs. 24, 24a). Loc. cit. p. 813, o*}

5. $16 \mathrm{~mm}$. long. Very similar to the preceding species, from which it differs as follows. Apical margins of the first five tergites testaceous. Behind the apical margin is a black band, sometimes adjacent, and sometimes separated by a narrow line, of the same glaucous white colour as the basal part of the segments. 
(In seven specimens before me, the pattern of the tergites is singularly asymmetrical, the bands in many cases traversing only half or three-quarters of the segments.) On the seventh tergite the apical yellowish white mark is much larger than in intermedia. The seventh sternite usually has a yellow spot on each side at the apex; these are also sometimes present in intermedia, but are not so large. The second sternite is carinate longitudinally as in intermedia, but the sculpture is different, the puncturation being larger, more sparse and without rugulosity. The sixth sternite has a short median carina on the apical half, sometimes very feeble or obsolete. The seventh sternite is like that of intermedia. Seventh tergite much wider at the apex and less narrowed in the apical half. The outer paramera of the genitalia are more acute at the apex and

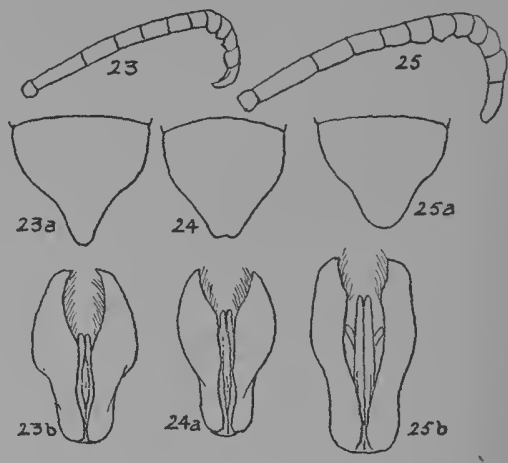

Fig. 23. Bembex intermedia, ${ }^{\star}$, flagellum; $a$, $\hat{o}$, seventh tergite $; b, \hat{\sigma}$, genitalia. Fig. 24. Bembex Boumanni, ô, seventh tergite; $a$, $\hat{o}$, genitalia.

Fig. 25. Bembex capicola, ox, flagellum; $a, 0$, seventh tergite; $b, \hat{o}$, genitalia.

the broad apical portion is widest at the middle and not at the base as in intermedia. The scapes are longer, more cylindrical, but the flagellum hardly differs from that of intermedia although the apical joint is less narrowed towards its end and the eighth to eleventh joints are not quite so dilated. Otherwise like intermedia.

Hex River, C. P.: Windhuk, S.W. Africa. (S.A. Museum.)

B. capicola Handl. (figs. 25, $25 a$ and $b$; Plate VI, figs. 20, 2I). Loc. cit. p. 8I, $\mathrm{o}^{1}$. o. I 7-2I mm. long. Black. The tergites chiefly yellow. Labrum, clypeus, mandibles excepting the apex, base of the face between the antennal sockets, scapes below, posterior orbits narrowly, posterior angles of the epinotum, legs, tergites I -6 excepting the declivous face of the first, the apical margins of the first five, a small black spot on each side of the middle of the second and third, and triangular marks on each side of the apical margins of the second to fifth sternites, lemon yellow. Sides of the face, two round spots below and two triangular spots behind the ocellar area, a band on the posterior margin of the pronotum, pronotal tubercles, tegulae in front, the lateral margins of the mesonotum adjacent to the tegulae, posterior margins of the scutellum and metanotum and an arcuate band, interrupted in the middle, on the brow of the epinotal declivity, yellowish white. Coxae and trochanters black, variegated with yellow. Flagellum black above, ochreous below. Wings hyaline, the veins pale brown. Head, thorax and base of the first tergite with long whitish pilosity. Mesonotum very finely, closely and shallowly punctured, the mesopleurae less closely and less finely, the sides of the epinotum with a shallow and sparse puncturation in the middle. Sternites shining, the second with a sparse and very coarse puncturation, its sides somewhat more finely punctured. Third to sixth sternites a little more finely punctured than the second. Clypeus slightly flattened in the middle in front. Eyes very feebly divergent below. Scapes clavate, about two and a half times longer than wide. Second joint of the flagellum three-fourths longer than the third, the sixth slightly swollen behind, the seventh distinctly dentate on the posterior margin, the eighth to eleventh dilated and also excavated below, the apical joint 
slightly curved, very little narrowed towards the apex and about one-third longer than the preceding joint. Interocular distance on the vertex equal to the length of the first five joints of the flagellum plus half of the sixth. Second sternite with a well-developed median longitudinal carina which ends in a subacute angle before the apical margin. Sixth sternite with a triangular platform somewhat obtuse at the apex, the seventh with a sharp median longitudinal carina. Seventh tergite triangular, the apex widely rounded, the sides slightly sinuate, the puncturation somewhat obliterated in the middle. Anterior tarsi with a comb of yellowish spines, of which there are six on the basal joint. Middle femora not dentate, middle tibiae with one spur.

ᄋ. $17 \mathrm{~mm}$. long. Clypeus with two black spots near the base. Scutellum and metanotum usually entirely black, the arcuate band on the epinotum and the posterior angles of that segment lemon yellow. Tergites $1-5$ with yellow bands across the middle, that on the first interrupted and much narrowed medially, that of the second and also sometimes of the third enclosing two black maculae near the base. The greater part of the femora black at the base, the tibiae with a black streak below. Mesonotum less finely punctured than in the $o$, the sternites sparsely and coarsely punctured, the sixth tergite closely punctured. Sixth sternite with a distinct median carina which almost reaches the base. Scapes less clavate than in the $\hat{o}$, three and a half times longer than wide at the apex. Second joint of the flagellum half as long again as the third. Interocular distance on the vertex equal to the length of the first four joints of the flagellum plus half of the fifth. Tarsal comb pale ferruginous. Otherwise like the ot.

Cape Town, Lady Grey and Grahamstown, C. P.; Johannesburg. (R.M. and T.M. colls.)

B. Braunsii Handl. (figs. 26, $26 a$ and $b$; Plate VI, fig. 22). Loc. cit. p. 81 5, ô, q.

"Similar to, and allied to capicola. The head as in that species, the labrum half as long again as wide, the clypeus fairly prominent. In the $o^{*}$ the ninth and tenth joints of the antennae are slightly spinulose below, the tenth to twelfth distinctly excavated below, the last joint fairly long, curved, rounded at the apex. Wings almost two and a half times longer than the width of the thorax in front, the medial cell of the hind wing emits two longitudinal veins at the apex. Basal joint of the anterior tarsi with six spines. Anterior femora in the ô unarmed, the middle femora crenulate-dentate behind. Tibiae and tarsi normal. Abdomen conical, the sixth tergite in the $q$ smooth at the apex and fairly widely rounded, without a median carinula. Seventh tergite in the $\hat{o}$ fairly narrowly rounded at the apex, the lateral margins not sinuate, the second sternite with a distinct longitudinal carina, the sixth with a small compressed and acute tubercle, the seventh distinctly carinate longitudinally. The

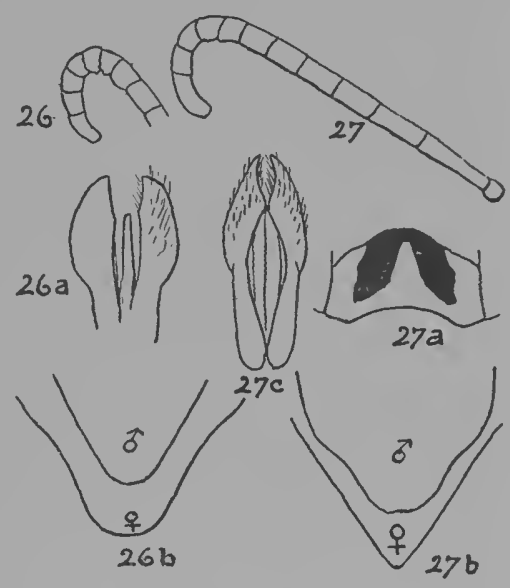

Fig. 26. Bembex Braunsii, ô, flagellum; $a, \hat{o}$, genitalia; $b, \hat{o}$ and $q$, apical tergites (after Handlirsch).

Fig. 27. Bembex Kriechbaumeri, ô, flagellum; $a, q$, clypeus $; b, \hat{o}$ and $q$, apical tergites; $c, \hat{\sigma}$, genitalia. genitalia almost the same as in capicola, the outer paramera almost truncate at 
the apex. Head, thorax and base of the abdomen with a fairly dense, greyish pilosity; thorax above densely and moderately punctured, second sternite shining in the middle, and fairly coarsely punctured. Black; orbits, lower part of the face, the clypeus excepting two basal black spots, labrum, the pronotal tubercles and greater part of the pronotum, lateral margins of the mesonotum and often, in the , two thin streaks on its disc, narrow bands on the scutellum, metanotum and epinotum (almost obsolete in the ô), more or less large maculae on the sides of the thorax and epinotum, a very wide band on the first tergite, emarginate in the $\delta$ and often interrupted in the $q$, very wide bands enclosing two black spots on the second and third tergites, narrower bands bisinuate in front on the fourth, fifth and in the 0 also the sixth and lateral spots on the sternites, deep yellow. Antennae black, pale below towards the base. Legs yellow, variegated with black basally. I 5-18 mm. long."

French Guinea.

I have seen the type of the $q$ in the Braunsian collection. The sixth sternite is somewhat raised lengthwise in the middle but not so much so as to be carinate except close to the apex. The second joint of the flagellum is about one-third longer than the third. The interocular distance on the vertex is nearly as long as the first six joints of the flagellum. The medial cell in the hind wing emits only one longitudinal vein at the apex.

\section{B. Kriechbaumeri Handl. (figs. 27, $27 a-c$; Plate VI, figs. 23, 24). Loc. cit. p.816,} ô, q.

ô. I4-I $5 \mathrm{~mm}$. long. Black. Mandibles excepting the apex, labrum, clypeus excepting two black spots near the base, the sides of the face and its base between the antennae, two spots below the ocellar area and the scapes below, lemon yellow. The posterior orbits whitish yellow. Posterior margin and sides of the pronotum, posterior half of the pronotal tubercles, a streak on the anterior angles of the mesonotum, the lateral margins of the same, the posterior margins of the scutellum and metanotum, an arcuate band, interrupted in the middle, on the epinotal declivity, the posterior angles of the epinotum and a streak on the sides of the same in front, lemon yellow. Tergites $\mathrm{I}-5$ and sometimes also the sixth with broad whitish yellow bands, that on the first narrowed medially, on the second emarginate by the black in front and with a transverse black spot on each side which is sometimes confluent with the black at the base. The apical margins of the first two tergites are distinctly dark brown and not black. Seventh tergite black. Apical margin of the first sternite flavotestaceous, the second and third sternites with large triangular yellow marks at the sides. Legs yellow, the femora blackish, more extensively above than below, the apical half of the anterior coxae and a streak on the anterior tibiae below, black. Flagellum dark brown above, ochreous below. Head, thorax and first tergite with a long, yellowish grey pilosity. Mesonotum and scutellum with a very close fundamental and microscopic puncturation, with which is intermixed a larger puncturation. Sternites shining, sparsely punctured except on the sides of the second, the punctures very shallow, fairly large on the second and third, small on the other sternites. Seventh tergite very finely punctured, the apical third impunctate. Clypeus distinctly flattened in the middle in front. Eyes parallel. Second joint of the flagellum half as long again as the third, all the joints simple, the apical joint not narrowed towards the apex, slightly curved and nearly twice as long as the preceding joint. Interocular distance on the vertex equal to the length of the first four joints of the flagellum plus half of the fifth. Second sternite with a low median carina, the sixth simple, the seventh carinate lengthwise in the middle. Seventh tergite narrowly 
rounded at the apex, the sides feebly sinuate. Basal joint of the anterior tarsi with six spines. The middle femora not dentate on the posterior margin. Outer paramera of the genitalia acute at the apex.

f. I $5 \mathrm{~mm}$. long. Clypeus with a large $\Lambda$-shaped black mark at the base, almost reaching the anterior margin. Mesopleurae with a vertical yellow bar near the posterior margin. Tibiae streaked with black above and below; tarsi reddish ochreous, the basal joint of the posterior pair somewhat fuscous above. In one specimen the first four tergites have transverse lemon yellow bands, the first much narrowed medially, the second and third each enclosing black maculae, and the fourth bi-arcuate and interrupted in the middle (Plate VI, fig. 24). In the other specimen the band on the first is very much narrowed medially and interrupted, the second is broken at the base by a propeller-shaped black macula, the third encloses two black spots, and the fourth to sixth are entirely black. In the first specimen there are two thin yellow longitudinal lines on the anterior half of the mesonotum, and the greater part of the mesopleurae, sides of the epinotum and lower half of the metapleurae are yellow. In both specimens only the second sternite has small yellow spots at the sides. Interocular distance on the vertex as in the $\delta$. Second joint of the flagellum half as long again as the third. Sixth tergite triangular, convex transversely, smooth and shining in the middle and feebly subcarinate over the middle third of its length. Sixth sternite convex transversely, but without any trace of a median carina. Otherwise like the $\hat{0}$.

I have seen three $\sigma^{\top} a$ and two 우 in the Braunsian coll. from Lower Guinea and Liberia, all of which bear Handlirsch's labels as types! B. Silvestrii Maidl (Boll. del. Lab.di Zool. Portici, Ix, p. I49, o, I9I4) is very closely allied to this species if it is not merely a race of it. It differs, to judge by the description and figures, only in having the colour black and dirty white, instead of black and yellow, in the slightly deeper sinuation of the sides of the seventh tergite and in the seventh joint of the flagellum which is feebly angular, hardly spinose, on the posterior margin. The genitalia are the same as in Kriechbaumeri.

\section{Kriechbaumeri, race scitula n.r.}

Three $q$ f from Narugas and Tsintsabis, S.W. Africa, in the South African Museum and numerous specimens from Sawmills, differ from the type in being on the average somewhat smaller, $14 \mathrm{~mm}$. long, and in having the two yellow longitudinal streaks on the mesonotum larger and connected with a transverse streak at the base, forming a distinct $U$-shaped mark. The face is also more extensively yellow, that colour covering the whole face as far as the level of the anterior ocellus excepting two triangular black spots below the ocellus. There are also two yellow spots behind and slightly to the side of the ocellar area; in some specimens these marks are connected by a streak with the yellow below the ocellar area. The mesonotum lacks the fundamental microscopic puncturation present in the type of the species. The apical half of the sixth sternite has a distinct, but low, median longitudinal carina; the sixth tergite has no trace of a carina and is closely punctured all over except just behind the apex.

\section{B. modesta Handl. (figs. 28, $28 a$ and b). Loc. cit. p. $82 \mathrm{I}$, o.}

o. I $5 \mathrm{~mm}$. long. In colour and sculpture this species is very much like the melanic form of labidura from Basutoland. The antennae and sternites do not differ appreciably from those of labidura, although the dentiform tubercle on the sixth sternite is blunt at the apex. The apical half of the posterior margin of the middle femora is irregularly serrate, the teeth small and of 
unequal size, the largest being near the apex. It differs from labidura in having the seventh tergite sinuate at the sides, so that the apical third of the segment is narrower than the rest. The genitalia are of quite a different shape, the outer paramera not having the narrow apical termination which is seen in labidura. Interocular distance on the vertex equal to the length of the first six joints of the flagellum, the second joint of the latter is two-thirds longer than the third. Spines of the tarsal comb all yellow, the basal joint with six spines.

Guinea. (I have seen the type, which is in the Vienna Museum.)
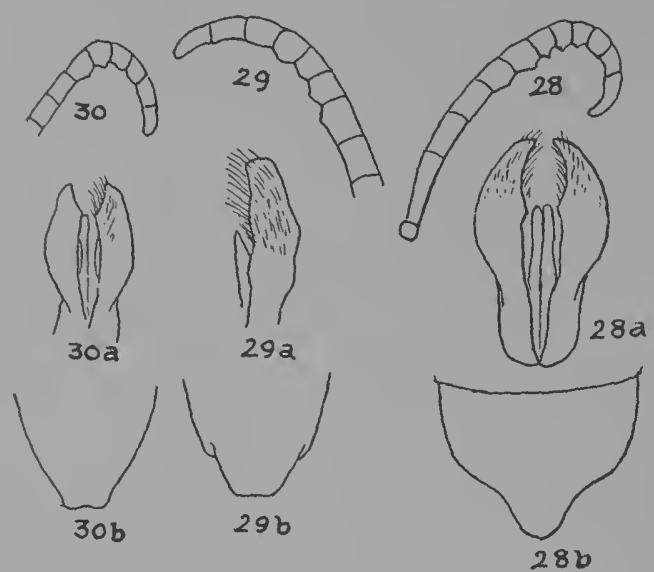

Fig. 28. Bembex modest $a, \hat{o}$, flagellum; $a, \hat{o}$, genitalia; $b, \hat{o}$, seventh tergite.

Fig. 29. Bembex Stadelmanni, $\hat{\sigma}$, flagellum; $a, \hat{\sigma}$, genitalia; $b$, $\hat{o}$, seventh tergite (after Handlirsch).

Fig. $3 \circ$. Bembex velox, $\hat{0}$, flagellum; $a$, $\hat{0}$, genitalia ; $b$, $\hat{o}$, seventh tergite (after Handlirsch).

B. velox Handl. (figs. 30, $30 a$ and b). Loc. cit. p. 819, ot. $^{x}$

"Face wide, carinate between the antennae. Eyes slightly divergent towards the clypeus. Clypeus slightly prominent, evenly convex. Labrum half as long again as wide. Antennae slender, the eighth and ninth joints distinctly spinulose behind, the three following joints distinctly excavated below, the apical joint a little curved, and rounded at the apex. Wings slightly infuscated, the veins dark brown; two and a half times longer than the width of the thorax in front; the medial cell of the hind wing emits two longitudinal veins from the apex. Tarsi normal, the basal joint of the anterior pair with six spines; middle femora serrate-dentate behind, the tibiae not produced at the apex, but with one spur. Abdomen conical, the seventh tergite distinctly emarginate at the apex, barely sinuate at the sides, the second sternite with a low longitudinal carina, the sixth with a very obtuse tubercle, the seventh carinate lengthwise. Outer paramera of the genitalia fairly wide, barely truncate at the apex. Thorax fairly densely and moderately coarsely punctured above, and like the head, with a dense grey pilosity. Black; the anterior orbits widely, the posterior narrowly, the clypeus, labrum, posterior margin of the pronotum narrowly, short streaks on the sides of the mesonotum, a narrow band on the scutellum, a narrow and broken band on the first tergite, a wide one enclosing two black maculae on the second, feebly sinuate bands on the third to fifth and small lateral spots on the sternites, yellow. Antennae black, scapes yellow 
below, legs yellow, the base and the greater part of the femora black. $15 \mathrm{~mm}$. long."

Zanzibar.

B. Stadelmanni Handl. (figs. 29, $29 a$ and b). Loc. cit. p. 820, ô.

"Similar to, and allied to velox. Eyes not divergent below. Clypeus slightly prominent. Labrum half as long again as wide. Antennae slender, as far from each other as from the eyes, the seventh to tenth joints slightly spinulose below, the ninth to twelfth excavated below, the apical joint fairly long, curved, rounded at the apex. Wings hyaline, the veins fuscous, two and a half times longer than the width of the thorax in front, the medial cell of the hind wing emitting two longitudinal veins at the apex. Tarsi normal, the basal joint of the anterior pair with seven spines. Middle femora serrate-dentate behind. Middle tibiae not produced at the apex, but with a spur. Abdomen conical, the first segment very declivous at the base, seventh tergite almost truncate at the apex, the second sternite with an acute compressed tooth, the sixth with a fairly flat pyramidal tubercle, the seventh with a distinct longitudinal carina. Outer paramera of the genitalia roundly truncate at the apex. Thorax fairly densely and fairly finely punctured, and like the head, covered with grey pilosity. Second sternite shining in the middle and sparsely punctured. Black; anterior and posterior orbits widely, lower part of the face, clypeus, labrum, greater part of the prothorax, streaks on the sides and two spots on the disc of the mesonotum, a very narrow band on the scutellum, fairly large maculae on the sides of the thorax and epinotum, a narrow and broken band on the first tergite, broad bands enclosing two nearly complete black maculae on the second and third, broad bands on the fourth to sixth tergites and large maculae on the sternites, yellow. Antennae fuscous above, yellow below; legs pale yellow, variegated with black. I6 $\mathrm{mm}$. long."

Mombasa.

B. massaica Cam. (figs. 3 I, 3 I $a-e$; Plate VI, fig. I8). Sjöstedt's KilimandjaroMeru Exped. viII, p. 290, +, ô. Igro. Turner, Ann. Mag. N.H. xIx, p. 439. I9I7.

o. I7 mm. long. Black. Mandibles except at the apex, labrum, clypeus, sides of the face widely, the base of the same between the antennal sockets, scapes below, two spots below the ocellar area, posterior orbits, posterior margin and sides of the pronotum excepting a bilobed black spot above, a vertical bar on the mesopleurae, the sides of the epinotum in front and behind, lateral margins of the mesonotum and two clavate streaks on its disc in front, posterior margins of the scutellum and metanotum, and an arcuate band, angularly dilated in the middle, on the epinotum, pale yellowish white. Tergites I-6 with wide bands of yellowish white, those of the second and third each enclosing two oblong black spots near the base. The apical margins of sternites $\mathrm{I}-5$ and triangular maculae on each side of them, yellowish white. Legs yellowish white, the base of the femora below, streaks on their upper side, much reduced on the middle pair, and narrow streaks on the tibiae beneath, black. Anterior coxae yellowish white on the apical half below. Flagellum black above, fusco-flavous below. Wings hyaline, the veins brown. Pilosity of the head and thorax yellowish white. Puncturation of the mesonotum close, fine and shallow. Sternites $2-6$ coarsely and sparsely punctured, the second somewhat finely and closely punctured at the base. Seventh tergite closely and strongly punctured except at the apex. Clypeus very convex, not flattened in front. Eyes almost parallel, only slightly divergent below. 
Scapes fully three times as long as wide. Second joint of the flagellum nearly three-fourths longer than the third, the seventh spinose below near the base, the ninth and tenth slightly dilated, the ninth to eleventh feebly excavated below, the apical joint moderately curved, slightly compressed, the apex rounded. Interocular distance on the vertex nearly equal to the length of the first five joints of the flagellum. Second sternite with a high carina ending posterior in a hamate spine, sixth sternite with a raised triangular platform which is acute at the apex, the seventh sternite with a low median longitudinal carina on its apical half. Seventh tergite rounded at the apex, the sides distinctly sinuate beyond the middle. Tarsal comb composed of pale yellowish white spines, of which there are six on the basal joint. Middle femora very feebly serrate behind, middle tibiae with a large spur. Outer paramera of the genitalia roundly truncate at the apex.

․ $17 \mathrm{~mm}$. long. Clypeus with two black spots at the base. Tergites $\mathrm{I}-5$ with pale bands as in the $\delta$. Mesonotum with a transverse yellow band at the base, not extending to the lateral margins. All the pale markings, excepting

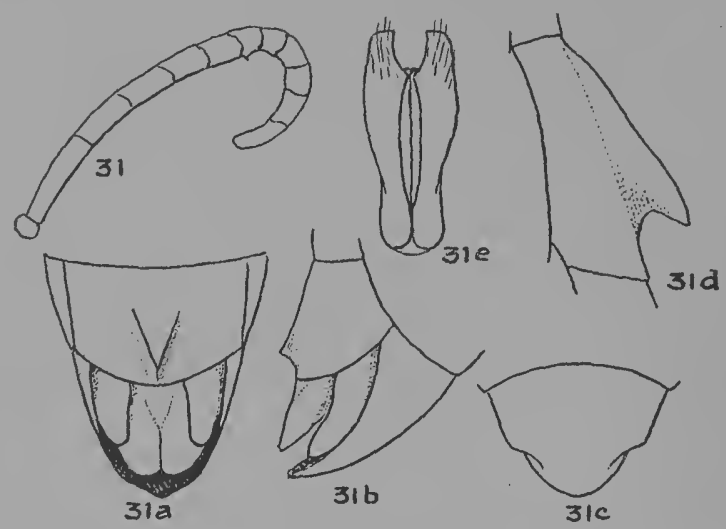

Fig. 3r. Bembex massaica, $\hat{\sigma}$, flagellum; $a$ and $b, \hat{\sigma}$, sixth and seventh sternites; $c$, $\hat{\sigma}$, seventh tergite; $d, \hat{o}$, second sternite; $e$, $\hat{\sigma}$, genitalia.

sometimes the clypeus and sides of the labrum, not so pale as in the $\hat{o}$, having a more yellowish tinge. Interocular distance on the vertex equal to the length of the first four joints of the flagellum plus one-third of the fifth. The second joint of the flagellum two-fifths longer than the third. Sternites shining, sparsely and more coarsely punctured than in the 0 , the sixth distinctly carinate lengthwise over the apical half, the apical margin slightly excised in the middle. Sixth tergite triangular, narrowly rounded at the apex, strongly and closely punctured except near the apex. Tarsal comb composed of pale brownish spines, the basal joint with six spines of which the first is short and thin. Otherwise like the ${ }^{*}$.

Meru, East Africa; Victoria Falls, Bembesi, Bulawayo and Umtali, S. R.

(R.M. and T.M. colls.)

Cameron does not refer to the genitalia but his description of the colour pattern is very detailed and I have little doubt about the correct identification of the insects described above. Turner wrongly synonymised Cameron's species with forcipata Handl. The latter has the genitalia like those of melanopa, which are entirely different from those of massaica. 
B. fraudulenta n.sp. (figs. $32,32 a$; Plate VI, figs. 4I, 42).

o. $13.5 \mathrm{~mm}$. long. Deceptively like B. albopilosa Arn. with a similar white pilosity but not so long and dense as in that species, and with a colour pattern on the tergites which is only slightly different.

Black. Mandibles excepting the apex, labrum, clypeus, sides of the face and its base between the antennal sockets, scapes below, posterior orbits, posterior margin of the pronotum including the tubercles, tegulae, a spot below them on the mesopleurae, sides of the mesonotum, posterior margin of the scutellum, and the tergites, lemon yellow. The base of the first tergite, and bisinuate basal bands on the second and third, black. Sternites black, the

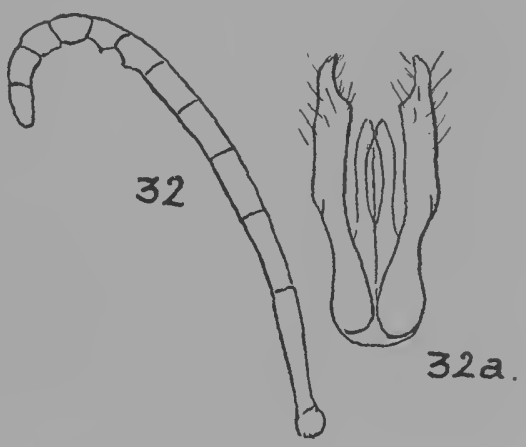

Fig. 32. Bembex fraudulenta, ô, flagellum; $a, o^{*}$, genitalia. apical margins and lateral angles of the second to sixth, lemon yellow, the seventh yellow at the apex. Legs chrome yellow, the basal half or more of the femora, black. Flagellum brown above, the first two joints darker, ochreous below. Wings hyaline, the veins brown. Mesonotum fairly closely punctured, but not so closely as in albopilosa. Second sternite finely, very shallowly and fairly closely punctured, moderately shining, the third to sixth sternites shining, very sparsely and finely punctured. Second and following tergites rather shining, the puncturation shallow, but larger and less close than in albopilosa. Clypeus very convex, distinctly flattened in the middle in front, three-fifths wider than long in the middle (twice as wide as long in albopilosa). Eyes parallel. Ocellar area with a median tubercle. Second joint of the flagellum five times longer than wide at the apex and half as long again as the third; the seventh and eighth feebly spinose behind, the seventh to eleventh slightly excavated below, the apical joint almost straight, rounded apically, not longer than the penultimate. None of the joints is dilated. Interocular distance on the vertex equal to the length of the first four joints of the flagellum. Second sternite with a low, but sharp, median longitudinal carina, nearly reaching the apical margin and not ending in a tooth. Sixth sternite not tuberculate, merely slightly tumid in the middle. Seventh sternite with a very weak median longitudinal carina. Seventh tergite widely rounded at the apex, subtriangular. Legs normal, the middle femora very feebly serrate on the posterior margin, the middle tibiae with a spur. Comb of the anterior tarsi composed of yellowish, flattened spines, of which there are seven on the basal joint. The genitalia resemble those of capicola.

ㅇ. $14 \mathrm{~mm}$. long. Black. Clypeus, labrum and mandibles whitish yellow. Upper margin and posterior half of the sides of the pronotum excepting a black mark in front of the tubercles, sides of the mesonotum, a vertical bar on the mesopleurae in front, tegulae, posterior half of the scutellum and metanotum, a broad arcuate band on the posterior half of the median area of the epinotum and the posterior angles of the same, pale lemon yellow. Colour pattern of the abdomen very similar to that of the ${ }^{2}$, but the tergites are pale greenish yellow excepting the basal portions of the first and second which are lemon yellow. The apical margins of the second to fifth tergites and the whole of the sixth are often creamy white. Sternites black, the second to fifth 
with small greenish yellow lateral maculae on the apical margin. Second sternite moderately shining, the middle portion with a sparse and very shallow puncturation, the third to sixth tergites moderately shining, a little more closely and more strongly punctured than in the 0 . Sixth tergite very shallowly, finely, and not closely punctured. Otherwise like the 0 in sculpture, colour and pilosity. Interocular distance on the vertex equal to the length of the first three joints of the flagellum plus four-fifths of the fourth. Flagellum long and slender, the second joint two-fifths longer than the third and more than five times longer than wide at the apex. Anterior tarsi with a comb of pale yellow spines, the basal joint with six or seven, of which the first is short and thin. Sixth tergite triangular, narrowly rounded at the apex. Otherwise like the 0 .

Durban, March. I o 8 우 (C. N. Barker). Types in the Durban Museum. Easily confused with albopilosa, but clearly separated in the $\sigma^{\star}$ by the shape of the genitalia, and the flagellum in the . From intermedia it may be distinguished by the different colour pattern on the tergites and the finer puncturation of the sternites.

\section{OCULATA Group.}

Face fairly wide. Eyes not strongly divergent below.

$\sigma^{x}$. Middle femora usually distinctly dentate, middle tibiae with a spur. Second and sixth sternites with more or less distinct tubercles or carinae, the seventh long, narrow and with three longitudinal carinae close together.

․ Second sternite shining and coarsely punctured.

Including ochracea Handl, harenarum Brauns, liturata Turner and perhaps lobatifrons Turner.

B. ochracea Handl. (figs. 33, $33 a-c$; Plate VI, fig. 25). Loc. cit. p. 864, ơ.

B. opima Turner. Ann. Mag. N.H. xix, p. 440, o, ㅇ. I9I7.

o. $16 \mathrm{~mm}$. long. Black. Mandibles except at the apex, labrum and clypeus, yellowish white. Sides of the face and the base between the antennae, posterior orbits, pronotum excepting a black area in front and a large black macula on each side, tegulae, lateral margins of the mesonotum, the posterior margins of the scutellum and metanotum, a band on the dorsum of the epinotum, sometimes obsolete, and the legs excepting the base of the femora, chrome yellow. Tergites I-6 chrome yellow; the declivous face of the first, narrow basal bands on the second to fifth or sixth, and the whole of the seventh, black. Sternites black, the second to sixth with large lateral maculae and apical bands chrome yellow. Flagellum blackish above, paleochreous below. Wings hyaline, distinctly tinged with yellow in the middle, the veins, excepting the subcosta, reddish yellow. Head, thorax and base of the first tergite with a dense but not very long, greyish pilosity. Mesonotum very closely and not very finely punctured, almost reticulate-punctate; the mesopleurae as strongly but less closely punctured. First tergite closely punctured like the mesonotum. Second sternite shining, coarsely, irregularly and fairly closely punctured, the sides somewhat less coarsely but more closely. Third to sixth sternites coarsely and fairly sparsely punctured. Clypeus prominent and very convex transversely, not flattened in front. Face with a very short carina at the base between the antennal sockets. Eyes nearly parallel. Second joint of the flagellum distinctly long, five and a half times longer than wide at the apex and nearly two and a half times longer than the third; the seventh and eighth distinctly spined below, the ninth with a very small spine near the apex, the tenth and eleventh dilated and moderately excavated below, the apical joint curved, not 
much narrowed towards the truncate apex and not longer than the penultimate. Interocular distance on the vertex equal to the length of the first four joints of the flagellum plus half of the fifth. Second sternite with a large compressed tooth, rounded at its apex; sixth sternite with a subtriangular platform, seventh sternite long and narrow, tricarinate, the lateral carinae not reaching the apical margin. Seventh tergite closely punctured, narrowly rounded at the apex. Basal joint of the anterior tarsi with six pale yellow spines; middle femora very indistinctly serrate behind, middle tibiae with two spurs.

․ $16 \mathrm{~mm}$. long. The black maculae on the sides of the pronotum are almost obsolete. Mesopleurae with a more or less clavate yellow mark, widest below. The bands on the scutellum, metanotum and epinotum are much wider than in the $\hat{\sigma}$, the posterior angles of the epinotum and the greater part of the declivity below, chrome yellow. Abdomen chrome yellow; only the declivous face of the first tergite, two small spots on the brow of the same, the first sternite excepting the apical margin, the median basal part of the

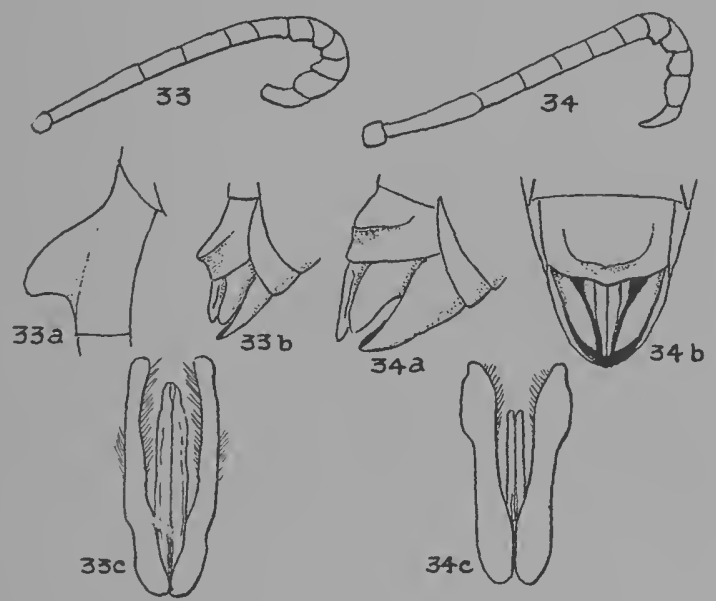

Fig. 33. Bembex ochracea, $\hat{\sigma}$, flagellum; $a, \hat{o}$, second sternite; $b, \hat{\sigma}$, sixth and seventh sternites, $c, \hat{o}$, genitalia.

Fig. 34. Bembex liturata, $\hat{\sigma}$, flagellum; $a$ and $b, \hat{\sigma}$, sixth and seventh sternites; $c, \hat{\sigma}$, genitalia.

second and the base of the sixth are black. Sixth tergite dull ochreous, blackish at the base. As in the of the apical half or more of the anterior coxae is yellow. Flagellum fusco-ferruginous above, pale ochreous below. The apex of the clypeus and the base of the labrum are sometimes stained with brown. Otherwise like the $o$ in colour, pilosity and sculpture, but the middle of the second sternite is only sparsely punctured. Sixth tergite fairly strongly and closely punctured at the sides, widely rounded at the apex. Second joint of the flagellum long, nearly six times longer than wide at the apex and nearly two and a half times longer than the third. Interocular distance on the vertex equal to the length of the first three joints of the flagellum plus half of the fourth.

Transvaal; Willowmore, C. P. (Dr H. Brauns).

The synonymy of opima Turner with this species is clearly established by the structure of the genitalia. The on sometimes has a black spot at the base of the clypeus, and the second tergite may have the two projecting bays of the basal black band separated as discrete maculae.

(R.M. and T.M. colls.) 
B. liturata Turner (figs. 34, 34a-c; Plate VI, figs. 26, 27). Ann. Mag. N.H. XIX, p. 440, ô, f. I 1917 .

o. $17 \mathrm{~mm}$. long. Black. Mandibles except at the apex, labrum, clypeus excepting a transverse black spot at the base, anterior and posterior orbits narrowly, the basal margin of the face below the antennae, the scapes below, posterior margin and sides of the pronotum including the lower half of the pronotal tubercles, the mesopleurae in front and the middle of the tegulae, lemon yellow. Tergites $2-6$ with narrow, slightly sinuate, dull whitish bands across the middle, becoming yellowish at the sides, the first tergite with a very narrow dull whitish streak on each side, often much reduced or obsolete. Sternites I-6 with the extreme apical margins yellow, and with lateral spots of the same colour on the second to fifth. Legs yellow, the anterior and hind femora above, and a streak on all the tibiae behind, black. Flagellum entirely black. Wings hyaline, the veins dark brown. Pilosity on the head, thorax and first tergite white, the clypeus with a dense, decumbent and white pubescence. Mesonotum shallowly and not very closely punctured, somewhat shining. Sternites shining, the second with a shallow, large and fairly close puncturation, the remaining sternites very sparsely and coarsely punctured. Seventh tergite semi-elliptical, shining, finely and fairly sparsely punctured. Clypeus strongly convex, not flattened in front. The base of the face without a distinct carina. Eyes almost parallel, very slightly divergent below. Second joint of the flagellum about five times longer than wide at the apex and fully twice as long as the third; the seventh joint emarginate at the apex below, the eighth spined below, the ninth to eleventh dilated and excavated below, the apical joint curved, rostrate and as long as the preceding joint. Interocular distance on the vertex equal to the length of the first four joints of the flagellum plus half of the fifth. Second sternite with a large compressed tooth, the sixth with a semicircular platform, the seventh tricarinate and very narrow, the lateral carinae not reaching the apical margin. Anterior tarsi with six spines on the basal joint. Middle femora feebly serrate behind, the middle tibiae with one spur.

․ I $5 \mathrm{~mm}$. long. Basal half of the clypeus black. Flagellum reddish brown above, dull ochreous below. Mesopleurae entirely black. The pale band on the first tergite much wider than in the $\hat{\alpha}$, sometimes interrupted in the middle. The bands on the second to fifth segments also wider than in the $\delta^{t}$. Second and third sternites fairly closely punctured at the sides, the puncturation on the middle of the second sparser and shallower than in the $\sigma^{t}$. Sixth tergite sparsely punctured in. the middle, fairly closely and coarsely at the sides, triangular, the apex narrowly rounded. Second joint of the flagellum twice as long as the third. Interocular distance on the vertex equal to the length of the first four joints of the flagellum. Basal joint of the anterior tarsi with seven spines.

Willowmore, C. P. (Dr H. Brauns).

\section{B. liturata, race flavopicta, n.r. (Plate VI, fig. 46).}

o. $\quad 17 \mathrm{~mm}$. long. Entirely like the type of the species in all structural characters, but totally dissimilar in coloration, in which it resembles Braunsii and massaica. Colour of the head like that of massaica, of the thorax like that of Braunsii. First tergite with a lemon yellow band, entire but narrowed in the middle; second tergite with a wide median band, lemon yellow in front, whitish posteriorly and enclosing two transverse black maculae, tergites $3-5$ with bisinuate whitish bands, those of the third and fourth very narrowly 
yellowish in front, the sixth tergite yellowish white, black at the extreme base; the seventh tergite black, whitish on the apical margin. Sternites I-6 lemon yellow, the third and sixth black at the base, the seventh black with the narrow apical portion dirty white. Legs lemon yellow.

Windhuk, S. W. Africa (C. Wilde). Type in the Transvaal Museum.

B. lobatifrons Turner. Trans. Ent. Soc. London, p. 747, o, ㅇ․ 1912.

" $\mathrm{o}$. Black; clypeus, labrum, basal half of the mandibles, the scapes which are black above, face excepting a large bilobed macula above the antennae, temples, a transverse and interrupted line on the occiput, pronotum, sides of the mesonotum and small streaks on its disc, scutellum, post-scutellum, arcuate apical bands on the epinotum, sides of the thorax which are more or less variegated with black, a wide sinuate band on the first tergite, wide bisinuate bands on the second to fourth tergites, nearly the whole of the fifth and sixth, the seventh narrowly at the apex, almost the whole of the first three sternites, wide apical bands on the fourth to sixth, the legs, thorax underneath excepting the mesosternum, pale yellow; wings hyaline, the veins brown.

?. Very much like the $\sigma^{t}$, the yellow bands on the second and third tergites have two black spots within them, ô, o. $14 \mathrm{~mm}$. long.

0 . Eighth and ninth joints of the antennae with a minute spine beneath, tenth to twelfth slightly excavated beneath, apical joint longer than the penultimate, distinctly curved and rounded at the apex. Fore tarsi normal, the basal joint with six spines on the outer margin, fore femora not serrate, intermediate femora with one or two small spines beneath near the apex, not distinctly serrate, basal joint of the intermediate tarsi normal, intermediate tibiae not produced at the apex. Seventh dorsal segment broad, narrowly truncate at the apex, the sides not sinuate. Second ventral segment with a longitudinal carina which is gradually raised into a rounded tubercle at the apex, the surface of the segment closely and evenly punctured; sixth ventral segment with a small, low, rounded tubercle in the middle; seventh ventral segment with three longitudinal carinae placed rather far apart. Wings rather short, not reaching when closed much beyond the apex of the third dorsal segment; cell of the hind wing emitting only one distinct vein from the apex.

q. Similar to the male except in the usual sexual characters; the sixth dorsal segment with a very large yellow apical spot, the sides not sinuate, the apex narrowly rounded. Second ventral segment evenly punctured. The colour of the female is a deeper yellow than in the male.

Hab. British East Africa. Uchweni Forest, March I-2; Lake Mpeketomi, near Kipini (S. A. Neave), March 4-5. Type in the British Museum."

I have seen only a specimen of the $q$ of this species. The eyes are almost parallel, being very feebly divergent below. The interocular distance on the vertex is equal to the length of the first four joints of the flagellum. The second joint of the latter is half as long again as the third. The $q$ bears a strong resemblance in the colour pattern of the upper side of the body to Kriechbaumeri, race scitula Arn., but in the latter the face is wider, the sides of the thorax are not almost entirely yellow and the sternites and apical tergite are black. The most distinct difference, however, lies in the shape of the vertex, lobatifrons having only very shallow depressions on each side of the ocellar area.

B. harenarum Brauns, n.sp. (figs. 35,35 ; Plate VI, figs. 28, 29). Brauns in litt.

๙. $16 \mathrm{~mm}$. long. Black. Mandibles excepting the apex and a spot on the inside at the base, labrum, clypeus, sides of the face widely as far as the level of the posterior ocelli, the base of the face between the antennae, a transverse 
bar or two spots below the ocelli, the scapes in front and the posterior orbits, lemon yellow. Flagellum blackish above, ochreous below. Posterior margin and sides of the pronotum, pronotal tubercles, a vertical streak behind them on the mesopleurae, two narrow longitudinal streaks on the mesonotum in front and the lateral margins of the latter, posterior margin of the scutellum and a vertical bar on the sides of the epinotum, lemon yellow. Tergites I-6 greenish white, the apical margins narrowly, the base of the first and two transverse maculae on both the second and third, black. Seventh tergite black, with a small whitish. spot on each side at about the middle. Sternites black, the second to sixth with narrow apical bands widely dilated at the sides, greenish white. Legs yellow, the femora with a short black streak below and a longer one above, the anterior tibiae with a black streak below. Wings hyaline, the veins brownish ochreous. Head, thorax and first tergite with a very

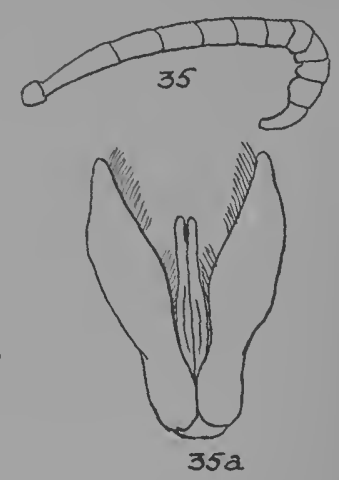

Fig. 35. Bembex harenarum, $\hat{0}$, flagellum; $a, \hat{o}$,
genitalia. dense, greyish pilosity. Mesonotum very shallowly, finely and fairly closely punctured. Second sternite not very shining, with a shallow, large and close puncturation all over, the remaining sternites shining, finely and very scantily punctured. Seventh tergite fairly finely punctured at the sides of the base, almost smooth elsewhere. Clypeus slightly flattened in the middle in front. Face carinate below. Eyes almost parallel. Second joint of the flagellum fairly short, about three times longer than wide at the apex and two-thirds longer than the third joint; the eighth to eleventh joints strongly dilated and also excavated below, the twelfth joint curved, narrowed towards the apex, and a little longer than the penultimate joint. Interocular distance on the vertex equal to the length of the first five joints of the flagellum. Second sternite with a low median longitudinal carina; sixth sternite slightly tumid near the apex, the seventh with a median longitudinal carina and a short blunt carina on each side near the base. Seventh tergite triangular, narrowly rounded at the apex, the sides feebly sinuate. Basal joint of the anterior tarsi with six whitish spines, the first one short. Middle femora distinctly serrate on the whole of the hind margin; the middle tibiae with one spur.

ㅇ. $15 \mathrm{~mm}$. long. Basal black spot on the mandibles larger than in the $\hat{o}$, the clypeus yellow only at the sides and on the anterior margin; the yellow at the sides of the face extends only two-thirds of the way up. Colour pattern like that of the of but the mesonotum lacks the two yellow streaks in front and the pale bands on the first five tergites are much narrower, occupying only a third of the length of each segment. Sixth tergite entirely black. Sternites with much smaller greenish white maculae. Last three joints of the flagellum brownish yellow above. Second joint of the flagellum four and a half times longer than wide at the apex and nearly half as long again as the third, the apical joint somewhat flattened, half as long again as the penultimate. Interocular distance on the vertex equal to the length of the first four joints of the flagellum plus half of the fifth. Sternites shining, the second coarsely and sparsely punctured in the middle, fairly finely and closely at the sides, the third to fifth sparsely and finely, the sixth sparsely and coarsely punctured. The sixth sternite is carinate lengthwise over its apical half. Sixth tergite triangular, strongly and fairly closely punctured except along the middle of its length, narrowly rounded at the apex. Comb of the anterior tarsi composed 
of long brownish yellow flattened spines, of which there are six on the basal joint.

Plettenberg Bay, C. P. January (Dr H. Brauns). Types in coll. Brauns.

\section{ı6. FUSCIPENNIS Group.}

This differs from the preceding group only in having the basal joint of the middle tarsi more or less dilated in the middle or near the base.

Including fuscipennis Lep., sibilans Handl., capensis Handl., compedita Turner and flavicincta Turner.

B. fuscipennis Lep. (figs. 36, $36 a$ and $b$; Plate VI, fig. 30). Hist. Nat. III, p. $27 \mathrm{x}, \mathrm{o}$, ㅇ․ $\mathrm{x} 845$.

o. r6 mm. long. Black. Mandibles dirty yellow, ferruginous at the apex, labrum and clypeus brownish amber yellow. A streak on each side of the face curving inwards above, two spots behind the antennal sockets and a band, often broken up into spots, below the ocellar area, and the temples narrowly, reddish orange. Scapes and flagellum, excepting the last four joints, pale ferruginous. Posterior margin of the pronotum dull yellow, tegulae ferruginous, a spot on the posterior angles of the epinotal dorsum pale yellow. Abdomen black, tergites $\mathrm{I}-5$ with very pale whitish yellow sinuous bands, that on the first widely interrupted in the middle; sixth and seventh tergites and apical margin of the fifth, ferruginous. Sternites $\mathrm{I}-5$ black, the second to fifth with small whitish yellow spots on each side near the apex, the middle of the second and the whole of the sixth ferruginous, the seventh fusco-ferruginous. Legs reddish ochreous, the coxae, trochanters and base of the femora below, black; the tibiae and basal joint of the hind tarsi whitish above. The femora and tibiae are noticeably slender. Wings pale brown, the apical third or more, hyaline. Pilosity on the head, thorax and first tergite white, neither dense nor long. Mesonotum fairly closely and by no means finely punctured, the mesopleurae a little more strongly than the mesonotum. Tergites fairly distinctly and not very closely punctured, sternites 2-5 shining, sparsely and coarsely punctured, the sixth closely and finely so at the base, more sparsely and more strongly at the sides. Eyes nearly parallel, barely divergent below. Clypeus not flattened in front. Second joint of the flagellum four and a half times longer than wide at the apex and twice as long as the third, the seventh and eighth feebly spined behind, the ninth to eleventh not dilated, slightly excavated below, the apical joint moderately curved, slightly narrowed towards the end, which is rounded. Interocular distance on the vertex equal to the length of the first four joints of the flagellum plus half of the fifth. Second sternite with a large compressed and curved tooth, the sixth with a high, subtriangular platform, the seventh feebly carinate lengthwise in the middle. Seventh tergite narrowly truncate at the apex. Basal joint of the anterior tarsi with six ferruginous spines. Middle femora not serrate or dentate, the basal joint of the middle tarsi dilated at the middle.

․ ${ }^{1} 5^{-1} 6 \mathrm{~mm}$. long. Sixth abdominal segment and the apical margin of the fifth tergite, ferruginous. Second sternite more sparsely punctured than in the $\hat{\delta}$. Sixth tergite narrowly rounded at the apex, closely and strongly punctured, subcarinate lengthwise in the middle. Second joint of the flagellum slightly longer than in the $\hat{\sigma}$. Otherwise like the $\hat{\sigma}$.

S. Rhodesia, Transvaal and Natal. A common species. Sometimes the wings in the $\delta$ are clear hyaline throughout. 
B. sibilans Handl. (figs. $37,37 a$ and $b$; Plate VI, fig. 3 I). Loc.cit. p. 852 , o , f.

o. $16 \mathrm{~mm}$. long. Very similar to fuscipennis and with the same colour pattern on the first six tergites. It differs from fuscipennis as follows.

Labrum chrome yellow. Clypeus black, only the anterior margin narrowly yellow. Markings on the face and the front of the scapes reddish ochreous. Scapes above and the flagellum black, the latter reddish brown below towards the apex. Sides of the pronotum and the lower anterior angle of the mesopleurae, lemon yellow. Seventh tergite and all the sternites black, without any ferruginous colour, the second to fifth with small yellow maculae at the sides. Legs ochreous yellow, the femora and the anterior tibiae streaked with black above. The wings are much paler, the brown stain on the basal two-thirds being much lighter than in fuscipennis. The pilosity is a little more abundant and longer. Flagellum thicker, the second joint only a little more than three times longer than wide at the apex, but also twice as long as the third, the sixth to eighth spinose posteriorly, the ninth slightly, and the tenth and eleventh joints distinctly dilated, the seventh to eleventh excavated below,
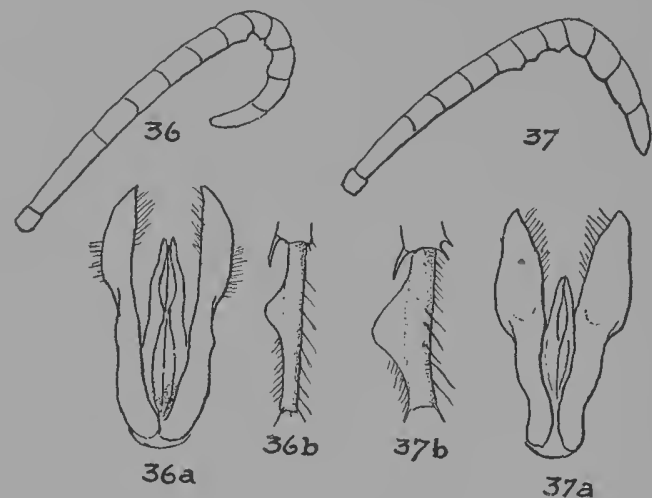

Fig. 36. Bembex fuscipennis, $\hat{0}$, flagellum; $a$, $\hat{0}$, genitalia; $b$, $\widehat{0}$, basal joint of middle tarsus.

Fig. 37. Bembex sibilans, $\hat{o}$, flagellum; $a, \hat{o}$, genitalia ; $b, \hat{o}$, basal joint of middle tarsus.

the apical joint very little longer than the penultimate, feebly curved, rounded at the apex. Interocular distance on the vertex equal to the length of the first six joints of the flagellum. Sculpture of the sternites not quite so coarse as, and a little closer than in fuscipennis, the tooth on the second not so long or high, the sixth as in fuscipennis, the seventh with a median and lateral carinae. The seventh tergite is much more widely rounded apically, being almost semicircular, and is also more strongly and less closely punctured; the outer paramera of the genitalia are much wider. The basal joint of the middle tarsi is thicker and has a wider and higher dilatation.

f. $18 \mathrm{~mm}$. long. The brown stain on the wings darker than in the ${ }^{-}$, but not so dark as in fuscipennis or. Colour of the head and legs as in the $\sigma^{\text {. }}$. Apical tergite fusco-ferruginous. The whitish yellow bands on the tergites are narrower than in fuscipennis and less deeply bisinuate in front. Face relatively narrower than in fuscipennis. Second joint of the flagellum two-thirds longer than the third, and about three and a half times longer than wide at the apex. Third to fifth sternites finely and closely punctured at the base, otherwise the sculpture of the sternites is the same as in fuscipennis. Sixth tergite with 
a median longitudinal carina which does not extend from the base much beyond the middle of the segment. Otherwise like the $t$.

Algoa Bay (Dr H. Brauns). (T.M. coll.)

B. compedita Turner (fig. 38, $38 a-c$ ). Trans. Ent. Soc. London, p. 746. I912. B. Kohli Turner (nec Morice 1897). Ann. Mag. N.H. Ix, p. 41 5, ô, q. I912.

3. $16 \mathrm{~mm}$. long. Black. Labrum and base of the mandibles yellow. Face and vertex as far as the level of the posterior ocelli, excepting a T-shaped median black mark below the anterior ocellus and the vertex behind the ocelli, antennae excepting the last four joints, and the temples, reddish yellow. Upper margin of the pronotum and the posterior half of the pronotal tubercles, yellow. Tegulae ferruginous. Tergites $2-5$ with bands of reddish ochreous yellow, widely interrupted in the middle on the second, slightly so on the third and fourth, the fifth and sixth entirely reddish yellow, the seventh ferruginous. Sternites 2-4 with narrow apical bands of reddish yellow, the sixth entirely of that colour except the median platform which, like the tubercle on the second, is ferruginous. Legs yellow, the femora blackish above at the base, the hind femora also black below. Wings hyaline, the veins brown.

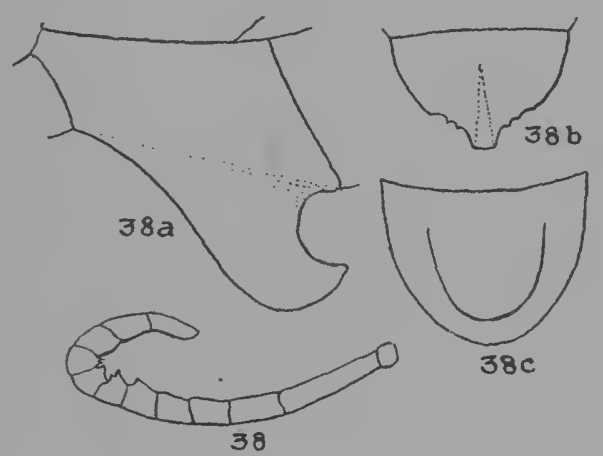

Fig. 38 . Bembex compedita, $\hat{\sigma}$, flagellum; $a, \hat{o}$, second sternite; $b, \hat{\sigma}$, seventh tergite; $c, \hat{o}$, sixth sternite.

Pilosity and pubescence brownish grey, the pubescence on the mesonotum somewhat fulvous. Mesonotum, scutellum and mesopleurae dull, closely and moderately strongly punctured, the punctures round. Tergites dull, closely and finely punctured, the seventh coarsely on each side, smooth and shining in the middle. Sternites shining, sparsely and coarsely punctured in the middle, less coarsely at the sides. Clypeus very convex, not flattened in the middle in front. Eyes almost parallel; the interocular distance on the vertex equal to the length of the first five joints of the flagellum. The second joint of the flagellum is two and a quarter times longer than the third, the tenth and eleventh are excavated below, the sixth to ninth spinose below. Second sternite with a large, curved and compressed tooth. Sixth sternite with a semi-elliptical platform. Seventh tergite broadly truncate at the apex, the apical half of the lateral margins concave and trisinuate. Femora not serrate. Basal joint of the anterior tarsi with six spines; the basal joint of the middle tarsi angularly dilated a little beyond the base.

f. I7 mm. long. Interocular distance on the vertex equal to the length of the first four joints of the flagellum. The second joint of the flagellum is 
twice as long as the third, the apical joint half as long again as the penultimate. Sixth tergite triangular, narrowly rounded at the apex. Otherwise like the $\hat{o}$.

Blantyre and Mlanje, Nyasaland. April to May.

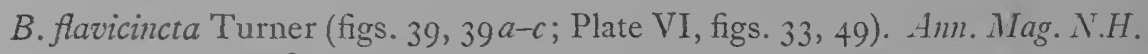
IX, p. $4^{\mathrm{I}}+1, \hat{0}$, ㅇ. I9I2.

o. $20-23 \mathrm{~mm}$. long. Lemon yellow. Two spots below the anterior ocellus, the ocellar area, sides of the vertex at the upper margin of the eyes, occiput, the mesonotum in the middle so as to enclose a yellow $\mathrm{U}$-shaped mark, the anterior margins of the scutellum and metanotum, epinotal dorsum in front narrowly and a streak on each side of its median area, black. The base and apical margins of the first six tergites narrowly, two transrerse spots on each of them, a median spot on the second sternite, the basal half or less of the third and fourth sternites, the fifth and sixth excepting their apical margins and the seventh, black. Seventh tergite flavo-ferruginous. Mesopleurae and narrow lines margining the sclerites on the

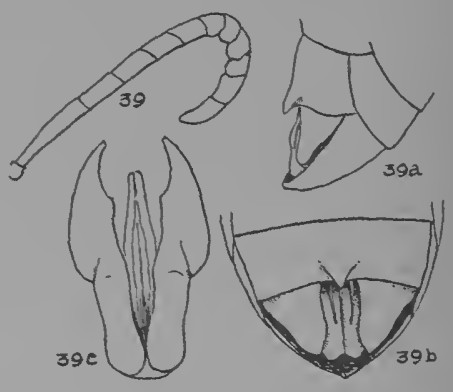

Fig. 39. Benbex flavicincta, $\hat{0}$, flagellum; $a$ and $b, 0$, sixth and seventh sternites; $c, 0$, genitalia. sides of the thorax, black. Flagellum ferruginous, darker at the apex. Legs yellow. Wings hyaline, the subcosta black, the other veins ferruginous. Pilosity and pubescence whitish and sparse. Thorax very shallowly, closely and finely punctured, the punctures oblique. Tergites closely punctured, the punctures a little larger than those of the mesonotum. Seventh tergite with a few large punctures. Sternites shining, very sparsely and moderately coarsely punctured. Eyes nearly parallel, slightly divergent above and below. Labrum and clypeus convex transversely. Interocular distance on the vertex nearly equal to the length of the first four joints of the flagellum. Second joint of the flagellum slightly more than twice as long as the third; the ninth to eleventh joints slightly excavated below, the seventh to eleventh slightly dilated, the apical joint a little curved, and a little longer than the penultimate. Second sternite simple, or sometimes with a trace of a median longitudinal carina on its apical half; sixth with a triangular compressed spine on its apical half and projecting over the apical margin, the seventh with two high longitudinal carinae, close together and not reaching the apical margin of the segment. The ventral flaps of the seventh tergite are very large and cover the greater part of the serenth sternite. Seventh tergite triangular, broadly rounded at the apex, slightly sinuate at the sides. Basal joint of the anterior tarsi with five or six spines. Niddle femora distinctly serrate along their whole length behind, the teeth large. The basal joint of the middle tarsi slightly swollen a little beyond the base.

‥ $24 \mathrm{~mm}$. long. Eyes slightly more divergent below than in the ${ }^{x}$. Sixth tergite coarsely punctured, closely so at the sides, the sixth sternite sparsely and very coarsely punctured in the middle. Otherwise like the $\sigma^{\prime}$.

Pakasa, N. Rhodesia (Silverlock); Sanyati Talley, S. Rhodesia (R. H. R. Stevenson). (R.M. coll.) 
B. capensis Lep. (figs. 40, 40a-c; Plate VI, fig. 32). Hist. Nat. III, p. 273, $\mathrm{o}^{*}$. I 845 .

B. natalis Dahl. Hymen. Eur. I. p. 489. 1845.

${ }^{*}$. I6-I7 mm. long. Black. Mandibles excepting the apex, labrum, sides and anterior margin of the clypeus, lower corners of the face, scapes below, posterior orbits narrowly, posterior margin and sides of the pronotum, the lower anterior angle of the mesopleurae, the lateral margins of the mesonotum opposite the tegulae, narrow bands, often obsolete, on the posterior margins of the scutellum and epinotal dorsum, posterior angles of the latter, and the legs, pale lemon yellow. Femora streaked with black above. Tergites I-5 with pale glaucous white bands, those on the first and second yellowish in front and at the sides, on the third to fifth yellowish at the sides only, the sixth tergite ochreous,
the seventh black at the base and reddish yellow on the apical half. The first sternite, excepting its apical margin, and the basal

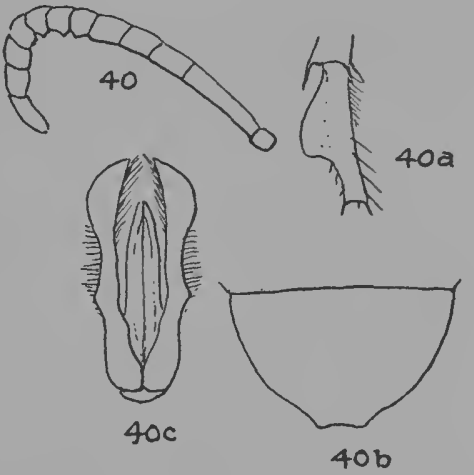

Fig. 40. Bembex capensis, ô, flagellum; $a$, $\hat{\sigma}$, basal joint of middle tarsus; $b, \hat{\sigma}$, seventh tergite; $c$, $\hat{o}$, genitalia. half of the second, black; the sides of the latter yellow, the tooth in the middle red. Sternites 3-5 yellow, stained with reddish brown in the middle, the sixth pale ferruginous in the middle, ochreous at the sides. The upper side of the scape and the flagellum black, the latter pale brown below. Pilosity on the head and thorax white and fairly dense, the clypeus covered with a decumbent silvery pubescence. Sculpture of the mesonotum and sternites like that of fuscipennis. Seventh tergite fairly strongly and closely punctured at the sides. Clypeus not flattened in front. Eyes very slightly divergent below. Second joint of the flagellum four and a half times longer than wide at the apex, and two and a third times longer than the third joint; the sixth to eighth joints spinose behind, the ninth slightly dilated, the tenth and eleventh distinctly so, the apical joint slightly curved and barely longer than the penultimate. Interocular distance on the vertex equal to the length of the first five joints of the flagellum. Second sternite with a large and compressed tooth. Sixth sternite with a triangular platform, higher and more acute at the apex than in fuscipennis, the seventh sternite tricarinate, the lateral carinae not quite reaching the apical margin. Seventh tergite almost semi-circular, widely truncate at the apex. Basal joint of the anterior tarsi with six yellow spines. Basal joint of the middle tarsi dilated over the basal two-thirds. Outer paramera of the genitalia distinctly angular on the outside below the middle.

. $16 \mathrm{~mm}$. long. Scapes black above, reddish ochreous below; flagellum ferruginous, the first and last three joints blackish. Tergites $1-5$ with lemon yellow bands, the sixth tergite and sternite reddish orange yellow. Second joint of the flagellum nearly five times longer than wide at the apex and two and a quarter times longer than the third. Interocular distance on the vertex equal to the length of the first four joints of the flagellum. Sixth tergite triangular, narrowly rounded at the apex. Tarsal comb composed of pale ferruginous spines. Otherwise like the $\hat{\delta}$. Africa.

A common species widely distributed throughout Rhodesia and South 


\section{ALBOPILOSA Group.}

Face very wide, the eyes slightly divergent above.

o. Legs normal. Middle tibiae with a spur. Second sternite with a small tubercle, dull, shallowly and finely punctured. Sixth sternite slightly swollen, not tuberculate. Seventh sternite with a feeble median carina. Seventh tergite triangular, widely rounded at the apex. 'The genitalia resemble those of $B$. cinctella Handl. and this group is allied to the cinctella group, differing chiefly in having no apical projection on the middle tibiae.

\section{B. albopilosa n.sp. (figs. 4I, $4 \mathrm{I} a-c$; Plate VI, fig. 40).}

o. I $4 \mathrm{~mm}$. long. Black. Mandibles excepting the apex, labrum, clypeus, sides of the face and its base between the antennal sockets, scapes below and the posterior orbits very narrowly, chrome yellow. Flagellum black above, brownish yellow below. Legs yellow, the basal two-thirds of the femora above, and the basal third below, black; the anterior tibiae with a black streak on the outside. Abdomen pale lemon yellow; the basal half of the first tergite, basal third of the second and the extreme base of the following tergites, black. (In the type the segments are invaginated, so that the basal black is not visible from above on the last four segments.) Sternites lemon yellow, the basal half of the first six, black. Wings hyaline, the veins blackish. Head, thorax and first tergite with a long, dense and white pilosity, very apparent when the insect is viewed from the side. Dorsum of

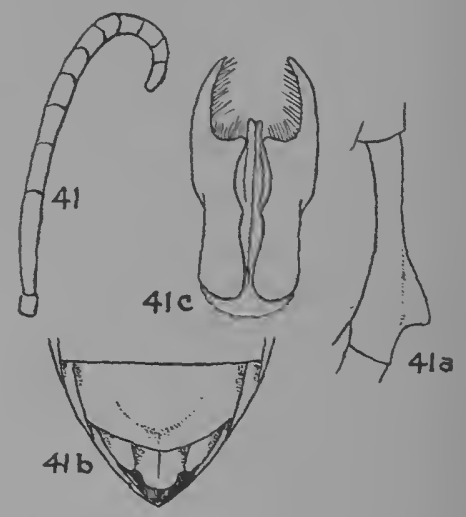

Fig. 4I. Bembex albopilosa, ô, flagellum; $a, o^{\pi}$, second sternite; $b, \hat{o}$, sixth and seventh sternites; $c, \hat{O}$, genitalia. the thorax shallowly, finely and closely punctured. Second sternite fairly dull, with a very shallow; fine and close puncturation all over; the third to sixth sternites somewhat shining, more finely and more closely punctured than the second. Seventh tergite fairly closely and finely punctured. Clypeus convex, not flattened in front. Eyes slightly divergent above, the interocular distance on the vertex being equal to the length of the first five joints of the flagellum, whereas it is equal to only a little more than the first four across the clypeus. All the joints of the flagellum simple, the second joint twice as long as the third and five times longer than wide at the apex, the last joint rounded at the apex and not much longer than the penultimate. Tertex not deeply impressed on each side of the ocellar area, the latter without a median tubercle. Second sternite with a curved compressed tooth extending over the third fourth of its length, sixth sternite with a low and indistinct, semi-circular swelling, the seventh with a feeble median longitudinal carina. Seventh tergite triangular, rounded at the apex, the sides slightly sinuate. Legs normal. The tarsal comb composed of yellowish spines of which there are six on the basal joint.

Klipfontein, I $\hat{o}^{*}$, type (L. Peringuey); Swakopmund, I $\hat{o}$. Both specimens in the South African Museum.

The specimen from Swakopmund is defective, lacking the antennae, and in the type all the joints of the flagellum are concave below, a condition which 
is not natural but due to shrivelling. The specimen looks as if at one time it had been preserved in alcohol.

The following species cannot be placed within any of the known groups owing to the absence of one sex or to insufficient description.

B. Junodi n.sp. (figs. $42,42 a-c$; Plate VI, fig. 45).

o. If mm. long. Black. Labrum, clypeus, mandibles excepting the apex, sides and base of the face, the whole of the scapes and the posterior orbits, lemon yellow. Flagellum ochreous, slightly reddish brown above. Posterior marginand sides of the pronotum, sides of the mesonotum, narrow bands on the posterior margins of the scutellum and metanotum, an arcuate band on the epinotum and the greater part of the sides of the thorax, lemon yellow. Tergites I-6 with dirty white bands which become yellowish at the sides, those on the first four dilated at the sides. Sternites black, the apical half of the first, the sides and base of the second, and lateral triangular maculae on the third to fifth, dirty yellow. Legs yellow,

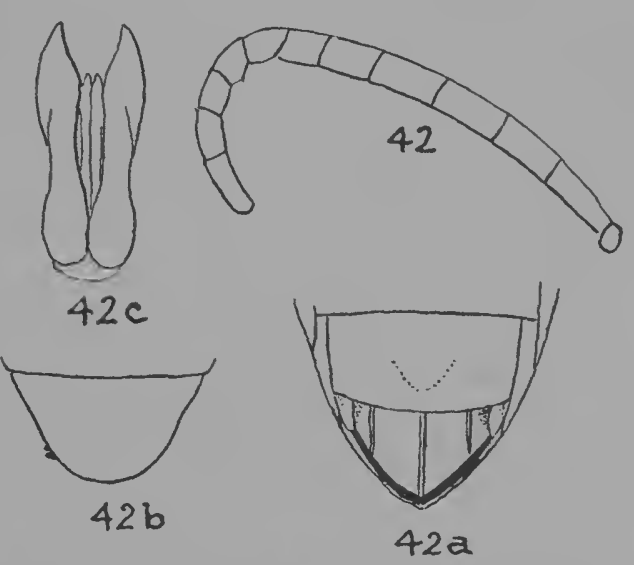

Fig. 42. Bembex Funodi, ô, flagellum; $a, \hat{o}$, sixth and seventh sternites; $b, \hat{o}$, seventh tergite; $c, \hat{\jmath}$, genitalia.

the trochanters and a streak on the upper side of the femora, black. Wings hyaline, the veins brown. Pilosity greyish, short and very scanty, absent from the first tergite as well as the rest of the abdomen. Mesonotum very finely and closely punctured. Sternites fairly dull, shallowly and closely punctured, the sixth a little more strongly and less closely than the rest. Clypeus not prominent, the anterior two-thirds in the middle very distinctly flattened. Face carinate between the antennal sockets. Eyes parallel. Flagellum long and rather thick, the last five joints thinner than the basal ones, the second distinctly short, barely more than one-fifth longer than the third and only three times longer than wide at the apex, the seventh and eighth not spinose but merely angular posteriorly; the apical joint cylindrical, nearly straight and half as long again as the penultimate. None of the joints dilated or excavated below. Interocular distance on the vertex equal to the length of the first three joints of the flagellum. The vertex is only very shallowly impressed on each side of the ocellar area; the latter lacks a median tubercle. Second sternite with a low median longitudinal carina, which does not reach the basal or apical margins. Sixth sternite with a feebly defined and very slightly elevated triangular area. Seventh sternite with three widely separated longitudinal carinae. Seventh tergite almost semi-circular, sparsely and coarsely punctured. Genitalia not unlike those of Baumanni and madecassa Sauss. Basal joint of the anterior tarsi with seven spines; the middle femora with two indistinct teeth near the apex below; the middle tibiae with one spur, the basal joint of the middle tarsi slightly flattened at the apex.

Lourenço Marques, 2 ơ ơ (Rev. H. A. Junod).

A species very distinctly characterised by the antennae, the second joint of the flagellum being unusually short. In the absence of the $q$ I am unable 
to place this species in any of Handlirsch's groups. Apart from the middle tibiae not being produced into a point at the apex, and the shape of the genitalia, it agrees fairly well with the gracilis group.

Type in the Transvaal Museum.

B. obtusa Tumer. Ann. Mag. N.H. xIx, p. 436, o. IgI7.

" $\hat{~}$. 2 I mm. long. Black; mandibles excepting the apex, labrum, clypeus, an oblique black (?) spot on each side of the face, scapes, posterior orbits, posterior margin of the pronotum, pronotal tubercles, prosternum, the mesosternum in front, a line on the mesonotum opposite the tegulae, an oblique line on each side of the scutellum, posterior margin of the metanotum and the legs, yellow; anterior femora streaked with black above, the anterior tarsi spotted with black underneath; first tergite with a transverse macula on each side and a very narrow median band, the second to sixth tergites with bisinuate transverse bands, the sternites $2-5$ with maculae on each side and a narrow apical band on the first sternite, olive yellow; flagellum ochreous below; apex of the sixth tergite and basal half of the seventh, ferruginous; wings hyaline, the veins fuscous, twice as long as the thorax.

o. Clypeus very broadly triangularly flattened on the apical half, labrum flattened at the base; a strong longitudinal carina between the antennae; sixth, serenth and eighth joints of the flagellum each with two or three small spines beneath, joints 9 and Io subdenticulate beneath, penultimate joint concave beneath, longer than the tenth, apical joint about half as long again as the penultimate, concave beneath, blunt and rather strongly curved at the apex. Fore tarsi rather stout, with a strong tarsal comb, the apical joint flattened, nearly as broad and less than half as long again as the penultimate, with a small spine on the middle of the outer margin; anterior and intermediate femora not serrate; intermediate tibiae produced into a distinct spine at the apex. Seventh dorsal segment very broad, with parallel sides on the basal portion to beyond the middle, the apex obtuse; the surface of the segment finely punctured, with coarse punctures intermixed near the apex. Second ventral segment with a very large tubercle, which is broadly truncate at the apex; sixth ventral segment with a slightly raised, broadly triangular area near the apex; seventh broad, with a longitudinal carina on each side; eighth produced into a stout blunt tooth. Median cell of the hind wing emitting only one vein from the apex.

Hab. Nyasaland, Mlanje, $2300 \mathrm{ft}$. (S. A. Neave), October.

The apical dorsal segment is shaped somewhat as in the variety of $B$. pugillatrix figured by Handlirsch (Sitzungsb. Akad. Wiss. Wien, cII, t. V. fig. I 5 ), but the parallel sides are continued much nearer to the apex than in that figure. In the antennae it approaches albofasciata Smith, also in the short wings, but differs in the legs and apical abdominal segments. The three intermediate joints of the fore tarsi are moderately dilated, about as broad as long, nearly as much dilated as in latitarsis Handl."

B. ornatilabiata Cam. and B. lineatifrons Cam. (Sjöstedt's KilimandjaroMeru Exped. vII, pp. 29I and 292), from Meru, East Africa, are insufficiently described in Cameron's paper, in spite of the considerable details given therein concerning the colour pattern. I am inclined to suspect that the first species is synonymous with melanopa Handl., but the second is unrecognisable. 


\title{
THE SPHEGIDAE OF SOUTH AFRICA
}

\author{
BY GEORGE ARNOLD, D.Sc., A.R.C.Sc., F.E.S. \\ Curator of the Rhodesia Museum, Bulawayo
}

\section{PART XIV}

\section{APPENDIX III}

\section{With Plate and 49 Text-figures}

IN the following pages this monograph will be completed by correcting errors and omissions and by the description of several new species which have come to my notice since the other parts of the work were published.

Key to the genera (Part I, Ann. Trans. Mus. IX, part II, 1922).

This should be revised as follows.

After paragraph (I) 4 , insert

(4d) 4 a. Venation greatly reduced, the radial and cubital cells obsolete. Pronotum large, fully as long as the mesonotum.

(4c) 4 b. No discoidal cell present; sixth tergite in the of without a pygidial area.

Miscophoides Brauns.

( 4 b) 4 c. One discoidal cell present; sixth tergite in the 9 with a pygidial area.

(4a) 4 d. At least one cubital cell present.

Saliostethoides Arnold

Paragraph (I4) I7. After "simple" add "Thyreopus Lep."

In the two following paragraphs add "species-group" before the words Encopognathus and Dasyproctus. For the other species-groups of Thyreopus the reader should refer to the key given on page 339 in Part viI (rol. XI, part IV, I926). follows:

Paragraph (26) 25. Delete "Gastrosericus Spinola" and continue as

(25 b) 25 a. Posterior ocelli elongated.

Gastrosericus Spinola

(25 a) 25 b. All the ocelli round and convex.

Paranysson Guérin, subgen. Mesopalarus Brauns

Paragraph (29) 32. Before "Abdomen" insert "( 32 b) 32 a" and continue as follows:

(32 a) 32 b. Abdomen not petiolate.

Spilomena Shuckard

Paragraph (7I) 74 should read "Abdomen rarely coarsely punctured."

Paragraph (96) 97. Delete "or..... . stalked."

Paragraph (IOI) I0o. Alter "Gorytes Latr." to "Arpactus Jurine." 


\section{LARRA Group. \\ Genus Gastrosericus Spin.}

\section{G. Braunsi Arn. var. unicolor n.v.}

o. $8 \mathrm{~mm}$. long. This differs from the type of the species in having the first five tergites black, with their depressed apical margins rufo-testaceous. The legs are ferruginous, the posterior tibiae pale yellow on the upper margin. The joints of the flagellum are somewhat thicker, and the middle third of the anterior margin of the clypeus is convex, not angular as in the type of the species. The tooth on the temples is smaller and placed farther forwards. The tubercle on the anterior coxae is also less developed.

Sawmills, S. R. I + . Type in the Rhodesia Museum.

\section{G. pratensis n.sp. (fig. I).}

9. $8 \mathrm{~mm}$. long. Black. Mandibles pale yellow at the base, the apical third ferruginous. Apical margins of the first three tergites widely, of the fourth and fifth narrowly, fusco-ferruginous. Scapes ferruginous below. Fore and middle legs, excepting the coxae, trochanters and upper side of the femora, ferruginous; hind femora and tibiae brownish black, the tibiae pale yellow on the outside, the hind tarsi ferruginous. Wings hyaline, faintly tinged with fuscous, the apical portion be-

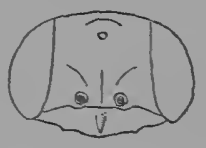

1

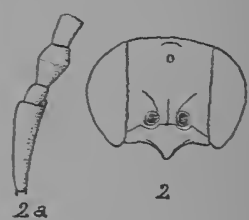

Fig. I. Gastrosericus pratensis, 우.

Fig. 2. Gastrosericus Turneri, $\hat{0} ; a, \hat{o}$, basal joints of the antenna. yond the cells more distinctly fuscous, the veins dark brown. Tegulae testaceous. First two sternites dull, the other sternites shining, with a few large and scattered punctures. Pubescence on the tergites of a brownish grey colour. The mesonotum somewhat more strongly punctured than in G. Braunsi, otherwise like that species in pubescence and sculpture. Eyes moderately convergent above; the interocular distance on the vertex is equal to the length of the first five joints of the flagellum. The temples are without a tooth. Clypeus short, with a very low triangular swelling in the middle, the anterior margin feebly convex and with a slight angle on each side, nearer to the sides than the middle. Second joint of the flagellum twice as long as the first and as long as the third. Pygidial area elongate triangular, fairly shining, strongly and closely punctured, twice as long as wide at the base. Anterior coxae without a tubercle. Venation like that of Braunsi.

Bulawayo, December, I o (G. Arnold). Type in the Rhodesia Museum.

\section{G. Turneri Arn. (figs. 2, 2a).}

0 (hitherto undescribed). $6.3 \mathrm{~mm}$. long. Pubescence of the face and clypeus silvery. Vertex much more finely punctured than in the \%. Sternites covered with a dense greyish pubescence which obscures the sculpture. Otherwise like the $\frac{\rho}{\mathrm{i}}$ in colour, sculpture and pubescence. Median area of the clypeus produced, forming a subacute angle. The interocular distance on the vertex is equal to the length of the first eight joints of the flagellum. The second joint of the flagellum is angularly dilated all round beyond the middle, twice as long as the first and a little longer than the third; the apical joint is half as long again as the penultimate. Anterior coxae with a very small, setigerous tubercle on the posterior inner angle. Seventh tergite triangular, dull, finely punctured, the extreme apex rounded and of a dull yellow colour. Otherwise like the $q$.

Bulawayo, November, I $\hat{o}$. Type in the Rhodesia Museum. 
G. pulchellus n.sp. (figs. $3,3^{a}$ ).

\%. $9 \mathrm{~mm}$. long. Black. Mandibles pale straw-yellow, fusco-ferruginous at the apex. Tibiae and apical half or less of the femora pale yellow, the fore and middle tibiae with a reddish streak in front; tarsi reddish ochreous. Sixth tergite reddish brown at the apex, the lateral and apical margins of the other tergites widely pale yellowish brown. Wings hyaline, the veins pale brown. Clypeus and face with silvery pubescence, the rest of the body, excepting the sternites, covered with a dull brassy golden pubescence, scanty on the head

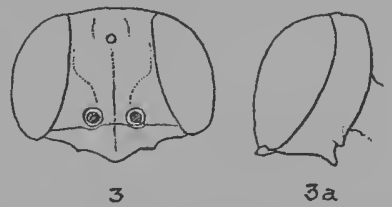

Fig. 3. Gastrosericus pulchellus, + , head; $a$, o, lateral view of the head. and scutellum, dense on the epinotum, where it obscures the sculpture, fairly dense and somewhat paler or greyish golden on the tergites. Head and thorax dull, microscopically and very closely punctured, much more finely punctured than either Turneri or pratensis. Tergites $\mathrm{I}-5$ dull, transversely and microscopically rugulose, the pygidial area triangular, longer than wide at the base, slightly shining, sparsely and coarsely punctured, the apex narrowly truncate. Sternites $\mathrm{I}$ and 2 dull and pubescent, the rest shining, all microscopically rugulose. Median area of the clypeus triangularly produced, but not so much as in Braunsi, the apex widely rounded, subcarinate lengthwise in the middle and obtusely angular on each side. Eyes moderately convergent above, the interocular distance on the vertex being equal to the length of the first four joints of the flagellum plus half of the fifth, and to three-fifths of the interocular distance across the clypeus. Second joint of the flagellum half as long again as the first, and a little shorter than the third. Temples wide, more than half as wide as the eyes, armed below with two rounded teeth, of which the lower one is the larger. Anterior coxae like those of Turneri but with a somewhat smaller lateral process. Abdomen fairly deeply constricted between the first two segments. Spines on the legs yellowish white, the basal joint of the anterior tarsi with six spines on the outer margin. First abscissa of the radius longer than the third and four times longer than the second, the latter a little shorter than the space between the two recurrent veins on the cubitus. Museum.

Rhodesdale, S. R. I o (R. H. R. Stevenson). Type in the Rhodesia

\section{G. lanuginosus Arn.}

of (hitherto undescribed). ro $\mathrm{mm}$. long. Tibiae and tarsi ferruginous, the apical margins of the tergites pale reddish brown, the colour obscured by the overlying pubescence. Face and clypeus with long silvery pubescence, much more abundant than in the $\hat{o}$ and completely hiding the sculpture below; on the vertex the pubescence has a slightly yellowish tinge. Thorax with a dense, outstanding pilosity, whitish at the sides and below, bronzy golden above. Apical margins of the first four tergites with bronzy golden pubescence, the pygidial area densely covered with decumbent and pale yellow setae. The puncturation of the vertex and thorax is similar to that of the $\sigma^{3}$ but larger. Median area of the clypeus produced into a rounded lobe, almost semicircular. The eyes are slightly more convergent above than in the $\delta$; the interocular distance on the vertex is nearly equal to the length of the first four joints of the flagellum. The second joint of the flagellum is as long as the third and nearly twice as long as the first. The pygidial area is elongate triangular, four-fifths longer than wide at the base, widely rounded at the apex. 
Tarsal comb composed of long, thin and pale reddish spines, of which there are eight on the basal joint. Otherwise like the ${ }^{t}$.

Sawmills, S. R. December (R. H. R. Stevenson). Type in coll. Stevenson.

\section{Genus Prosopigastra Costa}

P. carinata Arn. (fig. 4).

o (hitherto undescribed). $6.3 \mathrm{~mm}$. long. Tibiae darker on the outside, the mesonotum much more coarsely punctured than in the $o^{2}$, otherwise like that sex in colour and sculpture. The face and clypeus have only a scanty whitish pubescence, and the first tergite lacks the decumbent golden pubescence which is present in the $\delta^{\text {. }}$ Face and vertex shining, with a strong puncturation which is scanty on the sides of the face, more so on the median swelling, denser behind the ocelli; the space between the antennal sockets dull, closely and finely rugose. First sternite closely and finely punctured, the second sparsely so, the following sternites smooth and with a row of small punctures behind the apical margin. All the sternites are simple, without transverse carinae. Sixth tergite

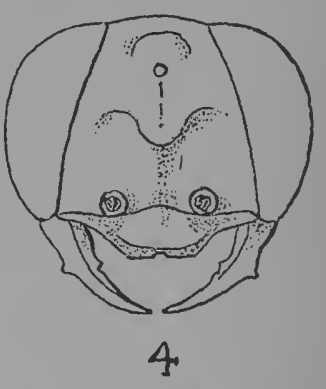

Fig. 4. Prosopigastra cari. nata, $q$. subtriangular, narrow, the apex broadly rounded. Mesopleurae unarmed. Head not unlike that of $P$. Neave $i$ but the clypeus is more produced in the middle, the eyes are more convergent above and the median swelling is less prominent and merges more gradually into the rest of the face. Interocular distance on the vertex equal to the length of the first three joints of the flagellum plus nearly half of the fourth joint, and only three-fifths as great as the interocular distance across the base of the clypeus. Second joint of the flagellum two-thirds longer than the first and slightly shorter than the third. Tarsal comb composed of long, thin and blackish cilia.

Bulawayo. Type in the Rhodesia Museum.

\section{T. egregius Arn.}

\section{Genus Tachysphex Kohl.}

우 (hitherto undescribed). $8 \cdot 5 \mathrm{~mm}$. long. Apical margins of the first five tergites with bands of whitish pubescence. Pygidial area elongate triangular, shining, very sparsely and finely punctured, acute at the apex. Otherwise like the $\sigma^{*}$ in colour, sculpture and pubescence. Interocular distance on the vertex equal to the length of the first three joints of the flagellum plus a third of the fourth joint. The median third of the clypeus is depressed behind the anterior margin, which is moderately convex. Second joint of the flagellum two-thirds longer than the first joint, the third joint one-fourth longer than the second. The comb of the anterior tarsi is composed of long blackish cilia. The second abdominal segment is moderately constricted at the base laterally, but less than in the $\delta$. The dorsum of the epinotum has the same sculpture as in the $\sigma^{x}$.

Lady Grey, C. P. (R. I. Nel). Type in the Rhodesia Museum. 
T. Braunsi Arn. var. rufopictus n.v.

o. $8 \mathrm{~mm}$. long. Eyes greenish yellow, first three tergites yellowish red. Wings pale flavo-hyaline. Median area of the clypeus triangularly produced as in the type of the species, but not so long or so acute at the apex. Antennae a little more slender. Otherwise like the type of the species.

Lady Grey, C. P. (R. I. Nel). Týpe in the Rhodesia Museum.

\section{T. Barkeri Arn.}

f. A slight variety of this species from Sawmills, S. R., differs from the type of the species in being slightly smaller, $10 \mathrm{~mm}$. long, and in lacking the superficial reticulate-rugosity on the dorsum of the epinotum. There is no yellowish tinge at the base of the wings, the venation of which is brown, not yellow as in the type of the species. The interocular distance on the vertex is also a little shorter, being somewhat less than the length of the second and third joints of the flagellum, but equal to that of the first and second.

Rhodesia Museum.

T. suavis n.sp.

․ $13 \mathrm{~mm}$. long. Allied to T. Hippolyta Arn., the colour, pubescence and asymmetry of the claws being as in that species. The puncturation of the face and vertex is relatively, in view of the greater size of this insect, much finer than in that species. Mesonotum shining, with a microscopic and very sparse puncturation, its anterior half with a few larger punctures. Scutellum, metanotum and mesopleurae very shining, with even more minute puncturation than the mesonotum. Dorsum of the epinotum dull, with sculpture similar to that of Hippolyta but stronger, and without a round smooth space at the apex; sides of the epinotum obliquely, the declivity transversely and strongly striate. Tergites $\mathrm{I}-5$ dull and microscopically punctured as in Hippolyta, the pygidial area moderately shining, shallowly and fairly closely punctate-rugulose; sternites 3-6 smooth and shining, the second dull and finely pubescent. Clypeus like that of Hippolyta in shape but much more coarsely punctured behind the depressed margin. Vertex wider than in Hippolyta, being equal to the length of the first two joints of the flagellum plus half of the third and nearly equal to half the interocular distance across the clypeus. The second joint of the flagellum is as long as the third and a little more than twice as long as the first. The vertex behind the ocellar area is smooth and lacks the $Y$-shaped furrow which is present in Hippolyta. Dorsum of the epinotum as long as the scutellum plus twice the length of the metanotum (shorter than the scutellum and metanotum united in Hippolyta). Fourth tarsal joint subtriangular, wider at the apex than long, the apical joint only two-thirds as long as the second.

Bulawayo, October, I o (G. Arnold). Type in the Rhodesia Museum.

Distinguished from Hippolyta by the greater size, wider vertex, different sculpture of the mesothorax, longer epinotum and by the relatively shorter fifth tarsal joint.

\section{T. ebeninus n.sp. (fig. 5).}

9. $9 \mathrm{~mm}$. long. Black. Last three or four joints of the tarsi reddish brown. Tegulae pale ochreous. Wings hyaline, the veins brownish ochreous. Face and clypeus with greyish pubescence, the thorax with a short, scanty and grey pilosity. Tergites with a thin whitish pubescence, very sparse and not forming fasciae on the apical margins. The whole body, excepting the clypeus, shining. 
Clypeus closely and finely punctured, the median area just behind the depressed anterior margin slightly shining and more coarsely punctured. Face and vertex finely punctured, the punctures separated by spaces about twice as great as their own diameter. Temples much more shallowly punctured than the vertex, almost impunctate. Mesonotum, mesopleurae, scutellum and metanotum a great deal more sparsely punctured than the vertex, the punctures of about the same size but shallower. Dorsum

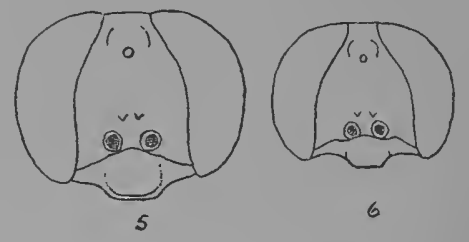

Fig. 5. Tachysphex ebeninus, ㅇ. Fig. 6. Tachysphex scabrosus, $0^{*}$. of the epinotum longitudinally striate, the striae arcuate outwards on each side of the middle third; the declivity and sides of the epinotum closely transversely striate. Tergites and sternites $I-5$ very finely and fairly closely punctured, the pygidial area elongate triangular, longer than wide at the base, acute at the apex, sparsely punctured at the sides, the punctures shallow and larger than those on the mesonotum. Median area of the clypeus not very convex transversely, its lateral angles rounded. Interocular distance at the base of the eyes two and a half times greater than across the vertex; at the latter point it is equal to the length of the first two joints of the flagellum plus a third of the third joint. Face shallowly impressed lengthwise in the middle as far as the anterior ocellus. The vertex is not impressed behind the ocellar area. Flagellum thin; the second joint as long as the third and twice as long as the first. Tarsal comb composed of long ochreous spines, of which there are six on the basal joint; the spines on the middle and hind legs are yellowish white. Inner spur of the hind tibiae shorter than the basal joint of the tarsus.

o. $7 \cdot 5-8 \cdot 5 \mathrm{~mm}$. long. All the tarsal joints, apices of the tibiae and the inside of the hind tibiae dark yellowish brown (raw umber). Face with pale golden pubescence. Eyes dirty brownish yellow. Otherwise like the $q$ in colour, sculpture and pubescence. Interocular distance at the base of the eyes twice as great as across the vertex, where it is equal to the length of the first two joints of the flagellum plus half of the third. Seventh tergite very widely rounded at the apex, almost semi-circularly. Otherwise like the $q$.

Redbank, S. R. I ㅇ, I $o^{*}$; Nyamandhlovu, S. R. I $o^{\star}($ R. H. R. Stevenson). Types in coll. Stevenson.

Allied to crassipes, but with a different sculpture on the epinotal dorsum, which resembles that of vulneratus; the striae are, however, finer and wider apart than in that species. In the specimen from Nyamandhlovu the tarsi are reddish, the tibiae fusco-ferruginous in front, a little paler behind. The dorsum of the epinotum is also distinctly punctured between the striae.

\section{T. scabrosus n.sp. (fig. 6).}

3. 7-8 mm. long. Black. Tarsi and apices of the tibiae pale ferruginous. Mandibles ferruginous in the middle. Wings hyaline, the veins blackish. Tegulae straw-yellow. Pubescence of the face and clypeus golden. Thorax with a scanty whitish pilosity, the abdomen with a thin, decumbent and whitish pubescence, somewhat more abundant on the apical margins, where it forms inconspicuous fasciae. Clypeus and face dull, closely and finely punctured. Ocellar area and vertex shining, the former finely, the latter strongly and not closely punctured, with a median impressed line behind the ocelli. Mesothorax and metanotum slightly shining, very strongly and fairly closely punctured, the spaces between the punctures a little wider than the 
latter. Dorsum of the epinotum very coarsely and rather closely reticulaterugose, the declivity with similar sculpture but punctured between the rugae, the sides strongly, transversely striate. Tergites very closely punctured, the first rather strongly so; the apical margins of the first four broadly, triangularly impressed, moderately shining and more finely punctured than the basal portion of the segments. Sternites shining, the second finely and closely, the following sternites microscopically punctured, the second to fourth with a row of outstanding yellowish hairs in the middle of their apical margins. Median area of the clypeus narrow, its anterior margin feebly convex, the lateral angles obtuse. Interocular distance across the clypeus nearly three and a half times wider than across the vertex, where it is equal to the length of the first two joints of the flagellum. Second joint of the flagellum nearly half as long again as the first, and a little shorter than the third. Apex of the seventh tergite widely rounded. Dorsum of the epinotum long, fully as long as the mesonotum and longer than the scutellum and metanotum united. Spines of the legs black.

Shiloh, S. R. 3 o (R. H. R. Stevenson). Type in coll. Stevenson.

A very distinct species characterised by the coarse puncturation of the mesonotum and by the very coarsely reticulate epinotal dorsum.

\section{T. Oberon Arn. var. mashona n.v.}

․ $9.5 \mathrm{~mm}$. long. Scapes and mandibles, excepting the apex, fuscoferruginous. Legs, excepting the coxae and trochanters, bright red. Sixth tergite piceous. Wings more deeply coloured than in the type of the species, distinctly ochreous hyaline, the apical margin distinctly fuscous. Vertex more shining and more finely punctured. Anterior margin of the median area of the clypeus with seven or eight indistinct teeth. Otherwise like the type of the
species.

Penkridge, Eastern Mashonaland, S. R. 2 q (R. H. R. Stevenson). Type in coll. Stevenson.

Specimens of Oberon i.sp. taken in the same locality also have more deeply coloured wings than in the type of the species, but as in the latter the legs and scapes are black.

\section{T. Braunsi Arn. var. debilis Arn.}

The name debilis is pre-occupied, having been applied by Turner to an Australian species of Tachysphex. I therefore propose the new name boer for this variety of Braunsi.

\section{Genus Tachytes Panzer}

It is remarkable that in treating of this genus no authors appear to have made use of the characters afforded by the $\hat{\sigma}$ genitalia. I omitted to do so myself in Part III of this work, largely on account of the paucity of material then available and of the wish to avoid damaging unique specimens. It is, however, not difficult to extract the genitalia without injuring the specimens, even with old material, provided that it has been sufficiently relaxed. The specimen should be held between the fingers of one hand, with the ventral surface upwards, and then with a fine pair of forceps the eighth ventral plate should be pushed back, i.e. towards the head; this opens the apex of the abdomen into which the forceps, slightly open, should be inserted nearly half way up the abdominal cavity. On closing the forceps and drawing them out with a downward motion the genitalia should come out fairly easily. 
The differences in the shape of the genitalia of closely allied species, e.g. opposita, melancholica and bulawayoensis, are certainly rather subtle, but they are rendered more apparent if drawings are made with a camera lucida on the microscope. The differences are most pronounced in the apical process of the outer paramera, which is usually only feebly chitinised and lamelliform. Seen from above, this part is often linear or nearly so, but when seen from the side it has the shape of a narrow tongue, abruptly dilated at the base. As I have already pointed out in these pages, the venation of the wings in the majority of the genera is of no value in the separation of species, but in this genus if the shape of the genitalia is used for the separation of species it will be found that the colour of the pubescence is just as unreliable as the venation. To take only one example; opposita and melancholica are closely allied species in which the only important differences are structural, i.e. the length of the galea and the shape of the genitalia. Perfectly fresh specimens of opposita can be recognised with the naked eye, but in faded examples, which can generally be recognised as such by the frayed margins of the wings, the brassy golden pubescence has faded to a greyish tint like that of melancholica, and without a careful comparison of the genitalia and galea, they are not separable. On the other hand, there are species which in colour of the pubescence resemble each other as closely as one egg does another, e.g. rhodesianus and midas, but in the $\delta$ sex these species are easily distinguished by the great dissimilarity of the genitalia.

I have therefore added a plate illustrating the genitalia of such species as were available. The complete revision of the African species of the genus cannot be made until the numerous species described by Turner have been re-examined for the genitalia.

It should be noted that the number of spines on the basal joint of the anterior tarsi is by no means constant within a species, and also that in those species in which the eighth ventral plate is emarginate the depth and width of the emargination and the acuteness of the angles on each side are subject to an appreciable amount of variation.

Below some corrections in synonymy are given and a few new species are described.

In the keys to the species the following corrections should be made:

Paragraph (I2) II. T. rhodesiana Bisch. The $q$ usually has five spines on the basal joint of the anterior tarsi, not six.

Paragraph (47) 42. ot $\delta$. The word "half" in the second line is to be deleted.

Paragraph (42) 47. After "neglecta" add, "and opposita."

\section{T. lichtenburgensis Arn.}

This should be considered as only a variety of nigro-annulata Bisch. from which it differs by the slightly greater size, stronger puncturation of the mesonotum and the more strongly striated epinotal dorsum. The genitalia are exactly like those of nigro-annulata (Plate VII, fig. I).

\section{T. melancholica Arn. (Plate VII, fig. I I).}

In fresh specimens the pubescence of the face and clypeus is pale golden. This species is closely allied to opposita Turner, from which it differs by the shorter and more rounded galea and by the narrower outer paramera of the genitalia. 
T. midas n.sp. (Plate VII, fig. I2).

o. I5-I $8 \mathrm{~mm}$. long. Colour, pilosity and pubescence exactly like that of rhodesiana Bisch. The sculpture is also for the greater part the same as in that species, but the rugulose puncturation of the epinotal dorsum is somewhat deeper and coarser. The interocular distance on the vertex is very nearly equal to the length of the first two joints of the flagellum, and the second joint is no longer than the third (in rhodesiana the interocular distance on the vertex is equal to the length of the second joint only, and not of the first two joints as stated in my description in Part II of this work, and the second joint is one-quarter longer than the third). As in rhodesiana the galea is distinctly shorter than the scape.

The genitalia are very different from those of rhodesiana, as may be seen by comparing figs. I 2 and ${ }_{1} 3$, Plate VII. The apical process of the outer paramera is broad, roundly dilated at the base; at about the middle of the paramera there is a vertical lamella, which, seen from the side, has the appearance of a spine. This is absent in rhodesiana, in which the apical process is also differently shaped. Otherwise like the of rhodesiana.

․ I $9 \mathrm{~mm}$. long. As in the other sex, the resemblance to rhodesiana is almost complete. The sculpture of the epinotum is stronger and the puncturation on the front of the mesonotum is different. In rhodesiana it consists of a very fine and very close puncturation all over, but in this species the anterior third of the mesonotum has a microscopic fundamental puncturation over which is scattered a fairly abundant and larger puncturation. First and second sternites very closely and finely punctured, the third to fifth shining and with a coarse and sparse puncturation just behind the apical margins, as in rhodesiana, but in this species the punctures are somewhat larger and more abundant. The second joint of the flagellum is very slightly longer than the third, whereas in rhodesiana it is a little more than one-third longer than the third joint. The basal joint of the fore tarsi has six ferruginous spines on the outer margin.

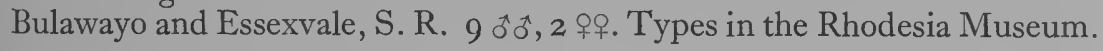

T. rhodesiana Bisch. (Plate VII, fig. I3).

$0^{*}$. The width of the vertex was incorrectly stated in my original description, and the correction has been given in the description of T. midas. The size of this species in the $\sigma^{-1}$ varies within wide limits. The smallest specimen which I have seen measures barely more than $10 \mathrm{~mm}$. long, and the largest $18 \mathrm{~mm}$.

T. bulawayoensis Bisch. (Plate VII, fig. Io).

o. I3 mm. long. The insect which I take to be the of this species resembles the $q$ in colour, sculpture and pubescence, except that the pubescence of the face is golden-silvery, and of the pygidial area golden. The interocular distance on the vertex is equal to the length of the second joint of the flagellum. Seventh tergite widely truncate at the apex; eighth sternite feebly emarginate, the apical angles rounded. Basal joint of the anterior tarsi with four spines. The subcosta is ochreous like the costa, not brown as in the ?.

Bulawayo, February. Taken in the same situations as the $q$. Type in the Rhodesia Museum.

T. lepida n.sp. (Plate VII, fig. I7).

o. $9 \mathrm{~mm}$. long. Black. First two joints of the tarsi brown, the rest ferruginous. The whole body, excepting the sternites, covered with a dense, decumbent and bronzy golden pubescence. The fifth tergite with fulvous pubescence, the face and epinotum with a scanty whitish pilosity. The first 
two sternites are closely and finely punctured, the second slightly shining, the remaining sternites shining and with a few large punctures near the apical margins. Clypeus shining in the middle in front, its anterior margin convex and without teeth. Face, vertex, mesonotum and scutellum closely and finely punctured, the dorsum of the epinotum finely and transversely rugulose. Interocular distance on the vertex equal to the length of the first two joints of the flagellum plus half of the third joint. The distance between the eyes across the clypeus is two and a half times as great as across the vertex. Second joint of the flagellum a little shorter than the third and about two-thirds longer than the first. Galea half as long as the scape, as long as wide at the base, widely rounded at the apex. Basal joint of the anterior tarsi with five yellowish spines. Wings hyaline, the veins ochreous.

o. $9 \mathrm{~mm}$. long. Black. Tibiae, tarsi and apices of the femora reddish ochreous, the middle tibiae and the hind ones on the outside sometimes black. Mandibles fusco-ferruginous. Fifth and sixth tergites with fulvous pubescence, elsewhere the pubescence is like that of the $q$ but less dense and slightly paler. Puncturation of the mesonotum coarser and less close than in the . Interocular distance on the vertex equal to the length of the first two joints of the flagellum plus a quarter of the third. Seventh tergite trapezoidal, the apex wide and transverse. Eighth sternite angularly emarginate. Apical process of the outer paramera of the genitalia broad, barely dilated at the base. Basal joint of the anterior tarsi with three or four whitish spines.

Sawmills, S. R. December. Types in the Rhodesia Museum.

This species is deceptively like nigro-annulata Bisch. but the genitalia are different and the rugulose sculpture of the epinotum is weaker.

\section{T. dilaticornis Turner (fig. 8).}

In this species, and also in T. Neavei Turner, the dilatation of the antennal joints is variable. In some specimens the enlargement is only slight and is not very noticeable except on the third to fifth joints of the flagellum. The genitalia, which are figured here, are distinctive, and enable the species in the $\delta^{t}$ sex to be recognised with ease. The size varies within fairly wide limits, from $10-13.5 \mathrm{~mm}$. in length.

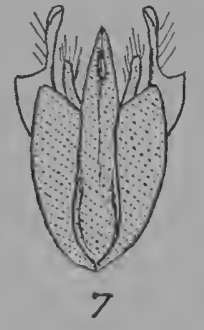

Fig. 7. Tachytes versatilis, genitalia.

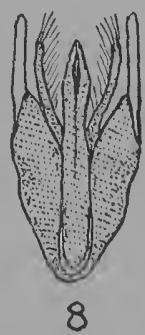

8

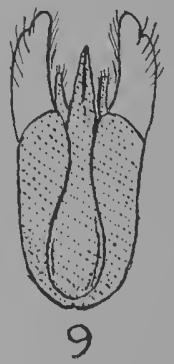

Fig. 8. Tachytes dilaticornis, genitalia. Fig. 9. Tachytes pulchricornis, genitalia.

\section{T. pulchricornis Turner (fig. 9).}

In perfectly fresh specimens of this species the pubescence of the thorax, legs and abdomen has no silvery tint, but is pale brassy yellow. The genitalia have the apical process of the outer paramera much broader than in most of the other species and almost as heavily chitinised as the basal part.

Additional localities are Bulawayo and Belas, P.E. A. (R. H. R. Stevenson). 
T. versatilis Turner (fig. 7).

In fresh specimens of the $\sigma^{t}$ the pubescent fasciae on the tergites are yellowish grey, and the first tergite has long fulvous pilosity like that of the thorax. In both sexes the pubescence of the thorax in the fresh condition is deep orange-golden and so dense as to hide the underlying sculpture. The genitalia of the $\hat{o}$ resemble those of bulawayoensis.

Additional localities are Dondo, P.E. A. (R. H. R. Stevenson); Victoria Falls (G. Arnold).

\section{T. Silverlocki Turner}

The pygidial area in the $q$ is covered with pale golden setae, not brownish golden as stated in my previous description. This error was due to confusing disputabilis with this species. The two are very closely allied, and, apart from the colour of the pygidial setae, the smaller size of Silverlock $i$ and the sculpture of the epinotum, there is very little to distinguish the two. In this species the epinotal dorsum is not quite dull, and is transversely rugulose, whereas in disputabilis it is dull and closely reticulate-rugulose.

\section{Genus Paranysson Guérin}

P. brevispinosus n.sp. (figs. 10, 10 $a$ and $b$ ).

․ $12 \mathrm{~mm}$. long. Allied to and closely resembling P. quadridentatus. Colour as in that species, the head and thorax black, abdomen and legs ferruginous, the sides of the tergites somewhat diffusely infuscated. Mandibles black, fusco-ferruginous in the middle. Sculpture of the head and thorax, excepting the epinotum, like that of quadridentatus. Dorsum of the epinotum narrower than in that species, with short and numerous longitudinal rugae on the basal and apical thirds, the middle reticulate-rugose; in quadridentatus the basal two-thirds are longitudinal rugose and the apical third is somewhat sparsely and irregularly reticulate. The lateral margins of the epinotal declivity have a wide triangular tooth at about the middle, much more distinct and larger than the slight angle which is present in quadridentatus. Abdomen more elongate or less cordiform than in quadridentatus and almost dull above, the puncturation distinctly closer than in quadridentatus, the fifth tergite shining, sparsely and coarsely punctured as in quadridentatus, the pygidial area triangular, sparsely and fairly strongly punctured, the apex subacute. Sternites shining, very sparsely and finely punctured. Pubescence like that of quadridentatus. Median area of the clypeus broadly and triangularly deflected in front, the anterior margin more deeply impressed than in quadridentatus, transverse and not convex as in that species, and with two stout teeth on each side. Second joint of the flagellum only twice as long as the first and barely longer than the third. Interocular distance on the vertex relatively greater than in quadridentatus, being equal to the length of the first four joints of the flagellum. The apical joint of the flagellum is not longer than the preceding one. The spine on the hind coxa is black, inserted at the apical angle, much shorter and less slender than in quadridentatus. The basal joint of the anterior tarsi has nine short spines on the outer margin. Otherwise like quadridentatus $q$.

Sawmills, S. R. Type in the Rhodesia Museum. 


\section{P. Oscari Turner, race servus n.r.}

o. $8 \mathrm{~mm}$. long. This race differs from the type of the species as follows. Vertex behind the ocelli more sparsely punctured. Apical joint of the flagellum more narrowed towards the end, nearly twice as long as the penultimate joint. Mesonotum more shallowly punctured; dorsum of the epinotum longitudinally rugose, with very few transverse anastomoses, the apex not margined by strong rugae but merging gradually into the declivity. The basal bifurcate lobes of the outer paramera of the genitalia are differently shaped.

Paiata, Liberia, type (Dr J. Bequaert); Stanleyville, Belgian Congo, 3 ơ ${ }^{*}$. The specimens from Stanleyville are a little larger, $9 \mathrm{~mm}$.

\section{P. congoensis n.sp. (figs. II, II $a$ and $b$ ).}

f. II.5 mm. long. Coxae and trochanters ferruginous, otherwise the colour and pubescence are the same as in quadridentatus, with which this species is closely allied. Puncturation of the head and thorax as close as in

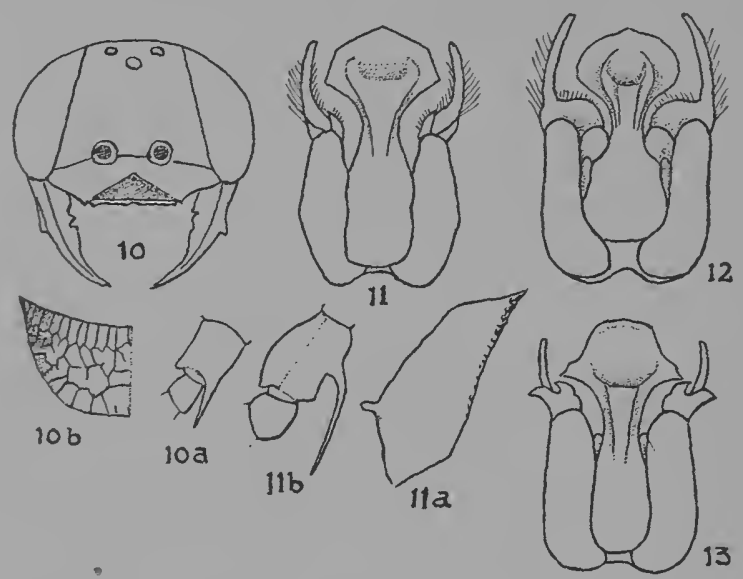

Fig. 10. Paranysson brevispinosus, $q$, head; $a, q$, hind coxa; $b, q$, half of epinotum.

Fig. I I. Paranysson congoensis, $\hat{\sigma}$, genitalia; $a, \uparrow$, epinotum, lateral view; $b, \wp$, hind coxa. Fig. 12. Paranysson quadridentatus, ô, genitalia.

Fig. I3. Paranysson Oscari, ô, genitalia.

quadridentatus, but distinctly smaller. The sculpture of the epinotal dorsum is like that of brevispinosus, but the longitudinal rugae on the basal third are less numerous, and the apical third, except the depressed median area, is reticulate like the middle third of the segment. The first three tergites are dull, more finely and much more closely punctured than in quadridentatus, the spaces between the punctures being barely wider than the latter (on an average two or three times as wide in quadridentatus). The teeth on the anterior margin of the clypeus are only feebly developed. The vertex is narrower than in quadridentatus, the interocular distance across the clypeus being two-thirds greater than on the vertex, whereas in quadridentatus it is barely more than one-half greater. The second joint of the flagellum is about twice as long as the first and hardly one-sixth longer than the third; the apical joint is slightly longer than the penultimate. The lateral margins of the epinotal declivity have a blunt tooth, longer than wide at the base, a little below the middle. Basal joint of the anterior tarsi with nine short ferruginous 
spines. Hind coxae with a long spine arising from the middle of the inner margin. Wings a little paler than in quadridentatus, otherwise like that species.

0 . Io $\mathrm{mm}$. long. Coxae and trochanters ferruginous, otherwise like the $q$ in colour. Pubescence of the face and clypeus greyish golden. Puncturation of the head, thorax and abdomen much finer than in quadridentatus $s$, the puncturation of the first four tergites very fine as in the + , the first six tergites dull, the seventh slightly shining, less coarsely punctured than in quadridentatus. The sculpture of the epinotal dorsum is like that of the . . Anterior margin of the clypeus convex, with a short and narrow rectangular projection in the middle and feebly bidentate on each side of the projection. Vertex distinctly narrower than in quadridentatus $\hat{0}$, the interocular distance across the clypeus being two-thirds greater than across the vertex (one-half greater in quadridentatus). The width of the vertex between the eyes is equal to the length of the first four joints of the flagellum. The posterior ocelli are separated from the eyes by a distance equal to the diameter of the ocellus (twice as great in quadridentatus). The second joint of the flagellum is twice as long as the first and barely longer than the third; the apical joint is a trifle longer than the preceding. The genitalia are quite different from those of quadridentatus but resemble those of Oscari, although the basal portion of the apical process of the outer paramera is differently formed (see figs. 12 and 13 ).

Stanleyville, Belgian Congo, I + , I $o^{*}$ (Dr J. Bequaert). Types in the Congo Museum, Tervueren.

\section{Genus LARRA Fab.}

L. proditor Kohl, var. rufa n.v.

A form of this species from Lubutu, Belgian Congo, differs in having the whole abdomen ferruginous, and of a paler tint than in the type of the species. The wings also are not quite so deeply tinged with brown.

Type in the Congo Museum, Tervueren.

\section{Genus Notogonidea Rohwer.}

The species of the sepulchralis and miscophoides groups are very much alike to the naked eye, and even with a fairly high magnification the differences in external structural characters, especially in the $\sigma^{t} \mathrm{sex}$, have to be searched for with care and patience. It is therefore fortunate that the structure of the genitalia is very diversified and specific, affording means whereby the $\delta \sigma^{*}$ of the several species can be easily recognised. I have therefore given figures here of the genitalia for these two groups. The inner paramera are usually lamelliform, plane, or spoon-shaped, and also sometimes twisted. In the normal position they are seen more or less on edge from above, and therefore appear very narrow, but seen from the side (fig. 27) they appear as broad plates projecting above the outer paramera. In my treatment of this genus in Part III too much weight was given to the venation, which the examination of a larger amount of material has now proved to be unreliable. Whereas the species can easily be separated in the $\sigma^{\top} \mathrm{t}$ by the genitalia, it is by no means so simple in the case of the 우․ In this sex the most valuable diagnostic characters are furnished by (I) the shape of the pronotal collar and of the pygidium, (2) the interocular distance on the vertex, (3) the claws, whether armed with teeth or not, (4) the colour of the wings, and (5) the sculpture. In the sepulchralis and miscophoides groups the sculpture on the epinotal dorsum is somewhat variable within the species. 


\section{N. sepulchralis Gerst.}

On reading the fuller description of this species given in Peter's Reise nach Mozambique, it is clear that the synonymy given on P. 244, Part III, which I accepted from the arrangement in the British Museum's collection, is incorrect. Gerstaecker's species has the sixth tergite in the $q$ smooth and shining, and is very probably the same as the variety of pompiliformis which I described as intermedia.

The species described by me as sepulchralis is without doubt the $N$. radialis of Saussure, and the name on p. 244 should be corrected accordingly. $N$. antaca Sauss. is the $q$ of radialis, the latter name having priority.

\section{N. Bequaerti n.sp.}

․ I I mm. long. Allied to pseudoliris Turner but smaller and with much less slender antennae. Black. Tegulae and legs ferruginous, the scapes dark brown in front, the mandibles fusco-ferruginous. Fourth and fifth tergites dark brown at the apical margin. Wings flavo-hyaline, somewhat paler than in pseudoliris, the apical margin very faintly fuscous, the veins reddish ochreous. Clypeus, face, temples and thorax with a pale brassy pubescence, scanty on the thorax. First three tergites with a very fine brassy golden pubescence, much finer and shorter than in pseudoliris and confined chiefly to the apical halves of the segments. Pygidial area covered with pale yellow pubescence, the apical margin with five ferruginous spines. Sternites I-3 dull, closely and microscopically punctured and covered with fine pubescence, the remaining sternites glabrous, shining, sparsely and coarsely punctured. The sculpture of the thorax is like that of pseudoliris but finer, especially on the epinotal dorsum. Anterior margin of the clypeus feebly convex, with a very small and shallow excision in the middle. Interocular distance on the vertex equal to the length of the second joint of the flagellum plus one-third of the third. The joints of the flagellum are considerably shorter than in pseudoliris, the second joint is hardly twice as long as the first and only a trifle longer than the third, and only two and a half times longer than wide at the apex (four times longer in pseudoliris). The dorsum of the epinotum is a little wider across the base than long in the middle. The pygidial area is triangular, closely and finely punctured and more widely truncate at the apex than in pseudoliris. As in that species the claws are unarmed.

Zambi, Belgian Congo, I o (Dr J. Bequaert). Type in the Congo Museum, Tervueren.

\section{N. nitens n.sp. (fig. I4).}

o. $8 \mathrm{~mm}$. long. Black. Hind femora ferruginous, the tibiae, tarsi and apices of the fore and middle femora, fusco-ferruginous. Scapes in front and the middle of the mandibles also fusco-ferruginous. Wings fusco-hyaline, somewhat paler at the base, the veins and stigma black. Face and clypeus with silvery pubescence. Thorax and apical margins of the first three tergites with a scanty greyish pubescence, longer and more conspicuous on the epinotal declivity than elsewhere. Anterior margin of the clypeus smooth and shining, the rest of the clypeus and also the face dull, microscopically and closely punctured; vertex, scutellum and metanotum shining, finely and not closely punctured, the spaces between the punctures about three or four times wider than one of the punctures. Mesonotum and mesopleurae not quite dull, more closely and more coarsely punctured than the scutellum. Epinotum and metapleurae shining, the latter impunctate, the former strongly rugose, 
the rugae transverse on the dorsum and declivity, oblique on the sides. Abdomen microscopically and closely punctured and dull. Anterior margin of the clypeus obtusely angular in the middle. Second joint of the flagellum twice as long as the first, and as long as the third. Interocular distance on the vertex equal to the length of the first two joints of the flagellum plus a third of the third joint. Pronotal collar linear above. Dorsum of the epinotum fairly long, about as long as wide at the base and as long as the mesonotum, the posterior angles rectangular. Posterior femora not angulated at the base.

Coquilhatville, Belgian Congo, June, I $\sigma^{*}$, (Dr J. Bequaert). Type in the Congo Museum, Tervueren.

Superficially this species resembles $N$. thysanomera, race usambarensis Cam. but the genitalia are of an entirely different build.

N. egregia n.sp. (figs. I 5, I $_{5} a$ ).

o. $9 \mathrm{~mm}$. long. Black. Apical half of the flagellum dark brown. Wings faintly fusco-hyaline, the apical margin narrowly and more deeply fuscous, the reins brown. Clypeus and lower half of the face with silvery, the upper half of the face with pale golden, pubescence. Temples and thorax with a fine grey pubescence, the abdomen with an exceedingly fine, decumbent and dark brown pubescence, the first three tergites with apical fasciae of greyish pubescence, the sixth laterally and the whole of the seventh with longer yellowish grey pubescence. Fifth sternite arcuately emarginate over the greater part of the hind margin and bearing on each side a pencil of long brown hairs. Wings faintly fusco-hyaline, the apical margin more deeply fuscous, the veins dark brown. Whole body dull; head microscopically and closely punctured, mesonotum very finely and closely punctate-rugulose, the mesopleurae microscopically reticulatepunctate, the scutellum and metanotum closely and finely punctured. Dorsum of the epinotum transversely and closely striate, almost rugose. Anterior margin of the clypeus smooth, moderately convex, not excised in the middle. Interocular

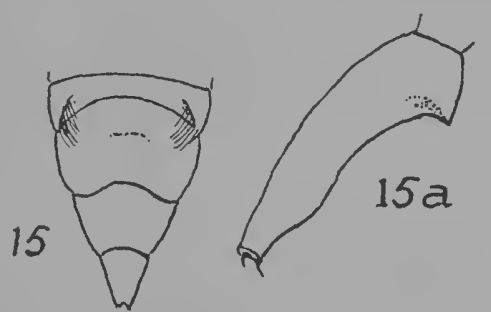
distance across the base of the clypeus

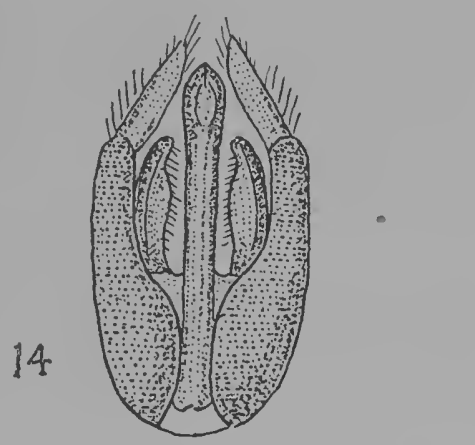

Fig. I4. Notogonidea nitens, ฮิ, genitalia.

Fig. 15. Notogonidea egregia, $\mathrm{O}^{+}$, apical sternites; $a, \hat{o}$, left femur from below.

about three-fourths greater than across the vertex, where it is equal to the length of the first two joints of the flagellum plus one-third of the third joint. The second joint of the flagellum is half as long again as the first and distinctly shorter than the third. Pronotal collar oblique, its dorsal face linear. Dorsum of the epinotum one-fifth longer than wide at the apex, four times longer than the scutellum. Seventh tergite trapezoidal, the apical margin wide and feebly concave. Eighth sternite arcuately emarginate. Posterior femora strongly angulated at the base, almost dentate.

Coquilhatville, Belgian Congo, $2 \sigma^{\pi}$ (Dr J. Bequaert). The type in the Congo Museum, the paratype in the Rhodesia Museum. 
Easily recognised by the peculiar fimbriae on the fifth sternite, the strongly angulated posterior femora and by the structure of the genitalia (fig. I6).

\section{$N$. thysanomera Kohl, race usambarensis Cam.}

A variety of this race is to be recorded from Bulawayo, in which the $q$ has the last two abdominal segments and the scapes of a reddish colour.

N. pompiliformis F. race intermedia Arn. (fig. I9).

This varies in size rather considerably, the $0^{*} 0^{*}$ measuring from 6 to $9.5 \mathrm{~mm}$. in length, and the of from 9.5 to $12 \mathrm{~mm}$.

Two of in the R. M. coll. from S. Rhodesia differ from the typical form in having the pygidial area dull and the sides straight. Specimens of $N$. simulatrix in both sexes in a worn condition may be mistaken for this species, but

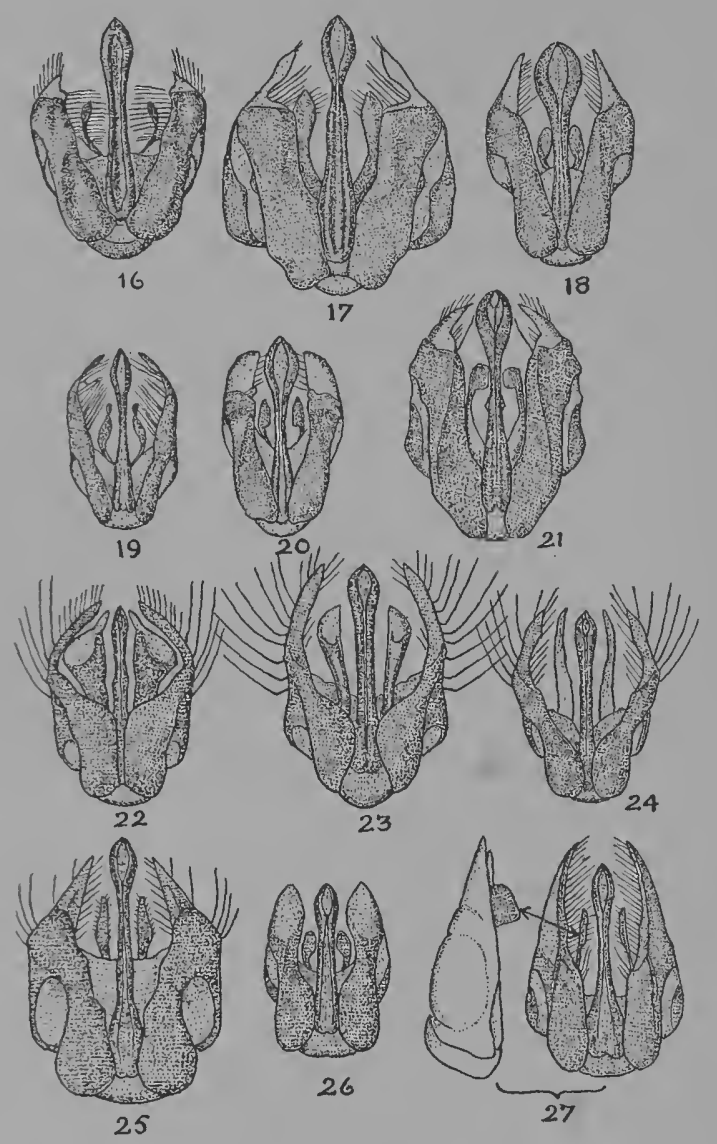

Fig. 16. Notogonidea egregia, $\hat{0}$, genitalia.

Fig. 17. Notogonidea radialis.

Fig. 18. Notogonidea felina.

Fig. I9. Notogonidea pompiliformis-intermedia.

Fig. 20. Notogonidea angustiventris.

Fig. 21. Notogonidea thysanomera.

Fig. 22. Notogonidea gracilicornis.

Fig. 23. Notogonidea minima.

Fig. 24. Notogonidea miscophoides.

Fig. 25. Notogonidea nigricans-palumbula.

Fig. 26. Notogonidea ciliata.

Fig. 27. Notogonidea simulatrix, lateral and dorsal views. 
simulatrix has the basal half of the wings tinged with ochreous, and the veins in that part are also ochreous, whereas in pompiliformis-intermedia there is no ochreous tint, and the veins are black.

N. miscophoides Arn. (fig. 24).

o (hitherto undescribed). $5 \cdot 2-6 \cdot 3 \mathrm{~mm}$. long. Tarsi black or dark brown, the last two abdominal segments piceous, otherwise coloured like the o. Seventh tergite trapezoidal, the apical margin wide, fairly closely covered with large and shallow punctures. Eighth sternite widely rounded at the apex, nearly semi-circular. Interocular distance across the base of the clypeus fully two and a half times greater than across the vertex, where it is equal to the length of the first two joints of the flagellum. The second joint of the latter is as long as the third and not quite twice as long as the first (in the $q$ the interocular distance on the vertex is equal to the length of only the second joint). Outer paramera of the genitalia much narrowed towards the apex from beyond the middle, curved inwards, fringed with numerous hairs on the inner, and with six long hairs on the outer margin; the inner paramera thin, cultrate, translucent and flat. Otherwise like the of.

Hope Fountain and Khami, S. R. Type in the Rhodesia Museum.

N. minima Arn. (fig. 23).

The o varies in size from $6 \cdot 5-8 \cdot 2 \mathrm{~mm}$.

of (hitherto undescribed). $6-7 \mathrm{~mm}$. long. Tarsi black, otherwise like the of in colour, sculpture and pubescence. Median area of the clypeus subcarinate in the middle, its anterior margin straight and entire, not slightly excised as in the . Second joint of the flagellum twice as long as the first and as long as the third. Interocular distance across the base of the clypeus nearly three times as great as across the vertex, where it is equal to the length of the first two joints of the flagellum. Genitalia not unlike those of miscophoides, but the outer paramera have about I4 hairs on the outer margin and the inner paramera are ampliated over the apical third and are somewhat hollowed out above. Otherwise like the o.

Bulawayo, June to July. Type in the Rhodesia Museum.

Dr Maidl has given the name minima to a species of Notogonidea from El Obeid (Denkschr. Akad. Wiss. Wien, vol. xcIx, p. 237, 1924). Since minima Arn. has priority, I propose for Dr Maidl's species the name Maidli, n.nov.

\section{N. gracilicornis Arn. (fig. 22).}

ô (hitherto undescribed). $5 \mathrm{~mm}$. long. Tarsi blackish brown. Apical margins of the second to sixth tergites dark brown. Pubescence like that of the $q$ but much scantier. Dorsum of the epinotum not quite dull, closely, transversely and finely rugulose and very shallowly reticulate between the rugae. Sternites moderately shining, very finely and shallowly punctured. Otherwise like the $q$ in colour and sculpture. Interocular distance across the clypeus barely more than twice as great as across the vertex, where it is equal to the length of the first two joints of the flagellum. Median area of the clypeus longitudinally carinate, the anterior margin transverse. Second joint of the flagellum as long as the third and half as long again as the first. Pronotal collar as in the . Seventh tergite trapezoidal, the apical margin straight and wide, the eighth sternite subquadrate, wider than long, the apical margin convex. Outer paramera of the genitalia with the apical portion narrower than in either miscophoides or minima, and more incurved, the outer margin with 
about $\mathrm{r}_{4}$ hairs; the inner paramera subtriangularly dilated and swollen apically, the extreme apex subulate.

Matopos and Bulawayo, May to June. Type in the Rhodesia Museum.

Not taken with the + , but I think this $\sigma^{x}$ is co-specific with the type on account of the structure of the pronotum and the puncturation of the head and mesonotum.

\section{Genus Palarus Latr.}

\section{P. Handlirschii Brauns, race occidentalis n.r.}

․ I I $\mathrm{mm}$. long. Allied to the variety nigrior Arn. from which it differs chiefly in colour and puncturation.

Clypeus and the two supra-antennal spots, which are larger than in nigrior, white. The spots on the tegulae and the streaks on the fore and middle femora are.also white, instead of yellow as in nigrior. Tergites $\mathrm{I}-5$ ivory white, the declivous base of the first, and the extreme base of the other tergites, black; the depressed apical margins of the segments brown. Middle and hind tibiae and tarsi reddish yellow. Mesonotum very convex, and like the scutellum, shining and sparsely punctured, much more sparsely than in nigrior; the mesonotum is also less pubescent than in that variety. Tergites more sparsely and slightly more finely punctured. The pygidial area as in nigrior. Face more prominent in the middle above the antennae. Otherwise like var. nigrior .

o. $12.3 \mathrm{~mm}$. long. Colour of the head and thorax as in the \%. The markings on the abdomen like those of nigrior $\sigma^{*}$ and of the same colour, yellowish white, but the maculae on the first tergite are larger. As in the +, the mesonotum is much more convex than in nigrior, and like the scutellum it is shining and much more sparsely punctured than in nigrior. The seventh tergite is much less ampliated at the sides, so that it is longer than wide, whereas in nigrior it is wider than long. Mesopleurae much more finely punctured than in nigrior 0 . Otherwise like that variety.

Kaross, S.W. Africa, I $q$, I 0 . Types in the South African Museum.

\section{MISCOPHUS Group.}

\section{Genus Nitela Latr.}

N. parallela n.sp. (figs. $28,28 a$ ).

․ $3 \cdot 2 \mathrm{~mm}$. long. Black. The anterior tibiae and all the tarsi brown. Wings hyaline, the veins black. Clypeus and lower third of the face with a sparse silvery pubescence. Head dull, closely punctured (the punctures not distinct with a magnification of less than 30 diamcters), the temples more shallowly punctured than the vertex. Pronotum dull, the dorsal face of the collar closely reticulaterugose. Mesonotum and scutellum not quite dull, as finely and as closely punctured as the vertex, but more shallowly, with a few longitudinal rugae at the base. Mesopleurae moderately shining, punctured like the mesonotum, and with a clathrate groove extending from the episternal suture to the metapleurae, the latter smooth and shining. Dorsum and sides of the epinotum dull, longitudinally rugose and with numerous transverse anastomoses, the declivity reticulate-rugose and dull. Abdomen smooth and shining.

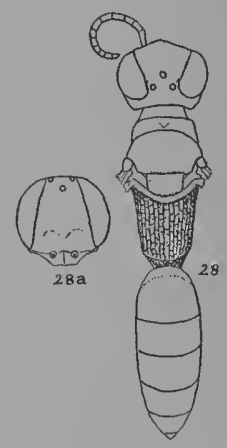

Fig. 28. Nitela parallela, 우 $a$, ㅇ, head. Median area of the clypeus carinate lengthwise in the middle, the anterior 
margin transverse. Eyes strongly divergent below, the interocular distance across the clypeus being twice as great as across the vertex, where it is equal to the length of the first three joints of the flagellum. Posterior ocelli separated from the eyes by less than their own diameter, five times as far from each other as from the eyes. First joint of the flagellum a little longer than the second and nearly as long as the third. Pronotal collar about four times wider than long in the middle, the shoulders rounded. Dorsum of the epinotum long: as long as the mesonotum and pronotum united, and distinctly longer than wide at the apex. The whole thorax is rather narrow. Abdomen narrow, for the greater part parallel-sided, the first segment the longest.

Umtali, S. R. May, I + (R. H. R. Stevenson). Type in coll. Stevenson.

\section{N. lubutuana n.sp. (fig. 29).}

. $6 \mathrm{~mm}$. long. Black. Legs pale ferruginous, the middle femora slightly fuscous basally, the hind femora blackish over the basal two-thirds. Mandibles ferruginous, blackish at the base, with a tooth on the inner margin some distance from the acute apex. Wings hyaline, faintly tinged with fuscous, the veins and stigma dark brown. Lower half of the face with a thin whitish pubescence, the rest of the head and the thorax with a greyish, scanty and microscopic pubescence. Anterior margin of the clypeus with eight brownish porrect bristles. Head dull, closely and microscopically punctured, only the anterior margin of the clypeus in the middle being smooth and shining. Pro-mesonotum and meta-

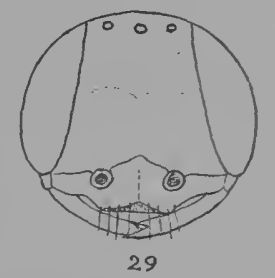
notum dull. The pronotum is closely rugulose and coriaceous, the dorsal face with two curved grooves on each side of the middle. Mesonotum and mesopleurae behind the episternal suture closely and finely punctured, the mesonotum with a few irregular transverse rugae at the sides in front; the mesopleurae rugose in front of the episternal suture, from which near the base a clathrate groove extends back as far as the middle of the segment. Above the groove is a deep pit. Scutellum flat, much more finely and less closely punctured than the mesonotum. Metanotum microscopically punctured. Epinotum widely reticulate-rugose, the rugae emphasised longitudinally on the dorsum and the sides, the spaces between smooth and shining on the dorsum, coriaceous on the sides, the declivity reticulate-rugose. Abdomen smooth and shining, with a puncturation which is barely visible under a magnification of 40 diameters. Antennal sockets separated from the anterior margin of the clypeus by a distance equal to half the length of the first joint of the flagellum. Median area of the clypeus with a strong carina which extends beyond it as far as the end of the concave portion of the face. Eyes moderately convergent above. Second joint of the flagellum as long as the first and distinctly shorter than the third. Interocular distance on the vertex equal to the length of the first three joints of the flagellum. Posterior ocelli three times as far from each other as from the eyes. Pronotal collar about four times wider than long, the anterior angles rounded. Dorsum of the epinotum a little longer than wide at the apex and nearly as long as the promesonotum. Second sternite transversely impressed on each side at the base, the sixth sternite transversely compressed but not carinate lengthwise. Maxillary palpi ochreous and long, fully half as long as the antennae.

Lubutu, Belgian Congo, January, 3 of (Dr J. Bequaert). Type in the Congo Museum, Tervueren, paratype in the Rhodesia Museum. 
Allied to capicola Brauns of which only the of is known. It is, however, too large to be the $q$ of that species, and, moreover, the sculpture of the mesonotum and scutellum is different.

\section{S. scrobiculata Brauns.}

\section{Genus Solierella Spin.}

ot (hitherto undescribed). $3-3 \cdot 3 \mathrm{~mm}$. long. Basal joint of the tarsi varying from pale ochreous to brownish ochreous, the other joints pale brown. The hind tarsi are slightly thickened, especially the first two joints. Antennae $\mathrm{r} 2$-jointed as in the 9 . Seventh tergite widely rounded at the apex. Eyes slightly more divergent below than in the \%; otherwise like that sex.

Bulawayo, May to June and December, numerous specimens of both sexes, nesting in sand (R. H. R. Stevenson). Type in the Rhodesia Museum.

\section{S. rhodesiana Arn.}

o (hitherto undescribed). $3 \mathrm{~mm}$. long. Tibiae and tarsi, excepting the apical joint, pale lemon yellow, the apical joint brownish. Puncturation of the head and scutellum stronger, otherwise like the $q$ in sculpture, colour and pubescence. The clypeus is not produced in the middle as in the + , but the carina is sharper than in that sex, and there is a small sharp tooth at the middle of the anterior margin. Antennae I3-jointed, the apical joint very long, fully as long as the five preceding joints united. Seventh tergite triangular, narrowly rounded at the apex.

Bulawayo, September to October, found in the same situations as scrobiculata. Type in the Rhodesia Museum.

\section{M. verecundus Arn.}

\section{Genus Miscophus Jur.}

o (hitherto undescribed). $5 \mathrm{~mm}$. long. Second abdominal segment red, the tergite with a brownish patch on each side. Legs a little paler than in the $\hat{\sigma}$, otherwise like that sex in colour, sculpture and pubescence. Flagellum slender, all the joints except the first much longer than wide, the first joint twice as long as wide, the second joint twice as long as the first and a little longer than the third. Interocular distance on the vertex equal to a little more than the length of the first three joints of the flagellum. Median area of the clypeus distinctly gibbous, its anterior margin less convex than in the $\sigma^{*}$. Apical tergite broadly conical, the apex narrowly rounded. Otherwise like the $\sigma^{t}$.

Matopos, S. R. October (R. H. R. Stevenson). Type in the Rhodesia Museum.

In another $q$ from the same locality all the tergites are reddish brown.

\section{M. bellulus Arn.}

$\hat{o}$ (hitherto undescribed). $4 \cdot 3-5 \mathrm{~mm}$. long. Mandibles pale yellow, fuscoferruginous at the base and apex. Anterior margin of the clypeus, scapes and the underside of the first three joints of the flagellum, dirty yellow. Legs entirely yellowish red. Last three abdominal segments pale ferruginous, the purplish patches on the first two tergites less distinctly defined than in the $q$, or sometimes extending over the whole of the second tergite. Otherwise like the $q$ in colour, sculpture and pubescence. Interocular distance on the vertex equal to the length of the first four joints of the flagellum. Posterior ocelli a little nearer to each other than to the eyes. As is usually the case in the genus, the joints of the flagellum are shorter and less slender than in the $q$; the second 
joint is about half as long again as the first and a little longer than the third. The median area of the clypeus is produced farther forwards than in the and its anterior margin is truncate. Otherwise like the $o$.

Matopos and Shikore River, S. R. October (R. H. R. Stevenson). Type in the Rhodesia Museum.

M. modestus n.sp. (figs. $30,30 a$ ).

7. $6.3 \mathrm{~mm}$. long. Black. Legs pale ferruginous, the femora diffusely fuscous abore. Mandibles fusco-ferruginous, reddish yellow at the base. Anterior margin of the clypeus reddish brown in the middle. Scapes in front pale ferruginous. Wings hyaline, the apical portion beyond the cells faintly fuscous, the veins brown.

Face and clypeus with a short, decumbent and rather sparse, yellowish pubescence, the thorax with a similar but longer pubescence. The abdomen has a fine, greyish yellow and decumbent pubescence, fairly dense on the tergites where it obscures the sculpture, especially on the apical margins of the first three where it forms fasciae which are more distinct at the sides than in the middle. Median area of the clypeus sparsely punctured, its widely

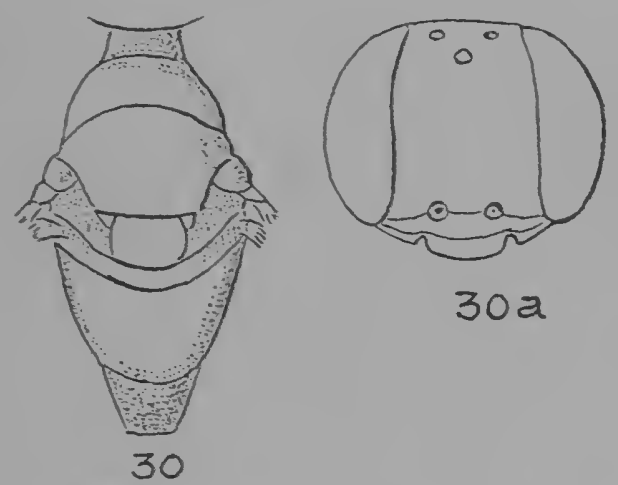

Fig. 30. Miscophus modestus, 우, thorax; $a$, 우, head.

depressed apical margin smooth and shining. Head dull, closely and finely punctured, or reticulate-punctate. Pronotum dull, closely and transversely striato-rugose, punctured between the rugae. Mesothorax closely reticulatepunctate, the punctures larger than those on the head, the mesopleurae with a few transverse rugae at the posterior margin. Dorsum of the epinotum reticulate-rugose, the rugae emphasised longitudinally and curved towards the sides, the spaces between the rugae somewhat shining; the sides of the epinotum more closely reticulate-rugose than the dorsum, the declivity transrersely rugose in the middle. Abdomen dull, closely and very finely punctured; the second tergite has a slightly bluish black colour. Eyes moderately divergent below, the interocular distance across the base of the clypeus half as great again as across the vertex, where it is equal to the length of the first two joints of the flagellum plus half of the third. Clypeus excised on each side between the lateral and median sclerites, the anterior margin of the latter convex. Second joint of the flagellum as long as the third. Collar of the pronotum convex transversely, sloping fairly gradually towards the neck, three times wider than long in the middle and fully half as long as the mesonotum. Dorsum of the epinotum nearly flat, as long as the declivity and not longer than the 
mesonotum, its junction with the declivity obtusely angular. Spines on the legs black. The stalk of the second cubital cell is about as long as that cell is high, and meets the radius a little before its middle.

Sanyati Valley, S. R. December, I \& (R. H. R. Stevenson). Type in coll. Stevenson.

\section{M. ichneumonoides n.sp. (figs. $31,3 \mathrm{I} a$ ).}

o. $5.3 \mathrm{~mm}$. long. Black. The extreme apex of the epinotal declivity and the first two abdominal segments ferruginous, the third tergite and the third to seventh sternites fusco-ferruginous. Tarsi brown, anterior tibiae yellowish brown above. Mandibles brownish yellow, the apex fuscous. Wings hyaline, strongly iridescent, the veins dark brown. Face, clypeus and sides of the first three tergites with a microscopic and fairly sparse silvery pubescence. Just above the antennal sockets there is a line of yellowish white pubescence extending from eye to eye. Clypeus finely and transversely rugulose, the depressed apical margin smooth and shining. Lower third of the face transversely rugulose and dull, the middle third slightly shining, with a small pit in the middle and an ill-defined hollow on each side below it, the upper third of the
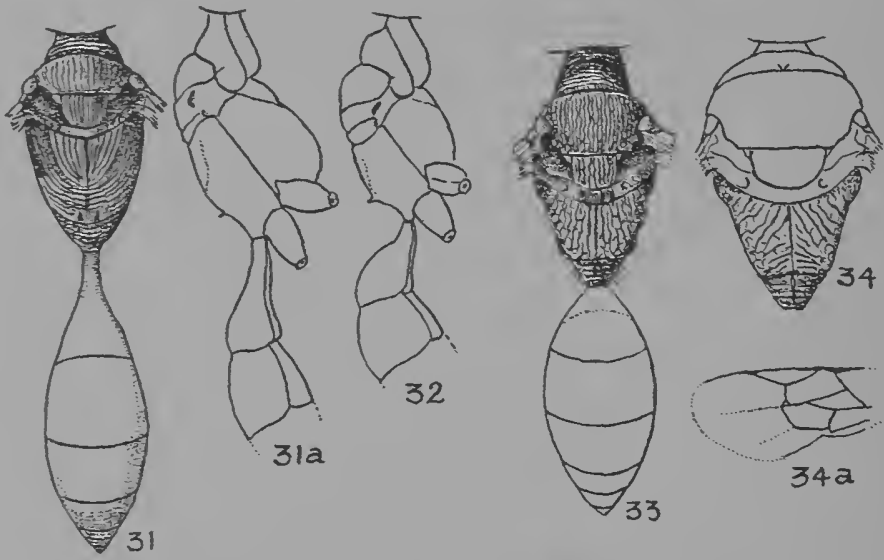

Fig. 31. Miscophus ichneumonoides, $\hat{o}^{1} ; a$, lateral view of thorax.

Fig. 32. Miscophus Kohli, ô, lateral view of thorax.

Fig. 33. Miscophus infernalis, 9 .

Fig. 34. Miscophus lugubris, $q$; $a$, apex of front wing.

face shining, microscopically reticulate or alutaceous. Vertex shining, transversely striate, the striae continued down over the temples. Pronotum transversely, mesonotum and scutellum longitudinally costate, the spaces between the costae fairly wide. Mesopleurae and sides of the epinotum transversely and closely rugose. Dorsum of the epinotum with a median longitudinal carina, longitudinally rugose on each side of the same, the rugae converging inwards towards the apex, the declivity transversely costate. Halfway down the declivity there are two small, erect teeth, and an impressed line extends from them to the dorsum. The dorsum and declivity merge together in a low curve. Metanotum smooth and shining. The whole thorax is fairly shining. Abdomen shining, very finely and not closely punctured. Interocular distance on the vertex equal to a little more than the length of the first two joints of the flagellum. The eyes are only moderately divergent 
below. Posterior ocelli a little farther from the eyes than from each other. Flagellum long and slender, all the joints, excepting the first and last, considerably longer than wide; the second joint is nearly three times longer than the first and two-fifths longer than the third. Pronotal collar long, the dorsal face very oblique, only a little shorter than wide at the base. Mesonotum very short, not much longer, measured tangentially, than the scutellum. First abdominal segment subpetiolate, three and a half times wider across the apical margin than at the base, longer than the second segment. The stalk of the second cubital cell meets the radius in the middle, the second recurrent vein meets the cubitus a little beyond the middle of the second cubital cell.

Sanyati Valley, S. R. November, I ô (R. H. R. Stevenson). Type in coll. Stevenson.

A very distinct species, distinguished from all our other species by the strong sculpture and subpetiolate abdomen. Allied to Kohli Brauns but the first abdominal segment is much longer and the shape of the epinotum quite different.

M. infernalis n.sp. (fig. 33).

+. $5.3 \mathrm{~mm}$. long. Black. Face and posterior margin of the pronotal collar with a few scattered silvery hairs. Metanotal disc, anterior angles of the epinotum and lateral margins of the declivity with similar, but longer and coarser, pubescence. Abdomen with a microscopic, sparse and greyish pubescence, a little more abundant on the apical margins of the first three tergites, but not forming distinct fasciae. Wings pale fuscous, their middle portion, or the greater part of the first cubital and both discoidal cells, clear hyaline; the veins dark brown. Head dull; the clypeus transversely rugulose, the lower third or more of the face strongly, transversely rugose, the rest of the face, the vertex and occiput closely reticulate-rugose, the temples striate lengthwise. Pronotum closely and transversely rugose above, feebly rugose and closely punctured at the sides. Mesonotum and scutellum longitudinally rugose, the former also reticulate at the sides posteriorly. Mesopleurae closely and transversely rugose, finely punctured between the rugae. Metapleurae less closely rugose than the mesopleurae. Dorsum of the epinotum widely reticulate-rugose, the rugae emphasised longitudinally, the lateral margins with two or three very strong rugae, the declivity slightly shining, and like the sides strongly and transversely rugose, the sides also punctured near the front. The whole thorax, excepting the declivity, nearly dull. Abdomen dull, the first two tergites very closely and very finely punctured, the remaining tergites microscopically and densely punctured, the sternites microscopically rugulose. Eyes moderately divergent below, the interocular distance across the base of the clypeus being only half as great again as across the vertex, where it is equal to the length of the first two joints of the flagellum plus half of the third. Posterior ocelli twice as far from each other as from the eyes. Second joint of the flagellum twice as long as the first and one-third longer than the third. Pronotal collar convex, merging with the neck by a short and gradual curve, the dorsal face about one-third as long as the mesonotum. Dorsum of the epinotum about as long as the scutellum and metanotum united, the lateral margins slightly raised. The stalk of the second cubital cell is only half as long as that cell is high and meets the radius a little before its middle. Tarsal spines long, thin and black.

d. $4.5 \mathrm{~mm}$. long. First six tergites equally punctured, the puncturation somewhat stronger than on the first two tergites of the . Eyes less divergent below than in the $q$, the interocular distance across the clypeus being only 
one-third greater than across the vertex, where it is equal to the length of the first three joints of the flagellum plus half of the fourth. Median area of the clypeus produced into a short, acute tooth. Second joint of the flagellum less than twice as long as the first, and about as long as the third. Otherwise like the o.

Bulawayo, August, I + , I $\sigma^{\wedge}$ (R. H. R. Stevenson). Types in coll. Stevenson.

\section{M. lugubris n.sp. (fig. 34).}

ㅇ. $4.3 \mathrm{~mm}$. long. Black. Wings hyaline, the apical portion beyond the cells slightly fuscous, the veins brown. Pubescence white and fairly coarse, very scanty on the clypeus and lower third of the face, a little more abundant on the temples and thorax, excepting the mesonotum, scutellum and epinotal dorsum. On the abdomen the pubescence is confined to the apical margins of the first four tergites. Head dull, finely, shallowly and closely punctured, the punctures separated by spaces about as wide as the punctures. Thorax dull; pronotum, mesonotum and scutellum as closely punctured as the head, but more strongly so, the metanotum more finely so. Mesopleurae coriaceous. Dorsum of the epinotum rugose, the rugae radiating outwards from the base, the sides and declivity coarsely and transversely rugose. Abdomen slightly shining, finely punctured, the punctures smaller and not so close together as those on the vertex. Eyes almost parallel, the interocular distance on the vertex being only slightly less than across the clypeus, and equal to the length of the first three joints of the flagellum. Posterior ocelli fully twice as far from each other as from the eyes. Flagellum not very slender, the second joint not quite twice as long as the first. Pronotal collar short, one-fourth as long as the mesonotum. Dorsum of the epinotum as long as the mesonotum. Abdomen ovate. Second cubital cell triangular, very small and almost obsolete, its stalk three times as long as the cell is high.

Nyamandhlovu, S. R. June, I \& (R. H. R. Stevenson). Type in coll. Stevenson.

\section{Genus SAliostethus Brauns.}

\section{S. capicola Brauns (figs. 36, 36a).}

This species has been collected also at Plat River, Waterberg district, Transvaal (C. J. Swierstra).

\section{S. rhodesianus n.sp. (figs. $35,35 a$ ).}

ㅇ. $4 \mathrm{~mm}$. long. Closely allied to capicola Brauns, from which it differs as follows.

First tergite, the middle of the second and the whole of the sixth, ferruginous; the third to fifth and the second at the sides, black; the apical margins of the second to fifth, flavo-testaceous. The colour of the rest of the body and of the legs as in capicola. Pubescence and colour of the wings as in capicola. Face with a stronger sculpture than in that species, consisting of a very fine and close reticulate puncturation. Dorsal face of the pronotal collar, mesonotum and scutellum rather coarsely reticulate-punctate. Mesopleurae shining, sparsely and coarsely punctured. Dorsum of the epinotum rugulose and also microscopically punctured, without the triangular depression which is present in capicola, not transversely striolate in the middle; it has a median carina which does not reach the apical margin. Sides of the epinotum shallowly, finely and fairly closely punctured. Abdomen with sculpture similar to that of capicola, but somewhat stronger, the second tergite distinctly striolate lengthwise (magnification of not less than 35 diameters). 
Eyes a little more convergent above, the interocular distance on the vertex equal to the length of the first three joints of the flagellum plus half of the fourth. The flagellum is thicker and shorter than in capicola, only the first three and the last joints being clearly longer than wide; the first joint is a little longer than the second, which is one-third shorter than the third. Pronotal collar shorter, its anterior face much less oblique than in capicola. The anterior tarsi differ considerably from those of capicola. The basal joint is produced at the apex outwardly and has six flattened spines, the first five inserted on the middle line underneath, the second joint has a very long spine at the apex and each joint is clearly narrower than the one behind it. In capicola the basal joint
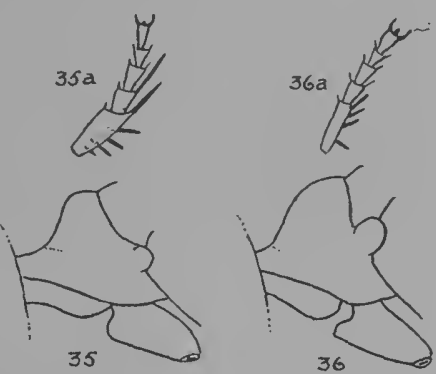

Fig. 35. Saliostethus rhodesianus, $q$; $a, q$, anterior tarsus.

Fig. 36. Saliostethus capicola, + ; $a$,, anterior tarsus. is not produced and has only four spines which are inserted on the outer margin. Venation like that of capicola.

o. $3.5 \mathrm{~mm}$. long. Head and thorax black, the mandibles pale yellow, the scapes and first two joints of the flagellum underneath creamy white. The pronotal tubercles and disc of the metanotum creamy white as in the 9 . Tibiae pale reddish below, straw-yellow above, the apices of the femora and the first two joints of the tarsi also of that colour. Fore and middle femora brown, suffused with pale yellow behind, the hind femora ferruginous. Face with widely spaced tufts of decumbent, silvery pubescence. Clypeus with a fairly dense silvery pubescence, its anterior margin bluntly angular in the middle. Pro-mesonotum more closely and less coarsely punctured than in the 7. The apical portion of the fore wing is less deeply fuscous than in the . First and second joints of the flagellum of about equal length, the third nearly half as long again as the second. Interocular distance on the vertex equal to the length of the first four joints of the flagellum. Seventh tergite widely rounded at the apex. Anterior tarsi normal, slender and long, without a comb. Otherwise like the + .

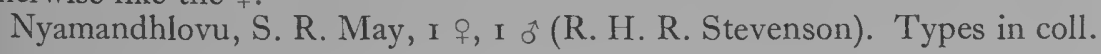
Sterenson.

\section{PEMPHREDON Group.}

\section{Genus Psenulus Kohl.}

P. luctuosus n.sp. (figs. $37,37 a$ ).

. $9 \mathrm{~mm}$. long. Black. Apical margin of the fourth tergite and the whole of the fifth and sixth abdominal segments, ferruginous. Scapes below, first four joints of the flagellum, anterior tibiae and tarsi and extreme base of the middle tibiae, fusco-ferruginous. Wings hyaline, very slightly smoky, the veins and stigma black. Face, clypeus and the thorax with a scanty white pubescence, but on the mesosternum long and dense. Clypeus and face below the antennae nearly dull, very finely, sparsely and very shallowly punctured; the rest of the face, the vertex and the temples shining, the vertex and temples more sparsely punctured than the face. Pronotal collar shining, with a few large punctures. Mesonotum, scutellum and metanotum dull, with a few large and shallow punctures. Mesopleurae dull, impunctate. Dorsum of the epinotum very finely striolate on each side of a median and more or less $T$-shaped shining 
groove, which is strongly clathrate; the sides of the epinotum are smooth and shining in front, like the declivity, and reticulate-rugose behind. Abdomen smooth and shining, with a few very fine punctures. Clypeus with two blunt teeth in front, as in bidentatus, but the clypeus is longer than in that species. The transverse carina below the antennal sockets is shorter than in bidentatus and is more acutely angular in the middle. In place of the median longitudinal carina which is present in bidentatus, there is a broad wedge which is expanded on top to form a lozenge-shaped and slightly concave area. The antennae are thicker than in bidentatus, the second joint of the flagellum is less than twice

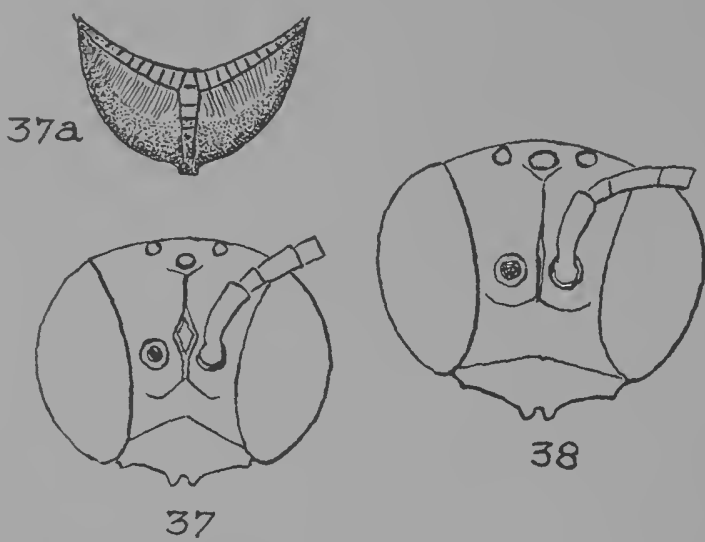

Fig. 37. Psenulus luctuosus, ㅇ, head; $a$, ㅇ, epinotum.

Fig. 38. Psenulus bidentatus, $q$, head.

as long as the first and only twice as long as wide (two and a half times in bidentatus). The proportions of the thoracic segments are like those of bidentatus, but the groove on the epinotum is narrower, especially the basal arm, and more strongly clathrate. Abdomen wider or less lanceolate than in bidentatus, the first tergite is wider at the apex than long, whereas in bidentatus it is one-fifth longer than wide, the second tergite is nearly twice as wide at the apex as long (only one-third wider in bidentatus).

Vumbu Mts, Umtali, S. R. February, I o (G. Arnold). Type in the Rhodesia Museum.

\section{Genus Passaloecus Shuck.}

\section{P. Braunsi Kohl, var. ferrugineipes n.v.}

. This variety differs from the type of the species in having the upper side of the scape and the whole of the first two joints of the flagellum yellowish red; the rest of the flagellum is brown. Legs pale ferruginous, the fore and middle tibiae in front and the hind tibiae at the base yellowish white as in the type of the species.

Memeh Town, Liberia, August (Dr J. Bequaert). 'Type in the Congo Museum, Tervueren.

\section{P. Bequaerti n.sp. (fig. 39).}

ㅇ. $5 \mathrm{~mm}$. long. Black. Scapes below, first joint of the flagellum, apex of the mandibles, anterior tibiae, tarsi and base of the femora, pale reddish brown; the rest of the legs, including the whole of the middle and hind tibiae, dark brown. Wings hyaline, the costa, stigma and radius black, the rest of the veins 
testaceous, the second cubital cell almost as wide on the radius as on the cubitus. Clypeus smooth and shining, almost glabrous, angularly produced in the middle in front. The facial concavity is much deeper than in Braunsi, finely striolate transversely in the middle, closely and finely rugose and reticulate at the sides. The vertex is dull, closely and finely punctate, transversely striate between the posterior ocelli and the eyes. Mesonotum dull, very closely punctured, almost reticulate-punctate; the basal third, between the clathrate longitudinal grooves, with about eight short rugae instead of being reticulate-rugose as in Braunsi. The epinotal dorsum is much more sharply and more

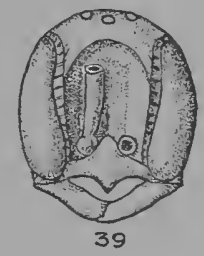

Fig. 39. Passaloecus Bequaerti, ㅇ. coarsely reticulate than in Braunsi. Abdomen very shining, all the segments microscopically and sparsely punctured. Otherwise like Braunsi, from which it is distinguished chiefly by the shape of the clypeus, the different sculpture of the vertex, mesonotum and first tergite, and by the more slender and relatively longer flagellum.

Lubumbashi, Katanga, Belgian Congo, June, I + (Dr J. Bequaert). Type in the Congo Musetim, Tervueren.

\section{PHILANTHUS Group.}

P.gwaaiensis n.sp. (figs. 40, 40a).

o. $9 \mathrm{~mm}$. long. This species belongs to the fuscipennis species-group. Colour as in fuscipennis Guérin, but the face has only two yellow marks above the antennal sockets. The pronotal collar is entirely black and the tegulae have only a small yellow spot in front, and there is a very small yellow spot on the middle of the temples. Face and clypeus with a short, scanty and whitish pubescence. Clypeus and the creamy white lower part of the face shining, very shallowly, sparsely and finely punctured. Upper part of the face and the vertex as far as the posterior ocelli dull, closely reticulatepunctate. Behind the posterior ocelli
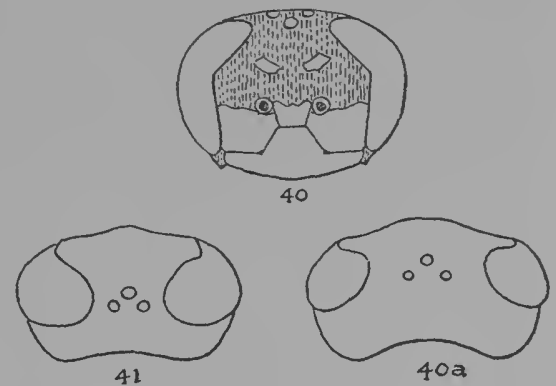

Figs. 40 and $40 a$. Philanthus gwaaiensis, $0^{\star}$. Fig. 4I. Philanthus fuscipennis, $\sigma^{t}$. the vertex and the temples are slightly shining, coarsely punctured, much more so than in fuscipennis, the punctures and the spaces between them of about equal width. Pronotum closely punctured, with a distinct although short collar, not linear above as in fuscipennis. The sculpture of the mesothorax and metanotum is as in that species, but somewhat closer. The sculpture of the epinotal dorsum is like that of fuscipennis, but the triangular area is margined at the sides by a shallow groove instead of a raised line. Tergites smooth and shining, the first five with a few shallow punctures at the sides, the sixth punctured all over. First and second sternites smooth and shining, the apical margin of the second and all the following sternites shallowly, closely and not very coarsely punctured. Sternites 3-7 dull. Median area of the clypeus wider than long, the anterior margin feebly convex and without teeth. Second joint of the flagellum half as long again as the third (twice as long in fuscipennis). Eyes nearer together above than in fuscipennis, 
the interocular distance on the vertex being equal to the length of the first four joints of the flagellum (to the first six in fuscipennis). The vertex is also much shorter than in that species (fig. 4I). Thorax less robust than in fuscipennis, the epinotal dorsum at the posterior margin somewhat less than twice as wide as long, whereas in the other species it is about two and a half times as wide as long.

Gwaai, S. R. January, 2 ô (G. Arnold). Type in the Rhodesia Museum.

\section{THYREOPUS Group. \\ Genus Thyreopus Lep.}

T. libertinus n.sp. (figs. $42,42 a$ ).

o. $6.5 \mathrm{~mm}$. long. Black. Scapes in front, pronotal collar above excepting the middle, disc of the metanotum, a streak on the front of the pronotal tubercles, a round spot on the mesopleurae below the tegulae, anterior tibiae, tarsi and lower half of the femora, apical three-fourths of the middle femora below and the apical two-thirds of the middle tibiae on the outside, lemon yellow. A small round spot on each side of the second tergite and transverse oblong spots on each side of the third to fifth tergites, pale yellow. Wings pale fusco-hyaline, darker apically, the veins black. Clypeus, sides of the face and the temples with silvery pubescence. Vertex, upper part of the temples and the mesonotum with a sparse, erect and brownish pubescence, the sides of the thorax with grey pubescence. Clypeus dull, closely and finely punctured. Face finely punctured at the sides, the concavity smooth and shining. Vertex shining, fairly strongly punctured in front, smooth and shining behind the anterior ocellus. Pronotum coriaceous and dull at the sides, smooth and shining above. Mesonotum and mesopleurae smooth and shining. Scutellum closely and fairly strongly striate lengthwise. Dorsum of the epi-

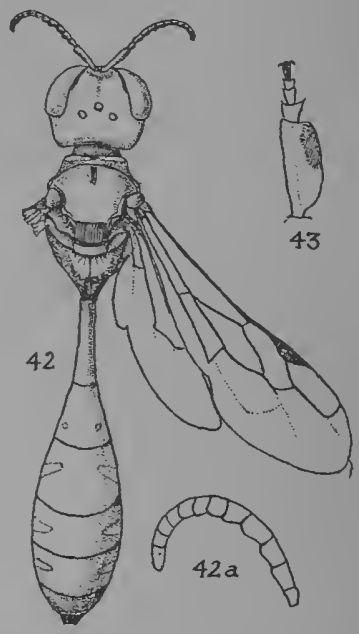

Fig.42. Thyreopus libertinus, $\hat{0} ; a$, ô, flagellum.

Fig. 43. Rhopalum ripariumnemoralis, $\hat{0}$, anterior tarsus. notum with a poorly defined median area which is sparsely and feebly punctured, and sparsely rugose at the base. The brow of the declivity is feebly reticulate-rugose, its base, like the sides of the epinotum, is smooth and shining. Abdomen impunctate, smooth and shining. Mandibles bidentate at the apex. Clypeus carinate lengthwise in the middle and angularly produced, the apex of the angle shallowly emarginate. Antennal sockets contiguous with each other and with the eyes. Labial palpi 4-, maxillary palpi 6 -jointed. Scapes long. Antennae 13 -jointed, not fringed with hairs below, the second to fifth joints of the flagellum very distinctly swollen below at the apex, the second joint twice as long as the first. Eyes strongly convergent below. Ocelli set in a low triangle, the posterior pair twice as far from each other as from the anterior ocellus and slightly farther from each other than from the eyes. Temples and vertex well developed, the distance from the occipital margin to the anterior ocellus being distinctly greater than from the latter to the brow of the facial concavity. The vertex has a narrow fovea on each side in front. Pronotal collar not linear, the dorsal face impressed and excised in the middle, 
the shoulders subangular. Mesonotum with a deep median sulcus extending over the anterior third of its length. Mesopleurae with a narrow epicnemium in front, without a ridge in front of the middle coxae. Dorsum of the epinotum with a median longitudinal groove which is continued over to the bottom of the declivity. Abdomen petiolate, the first segment being nearly four times longer than wide at the apex and not much wider there than at the base; the remaining segments form a lanceolate complex. The second segment is two and a half times wider at the apex than at the base and is about as long as wide at the apex. Seventh tergite trapezoidal, the sides marginate over the apical half and forming a slight pygidial area. Legs simple, not dilated. The recurrent vein meets the cubital cell very distinctly beyond its middle. The basal lobe of the hind wing is not longer than the submedial cell.

Gbanga, Liberia, September, I o (Dr J. Bequaert). Type in the Congo Museum, Tervueren.

In Kohl's key to the species-groups of Thyreopus (Die Crabronen der Pal. Reg. I915), this species runs down to the species-group Cuphopterus Mor. Whether the eighth ventral plate has a transverse torus or not I am unable to say, as that segment is not visible in this specimen.

\section{Species-group Rhopalum Kirby.}

T. (Rhopalum) riparium Arn. var. nemoralis Arn. (fig. 43).

$0^{*}$ (hitherto undescribed). $5.5 \mathrm{~mm}$. long. Dorsal face of the pronotal collar in the middle, prosternum, anterior margin of the mesopleurae, middle and hind legs excepting the apical joint of the tarsus and the anterior half of the outside of the basal joint, pale yellow. Hind femora dirty yellow above. Pronotal collar a little longer than in the $q$. Basal joint of the anterior tarsi patelliform, the second also somewhat widened. Head much narrower behind the eyes than in the $q$, the clypeus somewhat longer than in that sex. Otherwise like the 9 .

Moodie's Nek, S. R. (R. H. R. Stevenson). Type of o in coll. Stevenson.

KAROSSIA gen. nov.

Characters. Face wide, not hollowed out, the eyes nearest together at about the middle of the face, thence fairly strongly divergent above and below. Clypeus short, very similar to that of Oxybelus, but without a median carina. The facets on the inner side of the eyes are enlarged, as in Thyreopus. A shallow $\mathrm{V}$-shaped groove lies a little above the middle of the face, extending on each side to the margins of the eyes. Ocelli round and normal. Vertex. with a distinct fovea on each side adjacent to the eyes. Mandibles deeply excised on the outer margin, the inner margin with two small teeth at about the middle, the apex subacute. Labial palpi 4-, maxillary palpi 6-jointed. Antennae (f) I2-jointed. Pro- and mesothorax like that of Oxybelus, the mesopleurae with a broad and sharply marginate epicnemium in front. Scutellum and metanotum fairly flat, without lateral lamellae or squamae at the posterior margin. Dorsum of the epinotum very short, without a median process at the base, very coarsely sculptured. Abdomen ovate, not cordiform as in Oxybelus, the declivous face of the first tergite not deeply impressed in the middle, the apical margins of the tergites not much depressed, their lateral margins not forming a sharp edge with the ventral fold, and therefore like the tergites of Oxybelus. Sternites convex. Second sternite with a fovea on each side. A distinctly defined and triangular pygidial area is present. Apical joints of the tarsi not swollen; middle tibiae with two spurs. Middle 
and hind femora strongly spinose, the anterior tarsi with a distinct comb, the anterior femora strongly flattened. Venation of the wings like that of Oxybelus, except that the cubital vein between the cubital and discoidal cells is not obliterated, so that those two cells are not confluent. The basal lobe of the hind wing is shorter than the submedial cell, as in Oxybelus. Sculpture fairly coarse. Genotype, Karossia Hessei.

This is an annectant genus, having some affinities with Thyreopus s. lat. such as the venation, the unarmed epinotum, simple scutellum and metanotum and the simple apical joints of the tarsi. Otherrise it is more closely allied to Oxybelus, and more especially to the subgenus Anoxybelus Kohl.

\section{K. Hessei n.sp. (figs. $44,44 a-c$ ).}

․ $8.5 \mathrm{~mm}$. long. Head and thorax black. Mandibles ochreous, the apex ferruginous. Dorsal face of the pronotal collar, a large spot on the anterior upper angle of the mesopleurae, anterior two-thirds of the scutellum, the metanotum and tegulae, lemon yellow. Tergites chrome yellow, the base of

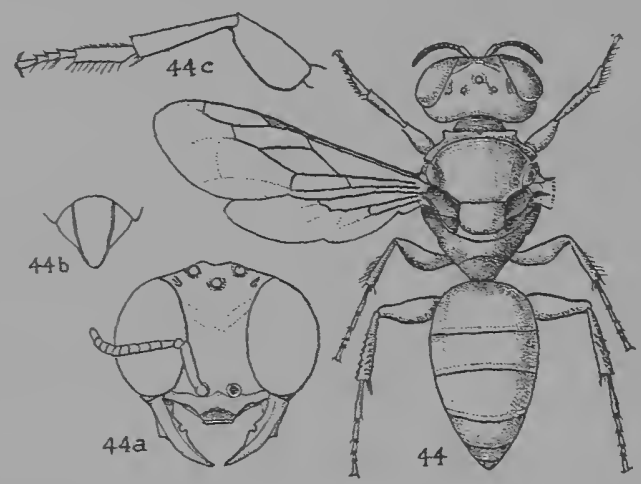

Fig. 44. Karossia Hessei, $q$; $a, q$, head; $b, q$, pygidium; $c, q$, fore leg.

the first and the apical margins of the first five and the whole of the sixth, reddish yellow. Sternites reddish yellow. Legs chrome yellow, the femora excepting the anterior edge, reddish yellow. Wings hyaline, faintly fuscous beyond the cells, the costa, subcosta and stigma dark ochreous, the other veins ferruginous. Face, clypeus and temples with a dense, dull silvery pubescence. On the thorax and abdomen there is a very short and sparse whitish pubescence. Clypeus dull, closely and finely punctured. Face, from the posterior margin of the clypeus to the shallow $V$-shaped groove, transversely striated, the rest of the face, the vertex and temples dull, closely punctured, the punctures largest on the vertex. Pronotum dull, rugulose, the dorsal face of the collar sparsely and not very finely punctured. Mesonotum, scutellum and mesopleurae strongly punctured, the punctures a little larger than those on the vertex, but not so close together, the spaces between the punctures slightly shining. Metanotum closely and finely punctured. Dorsum of the epinotum very coarsely reticulate-rugose, the declivity more finely so, the sides shining and transversely striate near the hind margin. Abdomen shining, the first three tergites coarsely and not closely punctured, the punctures larger than those of the mesonotum, the fourth and fifth more finely and more closely punctured; pygidial area coarsely and closely punctured, covered with short yellowish setae, elongate triangular, two-thirds longer than 
wide at the base, the apex widely rounded. The slightly depressed apical margins of the second to fifth tergites are smooth. Second sternite closely and finely punctured and moderately shining, excepting the lateral ovate foveae, nearly smooth at the base. The third to sixth sternites have their basal twothirds smooth and shining and sharply delimited from the apical third which is dull and closely punctured. Median area of the clypeus moderately convex, the apex triangularly depressed and shining. Eyes closest together at about the middle of the face, where the distance between them is about as long as the scape. The interocular distance on the vertex is greater than the length of the whole flagellum. The first joint of the latter is wider than long, the second and third are longer than wide, the fourth and fifth as long as wide, the sixth to tenth wider than long, the second nearly twice as long as the first. Temples well developed, at their widest about as wide as the eyes, seen from the side. Pronotal collar sharply angular at the shoulders, as in Oxybelus. Thorax robust, the mesonotum twice as long as the scutellum, which is wider than long; the dorsum of the epinotum is about twice as long as the metanotum. Anterior femora strongly compressed from above to below, widest in the middle, nearly three times longer than wide there. Basal joint of the anterior tarsi longer than the other joints united, with nine ferruginous spines on the outer margin. For the rest, see characters of the genus.

Kaross, S.W. Africa, February, I o (Dr A. J. Hesse). Type in the South African Museum.

\section{Genus Belomicrus A. Costa.}

B. funestus n.sp. (figs. $45,45 a$ ).

f. $8 \mathrm{~mm}$. long. Black. Tibiae pale yellow at the base, the anterior pair fusco-ferruginous, the tegulae reddish brown. Flagellum brown below. Wings hyaline, faintly tinged with fuscous apically. Clypeus and lower half of the face with silvery pubescence, the vertex with an erect, short and pale fulvous pubescence. Apical margins of the first four tergites with a sparse whitish pubescence, forming inconspicuous transverse fasciae. The whole body fairly shining, excepting the epinotum and epicnemium, sides of the clypeus and
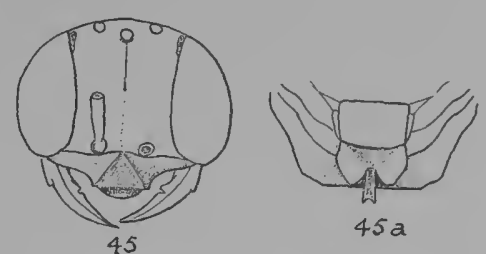

Fig. 45. Belomicrus funestus, ㅇ, head; $a,+$, posterior half of thorax. base of the face between the antennal sockets. Median area of the clypeus with a slightly concave and shining triangular area, the anterior margin beyond the area convex, the lateral angles acute; the lateral sclerites of the clypeus, like the base of the face between the antennal sockets, are closely and finely punctured. Mandibles excised on the outer margin. The face has two smooth and shining depressions for the accommodation of the scapes; the upper part of the face is closely and fairly strongly punctured, the vertex and temples much more strongly but less closely punctured. Pronotum finely and very closely punctured, the dorsal face of the collar less closely. Mesonotum and mesopleurae coarsely and irregularly punctured, the former with a longitudinal median impression which is more distinct in front than behind. Scutellum with a few large punctures at the sides and a more closely and finely punctured longitudinal impression in the middle, the lateral margins slightly reflected. Metanotal squamae concave, shining, finely and very sparsely punctured, longer than wide, their posterior margins widely rounded. Epinotal process gutter-shaped, longer than wide at the apex, wider there than at the base and 
arcuately emarginate. The median area underneath the process is shining and finely rugose lengthwise, the lateral areas of the dorsum and the declivity are closely reticulate-rugose, the sides of the epinotum are rugose and coriaceous. Metapleurae transversely striate. Tergites $\mathrm{I}-5$ fairly strongly but not closely punctured, the punctures on the first two about as large as those on the vertex, on the third to fifth somewhat smaller; the pygidial area is triangular, about as long as wide at the base, rounded at the apex, coarsely and closely punctured. The depressed margins of the first five tergites and their lateral ventral folds are closely and finely punctured. Sternites sparsely and finely punctured. Face narrowest below the middle, the interocular distance on the vertex greater than the length of the whole flagellum. Posterior ocelli twice as far from each other as from the eyes. Second joint of the flagellum a little longer than the third. Temples well developed, as wide at their middle as the eyes, when seen from the side. Collar of the pronotum like that of $B$. Kohli Brauns, the shoulders dentate.

o. $6.5 \mathrm{~mm}$. long. Apical third of the scapes underneath pale yellow. Anterior tibiae brownish yellow, the bases of all the tibiae more extensively yellow than in the . . Anterior and middle tarsi pale brown. Seventh tergite subquadrate, slightly wider at the base than at the apex, which is arcuately emarginate. Otherwise like the o.

Van Rhynsdorp, Cape Province, I,+ 2 ô (Dr H. Brauns). Types in the Rhodesia Nuseum.

By the structure of the mandibles this species falls within the group of Oxybelomorpha.

\section{Genus OxyBelus Latr.}

\section{O. bicornutus n.sp. (figs. $48,48 a$ ).}

․ $6.5 \mathrm{~mm}$. long. Black. Mandibles ferruginous, black at the apex. Scapes dark brown, paler at the base and apex, flagellum ferruginous, the basal joints brownish above. Anterior tarsi and tibiae ferruginous, the latter with a pale yellow streak above at the base. Middle and hind femora and tibiae black, the latter with a short pale yellow streak at the base, the middle femora with a similar mark at the apex outwardly. Middle and hind tarsi pale ferruginous, the two basal joints fuscous. A small spot on each side of the scutellum, the inner margin of the otherwise hyaline metanotal squamae and transverse maculae on the first four tergites, pale lemon yellow. The abdominal maculae are like those of lingula in shape and size. Wings hyaline, the veins brown. Tegulae brownish, with a pale yellowish spot in front, the axillary sclerites black. Pubescence of the head and thorax silvery and similar to that of lingula. Puncturation of the head like that of lingula, the mesonotum more coarsely and less closely punctured than in that species, the spaces between the punctures more shining. The sculpture of the rest of the thorax is like that of lingula. The scutellum and metanotal squamae as in that species, but the foliaceous epinotal process is different. Its sides are more convex, the median carina is stronger and emits on each side five or six curved branches, much more distinct than those of lingula, which are oblique and more numerous. The sculpture of the abdomen and the shape of the pygidial area are like those of lingula. The median area of the clypeus bears at the base a subporrect plate which is slightly wider than long and bicornuate, owing to the deep arcuate emargination of its apex.

This last feature and the coarser puncturation of the mesonotum serve to distinguish this species from lingula, to which it is most nearly allied. 
Mafa, S.W. Africa, February, I $\$$ (Dr A. J. Hesse). Type in the South African Museum.

O. Hessei n.sp. (figs. $47,47 a$ and $b$ ).

o. $6-6 \cdot 7 \mathrm{~mm}$. long. Black. The following parts are lemon yellow: the pronotal collar above and the tubercles, a large oblong spot on each side of the

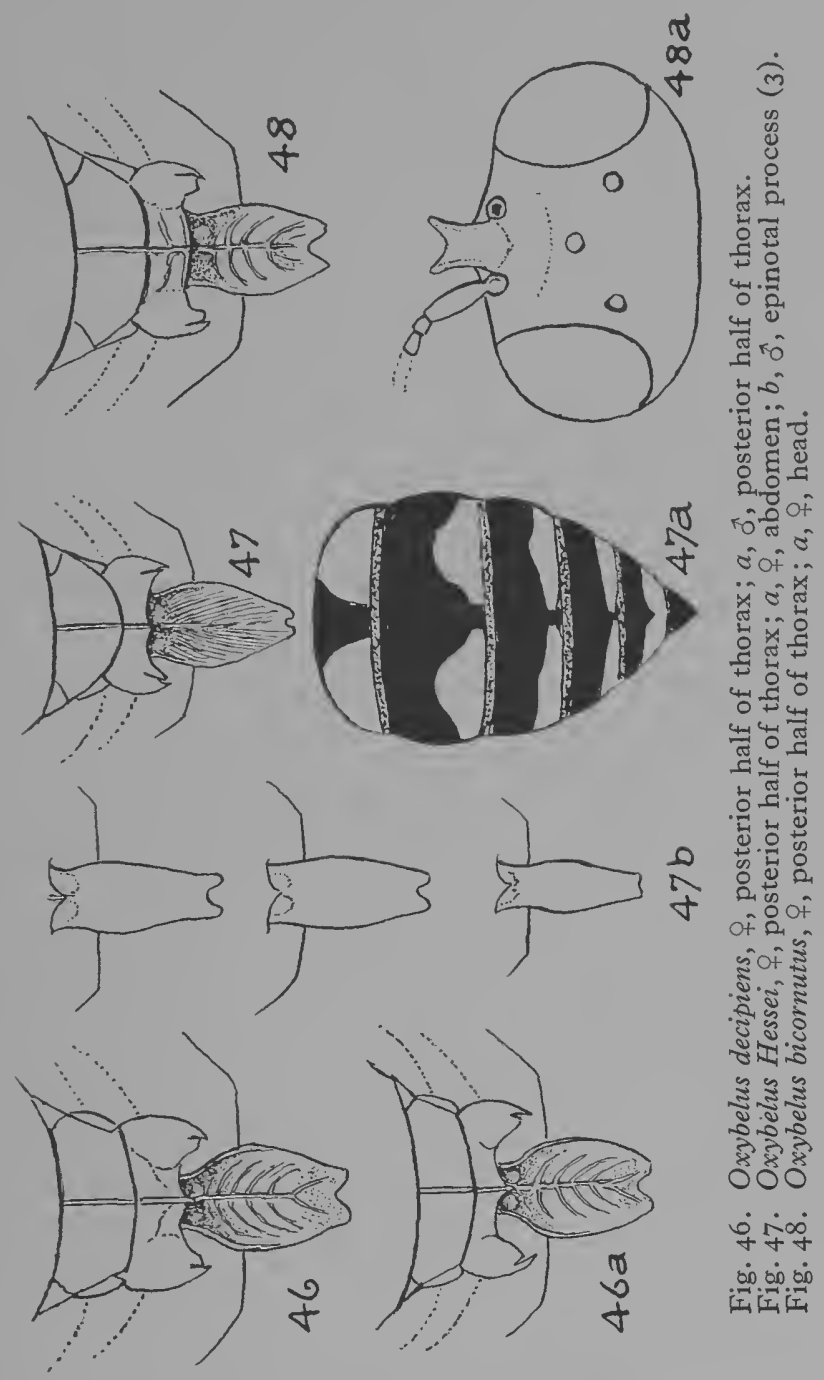

scutellum, the posterior margin of the metanotum and the inner margin of its hyaline squamae, a semi-circular macula on each side of the first tergite and covering the greater part of the segment, a transverse streak, widened in the middle, on each side of the second tergite, transverse apical bands on the third and fourth tergites, entire or only very narrowly interrupted in the middle, and a broad band on the fifth, covering the greater part of the segment. 
Pygidial area black, slightly ferruginous at the apex. Scapes dirty yellow in front, black behind; the flagellum pale ferruginous, somewhat darker at the base above. Mandibles, epinotal process and the legs in greater part, ferruginous. The anterior femora black below, with a lemon yellow mark at the apex, the middle femora also indistinctly yellow at the apex. The bases of all the tibiae have a small yellow spot above. Wings hyaline, the veins brown. Tegulae lemon yellow in front, testaceous red behind, the axillary sclerite blackish, margined with ochreous. Pubescence of the head and sides of the thorax silvery, of the mesonotum slightly golden. Abdomen with an inconspicuous whitish pubescence and a few long white hairs on the sternites. Pygidial area clothed with pale golden setae. Head and mesonotum finely punctured, the punctures on the mesonotum shallow and distinctly smaller than in any other species of the lingula-lamellatus group. Mesopleurae a little more coarsely punctured than the mesonotum, about as strongly as in lamellatus. The sides of the epinotum shining and with the usual oblique striation. Scutellum and metanotum carinate longitudinally in the middle, moderately shining, sparsely and coarsely punctured. Tergites fairly dull; the first strongly punctured, the punctures as large as those of the scutellum, the puncturation of the remaining tergites becomes progressively smaller and closer on each succeeding segment except the last. The puncturation is, however, not so coarse as in lingula. Pygidial area closely and strongly punctured. Sternites shining, the second fairly strongly but not closely punctured. Anterior margin of the clypeus transverse, the median area with a cariniform tubercle. Metanotal squamae bifid at the apex, both lobes acute, the outer one curved downwards. The epinotal process is carinate longitudinally in the middle, closely and finely, obliquely striate on each side, widest at about the basal third, narrowed towards the apex, three-fourths longer than its greatest width, more or less elliptical, the apex with a small median excision, the apical angles rounded. The process is as finely striate as in lamellatus or lepturus, but in the former the shape is more of a broad oval, and in the latter it is shorter than in this species. Pygidial area triangular, as long as wide at the base, the sides barely convex. Tarsal comb and calcaria ferruginous, the spines on the middle and hind tibiae whitish.

$0^{\hat{*}} \cdot 4 \cdot 3-5 \cdot 3 \mathrm{~mm}$. long. Mandibles dirty yellow, brown at the apex. Flagellum brownish red, darker above at the base. Fore and middle tibiae pale yellow above, ferruginous below, the hind tibiae with the basal half yellow above. Fore and middle femora yellow on the apical half outwardly. Apical tergite dark brown or fusco-ferruginous. Otherwise coloured like the $o$; the colour of this sex is like that of lamellatus $\delta$, except that the flagellum and mandibles are darker. The bands on the tergites are narrower than in the $q$, and the sixth tergite is entirely black. The puncturation of the first two tergites is relatively coarser than in the $o$, and much more so and denser than in lamellatus $\delta$, which this insect resembles very closely. Epinotal process narrower than in the o and relatively longer, being from two to two and a half times longer than wide; it is widest at about the middle, and the apical excision is deeper and wider than in the o.

Zesfontein, S.W. Africa, types; Kaross Otavi and Otjikondo, S.W. Africa 8 of (Dr A. J. Hesse), and numerous ơ $\sigma^{t}$. Types in the South African Museum.

The nearest ally of this species is lamellatus O1., from which it differs by the puncturation of the mesonotum and tergites and by the shape of the epinotal process. The second sternite in the $o$ is more coarsely and more closely punctured than in lamellatus. 
O. decipiens n.sp. (figs. $46,46 a$ ).

o. $5 \mathrm{~mm}$. long. Black, the last two abdominal segments pale brick-red. Mandibles pale yellow, reddish brown at the apex. Scapes black behind, straw-yellow in front; flagellum pale reddish ochreous below, brownish ochreous above. The following parts are pale yellow, almost yellowish white: the shoulders of the pronotal collar and the pronotal tubercles, a small round spot at the anterior angles of the scutellum, the inner margin of the hyaline metanotal squamae, an elliptical transverse macula on each side of the first tergite and narrow pre-apical bands, widely interrupted in the middle, on the second to fourth tergites. Apical third or more of the fore and middle femora and all the tibiae pale yellow, the hind tibiae with a black spot on the outside in the middle and on the apical half below. Tarsi pale ochreous. Tegulae hyaline, with a white spot in front, the axillary sclerite black and margined with pale yellow. Wings hyaline, the veins brown. Epinotal process pale brown, darker at the base and down the middle. Pubescence of the face and clypeus silvery; the thorax and abdomen with a very sparse greyish pubescence. Upper third of the face not very closely punctured, the rest of the head closely so, the clypeus very finely, the vertex and occiput fairly strongly. Mesonotum and mesopleurae moderately shining, strongly punctured, the punctures larger than those on the vertex and as wide as the spaces between them. Scutellum less closely and more coarsely punctured than the mesonotum. Sides of the epinotum transversely rugulose, with very small punctures between the rugae. Dorsum of the epinotum dull, reticulate-rugose. Metanotum rugose in the middle; the metanotal squamae are fairly convex on the outer margin, bifid at the apex, the inner lobe blunt, the outer acute and bent downwards. The posterior margin of the scutellum is less convex than in flavicornis Arn. which this species resembles very closely, especially in the ot sex. Epinotal process foliaceous, the sides convex, widest at the middle, half as long again as wide there, the apex with a shallow arcuate excision. It is carinate lengthwise in the middle and obliquely rugose on each side. The first two tergites are very coarsely punctured, as in flavicornis, but the punctures are relatively shallower. The basal two-thirds of the third and fourth tergites are fairly strongly punctured, the punctures on the third larger than those on the fourth and slightly smaller than those on the mesonotum; the apical third of these two segments is smooth and microscopically reticulate. Fifth tergite as strongly punctured as the fourth. Pygidial area with coarse and elongate punctures, covered with short reddish yellow setae; it is a little longer than wide at the base and the sides are distinctly convex. Sternites shining, the second sparsely and coarsely punctured, the third to fifth with a few large punctures at the base. Anterior margin of the median area of the clypeus depressed, with two small teeth on each side; the median carina is raised at the base to form a compressed tubercle. Spines on the legs whitish, the calcaria pale ochreous, the basal joint of the fore tarsi with five spines on the outer margin.

J. $3 \cdot 5^{-5} \mathrm{~mm}$. long. First five tergites with pre-apical bands of pale yellow, widely interrupted in the middle, that on the first wider than the rest. Sixth tergite immaculate, the apical tergite and sternite ferruginous. The posterior tibiae usually lack the black spot which is present in the 9 . Scutellum immaculate, base of the flagellum darker than in the $q$, otherwise like that sex in colour. Puncturation of the first two tergites a little coarser than in the ?, otherwise the sculpture and pubescence is like that of the o. Anterior margin of the clypeus with one tooth on each side of the median area, the median carina lower at the base than in the ?. Epinotal process less narrowed towards 
the apex than in the 9 . Pygidial area quadrate, slightly longer than wide, the apical margin shallowly and arcuately excised. Otherwise like the $q$.

Zesfontein (types) and Koabendus, S.W. Africa, February (Dr A. J. Hesse), 5 우 and numerous $\hat{\sigma}^{\top}{ }^{\top}$. Types in the South African Museum.

The 0 of this species is very much like that of flavicornis, but as a rule is larger, and may be distinguished from that species by the epinotal process which is distinctly foliaceous, whereas in flavicornis it is intermediate between the gutter-shaped and foliaceous types. In addition the posterior margin of the scutellum is less convex in this species.

\section{BEMBEX Group.}

\section{Genus STIZUS Latr.}

\section{S. ctenopus $11 . s p$. (figs. $49,49 a$ )}

ㅇ. 10.5 mm. long. Black. Labrum, mandibles, pronotal collar above, tegulae, lateral margins of the mesonotum and the legs excepting the coxae, ferruginous. Anterior twothirds of the clypeus, scapes, first seven joints of the flagellum and the pronotal tubercles, reddish ochreous. Large maculae on the sides of the first three tergites (those of the third connected by a narrow apical band), and the whole of the fourth and fifth excepting the ferruginous apical margins, pale yellow. Sixth tergite
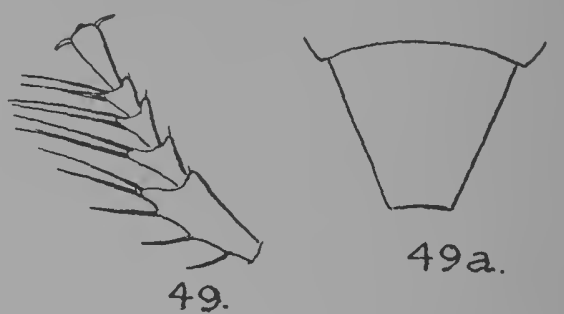

492.

Fig. 49. Stizus ctenopus, ㅇ, anterior tarsus; $a$, ㅇ, pygidium.

ferruginous. Sternites $\mathrm{I}-5$ black, the sixth fusco-ferruginous. Wings fuscous, with a violaceous lustre. Head and thorax with a short, scanty and yellowish grey pubescence. Labrum, clypeus, face and vertex dull, microscopically and very closely punctured, with a few larger punctures in addition on the upper part of the face and on the vertex. Temples and pronotum slightly shining, very finely punctured. The rest of the thorax, excepting the sides of the epinotum in front below, is dull and closely reticulate-punctate, most coarsely so on the scutellum and mesopleurae, fairly finely on the front of the mesonotum and on the metapleurae. The median triangular area of the epinotal dorsum is feebly defined by a thin raised line on each side. Tergites $\mathrm{I}-5$ with a close, fine, shallow and round puncturation, the sixth with stronger and oblique puncturation. Sternites shining, the first tricarinate, strongly punctured at the apical margin, the second and third fairly closely and shallowly punctured, the other sternites sparsely and finely.

Eyes convergent below, the interocular distance on the vertex somewhat less than one-third greater than across the base of the clypeus, and equal to the length of the first three joints of the flagellum plus half of the fourth. Face feebly carinate below between the antennal sockets. The distance between the posterior ocelli is half as great again as their distance from the eyes. Flagellum slender and moderately clavate, the second joint twice as long as the third and nearly five times longer than wide at the apex; the apical joint truncate. Sixth tergite widely truncate at the apex, trapezoidal. Legs, especially the middle and hind pairs, unusually long and slender. Anterior tarsi with a strongly developed comb of ferruginous and slightly flattened spines; the first two joints are strongly, the third and fourth feebly, asym- 
metrical. The first joint has three spines on the outer margin and two long ones at the apex, the second to fourth have each two long spines at the apex.

Mpudsi River, Umtali district, S. R. March, I f (R. H. R. Stevenson). Type in coll. Stevenson.

This species belongs to the tridentatus group.

The number of forms described in this work is 768 , comprising 682 species and 86 races and varieties. Of these, 23 I are new species, 19 new subspecies and $4 \mathrm{I}$ new varieties.

It will be observed that in describing new species where both sexes are present, I have stated where the types are deposited. This is contrary to the usage of the majority of entomologists, who designate a specimen of one sex as the type and of the other sex as the allotype. I am unable to agree with this method for the following reasons.

In the case of insects, excepting permanently parthenogenetic forms, if indeed such exist, the species in nature is composed of the male and the female, and in the case of social insects, not only of those two, but also of the various castes of workers. I shall make my views clearer by reference to the discussion on the subject of the "type" in Rothschild and Jordan's Revision of the Sphingidae, Novitates Zoologicae, Ix, Supplement, pp. xv-xxvi. With the conclusions of those authors $I$ am in agreement in general, but it seems to me that on one point there is a flaw in the argument.

On page xviii we read, "Families, subfamilies and all the other classificatory units down to the individual varieties require exposition by definition. The definitions bring into order the chaotic mass of individuals which forms the subject of classificatory research. However, instead of operating with the definitions, the systematist employs, for the sake of brevity, names for them, thus simplifying reference. EVERY NAME IS A TERM FOR A DEFINITION."

On page xxiv we read, "Some authors, accepting the word 'type' in the ordinary sense implying that the specimens called types are typical individuals, very properly reply that these types are often aberrant specimens, and very seldom the most typical for the group of individuals to which they belong. This confusion of the verbal and technical meaning of the word 'type; misleads those authors to insist further that, there being no 'types' in nature, one individual being no more a pre-eminent representative of the species (or variety) than another, the word 'type' as a nomenclatorial term has no standing. It is obvious that those authors fall into a deplorable error of confounding the NAMES, which are the product of scientists, with the OBJECTS named, which are the product of nature. Certainly THERE ARE NO TYPES in the nomenclatorial sense in nature, BUT THERE ARE ALSO NO NAMES. The type is as such not at all the type of the SPECIES, but is the type of the arbitrary NAME given to the first specimen or specimens, and applied by common consent to all the specimens which belong to the species, of which the type-specimen is only a member, like any other individual."

It is clearly emphasised that "every name is a term for a definition." But what does the systematist define? It is clearly his object to define what he conceives to be a species as it occurs in nature, to which species he also attaches a name; this name is not merely an arbitrary something connected with some particular specimen, but is a term for a definition. The question which we have to answer is this, Is the definition of a species, which consists of two sexes, complete when only one sex has been described? To my mind, obviously it is not. The definition of one sex will often fail to apply to the other, 
not only in structural characters, but also in size and colour and other superficial characters. To take an extreme case, we need only instance the Thynnidae, where the females are apterous and so different in structure and colour from their winged males that originally they were classified under separate genera. The description of a female Thynnid will certainly not apply to its male, and to make the definition of named species complete, both sexes must be described and made to share in the exemplification of the name. It is necessary to include both sexes in the concept of the "type of the species," for a definition based only on one sex defines only half of a species as it is known to nature. It follows from this principle that the two specimens of different sex which constitute the types of a species may occasionally be housed in different collections, this is certainly regrettable but sometimes cannot be avoided.

In bringing this work to a close I wish to express my great appreciation and thanks to the Editor of these Annals, Mr C. J. Swierstra, Director of the Transvaal Museum, for the liberal way in which he has allowed me to furnish text-figures and plates to illustrate it. The drawings have all been made with the aid of a Zeiss drawing-apparatus and have been provided in all cases where they appeared necessary, thereby making the monograph of greater value to the student.

G. ARNOLD

BULAWAYo,

23 rd August I928.

P.S. The revision of the proofs of the foregoing pages affords me the opportunity to record with deep regret the death, early in I929, of my friend Dr H. Brauns and to point out that on that account this work cannot yet be considered as concluded. Dr Brauns unfortunately was not spared to complete his monograph of the genus Cerceris, which he intended to do by the publication of a further part which would have included a key to all the Ethiopian species and descriptions of the species known from Tropical Africa and omitted from his work in Part 4, Vol. XI of these Annals.

It is my intention to rectify these omissions by the publication at the earliest opportunity of another and final part, which will also include the descriptions of numerous new species in the collection of the British Museum.

G. ARNOLD

8th October I 929 


\section{PLATES VI AND VII}




\section{PLATE VI}

1. Bembex albofasciata, $\delta^{*} . \times 4 \frac{1}{2}$.

2. B. albofasciata, ㅇ. $\times 4 \frac{1}{2}$.

3. B. ulula, ㅇ. $\times 4 \frac{1}{2}$.

4. B. cultrifera, ㅇ. $\times 4 \frac{1}{2}$.

5. B. anomalipes, $\sigma^{\wedge} \times 3$.

6. B. afra, o. $\times 4 \frac{1}{2}$.

7. B. Moebii, ㅇ. $\times 4 \frac{1}{2}$.

8. B. odontopyga, $0^{+} \times 3$.

9. B. Scotti,,.$\times 5$.

г. B. ugandensis, ㅇ. $\times 3$.

II. B. monedula, ․ $\times 3$.

12. B. albidula, o.$\times 3$.

13. B. carinata, ‥ $\times 5$.

14. B. carinata, ô. $\times 5$.

15. B. Arnoldi, ㅇ. $\times 4 \frac{1}{2}$.

16. B. melanopa, ㅇ. $\times 4 \frac{1}{2}$.

17. B. melanopa, o. $\times 4 \frac{1}{2}$.

8. B. massaica, ․ $\times 4 \frac{1}{2}$.

9. B. intermedia, ô. $\times 4 \frac{1}{2}$.

20. B. capicola, ô. $\times 4$.

21. B. capicola, ․ $\times 4 \frac{1}{2}$.

22. B. Braunsii, ㅇ. $\times 4 \frac{1}{2}$ (type).

23. B. Kriechbaumeri, oิ. $\times 6$ (type).

24. B, Kriechbaumeri, ㅇ. $\times 4 \frac{1}{2}$ (type).

25. B. ochracea, ô. $\times 4 \frac{1}{2}$.

26. B. liturata, ô. $\times 4 \frac{1}{2}$.
27. B. liturata, + . $\times 4 \frac{1}{2}$.

28. B. harenarum, $\sigma^{+} . \times 4 \frac{1}{2}$.

29. B. harenarum, ㅇ. $\times c a 4 \frac{1}{2}$,

30. B. fuscipennis, o. $\times 4 \frac{1}{2}$.

31. B. sibilans, ㅇ. $\times 4 \frac{1}{2}$.

32. B. capensis, ․ $\times 4 \frac{1}{2}$.

33. B. flavicincta, ㅇ. $\times 4 \frac{1}{2}$.

34. B. Cameronis, ठ. $\times 4 \frac{1}{2}$.

35. B. venusta, ô. $\times 4$.

36. B. Bequaerti, ㅇ. $\times 4$.

37. B. Bequaerti, ठิ. $\times 4$.

38. B. Bequaerti, var. dira,,.$\times 4$.

39. B. Bequaerti, var. dira, ô. $\times 4$.

40. B. albopilosa, $\hat{0}$. $\times 6$.

41. B. fraudulenta, $q$. $\times 6$.

42. B. fraudulenta, $0 . \times 6$.

43. B. ulula, thorax. $\times 9$.

44. B. cultrifera, + , thorax. $\times 4 \frac{1}{2}$.

45. B. Funodi, ot, thorax. $\times 9$.

46. B. liturata, race flavopicta, ô. $\times 4 \frac{1}{2}$.

47. B. venusta, ๙ิ. $\times 5$.

48. B. Stevensoni, $0^{\star} . \times 6 \frac{1}{2}$.

49. B. flavicincta,, . $\times 6$.

50. B. ugandensis, 0 . $\times 6$.

51. B. scaura, ô. $\times 6$. 


\section{PLATE VII}

I. Tachytes nigro-annulata. $\times \mathbf{2 4}$.

2. Tachytes opposita. $\times 16$.

3. Tachytes erynnis (?). $\times 16$.

4. Tachytes cataractae. $\times 16$.

5. Tachytes disputabilis. $\times 24$.

6. Tachytes Turneri. $\times 16$.

7. Tachytes Neavei $\times \mathbf{x} 6$.

8. Tachytes observabilis. $\times 16$.

9. Tachytes rufiscutis. $\times 16$

10. Tachytes bulawayoensis. $\times 16$.

II. Tachytes melancholica. $\times 16$.

12. Tachytes midas. $\times 16$.

13. Tachytes rhodesiana. $\times 16$.

14. Tachytes separabilis. $\times 16$.

15. Tachytes notabilis. $\times 24$.

16. Tachytes nudiventris. $\times 16$.

17. Tachytes lepida. $\times 35$.

I8. Tachytes punctuosa. $\times 16$. 

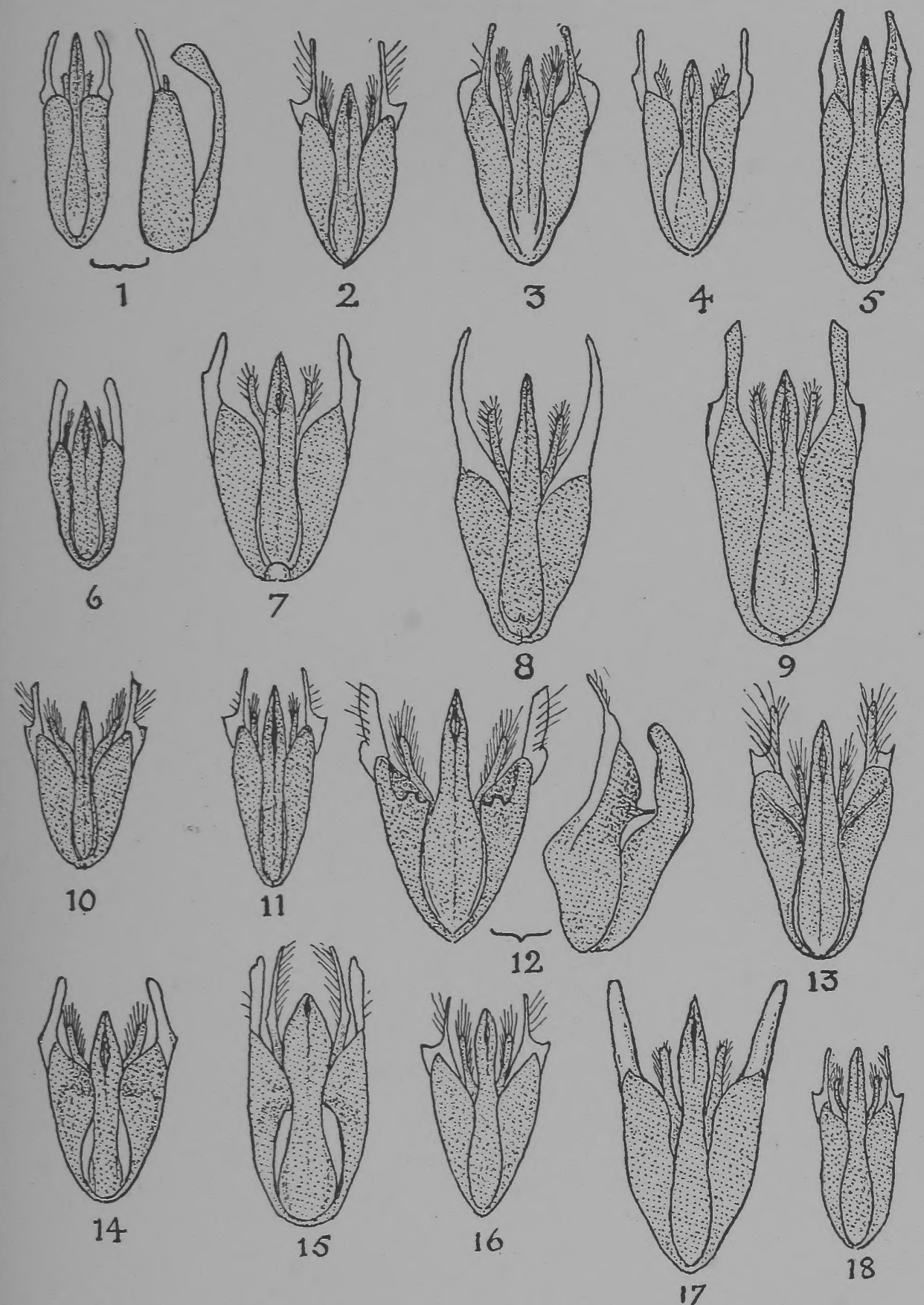

G.Arnoid del. 